\title{
La casa crecedera
}

El crecimiento programado de la vivienda con innovación europea y economía de medios latinoamericana.

TESIS DOCTORAL

Mtra. Lucía Martín López

2016

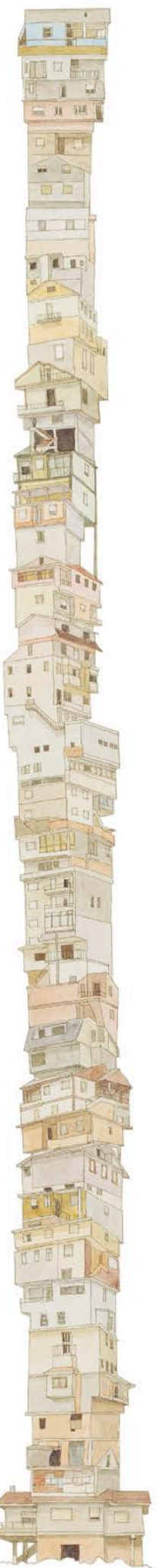




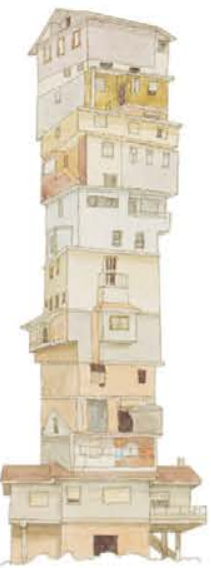


La casa crecedera. El crecimiento programado de la vivienda con innovación europea y economía de medios latinoamericana.

AUTORA: Mtra. Lucía Martín López.

DIRECTOR: Dr. Javier Maroto Ramos. 

Tribunal nombrado por el Mgfco. Y Excmo. Sr. Rector de la Universidad Politécnica de Madrid, el día

Presidente D.

Vocal D.

Vocal D.

Vocal D.

Secretario D.

Realizado el acto de defensa y lectura de Tesis el día

en la Escuela Técnica Superior de Arquitectura de Madrid

Calificación:

EL PRESIDENTE

LOS VOCALES

EL SECRETARIO 



\section{Resumen.}

El concepto de casa crecedera, tal y como lo conocemos en la actualidad, se acuñó por primera vez en 1932 en el concurso Das Wachsende Haus organizado por Martin Wagner y Hans Poelzig dentro del marco de la Exposición Internacional Sonne, Luft und Haus für alle, promovida por la Oficina de Turismo de la ciudad de Berlín. En dicho concurso, se definía este tipo de vivienda como aquella célula básica o vivienda semilla que, dependiendo de las necesidades y posibilidades de los habitantes, podía crecer mediante otras estancias, conformando una vivienda completa en sí misma en cada fase de crecimiento. Numerosos arquitectos de primer orden, tales como Walter Gropius, Bruno Taut, Erich Mendelsohn o Hans Scharoun, participaron en este concurso, abriendo una nueva vía de exploración dentro de la vivienda flexible, la del crecimiento programado.

A partir de ese momento, en Europa, y subsecuentemente en EEUU y otras regiones desarrolladas, se iniciaron numerosas investigaciones teóricas y prácticas en torno al fenómeno del crecimiento en la vivienda desde un enfoque vinculado a la innovación, tanto espacial como técnica.

Por otro lado, aunque dentro del marco de la arquitectura popular de otros países, ya se ensayaban viviendas crecederas desde el siglo XVIII debido a que, por su tamaño, eran más asequibles dentro del mercado. Desde los años treinta, numerosos países en vías de desarrollo tuvieron que lidiar con migraciones masivas del campo a la ciudad, por lo que se construyeron grandes conjuntos habitacionales que, en numerosos casos, estaban conformados por viviendas crecederas. En todos ellos, la aproximación al crecimiento de la vivienda se daba desde una perspectiva diferente a la de los países desarrollados. Se primaba la economía de medios, el uso de sistemas constructivos de bajo costo $y$, en muchos casos, se fomentaba incluso la autoconstrucción guiada, frente a las construcciones prefabricadas ensambladas por técnicos especializados que se proponían, por ejemplo, en los casos europeos.

Para realizar esta investigación, se recopiló información de estas y otras viviendas. A continuación, se identificaron distintas maneras de producir el crecimiento, atendiendo a su posición relativa respecto de la vivienda semilla, a las que se denominó mecanismos de ampliación, utilizados indistintamente sin tener en cuenta la ubicación geográfica de cada casa. La cuestión de porqué se prefiere un mecanismo en lugar de otro 
en un caso determinado, desencadenó el principal objetivo de esta Tesis: la elaboración de un sistema de análisis y diagnóstico de la vivienda crecedera que, de acuerdo a determinados parámetros, permitiera indicar cuál es la ampliación o sucesión de ampliaciones óptimas para una familia concreta, en una ubicación establecida.

Se partió de la idea de que el crecimiento de la vivienda está estrechamente ligado a la evolución de la unidad de convivencia que reside en ella, de manera que la casa se transformó en un hábitat dinámico. Además se atendió a la complejidad y variabilidad del fenómeno, sujeto a numerosos factores socio-económicos difícilmente previsibles en el tiempo, pero fácilmente monitorizables según unos patrones determinados vinculados a la normatividad, el número de habitantes, el ahorro medio, etc.

Como consecuencia, para el diseño del sistema de optimización de la vivienda crecedera, se utilizaron patrones evolutivos. Dichos patrones, alejados ya del concepto espacial y morfológico usualmente utilizado en arquitectura por figuras como C. Alexander o J. Habraken, pasaron a entenderse como una secuencia de eventos en el tiempo (espaciales, sociales, económicos, legales, etc.), que describen el proceso de transformación y que son peculiares de cada vivienda. De esta manera, el tiempo adquirió una especial importancia al convertirse en otro material más del proyecto arquitectónico.

Fue en la construcción de los patrones donde se identificaron los mencionados mecanismos de ampliación, entendidos también como sistemas de compactación de la ciudad a través de la ocupación tridimensional del espacio. Al estudiar la densidad, mediante los conceptos de holgura y hacinamiento, se aceptó la congestión de las ciudades como un valor positivo. De esta forma, las posibles transformaciones realizadas por los habitantes (previstas desde un inicio) sobre el escenario del habitar (vivienda semilla), se convirtieron también en herramientas de proyecto urbano que responden a condicionantes del lugar y de los habitantes con distintas intensidades de crecimiento, ocupación y densidad.

lgualmente, en el proceso de diseño del sistema de optimización, se detectaron las estrategias para la adaptabilidad y transformación de la casa crecedera, es decir, aquella serie de acciones encaminadas a la alteración de la vivienda para facilitar su ampliación, y que engloban desde sistemas constructivos en espera, que facilitan las costuras entre crecimiento y vivienda semilla, hasta sistemas espaciales que permiten que la casa altere su uso transformándose en un hábitat productivo o en un artefacto de renta.

Así como los mecanismos de ampliación están asociados a la morfología, se descubrió que su uso es independiente de la localización, y que las estrategias de adaptabilidad de la vivienda se encuentran ligadas a sistemas constructivos o procesos de gestión vinculados a una región concreta. De esta manera, la combinación de los mecanismos con las estrategias caracterizan el proceso de evolución de la vivienda, vinculándola a unos determinados condicionantes sociales, geográficos y por tanto, constructivos.

Finalmente, a través de la adecuada combinación de mecanismos de ampliación y estrategias de adaptabilidad en el proyecto de la vivienda con crecimiento programado es posible optimizar su desarrollo en términos económicos, constructivos, sociales y espaciales. Como resultado, esto ayudaría no sólo a mejorar la vida de los habitantes de la vivienda semilla en términos cualitativos y cuantitativos, sino también a compactar las 
ciudades mediante sistemas incluyentes, ya que las casas crecederas proporcionan una mayor complejidad de usos y diversidad de relaciones sociales. 


\section{Abstract.}

The growing house concept -as we currently know it- was used for the first time back in 1932 in the competition Das Wachsende Haus organized by Martin Wagner and Hans Poelzig during the International Exhibition Sonne, Luft und Haus für alle, promoted by Berlin's Tourist Office. In that competition this type of housing was defined as a basic cell or a seed house unit, and depending on the needs and capabilities of the residents it could grow by adding rooms and defining itself as a complete house unit during each growing stage. Many world-top class architects such as Walter Gropius, Bruno Taut, Erich Mendelsohn or Hans Scharoun, were part of this competition exploring a new path in the flexible housing field, the scheduled grownth.

From that moment and on, in Europe -and subsequently in the USA and other developed areas- many theorical and pragmatical researchs were directed towards the growing house phenomena, coming from an initial approach related to innovation, spacial and technical innovation.

Furthermore -inside the traditional architecture frame in other countries, growing houses were already tested in the XVIII century- mainly due to the size were more affordable in the Real State Market. Since the 30's decade many developing countries had to deal with massive migration movements from the countryside to cities, building large housing developments were -in many cases- formed by growing housing units. In all of these developing countries the growing house approach was drawn from a different perspective than in the developed countries. An economy of means was prioritized, the utilization of low cost construction systems and -in many cases- a guided self-construction was prioritized versus the prefabricated constructions set by specialized technics that were proposed -for instance- in the European cases.

To proceed with this research, information from these -and other- housing units was gathered. From then and on different ways to perform the growing actions were identified, according to its relative position from the seed house unit, these ways were named as addition or enlargement mechanisms indifferently utilized without adknowledging the geographic location for each house. The question of why one addition mechanism is preferred over another in any given case became the main target of this Thesis; the ellaboration of an analysis and diagnosis system for the growing house -according to certain parameters- would allow to point out which is the addition or addition process more efficient for a certain family in a particular location. 
As a starting point the grownth of the housing unit is directly linked to the evolution of the family unit that lives on it, so the house becomes a dynamic habitat. The complexity and the variability of the phenomena was taken into consideration related to a great number of socio-economic factors hardly able to be foreseen ahead on time but easy to be monitored according to certain patterns linked to regulation, population, average savings, etc

As a consequence, to design the optimization system for the growing house, evolutionary patterns were utilized. Those patterns far away from the spatial and morphologic concept normally utilized in Architecture by characters like C. Alexander or J. Habraken, started to be understood like a sequence of events on time (spatial events, social events, economic events, legal events, etc) that describes the transformation process and that are particular for each housing unit. Therefore time became something important as another ingredient in the Architectural Project.

The before mentioned addition or enlargement mechanisms were identified while building the patterns; these mechanisms were also understood as city's system of compactation through the tridimendional ocupation of space. Studying density, thorough the concepts of comfort and overcrowding, traffic congestion in the city was accepted as a positive value. This way, the possible transformations made by the residents (planned from the begining) about the residencial scenary (seed house), also became tools of the urban project that are a response to site's distinctive features and to the residents with different grownth intensities, activities and density

Likewise, during the process of designing the optimization system, strategies for adaptations and transformation of the growing house were detected, in other words, the serial chain of actions directed to modify the house easing its enlargement or addition, and that comprehends from constructive systems on hold -that smooths the costures between grownth and housing seed- to spatial systems that allows that the house modify its utilization, becoming a productive habitat or a rental asset.

Because the enlargement mechanisms are linked to the morphology, it was discovered that the use it's not related to the location, and that the adaptation strategies of the houses are linked to constructive systems or management processes linked to a particular area. This way the combination of mechanisms and strategies characterizes the process of housing evolution, linking it to certain social and geographic peculiarities and therefore constructives.

At last, through the certain combination of enlargement mechanisms and adaptability strategies in the housing with scheduled grownth project is possible to optimize its development in economic, constructive, social and spatial terms. As a result, this would help not only to improve the life of the seed house residents in qualitative and quantitative terms but also to compact the cities through inclusive systems, given that the growing houses provide a larger complexity of uses and social relations. 
Índice.

Resumen

\section{Preámbulo.}

I.a. Objeto de estudio y estado de la cuestión

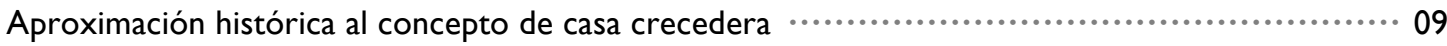

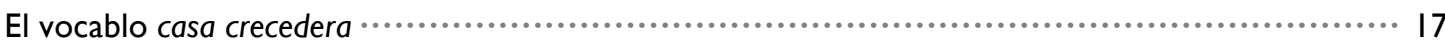

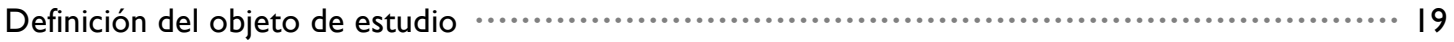

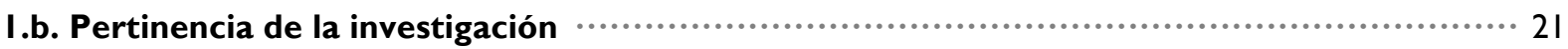

Problemática de la vivienda crecedera $\ldots \ldots \ldots \ldots \ldots \ldots \ldots \ldots \ldots \ldots \ldots \ldots \ldots \ldots \ldots \ldots \ldots \ldots \ldots \ldots \ldots \ldots \ldots \ldots \ldots \ldots \ldots \ldots \ldots \ldots \ldots \ldots \ldots \ldots \ldots \ldots$

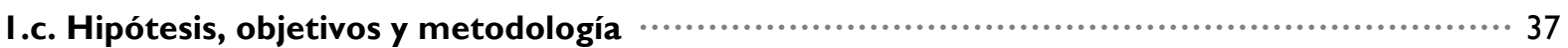

\section{La ampliación en la vivienda contemporánea.}

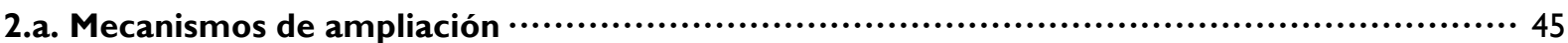

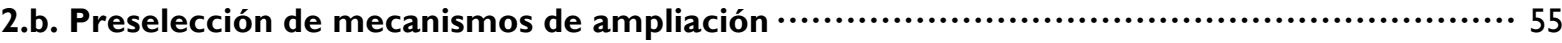

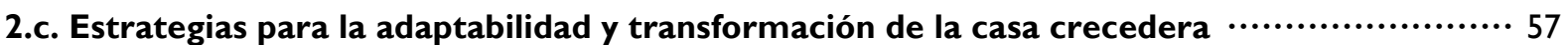

\section{Patrones evolutivos y parámetros.}

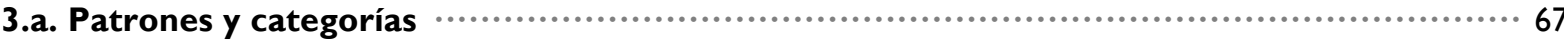

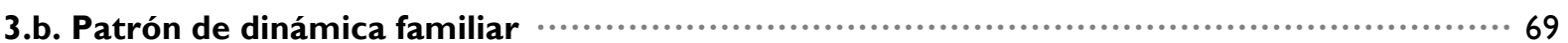

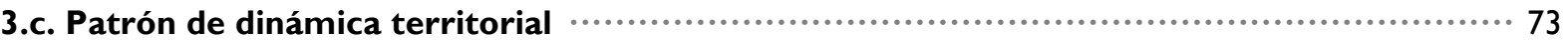

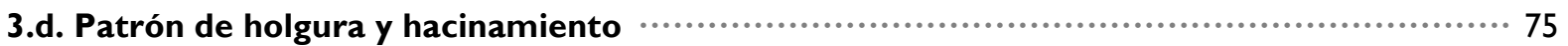




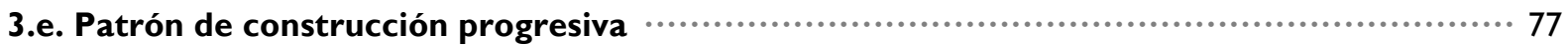

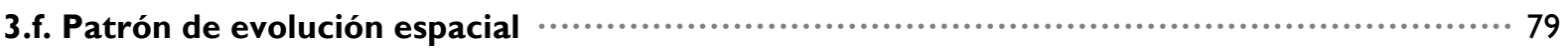

3.g. Patrón de evolución cualitativa de la vivienda $\ldots \ldots \ldots \ldots \ldots \ldots \ldots \ldots \ldots \ldots \ldots \ldots \ldots \ldots \ldots \ldots \ldots \ldots \ldots \ldots \ldots \ldots \ldots \ldots$

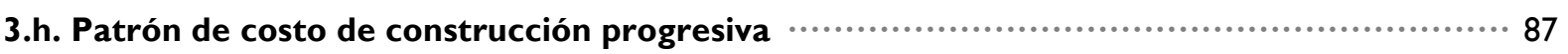

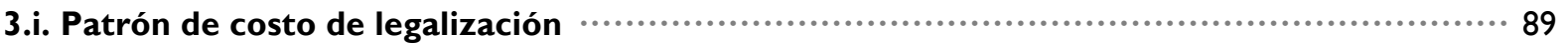

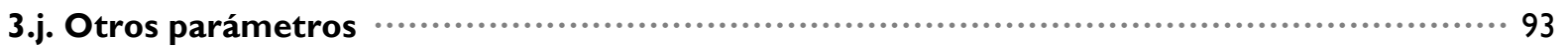

\section{Casos de estudio.}

4.a. Recopilación de casos y resultados estadísticos globales

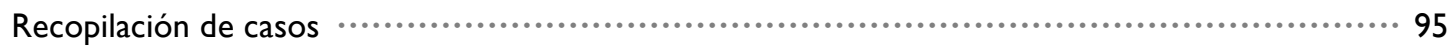

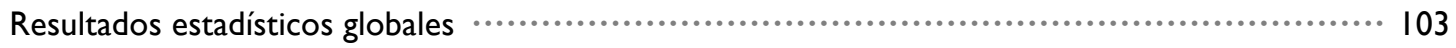

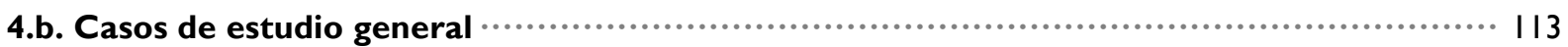

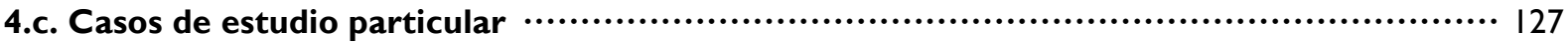

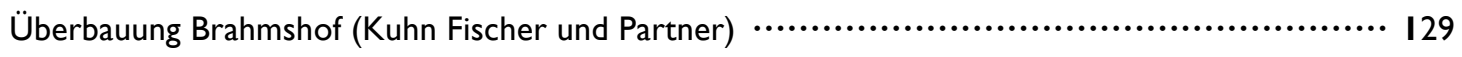

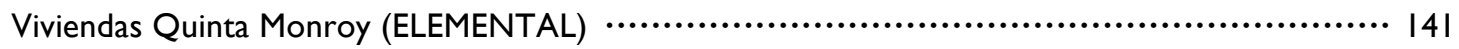

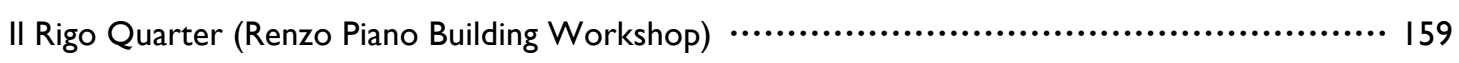

Población Rene Schneider (Percy Díaz Martínez) …........................................... I7|

\section{Aplicación a una unidad de convivencia real.}

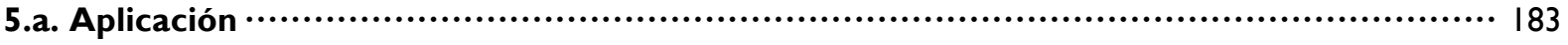

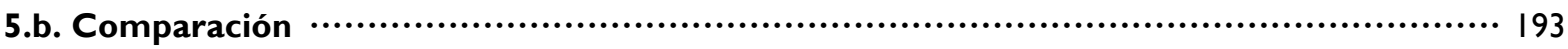

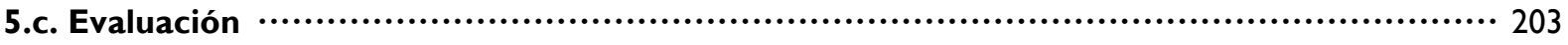

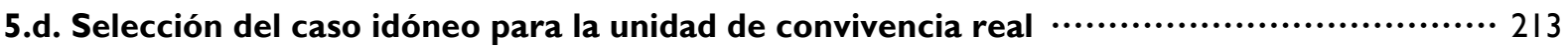

\section{Conclusiones.}

6. Conclusiones

\section{Bibliografía.}

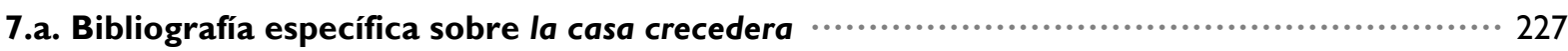

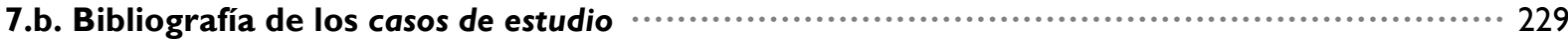


1. PREÁmbuLO.

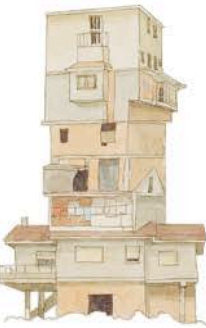





\section{1.a. Objeto de estudio y estado de la cuestión.}

El término de casa crecedera se acuña por primera vez en 1932 en el libro Das wachsende Haus: ein Beitrag zur Losung der Stadtischen Wohnungsfrage de Martin Wagner'. En este texto, Wagner describía la situación sufrida por las casas de los Stadtrandsiedlungen (barrios del extra radio de las ciudades alemanas) cuando pasaban de ser viviendas temporales a viviendas usadas durante todo el año.

Si bien este primer acercamiento al concepto por parte de Wagner no era muy parecido a lo que en la actualidad se conoce como casa crecedera, su descripción evolucionó en muy poco tiempo hacia un significado más similar al actual dando lugar a las bases del concurso Das Wachsende Haus (La casa crecedera). El concurso organizado por el propio Martin Wagner y por Hans Poelzig entre otros, formaba parte de la Exposición Internacional Sonne, Luft und Haus für alle promovida por la Oficina de Turismo de la Ciudad de Berlín en 1932. En este concurso se solicitaban propuestas de casas crecederas de acuerdo al concepto que utilizamos en la actualidad: una célula básica $\circ$ una vivienda semilla, que dependiendo de las necesidades y posibilidades de los ocupantes pudiera crecer hacia otros alojamientos, los cuales en cada estadío de crecimiento compondrían un todo cerrado².

Veinticuatro arquitectos entre los que se encontraban Erich Mendelsohn, Hans Scharoun, Bruno Taut, SäumeHafemann y Walter Gropius participaron con diversos proyectos en el concurso (Imagen 0I) iniciando una nueva vía de exploración en la vivienda dentro del campo de la flexibilidad: el crecimiento programado.
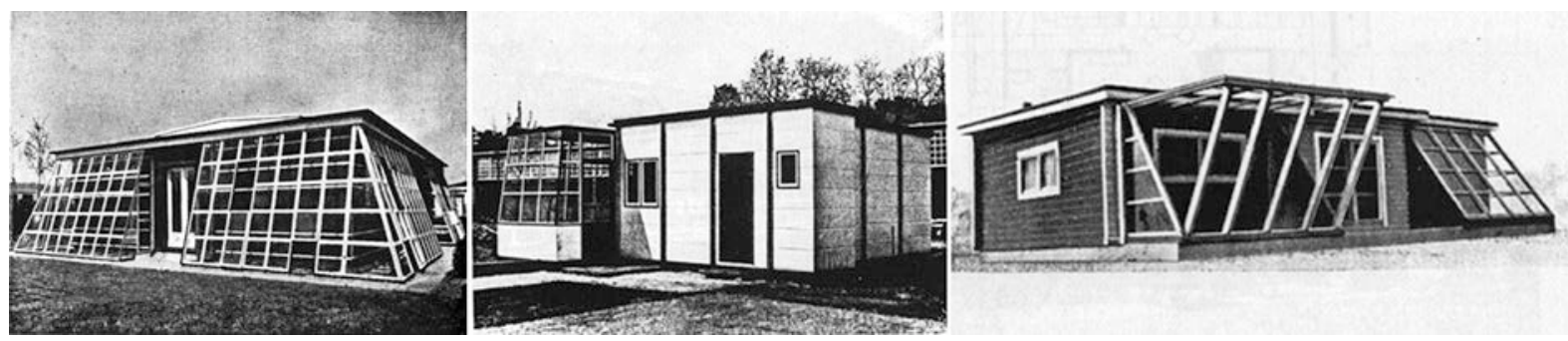

Imagen 0I. Propuestas para el concurso “Das Wachsende Haus”. M. Wagner, B. Taut y Säume-Hafemann

\footnotetext{
I (Wagner, 1932). La casa crecedera: un aporte para solucionar el problema de la vivienda urbana.

${ }^{2}$ Esta primera definición de casa crecedera se ha localizado en (Böttcher, 1932) «Das „Wachsende Haus“ ist ein vorstädtisches Gartenhaus, das aus einer Grundzelle oder einem Kernhaus besteht, an das je nach Bedarf und Vermögen des Besitzers andere Wohneinheiten so anwachsen können, dass das Haus in jedem Stadium seiner Ausbildung ein abgeschlossenes Ganzes bildet>>.
} 
Como hemos visto, 1932 es el año en el que se sientan por primera vez las bases teóricas de la casa crecedera. Sin embargo desde el siglo XVIII se venían desarrollando viviendas con estas características en el marco de la arquitectura popular de diversos países. Este es el caso de la alcoba italiana característica del Barroco que crecía por adición de recámaras o de las casas accesorias de taza y plato (Imagen 02) vecindades típicas del Barroco mexicano donde un espacio de gran altura permitía la colocación a posteriori de un tapanco o entrepiso dando la posibilidad de utilizar el doble de metros cuadrados mediante este crecimiento hacia el interior (Franco Flores, 2013).
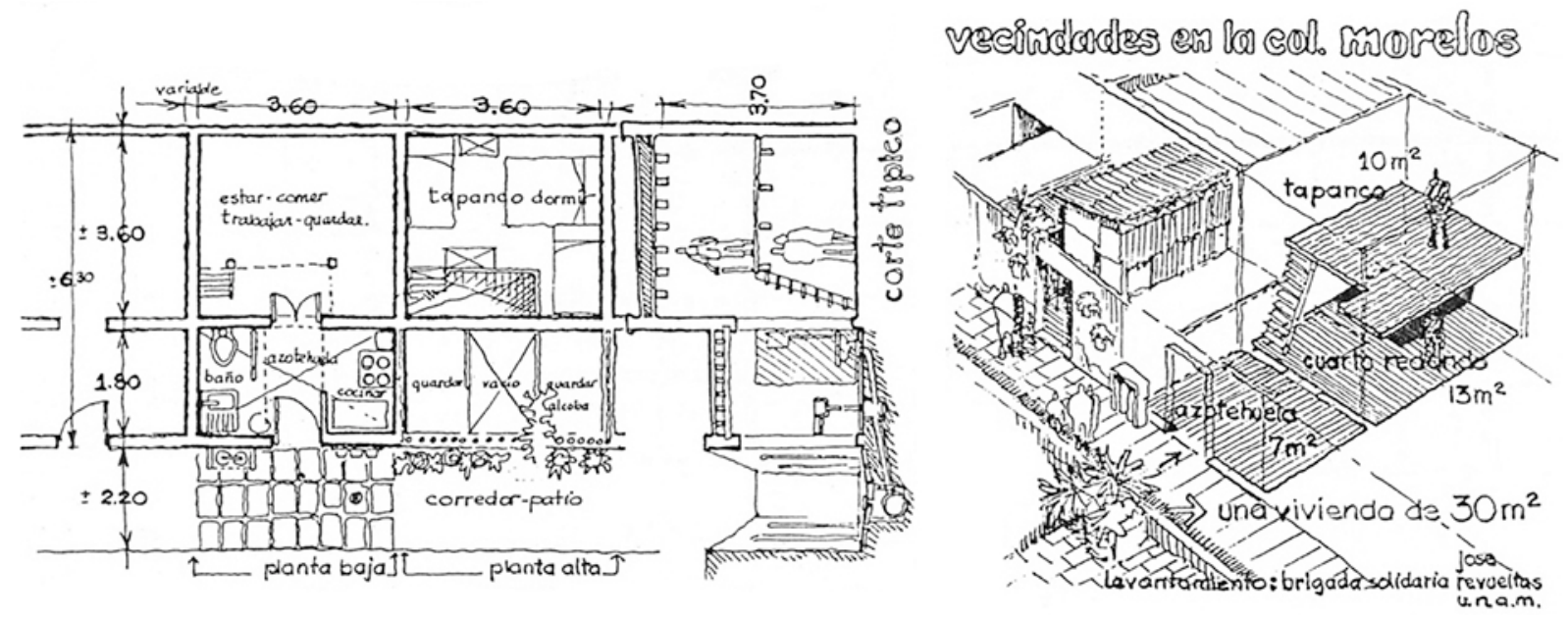

Imagen 02. Casas accesorias de taza y plato. Vecindad en la Colonia Morelos. México. (González Lobo, 1999).

Mientras en la década de los 30 se convocaba en Europa el concurso Das Wachsende Haus, en el que se buscaba expresamente el proyecto de una vivienda que aumentara su superficie progresivamente, en Latinoamérica, países como México trataban de lidiar con grandes migraciones del campo a la ciudad levantando grandes conjuntos habitacionales, en algunos casos crecederos como es el caso de las Casas para Obreros Mexicanos de Juan O'Gorman (Imagen 03) o del Conjunto Balbuena de Legarreta.
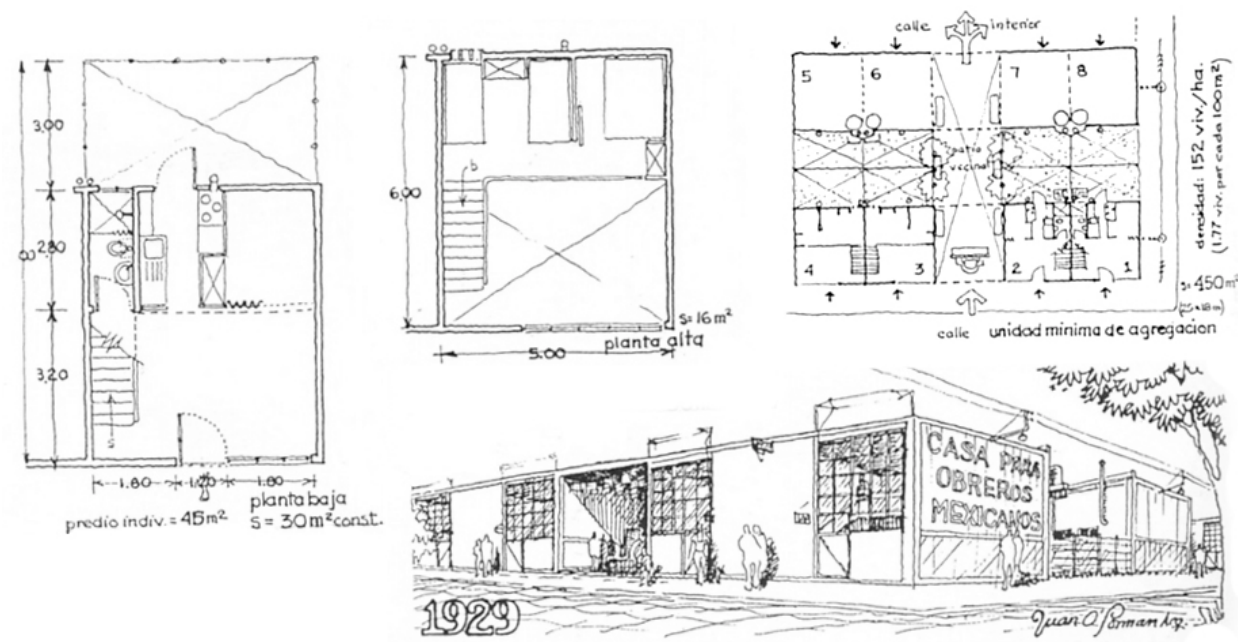

Imagen 03. Casa para Obreros Mexicanos, Juan O’Gorman. (González Lobo, 1999). 
Hasta los años 40 y 50 Estados Unidos no comienza a interesante por el asunto. Es en estas décadas en las que, según los casos localizados, Estados Unidos es el mayor productor de viviendas crecederas. Arquitectos como Karl Koch (imagen 04) o el grupo SOM eran algunos de los proyectistas que basaban sus proyectos en sistemas de crecimiento reversibles como la unión o la expansión ${ }^{3}$.
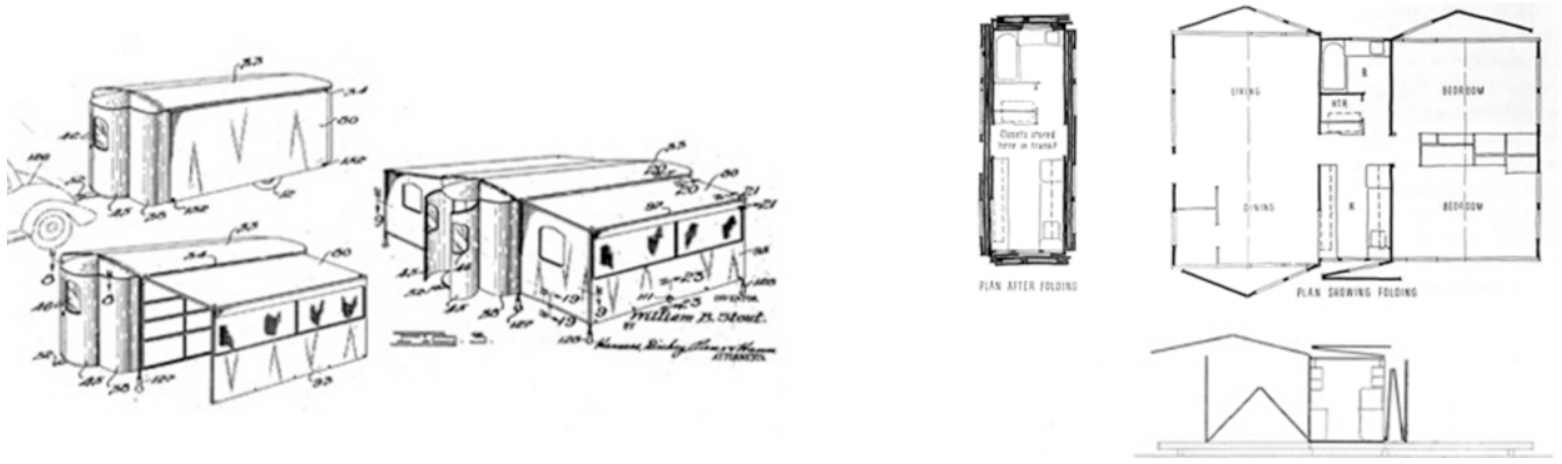

Imagen 04. Sistemas de crecimiento por expansión de W.B. Stout y Carl Koch.

Con la llegada de los años 50 y 60, en Europa comienza la crítica a la construcción en masa, la seriación y la deshumanización, fruto de la reconstrucción tras la Segunda Guerra Mundial. Este periodo fue el más fructífero para Europa en cuanto a producción de vivienda crecedera se refiere puesto que el $60,70 \%{ }^{4}$ de los casos localizados en esa época se construyeron en esta región. Se desarrollaron numerosos proyectos utópicos dentro de los cuales arquitectos como Bakema, Cedric Price (Imagen 05), Utzon o Hertzberger (Imagen 06) aprovecharon para ubicar de una forma más tangible sus proyectos de ampliación. Simultáneamente en Chile surgen los primeros programas de vivienda social dirigidos por el Gobierno basados en la construcción de viviendas progresivas (Castillo Couve, 2010, pp.3I-7I). Un gran ejemplo de este momento son los conjuntos habitacionales construidos y dirigidos por el arquitecto Fernando del Castillo (Imagen 07).

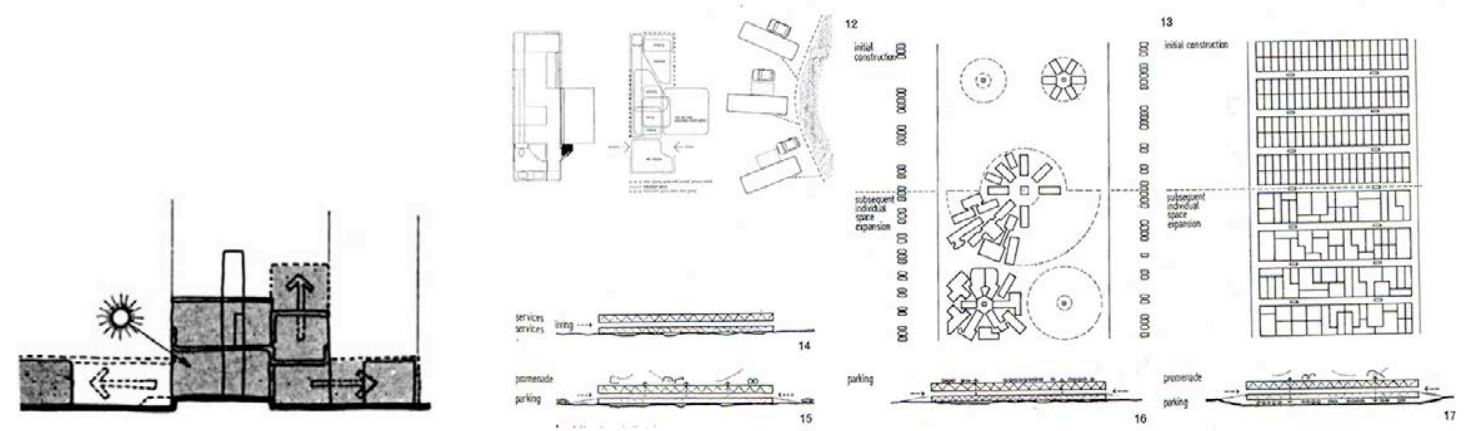

Imagen 05. Extendible houses 't Hool de J. van den Broek \& Bakema. Y Potteries Thinkbelt de C. Price.

\footnotetext{
${ }^{3}$ El crecimiento por unión, tal y como se explicará en el apartado de Mecanismos de ampliación, es una ampliación por co-propiedad, es decir, por la combinación de propiedades, donde una de ellas le cede superficie a la otra y, de esta manera, se producen simultáneamente la ampliación de una de las vivienda y la reducción de la otra. Mientras que el crecimiento por expansión es un sistema de crecimiento reversible que aumenta el volumen de la vivienda temporalmente. (Schneider \& Till, 2007).

${ }^{4}$ Los porcentajes señalados que se indican a lo largo de todo este apartado tienen como base de cálculo la selección de casos realizada para la investigación, donde se han localizado 214 casos de estudio en todo el mundo que se detallarán en el apartado Recopilación de casos.
} 

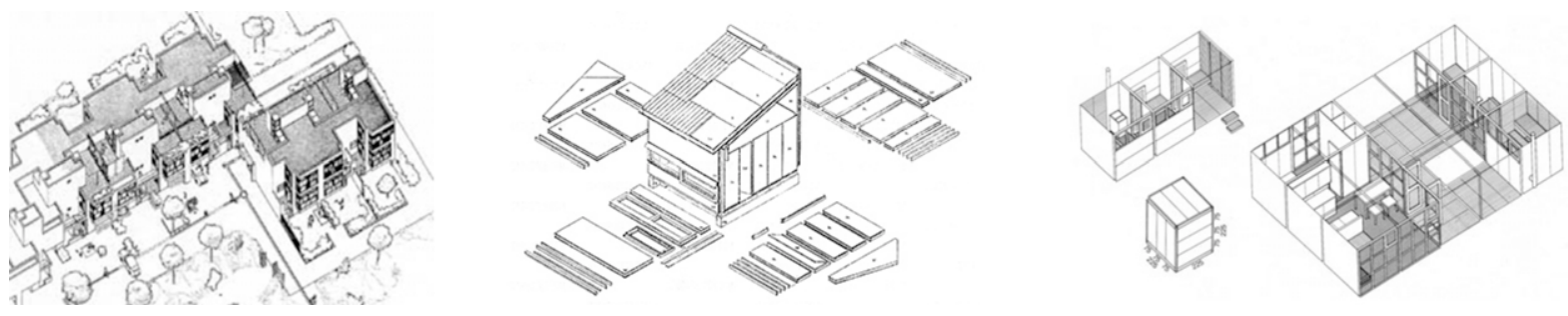

Imagen 06. Diagoon houses, Hertzberger; Expansive house system, Utzon; Moduli 225, Gullichsen \& Pallasmaa.
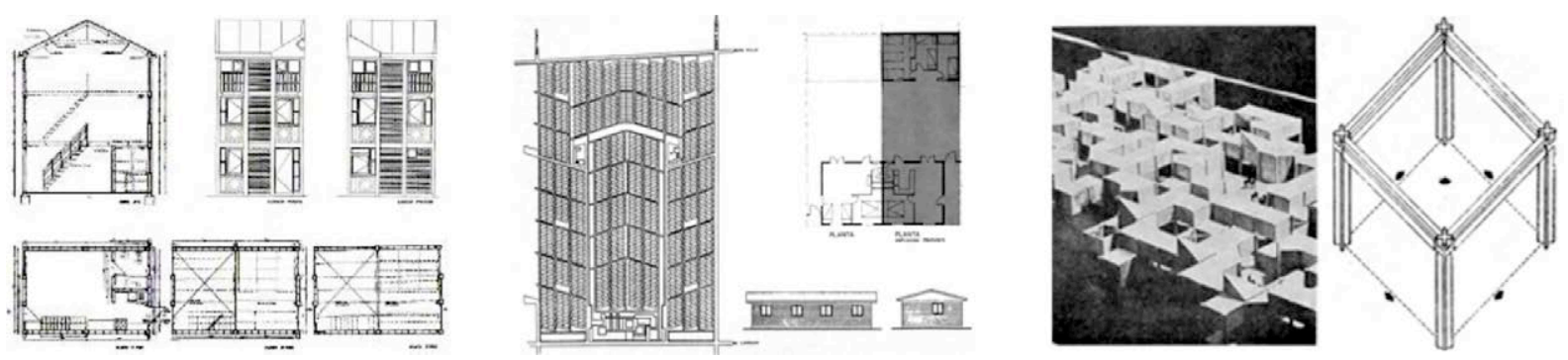

Imagen 07. Comunidad Andalucía y Villa la Reina, F. del Castillo. Puerto Rican Village Housing, R. M. Oxman.

En la década de los 70 se produce el gran apogeo de la vivienda crecedera en todo el mundo, ya que es la década en la que más casos se han localizado, el 22,46\% de los 214. (Figura 01). En Asia los metabolistas Kurokawa e Isozaki proponían grandes racimos de viviendas incrementales. Mientras que en Latinoamérica se centraban en resolver casos reales a través del concurso internacional PREVI en Perú (Imagen 08), o mediante las actuaciones en Chile del CORVI (Corporación de Reconstrucción y Auxilio) y en Argentina del CEVE (Centro Experimental de Vivienda Económica), entre otras.

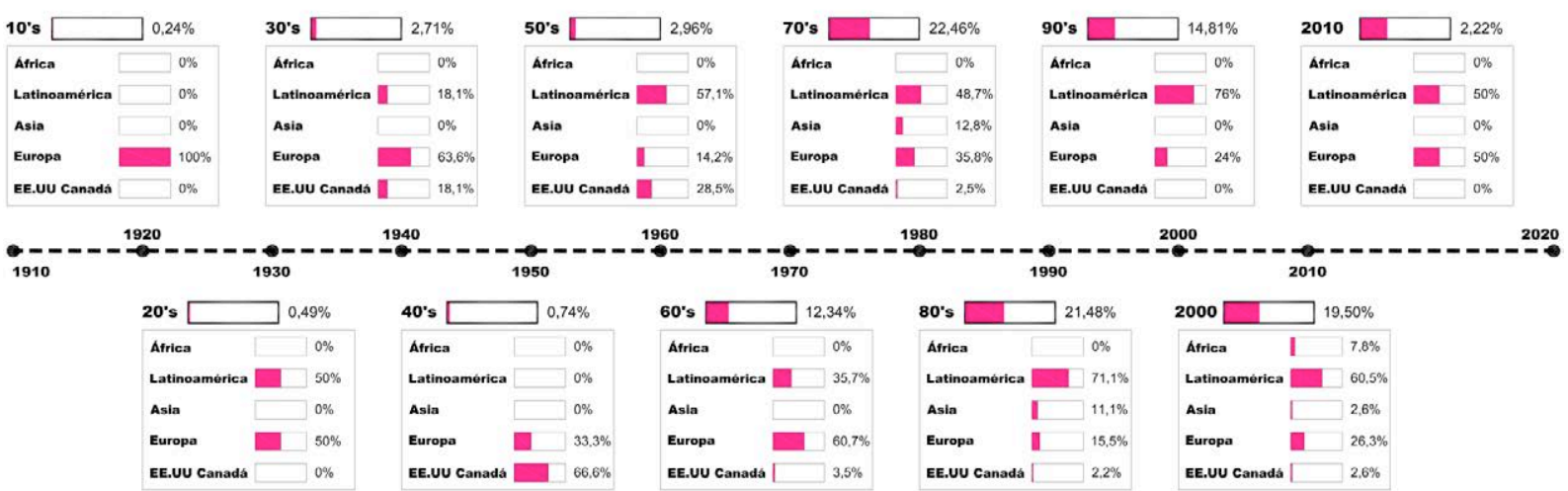

Figura 0I. Porcentaje de vivienda crecedera a nivel mundial por década según los casos localizados.

Latinoamérica continúa a partir de entonces en la construcción e investigación de la vivienda incremental como una posible solución al déficit de vivienda que padecen millones de personas en este territorio. Como es el caso de México, por ejemplo, donde el $85 \%$ de las viviendas que se construían en el Distrito Federal eran y son crecederas (Bazant, 2003). De este interés en el fenómeno deriva la cifra que indica que en la década de los 80 el 7I, II\% de los casos detectados se realizaron en la región Latinoamericana. 

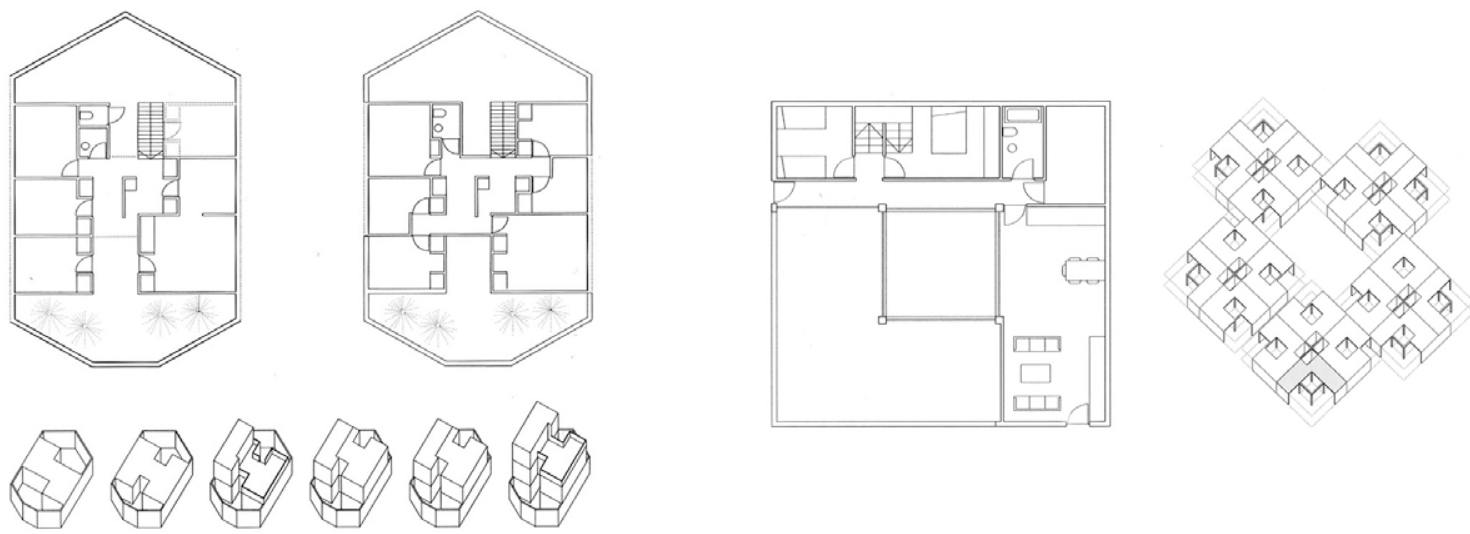

Imagen 08. Viviendas de Aldo van Eyck y James Stirling para el conjunto habitacional PREVI. Perú.
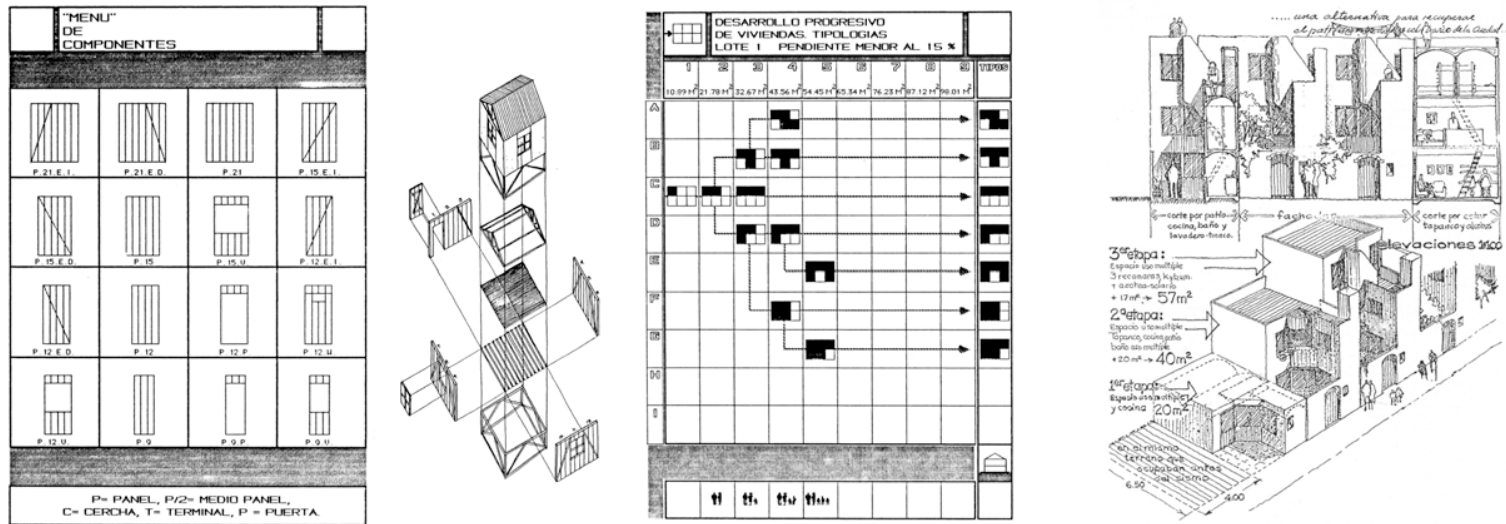

Imagen 09. Sistema normalizado en guadua y madera de J. Mogollón y G. Díaz. Y vecindad mejorada de C. González Lobo. México.
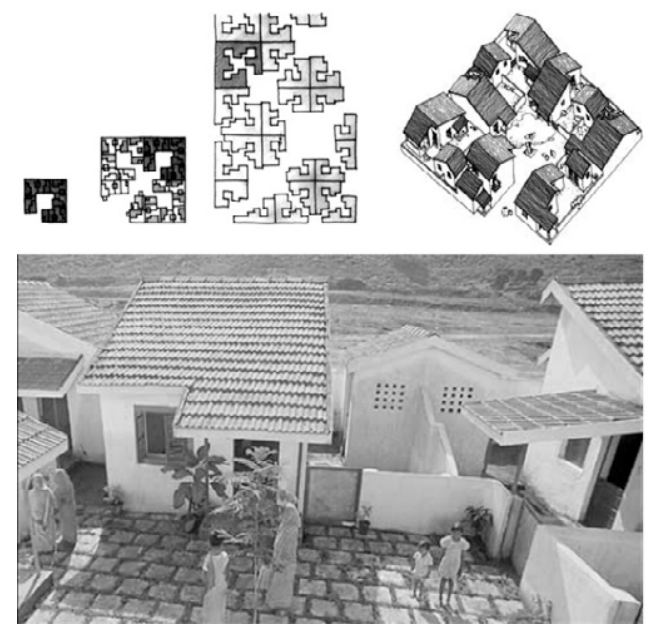

Imagen 10. Incremental Housing de Charles Correa. Viviendas para la ciudadela Aranya de B. V. Doshi. India.
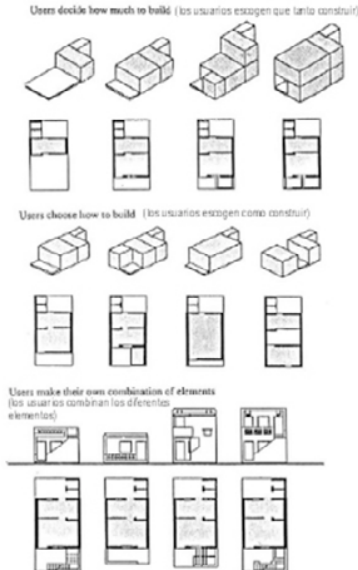

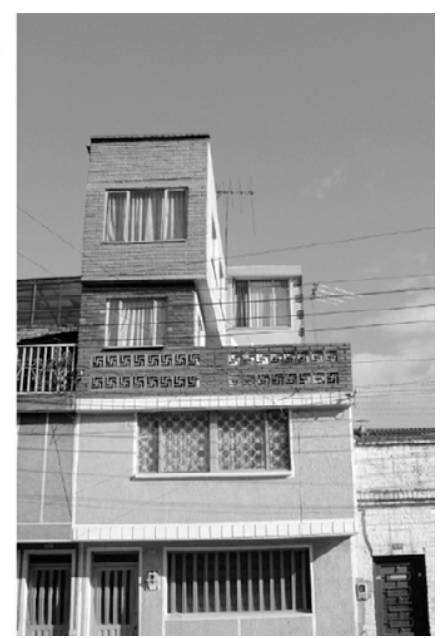


A partir de los años 90, mientras que en Europa, y sobre todo en España, comenzaba la burbuja inmobiliaria y las viviendas crecederas pasaban a un segundo plano por no ser un producto rentable para la venta, en Latinoamérica la construcción de viviendas progresivas continuaba $(76 \%$ de los casos localizados en el mundo en ese momento). (Imagen 08 e Imagen 09). Para potenciar la investigación de este tipo de viviendas se realizaron diversos concursos a nivel nacional e internacional como el Concurso nacional para el desarrollo de vivienda progresiva en Chile, o como el Concurso internacional elemental de vivienda incremental en el que participaron más de 520 equipos de arquitectos de todo el mundo (Aravena \& lacobelli, 20I2). (Imagen II).
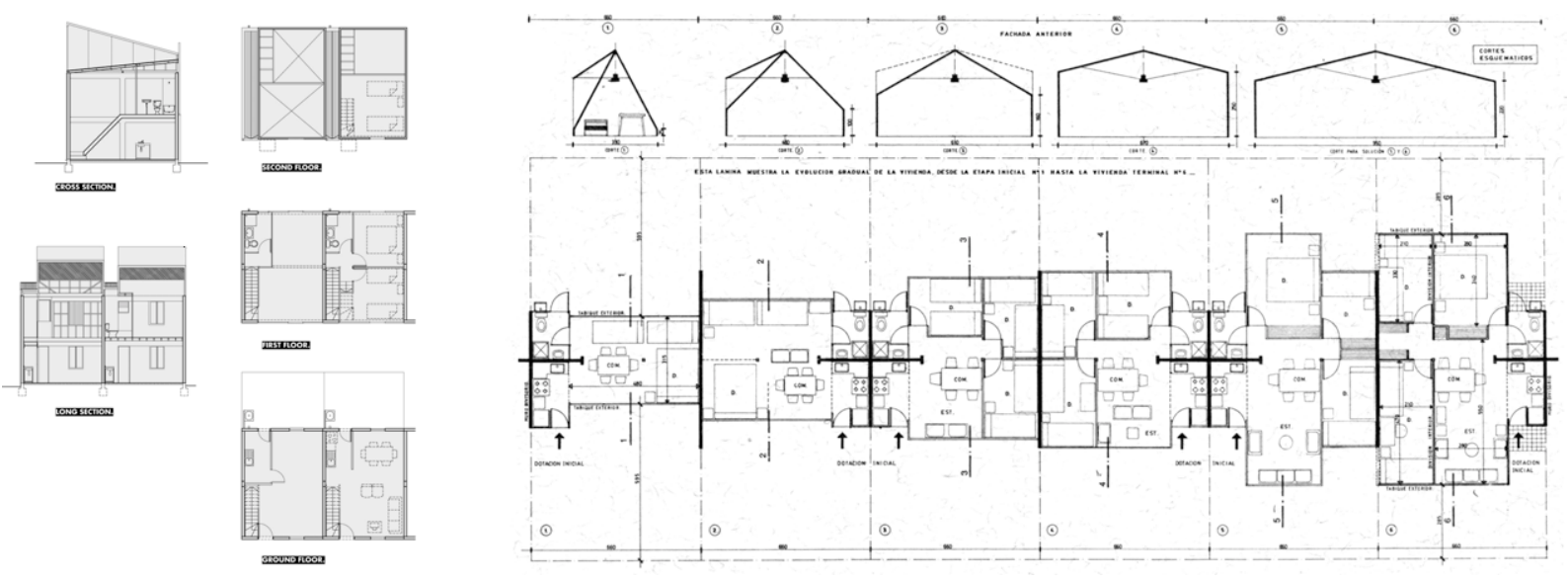

Imagen II. Concurso internacional elemental de vivienda incremental (La Renca) de ELEMENTAL. Concurso nacional para el desarrollo de vivienda progresiva de P.E. Urzúa y F. Manzo. Chile.

Mientras que simultáneamente en la frontera con Estados Unidos el acercamiento era distinto. Arquitectos como Teddy Cruz comenzaban a estudiar las viviendas crecederas autoconstruidas por los migrantes, entendiéndolas y replicándolas como mecanismos de transformación de las grandes extensiones monoculturales y mono-uso que caracterizan algunas megalópolis. (Imagen 12). Este tipo de casas, al ser económicas, permitir la extensión de la unidad de convivencia y facilitar la economía informal a través de la hipercasa, "alimentan la unidimensionalidad del paisaje urbano, transformándolo silenciosa e invisiblemente en sistemas de urbanización más inclusivos, promoviendo y apoyando nuevos programas hacia el vecindario". Transformando así las mencionadas ciudades en sistemas más complejos en cuanto a relaciones socioeconómicas. (Cruz, 20I2).
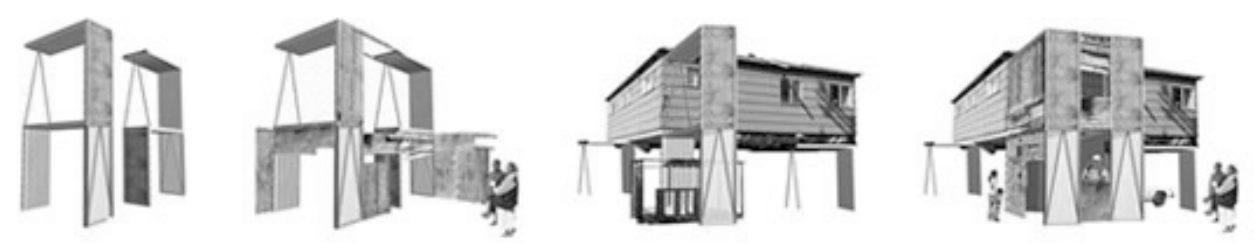

Imagen 12. Manufactured Sites. Teddy Cruz Architects. EEUU - México.

A partir del 2007, año en el que empieza la crisis inmobiliaria en países como España (Bernardos Domínguez, 2009, pp. 23-40), comienza a haber un cambio en la forma de ver la arquitectura por parte de los profesionales. Frases como "es el momento de pasar del Star System a la arquitectura de lo cotidiano, aquella que consigue cambiar y mejorar la vida de las personas" (Bosco, 20I2, p.28), enunciada por David Chipperfield en el marco de la Bienal de Venecia del 2012, parece que alientan a buscar una arquitectura más comprometida con la 
sociedad. Esta actitud cada vez más generalizada hace pensar que quizás es el momento de volver a retomar en Europa y principalmente en España estas soluciones crecederas que no comprometen tanto el futuro económico y espacial de las familias y que permiten explotar nuevas formas de flexibilidad.
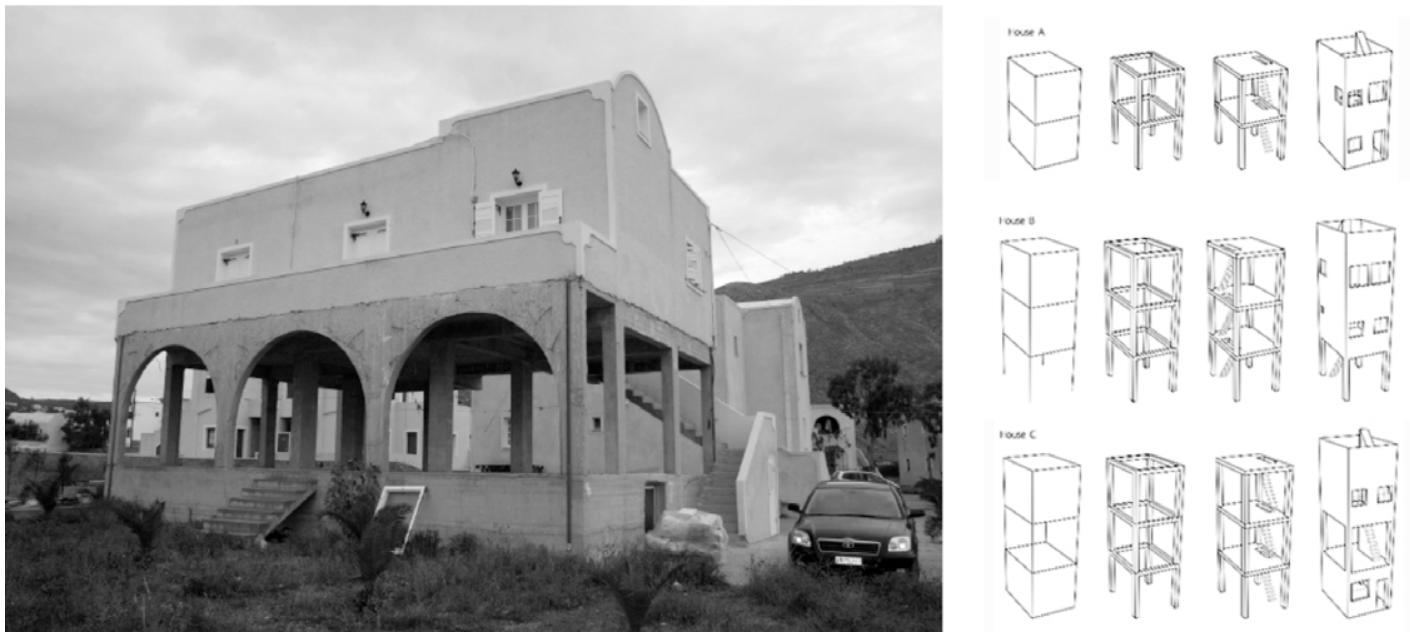

Imagen 13. Vivienda paralizada por la crisis en Santorini, Grecia. Incremental Housing Strategy F. Balestra y S. Göransson. 
I. Preámbulo 


\section{Aproximación histórica al concepto de casa crecedera.}

Para acercarnos a la definición de vivienda crecedera ${ }^{5}$ que utilizaremos en esta investigación se detallarán a continuación las aproximaciones que a lo largo del tiempo han realizado distintos arquitectos sobre el tema para que a partir de estos conceptos se puedan extraer las características de la vivienda crecedera que regirán la selección de los casos de estudio de la tesis.

En las bases del concurso Das Wachsende Haus mencionado anteriormente, se solicitaban casas crecederas. Es decir, viviendas que entre otros requisitos pudieran ampliarse hacia otros alojamientos, los cuales en cada fase de crecimiento compondrían un todo cerrado y dependerían de las necesidades y posibilidades de los ocupantes de esta vivienda semilla ${ }^{6}$. Este diseño debía contemplar desde la vivienda inicial o pérgola estructural, hasta la casa totalmente consolidada sin responder únicamente a un problema económico, si no que se centraría más bien en el aspecto técnico, sin olvidarse en último término del Mercado. Las viviendas propuestas para el concurso debían dejar libres todos sus lados para posibilitar futuros crecimientos o como máximo permitir la construcción adosada de otra vivienda unifamiliar en uno de los lados. La superficie habitable de la vivienda semilla solicitada tenía que estar diseñada de tal manera que la primera fase fuese autosuficiente, conteniendo al menos una cocina y un WC en alrededor de $25 \mathrm{~m}^{2}$, y no estaba permitido en ningún caso exceder la superficie de $80 \mathrm{~m}^{2}$ una vez que la vivienda estuviera totalmente construida. Finalmente, en la descripción de la casa solicitada se sugería que la planta debía tener un mobiliario noble y práctico cuyo coste tenía que reducirse al mínimo, siendo necesario diseñarlo․

Tras el concurso Das Wachsende Haus muchos arquitectos europeos siguieron investigando de manera independiente sobre el tema, proponiendo distintos tipos de viviendas que respondían a las características expuestas con anterioridad y acuñando nuevos nombres para el tipo. Este boom que se dio a partir de los años 60 de investigaciones prácticas y teóricas sobre la vivienda, en las que se enfatizaba la prefabricación y la flexibilidad, se produjo como respuesta a las construcciones alienantes y repetitivas construidas durante la época de la posguerra. Ejemplo de ello son las Extendible Houses (casas extensibles) de 1963 proyectadas por Van den Broek \& Bakema; la Expansive House (casa expansiva) que Jorn Utzon ideó en 1969 inspirándose en sus sistemas de arquitectura aditiva basados en los patrones de crecimiento de la naturaleza (Weston, 20I I); el espace habitable modulé, extensible transportable que propuso Jon D. Vredevoogd en 1970 o la casa evolutiva de Renzo Piano (Imagen 14) que en 1978 la describió como aquella casa progresivamente modificable donde las instalaciones están a la vista para facilitar las operaciones de transformación ${ }^{8}$. Estos casos a pesar de diferir por ciertas connotaciones en su nombre, compartían el mismo

\footnotetext{
${ }^{5}$ En muchos países latinoamericanos la casa crecedera se llama casa "crecedora". En el caso de esta investigación se ha optado por el término crecedera debido que la palabra crecedora no aparece en el diccionario de la Real Academia de la Lengua Española, mientras que el término crecedera (adj. Que está en aptitud de crecer) si se localiza.

${ }^{6}$ Vivienda semilla, analogía biológica que atiende a la posibilidad de que partiendo de una acción edificatoria básica esta "crezca" 。 "florezca" con el tiempo según el ritmo biológico, histórico, económico y social de desarrollo de la familia (González Lobo, 1999, p. 98).

${ }^{7}$ Descripción extraida de las bases del concurso Das Wachsende Haus en (Böttcher, 1932).

${ }^{8}$ Posteriormente en 1998 Raúl Di Lullo describe la vivienda evolutiva como aquella "compuesta de un núcleo inicial, como punto de partida, y el estudio sistemático de las alternativas de crecimiento que ese núcleo ofrece garantizando la variedad morfológica y secuencial y admitiendo la participación en el proceso de diseño y crecimiento de la vivienda de los futuros usuarios" (Di Lullo \& Martínez Camarotte, 1988).
} 
principio: Son viviendas concebidas para aumentar su superficie en algún momento, ya que fueron diseñadas para facilitar ese incremento gracias a su potencial para anticipar futuras extensiones.
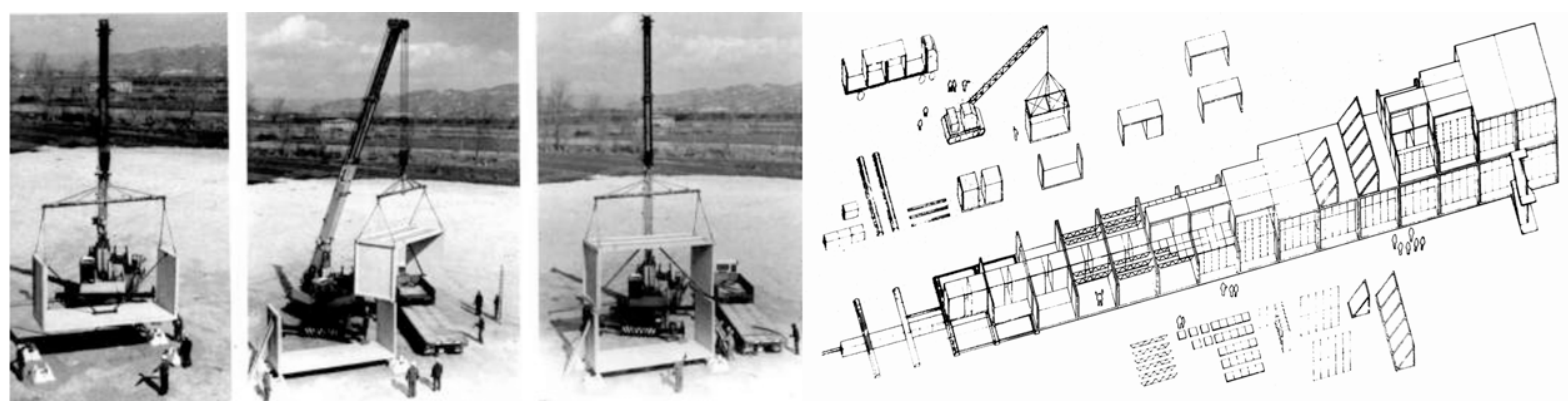

Imagen 14. Casa evolutiva Renzo Piano

En esa misma época, mientras que en Europa se estudiaba la vivienda flexible prefabricada, en Chile se levantaba el Movimiento de los Pobladores produciéndose en 1957 la primera toma de terrenos de Latinoamérica (La Victoria) consiguiendo un cambio en el paradigma de gestión de la Vivienda Social chilena. A partir de ese momento se proporcionaría un terreno con una mínima urbanización en lugar de una vivienda terminada, para poder cubrir las necesidades de un mayor número de personas, con lo que la autoconstrucción y la vivienda de muy bajo costo se convertirían en dos de los principios fundamentales de diseño residencial en ese momento. (Castillo Couve, 2010).

Sin embargo durante esos años, no era Chile el único país latinoamericano centrado en la mejora de la vivienda autoconstruida y de bajo costo. En 1966 el gobierno de Perú fue asesorado en sus Programas de Vivienda Social y Planeamiento por el arquitecto británico Peter Land introduciendo nuevas ideas, como el uso de la vivienda progresiva (aquel hogar que se habita mientras se construye) (Imagen I5), lo que se tradujo en operaciones urbanísticas como la de PREVI en Lima.
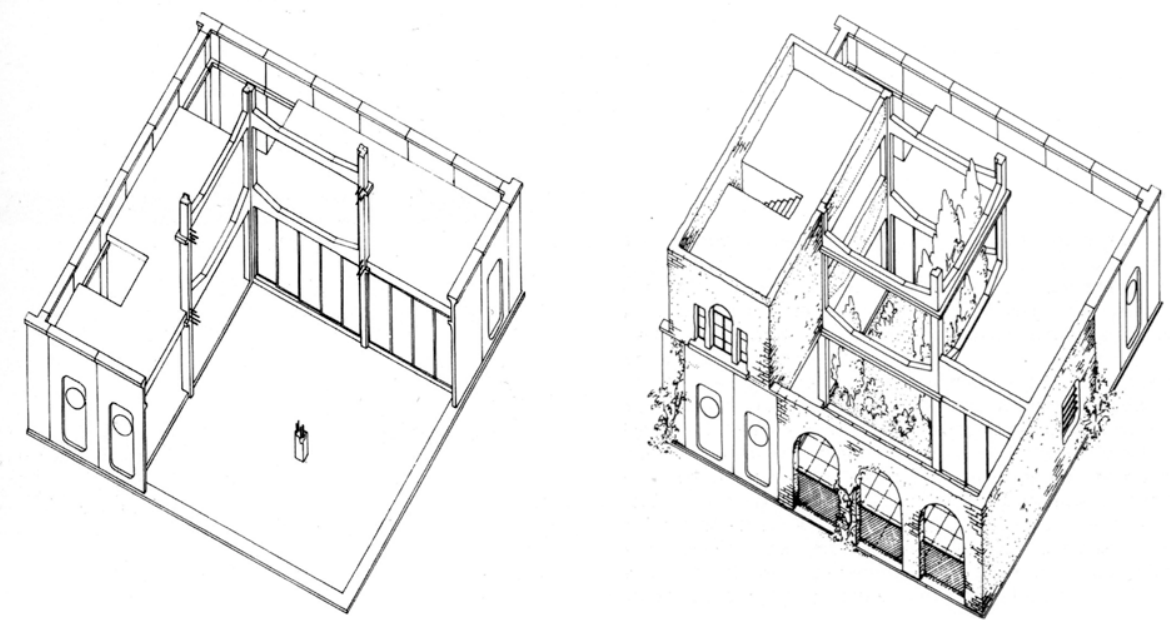

Imagen I5. El tiempo construye. Vivienda para PREVI de James Stirling.

Por otro lado, en 1967 Horacio Berretta funda el Centro Experimental de la Vivienda Económica (CEVE) en Córdoba, Argentina, donde desde entonces exploran la problemática socio-habitacional de esa región del país. En esa época se acuña en el Centro el término vivienda en semilla, analogía biológica que atiende a la 
posibilidad de que a partir de una acción edificatoria básica, la vivienda "crezca" o "florezca" con el tiempo según el ritmo biológico, histórico, económico y social de desarrollo de la familia hasta producir una vivienda plena (González Lobo, 1999, p. 98). Englobado en el concepto de la vivienda semilla encontramos por un lado la vivienda cáscara9 en la que se prevé desde el inicio de la construcción un cuerpo edificado con el mínimo de elementos que genere el máximo volumen habitable posible, y que por crecimientos ulteriores (internos y en seco) se convierta en una vivienda digna y plena. Y por otro lado, proponen el vocablo vivienda crecedora refiriéndose a aquellas viviendas que amplían su superficie exclusivamente mediante adiciones que implican un aumento de volumen.

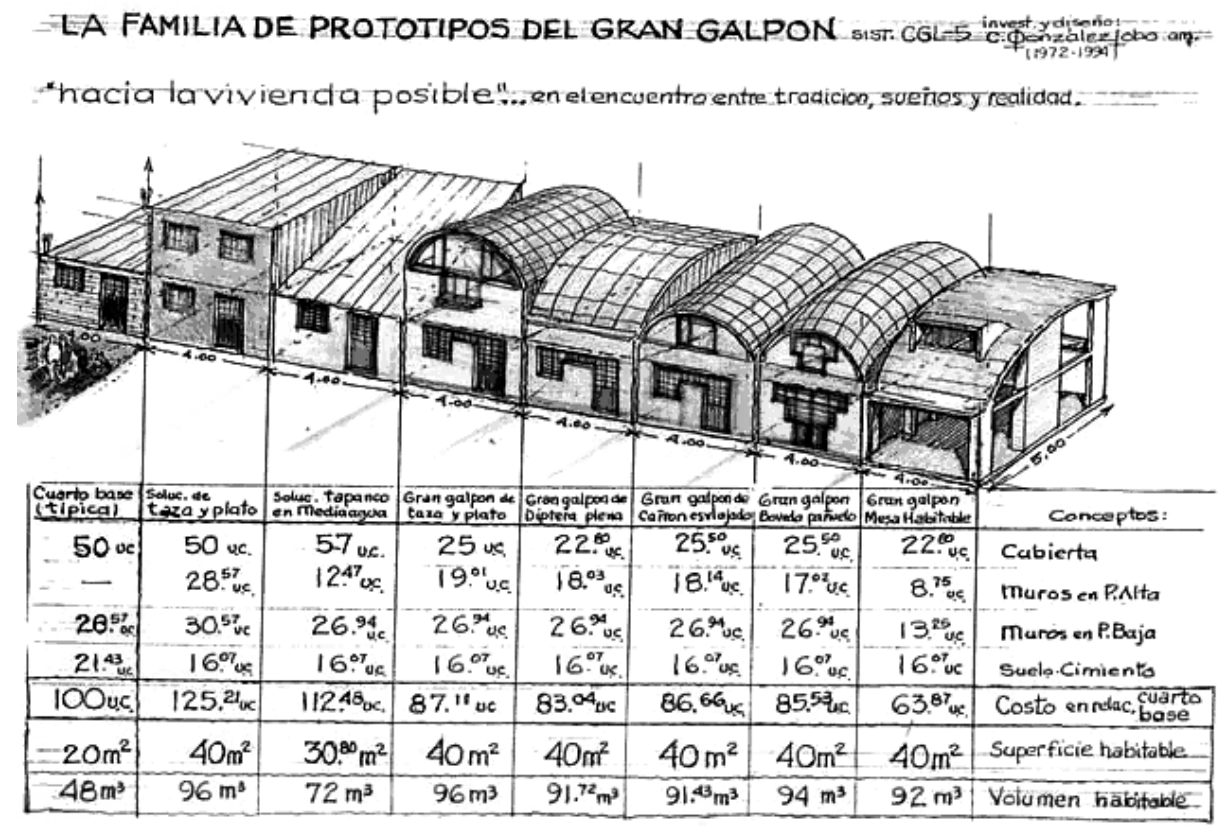

Imagen 16. Familia de prototipos del Gran Galpón, Carlos González Lobo.

En contraposición, mientras en Argentina proponían grandes habitaciones subdivisibles por crecimientos internos, en México, los programas estatales de vivienda social iban reduciendo los metros cuadrados de vivienda ofertada para así poder cubrir las necesidades de un mayor número de familias hasta llegar a promover en 1987 el pie de casa, un edículo o cuarto habitable con los servicios sanitarios mínimos que funcionaría como hogar base y que permitiría a la vivienda en un futuro crecer hasta su tamaño útil, óptimo y final mediante adiciones exteriores (González Ortiz, 200 I, p. 96), (Imagen I7).

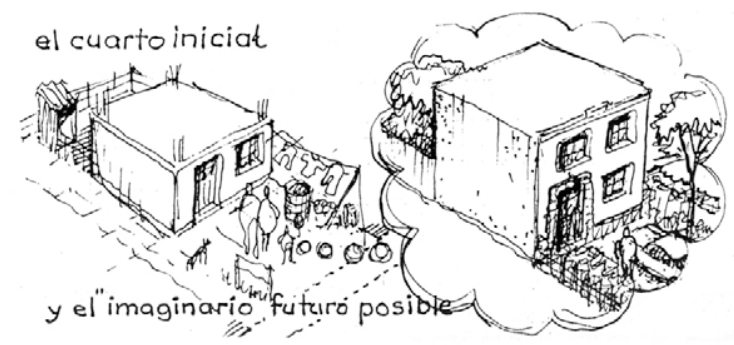

Imagen 17. Pie de casa y su “imaginario futuro posible” de Carlos González Lobo.

\footnotetext{
${ }^{9}$ Vivienda Galpón, para el arquitecto mexicano Carlos González Lobo.
} 
Mientras tanto el mismo año, el Chileno Edwin Haramoto, publicaba sus investigaciones sobre vivienda social de desarrollo progresivo (aquella cuyo énfasis está en el proceso y no en el producto final), (Haramoto, 1987, p.122), donde analizaba por un lado como los usuarios de bajos recursos ampliaban sus casas sin que estas fuesen diseñadas desde el inicio para crecer y por otro cuál era el impacto que estos crecimientos producían sobre el ámbito urbano. (Imagen 18). Tras evaluar este desarrollo progresivo y extraer diferentes modelos de crecimiento propuso nuevas alternativas habitacionales planteando las siguientes pautas de diseño: al hablar de un conjunto urbano se propondrán variedad de fases iniciales y se dará la posibilidad de que el desarrollo en etapas pueda diferir en orden y características; el diseño de la casa debe de contemplar que la inversión inicial en esta sea mínima y que garantice un cambio cualitativo en las condiciones de vida del habitante; el usuario participará de forma activa en el proceso de diseño y construcción de su vivienda a través de un proceso motivador y educativo según sus necesidades, aspiraciones y experiencias; las viviendas responderán a las diferentes formas de organización de las familias mediante su flexibilidad (familias nucleares pequeñas, nucleares numerosas, extendidas, multifamiliares); su construcción estará basada en una racionalización y modulación de sus componentes que permita la combinación de elementos sólidos y ligeros; y finalmente se tendrá en cuenta que para que se dé un desarrollo urbano de vivienda de desarrollo progresivo y que este funcione será imprescindible que todo el proceso se sostenga por organismos estatales y que haya un nivel de organización comunitaria básico para producir un mejoramiento gradual constante (Haramoto, 1987, Pp.88-122).

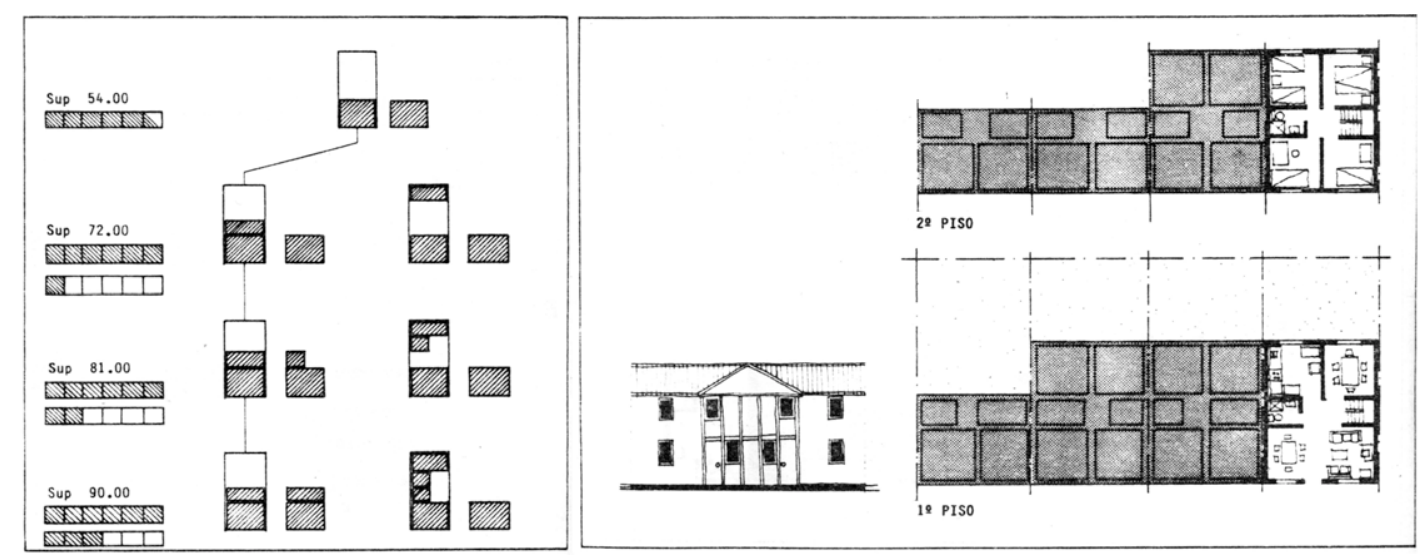

Imagen 18. Vivienda social de desarrollo progresivo de Edwin Haramoto.

Casi una década más tarde, en 1988, Monsterrat Palmer y Francisco Vergara apuntaban las siguientes características de la vivienda progresiva en Chile, destacando la relación entre vivienda y contexto urbano como algo totalmente inherente al diseño de la vivienda (Vergara Dávila \& Palmer Trias, 1988). Como primera característica sostenían que el diseño de la casa crecedera tendrá la voluntad de densificar en lugar de expandir; deberá estar abierto a diferentes modalidades de alojamiento, y no responderá a una única familia "tipo" propietaria de una casa hipotecada; se buscará una arquitectura variada, reconociendo su capacidad de satisfacer mejor las necesidades habitacionales complejas que las esquemáticas soluciones tipo; y finalmente se ajustará a las costumbres de sus habitantes con un gasto mínimo. (Imagen 19).

Sin embargo y a pesar de que Chile fue de los precursores en este ámbito, no fue hasta 1990 que se introdujo el concepto de casa crecedera en sus Programas de Vivienda, debido a la paralización sufrida en los Programas Habitacionales de carácter colectivo y de autoconstrucción, y al cese de las tomas de terreno causa del Golpe 
Militar de 1973. Es entonces, en 1990, cuando se desarrolla la ley DSI40/1990 (Ministerio de Vivienda y Urbanismo, 1990) junto con el primer programa masivo de vivienda progresiva en el que el habitante participaba en la construcción de la vivienda sin asistencia, ni asesoramiento técnico y social sustituyendo de esta manera la idea de que la vivienda se consume mientras se paga por la idea de que los hogares se habitan mientras se construyen. (Cilento Sarli, 1998).
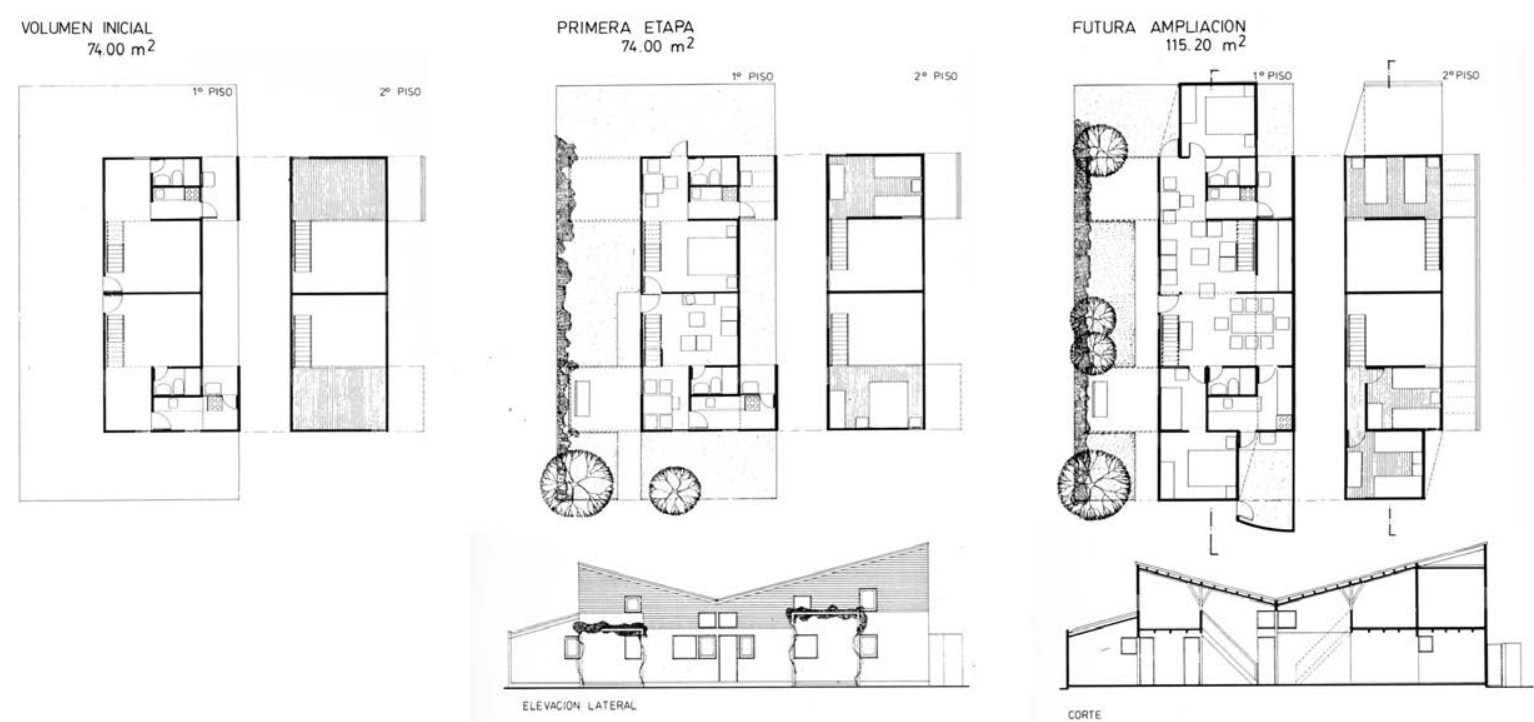

Imagen 19. Propuesta de vivienda progresiva. Monsterrat Palmer y Francisco Vergara. Lote 9x।8.

Al mismo tiempo, en la década de los 90, uno de los principales investigadores de la vivienda ampliable en Canadá, Avi Friedman, publica "The grow Home” y "Design for growth and adaptability in affordable Housing" donde establece el concepto de la asequibilidad (affordability) como principio base definidor de la vivienda ampliable. Según palabras de Friedman, "la forma de obtener una vivienda asequible es a través de las ampliaciones, donde el interior puede ser terminado de forma incremental ajustándose a las necesidades de espacio y a las circunstancias financieras de los propietarios" (Friedman, 1990). Esta noción adquiere un valor importante dentro del proceso histórico de la vivienda crecedera en los países desarrollados ya que el crecimiento se desvincula de la búsqueda de innovación y experimentación como aspiración principal ligándose a algo mucho más cercano al habitante, su economía familiar, estableciendo de esta manera un vínculo mucho mayor entre los tipos de viviendas crecederas propuestas en países en vías de desarrollo y los casos europeos vistos hasta el momento. De las teorías del arquitecto Avi Friedman se pueden extraer dos términos clave. Por un lado, la grow home (casa que crece), una vivienda parcialmente terminada, donde algunos de sus componentes pueden ser concluidos por los propietarios y donde algunos lugares (tanto en planta baja como a otros niveles) se han dejado sin compartimentar para ser completados en el futuro (Friedman, 1990). Y por otro lado la adaptable house (casa adaptable), aquella capaz de responder de forma efectiva al cambio de las necesidades de los propietarios sin requerir intensivas alteraciones de coste y energía (Friedman, 2002). (Imagen 20). 

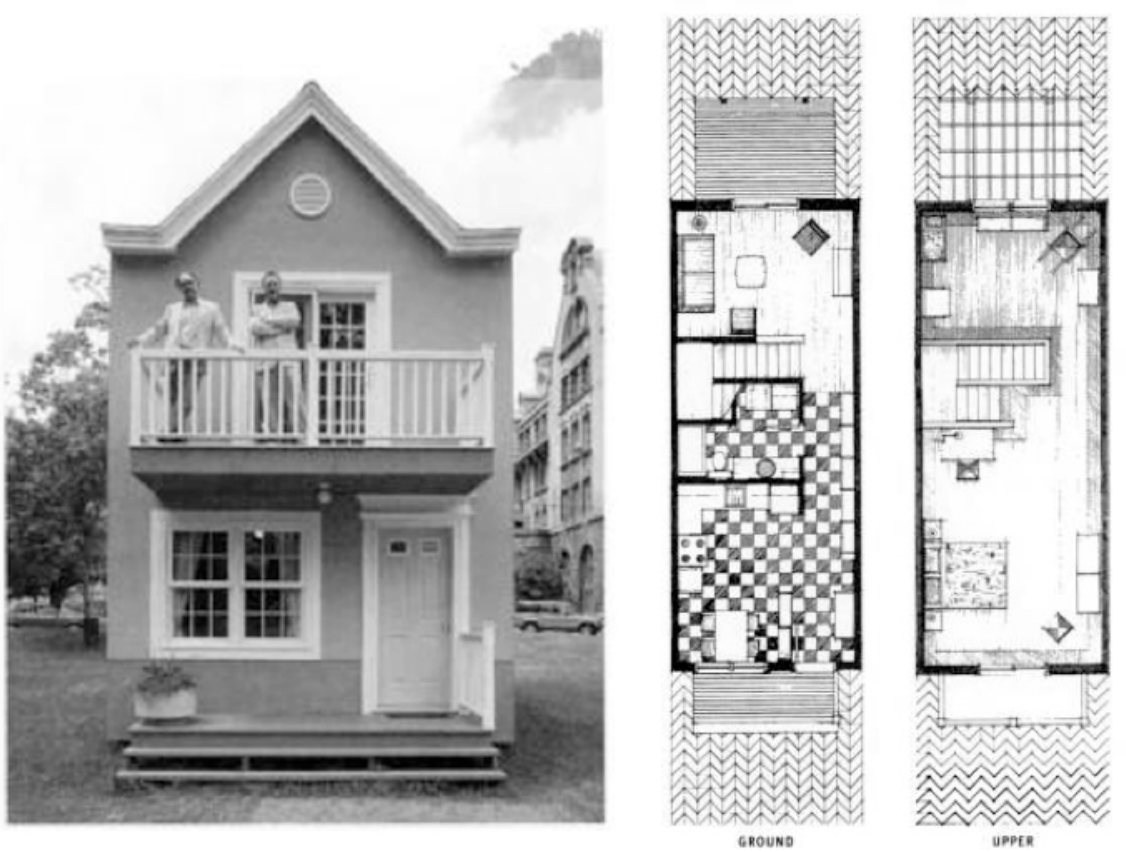

Imagen 20. Grow House de Avi Friedman.

Posteriormente aparecen dos conceptos, construcción incremental y vivienda elástica. El primero propuesto en 2009 por el grupo de investigación SIGUS (Special Interst Group in Urban Settlement) del MIT

(Massachusetts Institute of Technology) dirigido por Reinhard Goethert donde entienden la vivienda incremental como un proceso integral de desarrollo urbano en el que se construyen viviendas, comunidades y ciudades. Un proceso cuyas etapas de desarrollo son controladas por el habitante partiendo de una unidad básica, simple y asequible que será ampliada por los usuarios. Esta unidad básica es un núcleo de "arranque" eficaz (starter core) y está complementado por un marco que organice el desarrollo físico de cada núcleo en su solar, las infraestructuras que se requieren y las políticas gubernamentales necesarias para levar todo esto a cabo (Goethert, 2010). (Imagen 2I).
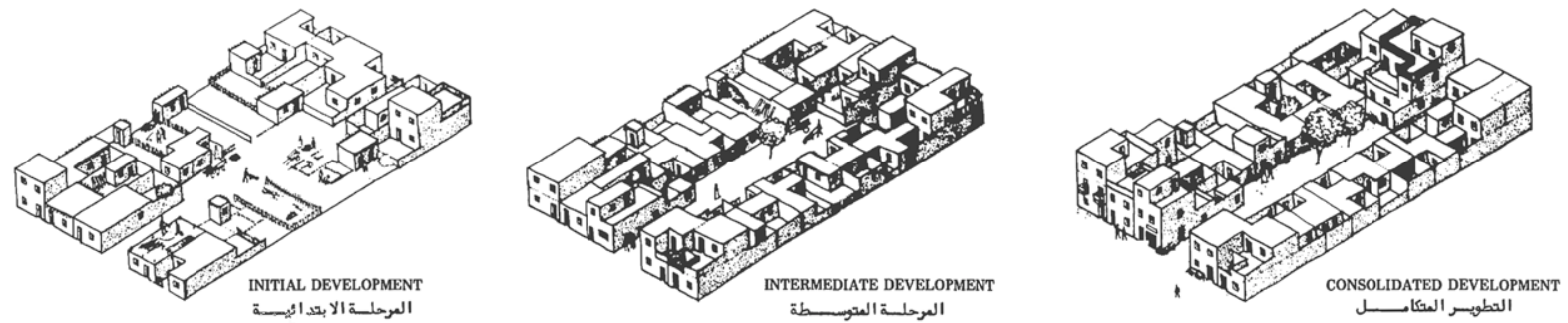

Imagen 2I. Etapas de desarrollo de una manzana con construcción incremental, Reinhard Goethert.

Por otro lado tenemos el segundo concepto que aparece en $20 \mathrm{II}$ en la investigación subvencionada por el Ministerio de Cultura de España "Más que una casa" (VV.AA., 20II). En esta se desarrolla entre otros conceptos el de vivienda elástica, considerada como aquella que permite un cambio de función en los espacios, con el aumento o disminución del tamaño o superficie de la vivienda. Esta definición da un paso más allá con respecto a todas las anteriores ya que no considera únicamente la posibilidad de aumentar la superficie 
de la vivienda, si no que contempla la opción de que tras ampliarla, se reduzca y e incluso se subdivida para rentar una parte.

Como se ha visto hasta el momento, la vivienda que crece se empezó a estudiar en los años 30 y tuvo su auge sobre todo en los años 70, pero sin embargo en la actualidad está volviendo a alcanzar un pico de interés gracias a figuras como el arquitecto Alejandro Aravena director del equipo ELMENTAL (una organización sin ánimo de lucro que trabaja en proyectos de infraestructura, transporte, espacio público y vivienda junto con la Universidad Católica de Chile y la Empresa Petrolera COPEC) que investigan sobre vivienda progresiva desde 2006 proponiendo un cambio significativo en este tipo, puesto que considera que "no hay que dejar la construcción acabada y esperar a que cada individuo la complete como se hacía anteriormente, sino que hay que diseñar esa progresividad identificando el conjunto de condiciones de diseño que se hacen cargo de la incrementalidad" (Aravena \& lacobelli, 20I2, p.18).

Es el marco de esta última definición de ELEMENTAL en el que surge la investigación de esta Tesis, que tratará de identificar cuáles son dichas condiciones de diseño que se hacen cargo de la incrementalidad y como se alteran según las condiciones del núcleo familiar. 
I. Preámbulo 


\section{El vocablo casa crecedera.}

En cuanto a la selección de la expresión a utilizar en la tesis para referirse a la vivienda anteriormente descrita se ha optado por la de casa crecedera ya que el resto de vocablos tenían acepciones que no se ceñían tan claramente al objeto de estudio por lo siguiente:

Casa extensible o casa expansiva: este término se utilizará a lo largo de la tesis pero para referirse a un tipo concreto de ampliación de la vivienda debido a lo concreto de su significado. Se utilizará por tanto la expresión ampliación por expansión para aludir al incremento en la vivienda que es reversible instantáneamente ya que se aumenta el volumen de forma breve y temporal.

Casa evolutiva: este es el concepto que más se aproxima al de la casa que crece puesto que la vivienda evoluciona con la transformación del núcleo familiar. Aunque se utilizará prácticamente como sinónimo de casa crecedera, no se ha elegido como título de tesis ya que el término evolución tiene connotaciones de progreso y puede estar asociado a conceptos no referidos únicamente al crecimiento, como pueden ser los avances tecnológicos.

Vivienda progresiva: toda casa crecedera es a su vez una vivienda progresiva ya que mejora “progresivamente" en el tiempo, igual que la economía familiar. Sin embargo no toda vivienda que progresa lo hace a través del crecimiento, ya que la mejora puede centrarse por ejemplo en cuestiones de acabados. Es por esto que, a pesar de que se use en numerosas ocasiones a lo largo de la investigación, se ha descartado por ser una expresión imprecisa.

Vivienda en semilla: se utilizará a lo largo de la tesis para referirse a la vivienda inicial previa a cualquier crecimiento. Se descartará su uso como concepto general para referirse a la vivienda que crece debido a la connotación de que al crecer la semilla esta se hace siempre grande, tal y como indica en sus descripciones Aurelio Ferrero, ya que de esta manera se deja fuera de la definición general de vivienda que crece a las ampliaciones que se dan hacia al interior sin incrementar su volumen.

Vivienda cáscara o vivienda Galpón: ambas acepciones se utilizarán durante la investigación para referirse al crecimiento tipo Adding-in o adición interior que se refiere a las ampliaciones, que sin incrementar su volumen, aumentan la superficie de la casa ocupando el espacio interior de la vivienda mediante la creación de nuevos forjados.

Pie de casa: este vocablo se refiere únicamente a las viviendas que inician con un cuarto redondo (aquel que contempla los usos en único espacio) y que crece posteriormente mediante adiciones. Es por esto que no se utilizará para hablar genéricamente de las viviendas que crecen, puesto que deja fuera el resto de tipos que crecen hacia el interior sin aumentar su volumen, a los casos cuya fase inicial contempla más que un cuarto redondo y a cualquier ejemplo de vivienda colectiva en bloque.

Casa adaptable: a pesar de que el crecimiento de la vivienda es claramente un mecanismo de adaptación, no se utilizará este nombre debido a que es demasiado genérico. Sobre todo, porque existen numerosas formas de hacer una vivienda adaptable sin necesariamente tener que crecer. 
I. Preámbulo

Construcción incremental: este término no se utilizará a lo largo de esta investigación para evitar posibles asociaciones erróneas con las teorías de crecimiento incremental de Delaunay que nada tienen que ver con el tema estudiado.

Vivienda elástica: tampoco se empleará esta acepción debido a que en los últimos años este término se está utilizando para aquella vivienda que adapta su precio al mercado y podría llevar a confusión. 


\section{Definición del objeto de estudio.}

Tas todo lo comentado anteriormente acerca del concepto de la casa crece, la vivienda que se estudiará en esta investigación será aquella que cumpla las siguientes características:

- La vivienda estará concebida desde el inicio del proyecto, para aumentar su superficie en algún momento ya que habrá sido diseñada para facilitar ese incremento gracias a su potencial para anticipar futuras extensiones (crecimiento programado).

- A partir de una acción edificatoria básica (germen de una vivienda plena) la casa crecerá según el ritmo biológico, histórico, económico y social de desarrollo de la familia.

- Responderá a las diferentes formas de organización de la familia a lo largo del tiempo gracias a su flexibilidad (familias nucleares pequeñas, nucleares numerosas, extendidas, multifamiliares) y se ajustará a las costumbres de sus habitantes a través de modificaciones que impliquen un gasto mínimo.

- El desarrollo en etapas de la casa podrá diferir en orden y características.

- Cada fase de crecimiento compondrá un todo cerrado.

- Se pondrá énfasis en el proceso y no en el producto final.

- Será aquel hogar que se habita mientras se construye.

- El habitante participará de forma activa en el proceso de diseño y construcción de su vivienda a través de un proceso motivador y educativo según sus necesidades, aspiraciones y experiencias.

- Su construcción estará basada en la racionalización y modulación de sus componentes.

- Su diseño tendrá la voluntad de densificar en lugar de expandir.

- Debido a su tamaño se volverá asequible en el Mercado para un mayor número de familias. 
I. Preámbulo 


\section{1.b. Pertinencia de la investigación.}

Los siguientes cuatro factores que se explicarán en profundidad en este apartado, son los principales desencadenantes de esta investigación sobre vivienda crecedera:

a. El hambre de vivienda digna en el mundo como suceso indiscutible, junto al patente deterioro de las condiciones del hábitat humano mundial de los últimos años'.

b. El hecho de que el $\mathbf{9 8 \%}$ de la gente que vive en regiones en vías de desarrollo no tenga un ahorro inicial lo suficientemente fuerte, ni la posibilidad de pedir un crédito, que les proporcione el dinero necesario para invertir en una casa acabada ${ }^{2}$. Situación que se está incrementando cada vez más en países desarrollados que han sufrido grandes crisis económicas en los últimos años.

c. El que las unidades de convivencia en la actualidad crezcan y se transformen de forma orgánica y compleja.

d. Y que los hábitos y costumbres desarrollados en la vivienda hayan cambiado en las últimas décadas reclamando un nuevo tipo de espacio más acorde a las necesidades contemporáneas.

A día de hoy en el mundo 1.400 millones de personas viven en alojamientos insalubres (de los cuales únicamente 128 millones son latinoamericanos y 187 millones africanos). Existen 100 millones de los denominados "sin techo". Y se estima que 25 millones de personas se alojan en campos de refugiados ${ }^{3}$. Además de este evidente problema de déficit de vivienda digna hay que tener en cuenta que entre 1950 y 1999 la población urbana mundial se ha incrementado un $47 \%$ pasando de 750 millones a más de 2.800 millones de personas ${ }^{4}$, manteniendo una tasa de urbanización del 2,5\%. Esto implica que, si se siguen estas perspectivas,

\footnotetext{
I "Según la evaluación de 2005, de la Comisión de Seguimiento de la Meta II de los Objetivos de Desarrollo del Milenio, la situación de las condiciones del hábitat humano mundial están sufriendo un franco deterioro ya que los índices netos de necesidades y de precariedad en el quinquenio 2000 - 2005 han aumentado en valores porcentuales a mayor ritmo que los de población total mundial y los de población pobre". (Salas Serrano, 20II).

2 (Bazant, 2003).

${ }^{3}$ (Salas Serrano, 20I I, p.16).

${ }^{4}$ División de Población de las Naciones Unidas, 1999. World Population Prospects: The 1999 Revision.
} 
para 2030 el 61\% de la población vivirá en ciudades y que probablemente según las estimaciones, el $94 \%$ de estas se localicen en países en vías de desarrollo. Las mismas fuentes pronostican a su vez, que de acuerdo a las tendencias actuales, todos estos nuevos crecimientos urbanos que se den en el Tercer Mundo continuarán siendo de carácter no estructurado y planificado lo que producirá una gran cantidad de asentamientos tugurizados. (Salas Serrano, 20II, PP. 13,17).

Por tanto, se puede afirmar según los datos anteriores, que en la actualidad más del $21,61 \%$ de la población mundial carece de una vivienda adecuada y que en las próximas décadas esta cifra aumentará junto a los déficits de habitabilidad derivados de los nuevos asentamientos urbanos.

Esta realidad afecta en su mayoría a paises en vías de desarrollo, pero iqué ocurre en paises desarrollados donde las problemáticas en torno a la vivienda son muy distintas a las mencionadas anteriormente?

Si se selecciona como ejemplo de país desarrollado el caso de España, este difiere totalmente con lo explicado con anterioridad a nivel global. Mientras mundialmente se preveé que el crecimiento poblacional aumente de manera exponencial. El Instituto Nacional de Estadística (INE) estima que al menos cinco millones de personas abandonarán el país en los próximos diez años; que los nacimientos se reducirán un 20\%; y que por tanto en las próximas cuatro décadas se perderá una décima parte de la población.

Si a esta situación se le añade el hecho de que, según el Informe de situación y perspectivas del mercado inmobiliario residencial en España elaborado por la consultora R.R. de Acuña y Asociados, existen casi dos millones de inmuebles en oferta actualmente (entre 1.715 .000 y 1.945 .000$)^{5}$ (Figura 02), es indispensable plantearse la pregunta de si es necesario seguir construyendo nuevas viviendas cuando nos enfrentamos a este panorama.

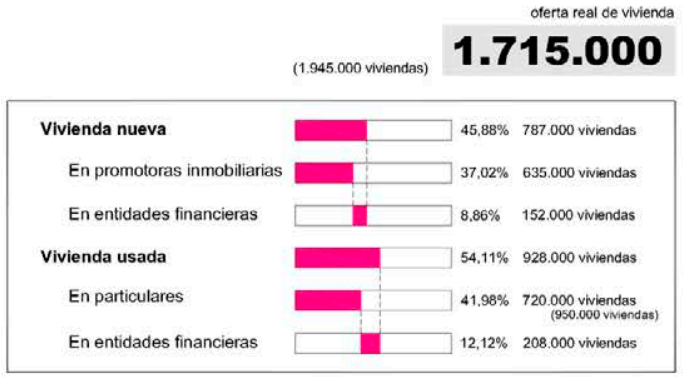

Figura 02. Stock de viviendas en oferta inmobiliaria. Elaboración propia según datos de (Gago Dávila, 20I3).

Los autores difieren enormemente en sus estimaciones oscilando desde la rotunda negación a la construcción de nuevas viviendas hasta posturas más especulativas que positivamente creen en la posibilidad de seguir ampliando el stock inmobiliario español.

Según el INE se estima que entre 2012 y 2022 el saldo neto de hogares (la diferencia de los que se crean por

\footnotetext{
${ }^{5}$ Cabe destacar el hecho que señala Jesús Gago Dávila en su artículo “Faltan viviendas? (Qué pasa con el censo... y algo más)”, que los datos ofrecidos por el Ministerio de Fomento y los brindados por el Instituto Nacional de Estadística (que ha sustituido el Censo de Viviendas que venía realizando desde 1960 por una macro Encuesta extendida al 12\% de la población), no coinciden en el número de viviendas disponibles, con una significante diferencia de 230.000 unidades. Esta discrepancia en los datos hace más difícil realizar algún tipo de estimación debido a los altos márgenes de variabilidad de las fuentes y de aquí que los autores que reflexionan acerca del tema se excusen para diferir de manera tan notable en sus previsiones.
} 
emancipación y los que desaparecen por extinción) será de 700.000 hogares (Gómez, 20I3). De acuerdo a esta cifra, Julio Vinuesa sugiere que se podrán construir 90.000 viviendas anuales durante los primeros cinco años de la década y otras 50.000 en cada uno de los años siguientes para cubrir ese deficit estimado de 700.000 hogares (Gómez, 2013).

A su vez, Germán Pérez Barrio, sugiere datos más optimistas, presuponiendo la necesidad de entre 220.000 y 500.000 viviendas al año durante la misma década (Gómez, 2013). Esta cifra está calculada al vincular la demanda no sólo a la estimación de necesidades de vivienda obtenida a través del axioma una familia una vivienda (700.000 hogares), tal y como hace Julio Vinuesa, si no basando el cálculo en las condiciones económicas generales de España. Aunque esta estimación de Pérez Barrio podría entenderse como más especuladora a primera vista, este racalca que parte de la presunta demanda se debería cubrir con el stock de viviendas existentes, lo que implicaría no construir todo el parque inmobiliario requerido, y si acaso, edificar nueva vivienda en las zonas en las que realmente no exista dicho stock.

En la oposición se encentra el punto de vista del arquitecto y urbanista Jesús Gago Dávila, que tras analizar los datos anteriores afirma que "a España, lejos de faltarle le sobra viviendas” (Gago Dávila, 20/3), por lo que considera totalmente innecesario la construcción de nuevos inmuebles hasta que no se resuelva el problema del invendido stock.

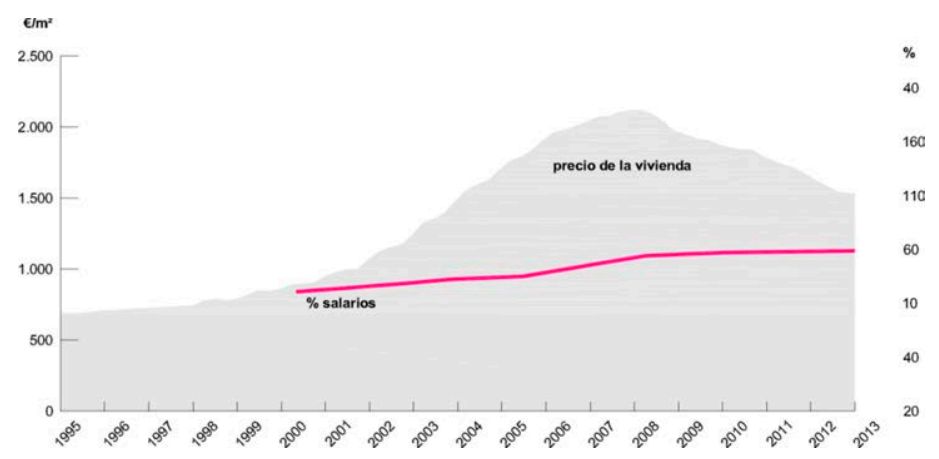

Tabla 0I. Evolución del precio de la vivienda, salarios (I995-2013). Elaboración propia según datos de (Sardina, 20I3).

Independientemente de si la respuesta a si es necesario construir nuevas viviendas en España es afirmativa o negativa, la realidad es que existe una demanda real de vivienda para un sector determinado de la población. Teniendo en cuenta la situación socioeconómica de España caracterizada según (Leal Maldonado \& Martínez del Olmo, 2013) por la restricciones hipotecarias; el incremento de las tasas de interés bancario en los préstamos; el elevado costo de las rentas que pesar de la bajada de los precios de venta no se ha reducido lo suficiente ${ }^{6}$; la precariedad del trabajo; la reducción de las viviendas sociales en alquiler; y la reducción de ayudas a inquilinos, especialmente los jóvenes; entre otros factores. Hace que el desahucio de los hogares por impagos hipotecarios (18.92I embargos en el segundo trimestre de 20I4) (Molina, 20I4); y la imposibilidad de acceder a una vivienda en renta y mucho menos en venta por jóvenes y trabajadores en situaciones precarias aumente considerablemente cada trimestre. (Tabla 0I).

\footnotetext{
${ }^{6}$ La tasa de esfuerzo media de los hogares españoles (porcentaje de renta familiar dedicada al pago de la hipoteca o la renta) se sitúa en el $33 \%$, nivel cercano a las cotas razonables de equilibrio pero que aún no las alcanza. (Consultora Deloitte, 20l4)
} 
Según Edwin Haramoto (Haramoto, 1987, p. 6), si bien es cierto que la carencia de vivienda constituye sólo uno de los indicadores de la marginalidad cultural, social y económica de la población que requiere de un desarrollo integral. En diversos estudios se sostiene que el sólo mejoramiento de la situación habitacional, se traduce en progresos importantes para el ser humano aunque los otros indicadores no sufran variaciones.

Es por esta afirmación que se considera necesario el hecho de continuar estudiando la vivienda, no sólo por la urgencia de solventar su déficit cuantitativo en el mundo, si no también para poder aplicarla como posible herramienta de mejoramiento en situaciones urbanas marginales que, con el tiempo, pueda actuar como semilla de progreso.

Se necesita entonces estudiar nuevas formas de alojamiento que respondan a una serie de elementos que no son fijos y que se transforman en función de los sistemas productivos y de la transformación de la propia sociedad. Es decir, se requiere entender la casa como un sistema con la suficiente flexibilidad como para hacerla asequible en un mercado que realmente necesita viviendas muy económicas y que a su vez sea capaz de transformarse en función de las variacianos económicas y sociales de la unidad de convivencia que la habita. Una vivienda barata y progresiva cuyo precio se ajuste al ahorro de la gente sin hipotecar su futuro.

Otro de los puntos cruciales que se han tomado como desencadénate de este estudio es la transformación de los hábitos llevados a cabo en la vivienda y la modificación de las unidades familiares desde el movimiento moderno hasta la actualidad.

La familia que se estudiaba durante el movimiento moderno y en décadas posteriores, respondía por lo general a una tendencia de crecimiento simple y lineal que ha quedado obsoleta para el estudio de la vivienda postmoderna.

En dicho modelo de crecimiento lineal existía una pareja que se casaba, entendiendo casar desde el punto de vista etimológico de la palabra latina casa (choza o cabaña) a vivir conjuntamente bajo un mismo techo. Una vez casados, la pareja tenía uno o varios hijos que con el transcurso del tiempo crecían, se hacían solventes e iniciaban de nuevo su propio ciclo independizándose y dejando a los padres viviendo solos una vez más sin que hubiera un reajuste de la cantidad de espacio habitable a lo largo de este proceso. (Figura 03).

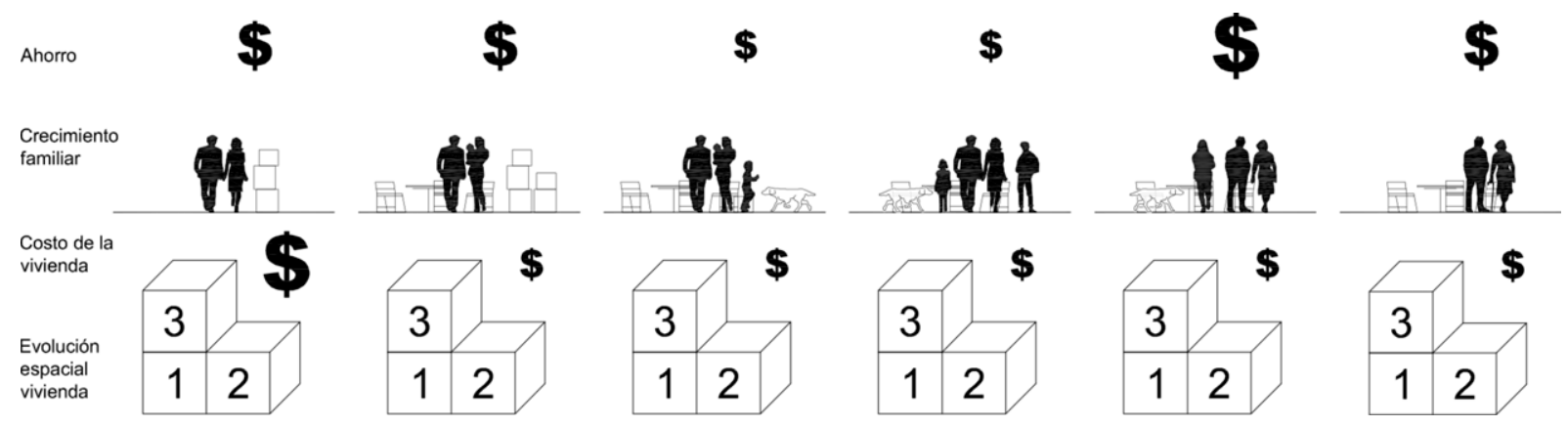

Figura 03. Familia tradicional según el modelo de análisis simplista.

Estas unidades familiares simples con crecimiento lineal, conformadas por padre, madre, dos o tres hijos e incluso mascota que se utilizaban como paradigma en el diseño de la vivienda moderna, han ido evolucionando y transformándose en las últimas décadas en sistemas mucho más complejos, que en numerosas ocasiones ni 
siquiera responden a lazos familiares. Estos sistemas de agrupación, cada vez más comunes, abarcan desde las parejas sin hijos $^{7}$ y las familias monoparentales, hasta los departamentos compartidos por amigos, los ancianos que viven solos ${ }^{8}$ o incluso los singletons ${ }^{9}$. Todas estas agrupaciones complejas, no solo en su composición si no también en su crecimiento y evolución, han comenzado a tenerse más en cuenta dentro de los procesos del diseño habitacional y están siendo reconocidas como algunos de los principales transformadores de la tipología de la vivienda contemporánea. Por ello y para no olvidar ninguna de estas agrupaciones, se está comenzando utilizar el término unidad de convivencia (Montaner, 2014) como sinónimo del de familia a la hora de elaborar terías y estudios entorno a la vivienda.

La figura del singleton, o personas que viven solas engloban desde los jóvenes solteros que en algún momento de su vida y de manera temporal llega a compartir su vivienda con otra persona para reducir gastos, hasta los ancianos que viven independientes o que son asistidos por alguien que acude puntualmente a cuidarlos. Estas unidades de convivencia se diferencian de otras, además de por vivir solos, por el alto consumo de espacio para almacenaje y desarrollo de ocio o trabajo dentro de la vivienda.

Para ilustrar el fenómeno, se ha seleccionado una unidad de convivencia sencilla real, el caso de Belén, una mujer independiente residente en la ciudad de Madrid en España. (Figura. 04).

Al analizar este caso concreto se puede observar que su patrón de dinámica familiar ${ }^{10}$ podría identificarse fácilmente con múltiples unidades de convivencia sencilla del mundo, por lo que para este estudio se supondrán los patrones de evolución del caso de Belén como significativos y característicos de este tipo de unidades.

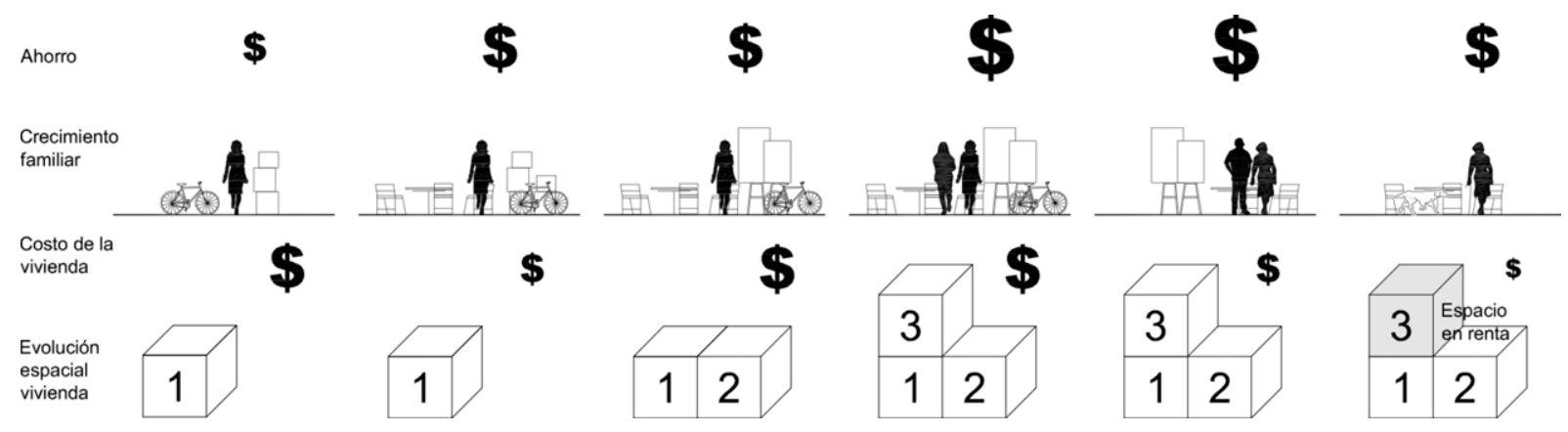

Figura 04. Modelo de crecimiento de la unidad de convivencia sencilla singleton. El caso de Belén.

Por otro lado, se encuentra el caso de las unidades de convivencia compleja donde el proceso de evolución difiere. En este caso, el crecimiento más significativo se debe a la fluctuación en el número de miembros de la unidad, en la que se desconoce inicialmente el número máximo y mínimo de miembros de la unidad de convivencia y su variación a lo largo del tiempo. Este es el caso, por ejemplo, de la familia Negrete residente en la delegación de Tlalpan del Distrito Federal de México, una familia que inició su evolución según el modelo

\footnotetext{
${ }^{7}$ Aproximadamente el $20 \%$ de la población en España. (Montaner, 2014).

${ }^{8}$ Más del 3,6\% de la población española (I,7 millones de personas). (Montaner, 2014).

${ }^{9}$ Los singletons o personas que viven solas representan en los países del norte de Europa entre un 40 y $45 \%$ de la población, mientras que en España corresponden al $20 \%$ de esta. (Montaner, 2014).

${ }^{10}$ Este patrón refleja el proceso de crecimiento de la unidad de convivencia a lo largo del tiempo en términos de número de integrantes, ritmo de crecimiento y relación familiar (Bazant, 2003) y se describirá en el apartado Patrones evolutivos y parámetros de esta tesis.
} 
simplista de crecimiento lineal (una pareja con hijos en la que una vez que los niños crecieron y se independizaron, dejaron a los padres solos). Sin embargo, en este caso, como en la mayoría de los casos de unidades de convivencia compleja con crecimiento orgánico, después de varios años, bien sea por circunstancias económicas o por tradición cultural de conservar el nido familiar amplio en torno a los padres, los hijos regresaron a la casa familiar con su pareja e hijos, aumentando de esta manera la unidad de convivencia a una familia extendida. La complejidad de estas unidades familiares puede llegar a ser amplísima reuniendo en un mismo nido hasta cuatro generaciones distintas. En algunos casos y si la vivienda lo permite se podrá albergar sin problemas a la nueva familia extendida, pero la mayoría de las veces, sobre todo cuando la ampliación de la vivienda no es suficiente y adecuada, se obtiene como resultado de esta incorporación un nido hacinado (Leal Maldonado \& Martínez del Olmo, 2013, p. 304), hogar en el cual debido al exceso de habitantes en un mismo espacio pueden llegar a producirse condiciones de habitabilidad indignas.

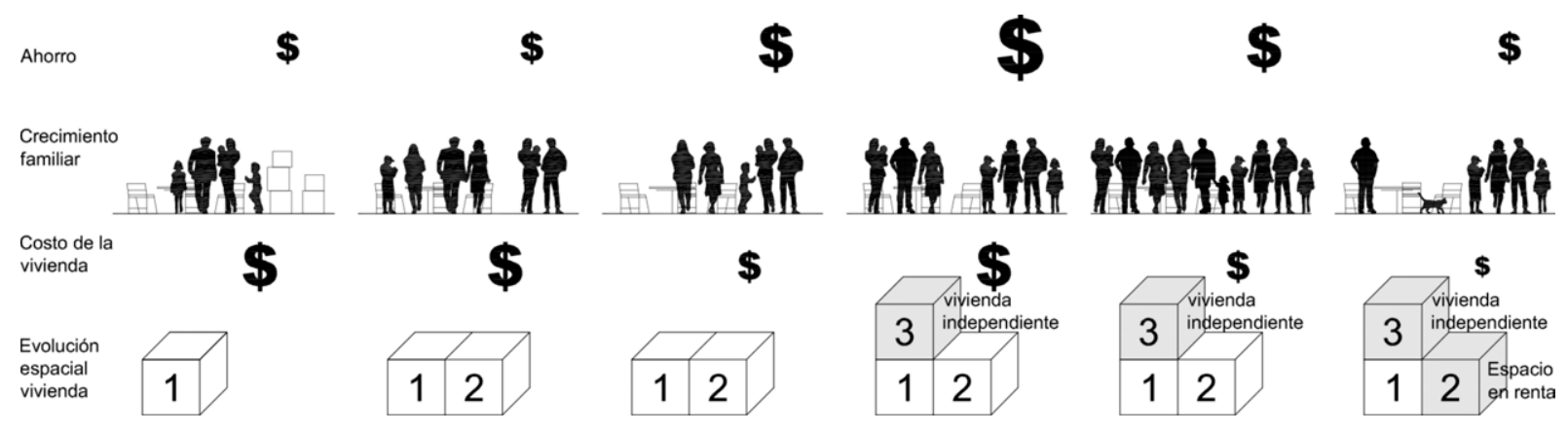

Figura 05. Familia compleja postmoderna según el modelo de análisis orgánico. La familia Negrete.

Cabe destacar que en los últimos años de crisis en Europa ha proliferado este último tipo de unidades de convivencia compleja. El retraso en la edad de emancipación, el aumento de parejas separadas que se ven obligadas a compartir una misma vivienda, familias que tienen que compartir casa con extraños por problemas de pobreza derivados del desempleo que imposibilitan alcanzar una vivienda digna, los hijos en edad de emancipación que regresan a vivir con sus padres, son algunos de los tipos que están aumentando en paises como España o con situaciones económico-sociales similares.

Algunos autores (Leal Maldonado \& Martínez del Olmo, 2013) consideran esta situación como un importante retroceso en el comportamiento de las familias españolas que tienden a repetir antiguas estructuras $y$ organizaciones familiares. Se podría suponer entonces, que al retomar el funcionamiento de las familias tradicionales se produce un mayor acercamiento a las tendencias familiares latinoamericanas y no tanto a las del resto de Europa. Por lo que ante esta posible reconfiguración en las tendencias globales de las unidades de convivencia, donde los modos de vida de los países europeos en crisis se acercan cada vez más a los modos de vida de los paises Latinoamericanos, se ha considerado pertinente analizar ejemplos localizados en las dos regiones (Europa y Latinoamérica) puesto que ambas se enfretan a la misma problemática a través de distintas soluciones arquitectónicas. Y así de esta manera será más fácil identificar los acercamientos más adecuados en función de cada situación.

En el estudio de las unidades de convivencia a través modelos complejos, en los que un sujeto puede involucrarse en distintas soluciones de vida proporcionando sistemas de convivencia totalmente dispares, se 
considera necesario que se manejen principios de diseño donde la flexibilidad y la ampliación tengan un papel fundamental. Permitiendo a la casa adaptarse a las distintas etapas del núcleo familiar derivadas de la dinámica de crecimiento propia (crecimiento vegetativo) o del crecimiento por factores externos a ella (allegamiento).

A su vez, hay que considerar la posibilidad de que la unidad de convivencia no sólo se amplíe, si no que disminuya en número de miembros en algún momento, por lo que el diseño de la casa tendrá que prever posibles particiones. Estas particiones permitirán la subdivisión de la vivienda en núcleos más pequeños e independientes entre sí, que faciliten que parte de la casa se rente o se utilice para conseguir mayores ingresos familiares, obteniendo así una híper-casa.

Por ello se ha elegido como objeto de estudio la vivienda crecedera, aquellas acciones edificatorias básicas, germen de una vivienda plena, que debido a su tamaño se convierten en asequibles en el mercado para un mayor número de familias, y que están concebidas desde el inicio del proyecto, para aumentar su superficie en algún momento según el ritmo biológico, histórico, económico y social de desarrollo de la unidad de convivencia ya que habrá sido diseñada para facilitar ese incremento gracias a su potencial para anticipar futuras extensiones. Tipologías residenciales alternativas, que permitan aplicar otras formas de tenencia y gestión, y donde para llevarlas a cabo, tendrán cabida sistemas adaptables de transformación. 
I. Preámbulo 


\section{Problemática de la vivienda crecedera.}

Cuatro son los fundamentales problemas de la vivienda crecedera que se tratarán en esta tesis:

a. La autoconstrucción y el binomio habitar - construir.

b. La legalidad y las normativas.

c. El ahorro de la unidad de convivencia.

d. El acertar en la planificación a futuro.

La autoconstrucción y el binomio habitar - construir

El fenómeno de la autoconstrucción ha sido estudiado en profundidad por diversos autores tales como Turner, Haramoto, Bazant, Vergara y Palmer " cuyos escritos se han tomado como referente para la realización de esta tesis. Al ser un tema tan complejo y exceder los límites de esta investigación, puesto que podría derivar en otra tesis doctoral, únicamente se citaran los problemas más habituales en relación al crecimiento y se realizarán unas breves reflexiones sobre el tema.

Tanto el proceso programado como el no programado de ampliación de la vivienda, sobre todo en países en vías de desarrollo, está directamente relacionado con sistemas autoconstruidos. El $85 \%$ de las casas de la ciudad de México (Bazant, 2003) están hechas de esta manera, al igual que el 45,32\% de las viviendas crecederas localizadas en esta investigación ${ }^{12}$.

Lo ideal en los casos en los que se necesite realizar la vivienda por autoconstrucción es que este proceso sea dirigido por un arquitecto o técnico especializado, de manera que la progresión por etapas mantenga una coherencia arquitectónica, gracias a la cual la secuencia lógico-constructiva será más eficiente a la vez que la edificación y la puesta de las instalaciones resultará más económica. Sin embargo, muchas veces, no es posible contratar a un técnico que asista la autoconstrucción, no tanto porque implique un mayor gasto, ya que a menudo construir por cuenta propia resulta incluso más caro, sino porque implica cumplir las Normas y Ordenanzas del lugar, lo que hace que se pierda la flexibilidad y la libertad en la vivienda que se necesita en estos casos.

Junto a esto hay otros dos factores que influyen en la relación autoconstrucción-crecimiento. Por un lado el que este sistema constructivo es probablemente el que se adapta mejor al nivel económico y las fluctuaciones en el tiempo de las unidades de convivencia de menos recursos. $Y$ por otro, porque es de los pocos que permiten que los habitantes sigan viviendo en la casa mientras que se construye, ya que como la construcción la desarrollan familiares, amigos y gente de confianza pueden mantener sus enseres en el lugar y realizar sus tareas cotidianas.

Estos procesos basados principalmente en el habitar-construir, puesto que la gente no espera a que la casa esté terminada para comenzar a ocuparla, han de ser planeados de forma estratégica para que sean factibles. En los crecimientos hacia el interior que se explicarán más adelante, gracias al diseño inicial se permite una ampliación

\footnotetext{
" (Turner, 1977), (Haramoto, 1987), (Bazant, 2003) y (Vergara Dávila \& Palmer Trias, 1988).

${ }^{12}$ Ver lista de casos en el apartado Recopilación de casos y resultados estadísticos globales.
} 
rápida y en seco, que apenas afecta el funcionamiento diario de la casa. Mientras que el crecimiento exterior se realiza ajeno a la vivienda hasta que, una vez listo, se conecta a la vivienda inicial mediante una pequeña intervención que no interfiere en la vida cotidiana del hogar. El planear que estos sistemas de ampliación no alteren la vida familiar es uno de los retos principales del diseño de la vivienda crecedera, que en muchos casos europeos, se ha solucionado con métodos de autoconstrucción mediante sistemas prefabricados modulares de montaje en seco que hacen el proceso rápido y eficaz.

Por lo general y con independencia del aspecto de la casa a lo largo de sus fases, los principales problemas derivados de la autoconstrucción son la inadecuada ejecución de la obra, sobre todo en las juntas entre la vivienda inicial y los crecimientos, que derivan en fallos estructurales y goteras; y la ausencia de un proyecto global a futuro, que considere la vivienda inicial como el germen de una casa mayor, haciendo la construcción ineficiente y más cara. Sin embargo y según Haramoto "las deficiencias y las imperfecciones de la vivienda son mucho más tolerables en la medida en que el poblador se siente responsable de ella" (Haramoto, 1987), por lo que al final los habitantes continúan realizando estas prácticas a pesar de lo anterior.

Si nuevamente regresamos al caso de España, se puede observar que los procesos de autoconstrucción no están regulados en este país. Causa por la cual es probable que haya resultado complicado localizar casos de vivienda crecedera españoles. El arquitecto Santiago Cirugeda señala que "la autoconstrucción en España no está legalizada, y por lo tanto el arquitecto que se involucra en ese problema (autoconstrucción), debe asumir responsabilidades civiles, penales y administrativas de todo tipo" (Cirugeda, 20I4). Puede que en efecto pocos arquitectos quieran arriesgarse a estos problemas, por lo que, los pocos ejemplos que encontremos construidos, se podrán considerar, según palabras del arquitecto sevillano, “jurisprudencia construida”.

Como fruto de esta relación entre crecimiento, autoconstrucción y normativa, se hace inevitable derivar el discurso al segundo de los aspectos a tener en cuenta a la hora de proyectar una vivienda crecedera, el concepto de legalidad, que se comentará en el siguiente apartado.

\section{La legalidad y las normativas.}

En numerosas ocasiones, cuando se explica qué es la vivienda crecedera (una casa pequeña, lo suficientemente asequible como para poder comprarla sin hipotecarse y que, a medida que uno va ahorrando más dinero, se puede ampliar según se necesite) surge la misma pregunta: ¿por qué no se construyen más casas crecederas? Cierto es que en parte viene asociado al desconocimiento de los tipos existentes y la posibilidad de aplicarlos en ciudades consolidadas de todo tipo, pero como ya hemos anunciado en el anterior apartado principalmente tiene que ver con la legalidad de las prácticas constructivas.

Partiendo de que la mayoría de las veces las casas crecederas construidas en los países en vías de desarrollo se levantan en zonas de la ciudad ocupadas ilegalmente, es difícil que, tras obtener el terreno de esa manera, la vivienda sea construida después siguiendo las ordenanzas y las normativas. Es por esto que allí los procesos de crecimiento se dan más fácilmente, puesto que no se rigen por el gran aparato burocrático que dificulta los procesos de ampliación en otros lugares haciéndolos más caros y dilatados en el tiempo. 
Sin embargo, esto no quiere decir que no se puedan dar casas crecederas en el caso de que uno quiera legalizar todo el proceso. Sí se puede hacer, solo que implica toda un protocolo notarial que hace el proceso mucho más caro, derivando posteriormente en un mayor pago de impuestos en función de una propiedad con más metros cuadrados. La perspectiva de pagar más impuestos, sumada a los gastos extra para realizar las legalizaciones $\mathrm{y}$ las restricciones constructivas de las normativas, provocan en muchos casos que familias de bajos ingresos se mantengan en la ilegalidad a la hora de construir su hogar. Por esto, sería interesante explorar figuras legales alternativas que facilitasen la construcción de la vivienda progresiva.

Poniendo de nuevo como ejemplo el caso de España, dentro del ámbito de la normatividad y en función del tipo de vivienda crecedera que se vaya a desarrollar se deben cumplir unas u otras reglas. Esencialmente hay dos grandes áreas de aplicación, la de la vivienda crecedera aislada que responde principalmente a la Normativa Urbanística Municipal y a la Ley del Suelo; y la de la vivienda crecedera en bloque que atiende además de a las anteriores, a la Ley de Propiedad Horizontal.

En el caso de la construcción particular de vivienda unifamiliar, la reglamentación de lo que se permite hacer en la parcela está contenida en la Normativa Urbanística Municipal y depende del municipio donde se encuentre el terreno sobre el cual se quiere edificar. Esta Normativa fija la determinación exacta del volumen edificable en función de los metros cuadrados de la parcela, la altura de la edificación, las alineaciones, las rasantes, las posibles servidumbres a establecer, etc. Además de esta Normativa, hay una serie de facultades y deberes de la propiedad que aparecen en la Ley del Suelo, pero no las consideraremos al no afectar de manera concreta a la construcción de futuras ampliaciones de la vivienda.

Si se tiene en cuenta que el objeto de esta investigación es la vivienda que está diseñada desde el primer momento para crecer en un futuro, se supondrá que el proyecto de esta tendrá previstas desde el inicio las restricciones urbanísticas existentes en la parcela. Y que por tanto considerará y respetará la normativa, desde la vivienda semilla hasta la última ampliación, sin que las restricciones legales pudieran suponer un problema en el futuro.

Es cierto que las normativas dificultan el proceso de proyecto y modificación de las viviendas a la hora de adaptarse a las necesidades de cada familia. Según Xavier Sust "nuestra sociedad y nuestra manera de vivir se han transformado radicalmente. De una dictadura se ha pasado a una democracia consolidada. Las ideologías dominantes han cambiado. (...) Los modelos de composición y de comportamiento familiar son muy diferentes. La ocupación media de las viviendas ha bajado sensiblemente. La construcción ha evolucionado. La tecnología, en especial en los campos de la informática y de las comunicaciones, ha tenido avances revolucionarios. La sensibilidad y la preocupación por el medio ambiente se han generalizado. Las preferencias estéticas han variado. La inmigración ha cambiado la composición de la población. Pero las ordenanzas sobre vivienda siguen siendo las mismas." (Sust, Borrell, Paricio, \& Ramón, 198I, p. 77). Esto en parte pone de manifiesto que las trabas que las normativas ponen al diseño no son algo intrínseco de la vivienda crecedera si no que sucede en cualquier tipo de construcción. Por lo que quizás con pequeñas modificaciones que actualizaran estas reglamentaciones se podría construir de forma más aproximada a las necesidades y medios actuales, y en extensión crecer más fácilmente. 
Por otro lado, y en el caso de la construcción de bloques habitación destinados a varias familias, además de las mencionadas Normativa Urbanística Municipal y Ley de Suelo, se deberá cumplir con la Ley de Propiedad Horizontal.

Esta Ley afecta directamente al fenómeno del crecimiento y permite crecer de muy pocas maneras sin implicar a terceras personas en el proceso. De acuerdo al texto, únicamente se podrá crecer sin mediar con terceros usando crecimientos internos sin incremento de volumen siempre que las modificaciones no afecten a los bienes comunes. (VV.AA., 1972, p. 5). Por tanto, se podrán realizar crecimientos mediante el sistema de unión de viviendas ${ }^{13}$, siempre que los dueños de las dos viviendas implicadas, estén de acuerdo y la comunidad de propietarios decida de forma conjunta las nuevas cuotas de participación de las viviendas resultantes. Mientras tanto, cualquier otro tipo de crecimiento, bien sea ocupación de terrazas o patios, crecimientos verticales $u$ horizontales, etc. implicará un incremento del volumen de la cosa privativa (la casa) y por tanto una alteración de lo común, involucrando a la comunidad de propietarios. Por ello nunca podrán realizarse estos últimos tipos de crecimiento sin que exista el consentimiento de los demás condueños aunque de ello pudieran resultar ventajas para todos. ${ }^{14}$

El hecho de tener que conseguir el apoyo de la mayoría de los condueños de la propiedad para realizar cualquier modificación de la vivienda que afecta al exterior de esta y a sus propios límites, hace que el proceso se complique mucho, sobre todo en el caso de comunidades con relaciones problemáticas, y esto hace que la mayoría de las veces se renuncie a realizar ampliaciones sin siquiera haber planteado el proyecto a la comunidad. Es decir, que no se crece no tanto por las restricciones normativas, que también, si no más bien por la desidia que produce todo el proceso.

La legalización de la casa es también uno de los factores determinantes a la hora de decidir si se hará una vivienda por fases dilatadas en el tiempo o si esta se construirá de una vez, ya que este proceso además de encarecer enormemente la construcción hace que esta se prolongue aún más en el tiempo.

Para comprobar esta premisa se decidió calcular el costo de legalización de dos viviendas. La casa $\mathrm{A}$ de $100 \mathrm{~m}^{2}$ construida de una sola vez y la casa B de $100 \mathrm{~m}^{2}$ igualmente pero construida en tres fases de 50,25 y $25 \mathrm{~m}^{2}$. Para calcular este costo se desglosó el monto total que implica realizar una ampliación. Obteniendo por un lado el coste material de la construcción y por otro el coste de los trámites y de los honorarios arquitectos. De esta manera se identificó el coste de legalización de la vivienda como la suma de los últimos (trámites y honorarios).

Los cálculos se realizaron ${ }^{15}$ según la Ordenanza de Edificación de Granada, que ha sido elegida como base ya que es la normativa más actualizada del país. Así se obtuvieron las cantidades mostradas en la Tabla 02 en la que por un lado se puede observar que ambos casos tienen el mismo costo material. Esto sucede porque los cálculos se han realizado a partir de los metros cuadrados construidos siendo el resultado idéntico puesto que se partía de la misma cifra final. Cabría destacar que esta cantidad es aproximada ya que probablemente al

\footnotetext{
${ }^{13}$ Ver el apartado "Mecanismos de ampliación en la vivienda contemporánea".

${ }^{14}$ Artículo 397 del Código Civil español.

${ }^{15}$ Ver el apartado Patrones evolutivos y parámetros.
} 
construir la vivienda de una sola vez se podrían comprar los materiales por mayoreo siendo estos más baratos. Y además, al hacer la vivienda en una única fase se evita que los materiales se echen a perder ya que no tienen que esperar largas temporadas a la intemperie para ser usados, por lo que la construcción se abarata.

\begin{tabular}{|l|c|c|c|c|}
\hline & \multicolumn{2}{|c|}{ Casa A $\left(100 \mathrm{~m}^{2}\right)$} & \multicolumn{2}{c|}{ Casa B $\left(50+25+25 \mathrm{~m}^{2}\right)$} \\
\hline Coste material & $60.000,00 €$ & $75,61 \%$ & $60.000,00 €$ & $64,51 \%$ \\
\hline Coste de legalización & $19.349,45 €$ & $24,39 \%$ & $33.006,15 €$ & $35,49 \%$ \\
\hline Coste total & $79.349,45 €$ & $100 \%$ & $93.006,15 €$ & $100 \%$ \\
\hline
\end{tabular}

Tabla 02. Comparación de costos entre la casa $A$ y la casa B.

Por otro lado, y observando de forma aislada los datos de la casa B, la construida por fases, podemos ver como la relación del costo material frente al costo de legalización es prácticamente de $35-65$. Estando el 64,5l\% del costo total destinado a material para la construcción y el resto, 35.49 \%, a los gastos indicados para la legalización de esta ampliación. Esta proporción casi de 35 - 65 resulta desproporcionada para muchas familias ya que el gasto que implica la legalización permitiría construir una superficie mucho mayor. Es por esto que a menudo la gente que realiza ampliaciones en su hogar, tanto en España como en otros países, no lo hace de forma legal, es decir, no lo notifica al Ayuntamiento correspondiente porque al no hacerlo únicamente desembolsan el $65 \%$ del gasto total, que no es poco. Esta costumbre es muy beneficiosa para los habitantes a corto plazo ya que no sólo se ahorran el costo de legalización si no también el incremento en el precio de los subsecuentes recibos del impuesto de bienes inmuebles. Sin embargo, a la larga trae numerosos problemas, ya que a la hora de vender, traspasar o subdividir la vivienda se requiere de la legalización que no se hizo en su momento, complicando y retrasando cualquier transacción. Pero sobre todo encareciéndola, ya que la Dirección General del Catastro cobra en el proceso de legalización de ampliaciones notificadas fuera de tiempo la cantidad de hasta 6.000 euros en concepto de multa, más los impuestos de años anteriores no pagados ${ }^{16}$.

La otra comparación significativa dentro de los resultados de nuestros dos casos de estudio es, a parte de la desproporcionada relación entre el costo material y el costo de legalización, la diferencia que hay entre los costes de legalización de cada caso.

El monto para legalizar la casa B, la vivienda por fases, es notablemente superior al de la vivienda construida de una sola vez (a razón del 170,57\%). Se puede observar por tanto que a mayor superficie de vivienda a legalizar de una sola vez se emplea menos porcentaje de coste de legalización y por tanto se paga proporcionalmente menos. Lo que podría corroborar la teoría anterior de que los usuarios de viviendas crecederas no legalizan sus casas más que en caso de que sea estrictamente necesario (ventas, traspasos, subdivisiones, etc.). $Y$ en el momento en el que se requiera, estos legalizarán todas sus ampliaciones conjuntamente pagando

\footnotetext{
${ }^{16}$ A partir del año 2013 y según el Boletín Oficial del Estado (BOE) se puso en marcha el Procedimiento de Regulación Catastral 20I32016, proceso con el cual se pretende regularizar el parque inmobiliario español construido de forma ilegal. En este proceso se sustituye la multa de hasta $6.000 €$ por una tasa de $60 €$ sin ninguna otra sanción a parte del pago de los impuestos de años anteriores.
} 
proporcionalmente menos que si se hubiera hecho por fases, (en teoría, porque ya hemos visto tendrán que pagar una multa y los impuestos retrasados).

Este desfase entre el costo de hacer la vivienda de una vez o progresivamente, refuerza la idea de que en España no se hacen más casas crecederas como solución del hábitat social, no porque no se quiera, si no porque lo que debería de ser una solución para la gente sin recursos se convierte en una iniciativa económicamente inviable para las familias. En el caso que se está estudiando, la diferencia entre hacer una vivienda de $100 \mathrm{~m}^{2}$ de una vez a hacerla por fases, implica que el que la haga por fases tiene que pagar 13.656,7 $€$ más en la legalización. Si consideramos los datos del 2013 en los que el salario mínimo en España era de $752,85 € /$ mes $^{17}$ y que el ahorro medio anual según el Instituto Nacional de Estadística es únicamente del 8,2 \% del sueldo. Se concluiría que el tiempo que una familia media en España tardaría en ahorrar únicamente la diferencia de lo que costaría legalizar la vivienda por fases en vez de hacerlo de una vez sería de 17 años (suponiendo además que esta unidad de convivencia recibiera 13 pagas anuales y dedicara absolutamente todos sus ahorros en el pago de la legalización de su vivienda).

Si se tiene en cuenta que la vivienda crecedera se aporta como una posible solución para generar vivienda social y de su construcción resulta que hay que pagar un $11,1 \%$ más de impuestos de legalización que si la vivienda se hiciera de una vez. No es de extrañar que los españoles hayan descartado completamente la posibilidad del crecimiento como forma de construir sus viviendas mientras que las condiciones actuales de las normativas se mantengan. Lo que frustra la posibilidad de hacer una arquitectura más adaptable y más flexible con un mayor potencial de futuro para el habitante medio.

\section{El ahorro de la unidad de convivencia.}

El crecimiento de la vivienda está estrechamente ligado a la noción de ahorro, ya que si no se dispone del dinero suficiente o de la posibilidad de que un préstamo sea concedido, no se podrá realizar un aumento del espacio habitable por más que se desee.

Es importante, debido a que el crecimiento es un proceso dilatado en el tiempo, hacer una estimación aproximada del ahorro medio mensual de la unidad de convivencia para elegir el sistema de ampliación más adecuado. A esto hay que sumarle el ahorro previo que se tenga o, si se parte de un modelo subvencionado por una institución, saber de qué monto se dispone, ya que igualmente estas cantidades restringirán la elección del tipo de crecimiento. Por ejemplo, se puede dar el caso de que el ahorro previo sea reducido, pero que el ahorro medio mensual sea constante, con lo que se podrán aplicar métodos de crecimiento por adición mediante la incorporación a la construcción de pequeños cuartos en función del ahorro progresivo, tal y como se explicará en consecuentes aparatados de la investigación. O que se dé el caso en el que el ahorro inicial sea mayor y el ahorro medio mensual imprevisible, pudiendo utilizar la estrategia de crecimiento por adición interna, donde se entrega una vivienda cáscara de mayor costo inicial, pero que está preparada para una futura compartimentación mediante crecimientos interiores de mucho menor costo. Es importante tener claro ante estas dos situaciones que el crecimiento por adición exterior será siempre más caro a nivel global que el crecimiento por adición interior, porque en el primer caso hay que hacer dos losas de forjado (una para cada

\footnotetext{
${ }^{17}$ Datos de julio 2013. Fuente Eurostat.
} 
planta), mientras que en el segundo caso se hará una sola losa de cubierta y un forjado intermedio ligero consiguiendo un costo final más económico.

Por lo tanto, ser consciente de la cantidad de dinero que se tendrá a lo largo del proceso será determinante a la hora de elegir el tipo de crecimiento a utilizar en cada momento.

\section{El acertar en la planificación a futuro.}

Como se ha visto, los procesos de crecimiento de la unidad de convivencia son complejos y por ello su capacidad de ahorro es relativamente imprevisible. Esto ocasiona que difícilmente se puedan hacer planes de cómo, cuándo y cuánto se podrá gastar en la construcción de la casa. Debido a esta incertidumbre, muchas familias de bajos ingresos no planean la totalidad de su vivienda desde el inicio, ya que, aunque decidan hacerlo es inevitable que tengan que ajustar continuamente la planeación para adaptarse a los incesantes cambios que van aconteciendo.

Es cierto que ante esta indeterminación es difícil hacer una previsión y que ésta se cumpla, pero se puede tratar, por un lado, de construir con un sistema abierto donde los componentes estén pensados para ser ensamblados sin seguir un orden predeterminado, lo cual permite variaciones en el proceso. $Y$ por otro lado, se puede intentar que el diseño de la vivienda sea igualmente adaptable durante su desarrollo permitiendo tomar distintos caminos de evolución en cada una de las fases.

De acuerdo a esta última característica, se considerará la posibilidad de crecimiento en una vivienda como un rango de libertad, y se buscará como óptima la vivienda que tenga el mayor grado, es decir el tipo que tenga un mayor crecimiento posible. Esto significa no solo que la casa pueda ampliarse el mayor número de metros cuadrados sino que en cada intervalo previo a una fase de crecimiento se pueda elegir entre el mayor número de opciones evolutivas. Es decir, se buscará tener el más amplio abanico de posibilidades de crecimiento en todas y cada una de las fases de progresión de la casa.

Para conseguir que el proceso de crecimiento sea lo más flexible se realizará un proceso mental de deconstrucción de la vivienda deseada. Se imaginará la vivienda completa en su estado de máximo crecimiento y, poco a poco, se irán eliminando estancias hasta llegar al mínimo construido que puedan permitirse los habitantes en ese momento. Esto se hará, en primer lugar, para evitar desperdiciar metros cuadrados en circulaciones innecesarias y en segundo lugar, para evitar dejar habitaciones sin iluminación y ventilación natural. Este mínimo plan de desarrollo hará más eficiente la construcción evitando demoler parte de lo ya construido o trasladar instalaciones para realizar nuevas ampliaciones. Y, sobre todo, a la larga conseguirá que el costo de materiales sea menor, ya que no se tendrá la necesidad de acopiarlos por largos períodos quedando inservibles y se podrán comprar por toneladas en vez de por menudeo ahorrando así entre un 10 y un $55 \%$ en el precio de estos.

Podemos recalcar nuevamente entonces que el fenómeno de la casa crecedera es complejo, variable y depende de factores difícilmente controlables, por lo que se ha de investigar en procesos de diseño que faciliten la adaptabilidad de la vivienda y la variación del proyecto en cualquier momento tomando como base sistemas constructivos que no requieran de procesos lineales. De esta manera será más fácil conseguir ajustarse a los 
requerimientos que exijan las familias de bajos ingresos en función de las variaciones de su núcleo familiar y de sus ingresos.

Para tratar de conseguir esto se han vinculado algunos de los aspectos condicionantes de la vivienda crecedera señalados anteriormente (la evolución familiar, el ahorro, el costo de la legalización...) con los patrones evolutivos (patrón de evolución familiar, patrón de costo material de las ampliaciones, patrón de costo de legalización...) que permitirán entender el fenómeno del crecimiento en cada caso de una forma más profunda lo que facilitará la toma de decisiones para optimizar el proceso. 


\section{1.c. Hipótesis, objetivos y metodología.}

\section{Hipótesis.}

Se considera que el proceso de crecimiento de la vivienda es un fenómeno complejo y dinámico sujeto a numerosos factores socio económicos difícilmente previsibles en el tiempo pero fácilmente monitoreables según unos parámetros determinados (normatividad, número de habitantes, ahorro medio...).

El crecimiento de la vivienda está estrechamente ligado a la evolución de la unidad de convivencia que la habita de manera que la casa se transforman en un hábitat dinámico que responde a las dinámicas familiares (número de habitantes, relación entre habitantes, ingreso medio, ahorro medio...).

Aunque cada proceso familiar es individual y responde a condicionantes muy particulares de cada familia. Se considera que, como secuencia de eventos a lo largo del tiempo, se mantiene un paralelismo entre unidades de convivencia que tienen similares condiciones socio económicas y de localización en la ciudad.

\section{Objetivos.}

El principal objetivo de esta investigación es la elaboración de un sistema de análisis y diagnóstico de la vivienda crecedera. Este sistema permitirá indicar cual es la vivienda semilla óptima que de acuerdo a determinados parámetros facilitará la evolución de una unidad de convivencia concreta.

Para ello, se tienen como objetivos secundarios los siguientes:

- Organizar las principales teorías sobre vivienda crecedera desde 1930 hasta la actualidad, independientemente de si estas fueron desarrolladas en (o para) países desarrollados o en vías de desarrollo. Para obtener un abanico lo más amplio posible de formas de crecimiento existentes.

- Situar durante los tres primeros años de investigación el mayor número de casos de viviendas crecederas publicados en revistas de prestigio independientemente de si estos están construidos o no, para crear una base de datos que permita sacar conclusiones generales en términos de producción de vivienda crecedera a lo largo 
del tiempo (ubicación predominante de casos en tiempo y área geográfica, y sistemas constructivos y mecanismos de ampliación más utilizados).

- Identificar los principales problemas de la vivienda crecedera.

- Localizar dentro de la arquitectura culta mecanismos morfológicos de ampliación y estrategias de flexibilidad que permitan aportar mayores posibilidades de crecimiento y decrecimiento a la vivienda con altos estándares de calidad espacial, independientemente de si la vivienda se produce dentro del sector formal o informal.

- Describir sistemática y objetivamente los principales elementos que intervienen en el proceso de diseño de la vivienda crecedera (parámetros y patrones evolutivos).

- Comprobación empírica de las hipótesis mediante la comparación de cinco casos reales a través del sistema de análisis y diagnóstico diseñado. 


\section{Metodología.}

Para la investigación del tema se siguió una metodología empírico-inductiva. El documento de esta tesis se centra en la presentación de la captura y procesamiento de datos y la interpretación de los resultados arrojados en la investigación.

A la hora de llevar a cabo dicha exploración se siguieron los siguientes pasos, descritos a continuación con más detalle.

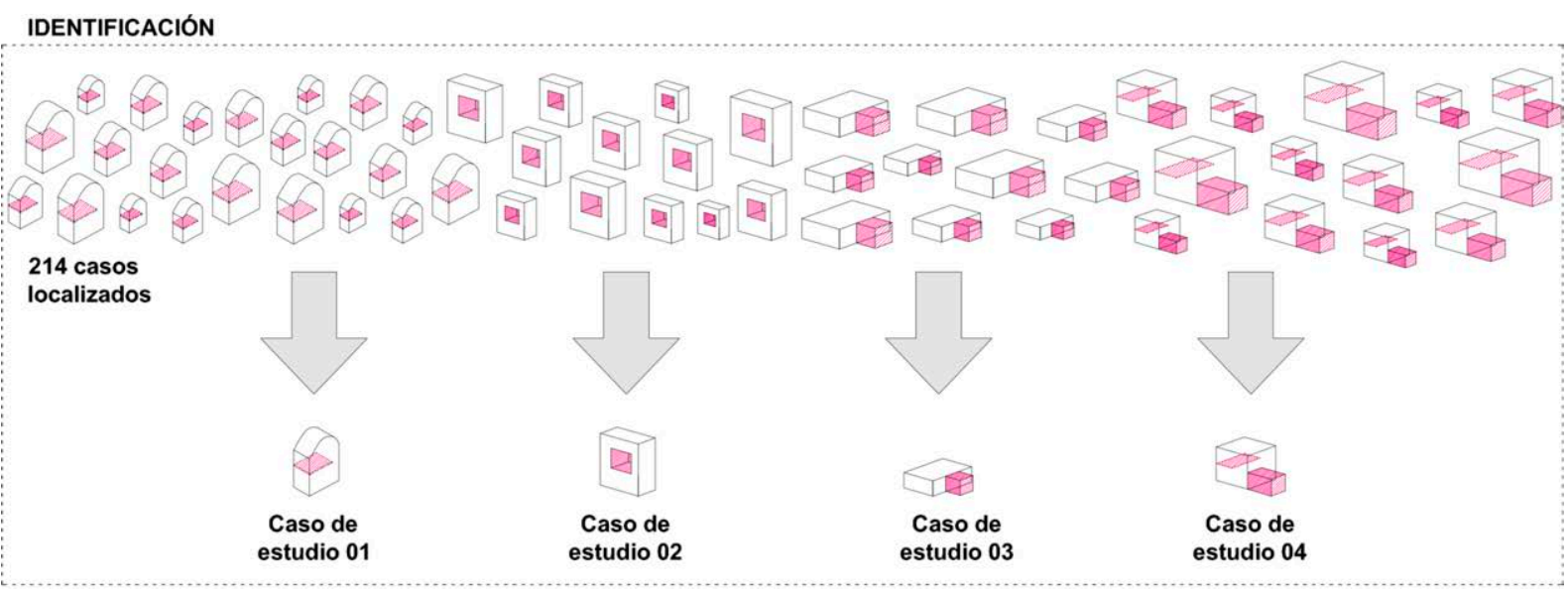

ANÁLISIS

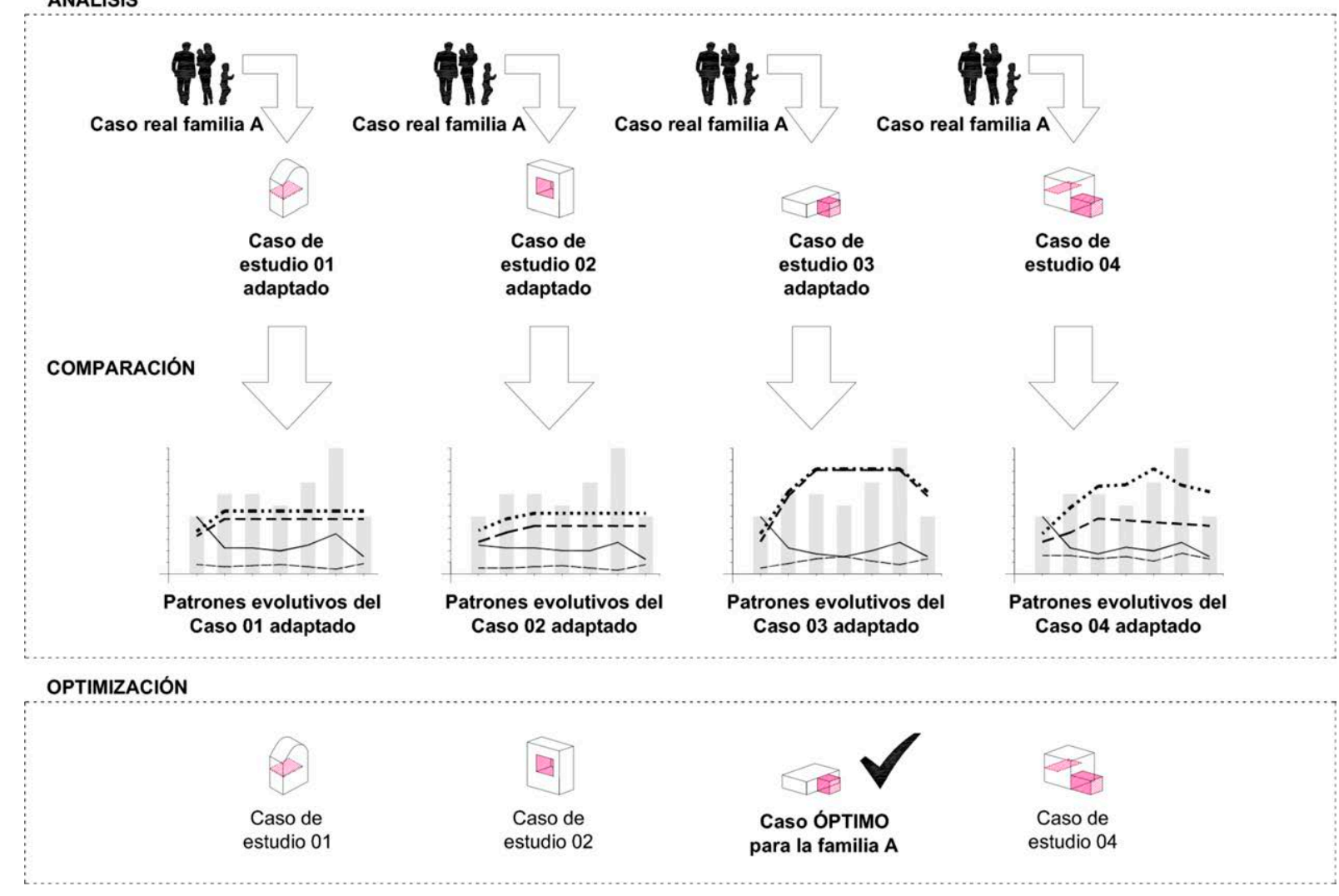

Tabla 03. Descripción del método de trabajo desarrollado en la investigación. 


\section{Identificación de la problemática.}

En primer lugar se identificaron los problemas de la vivienda crecedera, ya indicados en el apartado $I . b$ Pertinencia de la investigación.

a. La autoconstrucción. Práctica asociada a la construcción de viviendas crecederas que permite que la misma unidad habite la vivienda mientras esta se construye y que en los casos en los que no está bien planeada y organizada deriva en un proceso ineficiente.

b. La legalidad y las normativas, que dificultan la producción de casas crecederas en ciertas regiones. En primer lugar, porque se prohíbe la autoconstrucción, práctica que le da todo el poder y libertad al usuario. $Y$ en segundo lugar, porque la legalización de una vivienda construida por fases es mucho más cara y lenta que la legalización de una construida de una sola vez.

c. El ahorro de la unidad de convivencia. Que es en muchos casos variable e imprevisible y del cual se depende directamente a la hora de elegir el tipo de crecimiento en cada momento.

d. El acertar en la planificación a futuro. Debido a la incertidumbre a la que está ligado el proceso de crecimiento en la vivienda es complicado prever un objeto final predeterminado. La dificultad radica entonces en diseñar la vivienda como un proceso en el que se pueda tener el más amplio abanico de posibilidades en cada una de las fases de progresión de la casa, permitiendo un desarrollo no lineal y reversible.

\section{Recopilación de casos.}

Para poder obtener datos genéricos del fenómeno, se realizó un sondeo a nivel mundial en el que se localizaron 2/4 casos de viviendas que crecen. Esta selección se hizo dentro del marco temporal entre 19/4 y 2014, eligiendo únicamente viviendas diseñadas por arquitectos desde la vivienda semilla hasta la última ampliación. (Apartado 4. Casos de estudio). Para estar incluidas en la selección las casas debían haber sido publicadas en revistas de prestigio, tomando esto como indicador de calidad del proyecto. En la localización de los casos se rastrearon numerosas publicaciones (españolas, mexicanas, chilenas, francesas, italianas, holandesas, alemanas, japonesas, argentinas, colombianas, etc.) por lo que aunque se ha intentado estudiar el fenómeno desde el punto de vista más global, la procedencia de la de la bibliografía claramente condicionó la selección de casos. (Tabla 04).

Al haber decidido que el sistema para evaluar la calidad de los proyectos es la publicación de estos en medios especializados los datos comparativos globales se verán afectados puesto que la vivienda crecedera es un sistema de construcción característico de áreas informales que al no contar con un técnico especializado que les ayude en la construcción de su casa, prácticamente nunca tienen la posibilidad de publicar sus resultados en estos medios. Aún así se aceptará esta diferencia como asumible al considerar como primordial en el estudio la calidad de los datos seleccionados frente la cantidad de estos.

Tras recopilar los 214 casos, estos se analizaron en términos constructivos y morfológicos a través de sus múltiples fases identificando los distintos mecanismos de ampliación. 


\begin{tabular}{|c|c|c|c|c|c|c|c|c|c|c|c|c|c|c|c|}
\hline \multirow{3}{*}{\multicolumn{2}{|c|}{$\begin{array}{l}\text { Localización de los } \\
\text { casos de estudio } \\
\text { analizados }\end{array}$}} & \multicolumn{14}{|c|}{ Locallzaclón de las fuentes para el estudlo de cada uno de los casos } \\
\hline & & $\begin{array}{r}5,72 \% \\
\square \\
\end{array}$ & $\begin{array}{l}0.52 \% \\
\square \\
\end{array}$ & $\begin{array}{r}0.52 \% \\
\square \\
\end{array}$ & $\begin{array}{r}15,62 \% \\
\square \\
\end{array}$ & $\begin{array}{r}11,45 \% \\
\square \\
\end{array}$ & $\begin{array}{r}4,16 \% \\
\square \\
\end{array}$ & $\begin{array}{r}20,83 \% \\
\square \\
\end{array}$ & $\begin{array}{r}2,60 \% \\
\\
\end{array}$ & $\begin{array}{l}1,56 \% \\
\square \\
\end{array}$ & $\begin{array}{r}28,64 \% \\
\square \\
\end{array}$ & $\begin{array}{l}1,56 \% \\
\square \\
\end{array}$ & $\begin{array}{r}0.52 \% \\
\square \\
\end{array}$ & $\begin{array}{r}5,72 \% \\
\square \\
\end{array}$ & $\begin{array}{r}0.52 \% \\
\\
\end{array}$ \\
\hline & & Alemania & Argentina & Bélgica & Chile & Colombia & EE.UU. & España & Francia & India & Inglaterra & Italia & Japón & México & Suiza \\
\hline $8,06 \% \square$ & Alemania & 03 & & & & & 02 & 01 & 01 & & 07 & 01 & & & \\
\hline $4,83 \% \square$ & Argentina & & 01 & & 01 & & & 06 & & & & & & 01 & \\
\hline $2,68 \% \square$ & Austria & 01 & & & & & & & & & 04 & & & & \\
\hline $0,53 \% \square$ & Bélgica & & & 01 & & & & & & & & & & & \\
\hline $21,50 \% \square \square$ & Chile & 04 & & & 29 & 04 & 01 & & & & 01 & & & 01 & \\
\hline $1,07 \% \square$ & Colombia & & & & & 01 & & 01 & & & & & & & \\
\hline $1,07 \% \square$ & Cuba & 01 & & & & & & 01 & & & & & & & \\
\hline $0,53 \% \square$ & Dinamarca & & & & & & & & & & 01 & & & & \\
\hline $5,37 \% \square$ & EE.UU. & 01 & & & & & 03 & & & & 06 & & & & \\
\hline $0,53 \% \square$ & España & & & & & & & & & & 01 & & & & \\
\hline $0,53 \% \square \square$ & Filipinas & & & & & 01 & & & & & & & & & \\
\hline $1,07 \% \square$ & Finlandia & & & & & & 01 & & & & 01 & & & & \\
\hline $3,76 \% \square$ & Francia & & & & & & & & 03 & & 04 & & & & \\
\hline $0.53 \% \square \square$ & Haiti & & & & & & & 01 & & & & & & & \\
\hline $3,22 \% \square \square$ & Holanda & & & & & & & 01 & & & 05 & & & & \\
\hline $2,15 \% \square$ & India & & & & & 01 & & & & 03 & & & & & \\
\hline $6,45 \% \square \square$ & Inglaterra & & & & & & & 01 & & & 11 & & & & \\
\hline $1,07 \% \square \square$ & Italia & & & & & & & & & & 01 & & 01 & & \\
\hline $3,76 \% \square \square$ & Japón & 01 & & & & & & 01 & 01 & & 02 & 02 & & & \\
\hline $0,53 \% \square$ & Libano & & & & & & & & & & 01 & & & & \\
\hline $1,07 \% \square$ & Mauritania & & & & & & & & & & 01 & & & 01 & \\
\hline $12,90 \% \square$ & México & & & & & 15 & & 01 & & & & & & 08 & \\
\hline $0,53 \% \square \square$ & Namibia & & & & & & & & & & 01 & & & & \\
\hline $0,53 \% \square$ & Nicaragua & & & & & & & 01 & & & & & & & \\
\hline $1,07 \% \square \square$ & Paraguay & & & & & & & 02 & & & & & & & \\
\hline $8,60 \% \square$ & Penú & & & & & & & 15 & & & 01 & & & & \\
\hline $0.53 \% \square \square$ & Polonia & & & & & & & & & & 01 & & & & \\
\hline $0,53 \% \square$ & Puerto Rico & & & & & & 01 & & & & & & & & \\
\hline $0,53 \% \square$ & República dominicana & & & & & & & 01 & & & & & & & \\
\hline $0,53 \% \square \square$ & Suecia & & & & & & & & & & 01 & & & & \\
\hline $3.22 \% \square \square$ & Suiza & & & & & & & & & & 05 & & & & 01 \\
\hline $0,53 \% \square$ & Venezuela & & & & & & & 01 & & & & & & & \\
\hline
\end{tabular}

Tabla 04. Relación de los países de publicación de las fuentes y la ubicación de los casos publicados (Número de reseñas). Fuente: Elaboración propia.

\section{Definición de mecanismos de ampliación.}

Simultáneamente al análisis de los 214 casos se consultaron los autores que habían registrado en sus teorías alguno de estos mecanismos de crecimiento y se realizó la clasificación y la redefinición de los mecanismos identificados de acuerdo al compendio de casos detectados, recopilando, organizando y aclarando las clasificaciones y definiciones previas. (Apartado 2.a. Mecanismos de ampliación).

\section{Selección de casos de estudio.}

De la recopilación de los 214 proyectos localizados se sub-seleccionaron cuatro casos de estudio pormenorizado de acuerdo a los criterios establecidos en el capítulo 4. Casos de estudio: 
- Überbauung Brahmshof de Kuhn \& Fischer und Partner.

- Viviendas Quinta Monroy de ELEMENTAL.

- II Rigo Quarter de Renzo Piano.

- Población Rene Schneider de Percy Díaz.

Esta segunda discriminación que partía de los criterios de legibilidad y calidad, trató de que estuvieran reflejados todos los tipos de crecimientos mencionados en el apartado 2.a. Mecanismos de ampliación, valorado a su vez que la muestra fuera lo más heterogénea posible.

Es importante recalcar que en esta investigación, los cuatro casos que se han seleccionado para saber cuál es el óptimo para la familia López, se han extraído de la tabla de recopilación de casos existentes en el mundo. Sin embargo, esto no quiere decir que la lista de casos recopilados funcione como un "catálogo de casas crecederas" y que la optimización se haga únicamente respecto de estos proyectos. Si no que la intención de esta investigación es que una vez que se sepan los mecanismos de ampliación que se van a utilizar de acuerdo a la tabla presentada en el apartado 2.b. Preselección de mecanismos de ampliación, se proyecten varias posibles viviendas. Las cuales se analizarán respecto a los patrones evolutivos para una unidad de convivencia concreta permitiendo elegir la propuesta óptima entre las diseñadas exprofeso.

\section{Patrones evolutivos.}

A continuación se asociaron los problemas de la casa crecedera indicados en el apartado I.b Pertinencia de la investigación a determinados parámetros. (Apartado 3. Patrones evolutivos y parámetros). Dichos parámetros se estudiaron como una secuencia de eventos en el tiempo que constituyeron los patrones evolutivos característicos de cada vivienda. El contenido de los patrones se expresó gráficamente a través de historiogramas en los que se registraron los eventos más importantes de la vivienda o la familia a lo largo del tiempo caracterizando el proceso.

\section{Análisis de casos.}

Para comparar los cuatro casos de estudio seleccionados y poder analizarlos fácilmente se realizó una serie de fichas resumen descriptivas de cada ejemplo. Estas fichas contienen, en todos los casos, los mismos dibujos a idéntica escala pudiendo hacer comparable la información de una manera mucho más efectiva. (Apartado 4.b. Casos seleccionados). Dado que en ningún momento se quiso perder el enfoque proyectual de este trabajo se trató que gran parte de la carga de la investigación fuera gráfica, ya que es el método de expresión característico del proyecto de arquitectura. Por tanto, la labor de este trabajo no sólo consistió en clasificar y analizar cada uno de los tipos de ampliaciones posibles en una vivienda crecedera, sino que además se fijó como reto el investigar la forma más adecuada de representar gráficamente estos procesos de ampliación para que se pudieran estudiar tanto de forma aislada como de forma comparada. 
Para abordar el análisis morfológico se utilizaron cuatro sistemas de representación; la planta, la axonometría, la sección y el plano de contexto o situación. Tanto la planta como la sección son los instrumentos utilizados para la representación de la realidad construida. Son una abstracción del espacio habitable que permite la anticipación de posibilidades futuras. A través de la sucesión de las plantas y las secciones de las distintas fases de una vivienda crecedera, se puede comprender mejor la relación entre la ampliación y la vivienda inicial no sólo a nivel espacial si no a nivel constructivo. Mientras que estos primeros dibujos se utilizan para entender a detalle el proceso, la axonometría se aplica para obtener una concepción más global de éste. Al abstraer en un mayor grado la arquitectura, se captan claramente las alteraciones morfológicas y la diferencia entre un incremento de superficie y un incremento de volumen, por lo que se pueden entender de forma más precisa las distintas fases de ampliación. Finalmente, el uso de los planos de contexto a lo largo del tiempo permiten percatarse de cómo la actividad de la vivienda crecedera influye de forma directa en la estructura urbana, no sólo a nivel de densidad, sino que, en algunos tipos de ampliación, puede incluso afectar a la forma del espacio público y a la relación de la vivienda con éste.

A su vez, para comprobar la funcionalidad del sistema de análisis mediante los patrones evolutivos, se extrajeron los historiogramas de cada uno de los cuatro casos de estudio de acuerdo a la distribución y al amueblado interior propuestos por los arquitectos. Estos resultados se volcaron en otra serie de fichas comparables (con el mismo grafismo, escala y contenido) haciendo más fácilmente contrastable cada uno de los procesos de ampliación sin hacer ningún tipo de cálculo. Todos los patrones fueron elaborados sobre una misma línea de tiempo que organizó las fases, haciendo más comprensible la evolución temporal, superficial y volumétrica de las distintas viviendas crecederas. (Apartado 4.b. Casos seleccionados). La descripción pormenorizada de cómo se obtuvieron cada uno de estos patrones se puede consultar en el apartado 3. Patrones evolutivos y parámetros del documento de la tesis.

\section{Aplicación de la familia real escogida a las viviendas seleccionadas.}

Posteriormente se eligió una unidad de convivencia compleja real, típica de un país desarrollado en período de crisis, que fácilmente se podría asimilar a muchas de las familias de países en vías de desarrollo, la familia López, una unidad de convivencia compleja española del extra radio de Madrid. Se escogió esta familia porque es un ejemplo característico de evolución orgánica familiar en el tiempo, donde el número de miembros de la familia fluctúa notablemente y donde según las previsiones a futuro de la propia familia el núcleo familiar podría llegar a ser extendido hasta dos núcleos. Se escogió un caso español debido a que todos los análisis se están realizando en base a datos de la legislación española y a que la tesis se está presentando en España. Se analizó entonces, el proceso de evolución en el tiempo de la familia López y de acuerdo a las expectativas, el historial familiar y su situación socioeconómica se planteó un posible patrón de crecimiento a futuro. (Apartado 5.a. Aplicación).

Una vez identificada la familia real de estudio (la familia López) y para identificar cual de los cinco casos de estudio seleccionados era el óptimo para el desarrollo de esta unidad de convivencia, se procedió al redibujado de las plantas de cada uno de los casos suponiendo que la unidad de convivencia compleja seleccionada viviría 
en cada una de ellas. Y se calcularon los patrones evolutivos de cada una de las fases de cada una de las cinco casas paradigma en base a las mismas circunstancias. (Apartado 5.b. Comparación).

\section{Comparación de casos.}

Una vez analizadas las cinco viviendas paradigma en el caso de ser habitadas por la unidad de convivencia compleja seleccionada, se contrastaron los historiogramas de cada uno de los casos. (Apartado 5.c. Evaluación). De esta comparación se pudo extraer el valor óptimo en cada fase para cada uno de los parámetros valorados, de manera que se pudo escoger cual era la casa que daba una mejor respuesta para la unidad familiar elegida de acuerdo a los patrones evaluados. (Apartado 5.d. Selección del caso idóneo). 
2. LA AMPLIACIÓN EN LA VIVIENDA CONTEMPORÁNEA.

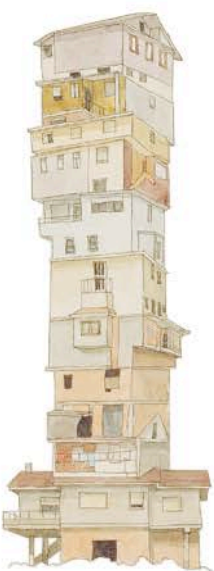





\section{2.a. Mecanismos de ampliación.}

Para estructurar más fácilmente la información producida en esta investigación en torno al fenómeno de la casa crecedera, se han decidido explorar las distintas formas en que crece una vivienda elaborando una serie de familias de prototipos crecederos que responden a distintos mecanismos de ampliación. Esta distinción por mecanismos o estrategias de crecimiento, servirá a lo largo de la investigación para organizarla y compartimentarla adecuadamente y para tratar de entender el porqué de que un tipo pueda crecer más que otro y cuál es el sistema de crecimiento óptimo en función de cada situación. Para ello, se han estudiado los diferentes mecanismos de ampliación desde el punto de vista morfológico, definiéndolos como las distintas disposiciones respecto de la vivienda semilla a través de las cuales se puede realizar un crecimiento.

La primera diferenciación que se hace dentro de las viviendas crecederas tiene que ver con la relación entre la ampliación y el espacio público, de acuerdo al tipo de propiedad del suelo que se ocupe. Por un lado existe el crecimiento en intrapropiedad en el que todas las estrategias de crecimiento llevadas a cabo se realizan dentro del límite de la parcela de la vivienda y la limitación en altura y planta las dictan unas leyes urbanísticas que son respetadas. Por otro lado, tenemos mecanismos por ampliación de parcela donde las expansiones ocupan parte del espacio público. Este concepto ha sido utilizado numerosas veces por el Ingeniero Julián Salas (Salas, 1998) bajo el término apropiación informal del suelo, definiéndolo como aquella ampliación de la vivienda que ocupa superficie de suelo público y produce una extensión informal' de su propiedad.

Esta misma idea ha sido descrita por García-Huidobro, Torres y Tugas en su investigación sobre PREVI (Proyecto Experimental de Vivienda), (García-Huidobro, Torres Torriti, \& Tugas, 2008), dándole el nombre de crecimiento por holgura en límites difusos. En esta investigación acerca del conjunto habitacional limeño se pueden encontrar entre otros, un modelo propuesto por Charles Correa y otro por Christopher Alexander donde, tras ser construidos en 1978 y una vez pasado el tiempo, las viviendas se extendieron claramente sobre la vía pública ocupando el límite que los arquitectos habían propuesto de manera ambigua entre la acera y la vivienda.

\footnotetext{
I "Informal is everything that is not formal, which is to say, everything that does not fall within the State's legal sphere, pertaining either private or public initiative". (Ateliermob, 2014).
} 
En España estas prácticas de ocupación del suelo público también se han producido a lo largo de la historia y se conocen tradicionalmente como abusivismo. Aunque afecta de forma directa a la forma del tejido urbano y es una de las principales problemáticas de la vivienda popular de numerosos países, no se estudiará de forma independiente a los crecimientos en intrapropiedad debido a que los mecanismos de ampliación aplicados sobre el espacio público son muy similares morfológicamente a los ejecutados dentro del lote, por lo que se equipararan y se estudiaran indistintamente.

Un caso excepcional dentro de esta primera clasificación vinculada a la tenencia del suelo es el proceso de extensión por unión ${ }^{2}$ (Figura 06). Ésta es una ampliación por co-propiedad, es decir, por la combinación de propiedades, donde una de ellas le cede superficie a la otra y de esta manera se producen simultáneamente la ampliación de una de las viviendas y la reducción de la otra. Existe la posibilidad de que la combinación de viviendas se realice de forma horizontal como sucede en el proyecto Battery Housing del Potteries Thinkbelt de Cedric Price propuesto en 1966 (Price, 1966, p. 493) o como ocurre en el conjunto Überbauung Brahmshof construido en 199I en Suiza por Kuhn \& Fischer und Partner (Brahmshof Zürich, 1993). Aunque también puede ocurrir que la combinación de propiedades se dé de forma vertical, como sucede en el Create Housing de Cedric Price, (Price, 1966, p. 491), donde la vivienda se une con la inmediatamente superior gracias a la introducción de nuevos sistemas de comunicación vertical.

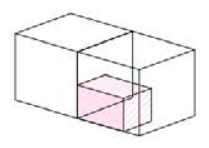

Figura 06. Crecimiento por unión.

Teniendo en cuenta que los crecimientos se tratarán de forma indistinta ocupen espacio público o espacio privado, siempre que morfológicamente atiendan a unos mismos principios, se podrá decir que la clasificación de los mecanismos conceptuales de ampliación se divide, ahora si, en tres grandes ramas que se explicarán a continuación: los crecimientos aditivos o hacia el interior (sin incremento de volumen), los crecimientos cristalográficos o hacia el exterior (con incremento de volumen) o los crecimientos combinados (que resultan de la superposición simultánea de varias de las estrategias anteriores).

Tal y como se acaba de mencionar, el crecimiento por volumen constante o crecimiento aditivo es el tipo al que pertenecen todas aquellas ampliaciones en las que no se produce un aumento del volumen de la vivienda. Todo crecimiento hacia el interior ha de ejecutarse, en la medida de lo posible, con sistemas constructivos en seco de tal manera que no se altere, ni se interrumpa, la habitabilidad de la vivienda semilla o madre. (González Lobo, 1999).

Dentro de esta estrategia podemos encontrar dos métodos para llevarla a cabo, la estructura cruda y la adición interna $^{3}$, e incluso podríamos considerar la unión como una posible forma de ampliación sin incremento de volumen, ya que a pesar de ocurrir fuera de la propiedad inicial, la extensión se produce ocupando una vivienda ya edificada sin incrementar el cuerpo construido.

\footnotetext{
${ }^{2}$ Del inglés: Joining together en (Schneider \& Till, 2007).

${ }^{3}$ Del inglés: raw structure y adding-in en (Schneider \& Till, 2007).
} 
Aquellos espacios sin terminar, con la estructura vista, y preparados para ser cerrados en un futuro creando un nuevo espacio que compute como ampliación de superficie y de volumen, son los calificados como estructuras crudas (Figura 07). Se ha considerado como ejemplo básico de este concepto y punto de partida para otras estrategias más complejas, la Maison Dom-ino de 1914 de Le Corbusier, que no es una casa al uso pero que potencialmente lo es todo. Donde la estructura de hormigón armado independiente de la fachada y sin ningún tipo de partición o de acabados está lista para ser ocupada, delimitada y posteriormente ampliada. Derivada de esta idea de Le Corbusier encontramos la versión Latinoamericana de Carlos González Lobo, la mesa habitable de 1983 (González Lobo, 1999). Mientras que a una mayor escala y más industrializado, tenemos el Principio del Botellero, una versión del proceso de soporte y relleno que Le Corbusier alude en su "Fruvre complète" en la que explica que primero se levanta una rejilla estructural que posteriormente se completará con viviendas que son insertadas en el soporte como si fueran botellas. Este último caso es por tanto la estructura cruda llevada al máximo extremo ya que generalmente las viviendas son cápsulas prefabricadas que permiten que las piezas habitables sean industrializadas, intercambiables y ampliables en el tiempo.

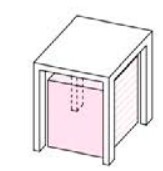

Figura 07. Crecimiento por estructura cruda.

El otro método de crecimiento hacia el interior es la adición interna que se refiere a aquellas ampliaciones, que sin incrementar su volumen al exterior, aumentan la superficie de la casa ocupando el espacio interior de la vivienda. Para conseguir esto se pueden aplicar dos métodos: la ocupación bajo cubierta o la creación de nuevos forjados.

Mientras la estrategia de ocupación bajo cubierta (Figura 08) consiste en invadir el espacio inferior de las cubiertas añadiendo una habitación bajo la estructura existente, tal y como ocurre en las viviendas proyectadas por ELEMENTAL en la Renca en 2002 (Aravena \& lacobelli, 20I2). El mecanismo de creación de nuevos forjados (Figura 08) se basa en la construcción de nuevos elementos horizontales dentro de la estructura existente, obteniendo de esta manera entrepisos o nuevas plantas que incrementan la superficie. Ambas estrategias se aprovechan del hecho de que cierto tipo de cubiertas proporcionan más metros cúbicos construidos con un coste menor únicamente en función de la forma que estas tengan. Esta línea de trabajo ha sido analizada por numerosos arquitectos centrados en viviendas de bajo costo, como es caso del grupo de investigación "Espacio máximo, costo mínimo" de la UNAM (Universidad Nacional Autónoma de México) en sus estudios acerca del Gran Galpón, o como el caso de las Viviendas Cáscara del argentino Aurelio Ferrero del CEVE (Centro Experimental de Vivienda Económica).
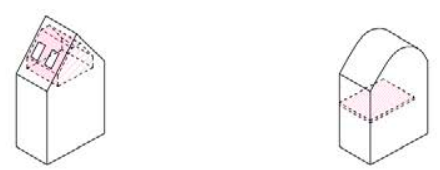

Figura 08. Crecimiento por ocupación bajo cubierta y creación de nuevos forjados. 
Hay que tener en cuenta en estos casos de volumen constante, que la estructura de la vivienda semilla adquiere un papel decisivo para tomar cualquier decisión y que ha de estar considerada desde el inicio. En el caso en el que la estructura inicial no sea lo suficientemente resistente como para tolerar una ampliación habrá que introducir nuevos soportes independientes a los anteriores que transmitan las nuevas cargas al terreno (Figura 09). Pero, sin embargo, si se da el caso de que la estructura de la vivienda madre esté sobredimensionada para albergar una ampliación, esta podrá hacerse mediante la construcción de un elemento autoportante sobre la vivienda existente, o bien, cerrando la estructura existente en el caso en el que esta lo permita (Figura 09). Muchas veces, únicamente el sobredimensionamiento del espacio, sin incluir elementos auxiliares como escaleras que permitan el crecimiento, basta para que se produzca la futura ampliación hacia el interior, como es el caso del conjunto de viviendas para obreros en Venustiano Carranza (México DF) de Juan Legarreta, donde la doble altura del salón invita a ejecutar un altillo.
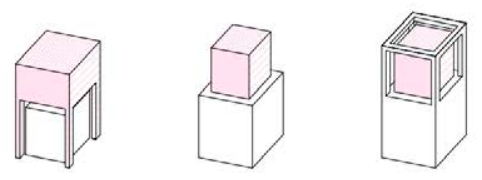

Figura 09. Estructuras independientes, elemento auto-portante y cierre de estructura existente.

La segunda gran familia de mecanismos de crecimiento son los que se realizan por incremento de volumen. Esta forma de crecimiento cristalográfico se realiza comúnmente mediante obras externas que no afectan al uso habitual y la habitabilidad de la vivienda semilla, de tal manera que una vez terminado el proceso de ampliación se integren vivienda semilla y crecimiento de forma instantánea a través de una obra puntual y mínima. Dentro de la estrategia de crecimiento cristalográfico podemos incluir cuatro subtipos según la posición relativa de la ampliación respecto de la vivienda inicial. Estos son la delimitación, la adición externa, la ocupación y la expansión.

La delimitación (Figura 10) es la intervención que consiste en completar forjados de cubierta. Esta es la más sencilla de esta familia de actuaciones ya que únicamente se necesita resolver un paramento y es una operación extremadamente fácil y económica en comparación con otras transformaciones. Esto ocurre en las viviendas proyectadas en 1978 por el arquitecto Toivo Korhonen en el conjunto PREVI en Lima o las proyectadas por Charles Correa para este mismo lugar (García-Huidobro, Torres Torriti, \& Tugas, 2008). Sin embargo, a la hora de realizar esta operación, es siempre muy importante tener en cuenta el no comprometer la ventilación y la iluminación de las estancias de la vivienda semilla ya que a menudo los usuarios delimitan espacios que no estaban pensados para estar cerrados.

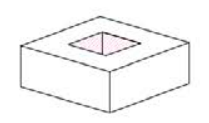

Figura 10. Delimitación. 
La adicción externa ${ }^{4}$ es por otro lado algo más compleja ya que se aumenta de superficie mediante la adición de un cuerpo habitable completo sobre la vivienda inicial. Con lo cual no sólo habrá que resolver la cubierta de la ampliación como en el caso anterior, si no también la estructura del habitáculo y sus cerramientos verticales. Ésta es la estrategia genérica de incremento de volumen dentro de una propiedad, y según el posicionamiento de la ampliación pertenecerá a uno o a otro subtipo.

Hablamos de adiciones horizontales cuando se ocupan terrazas (Figura II) tal como se aprecia en las Diagoon Houses de Herman Hertzberger de 1969 (Hertzberger, 1991) y en la alemana Ökohaus de Frei Otto y Hermann Kandel de 1980 (Nerdinger, Winfried, 2005). También es adición horizontal cuando se ocupan jardines (Figura II) como es el caso de las AA-system houses de Alvar Aalto de 1940 o el Expansiva housing system de Jorn Utzon de 1969, donde al tener un solar de mayor superficie que la construcción inicial se decide ocupar parte del área libre en planta baja adosando habitáculos a la vivienda existente.
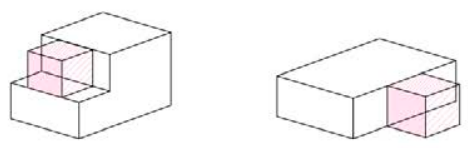

Figura II. Adición horizontal en terrazas y adición horizontal en jardines.

Por otro lado, cuando se presenta el método de adición vertical se puede reconocer por sus dos subtipos. La colonización de cubierta, en la que pequeños cuerpos son colocados sobre el último forjado de la vivienda semilla permitiendo el acceso a la ampliación desde la cubierta de la vivienda inicial (Figura I2), tal y como propone Stirling en sus ejemplos para PREVI (García-Huidobro, Torres Torriti, \& Tugas, 2008) o como hace Balkrishna V. Doshi en sus propuestas para la Ciudadela Aranya (Ospina \& Bermúdez, 2008). Y por otro lado, se puede identificar la adición vertical por su segundo subtipo que sería la extrusión (Figura 12), en la que se construye la proyección vertical del perímetro de la cubierta ocupando toda la superficie de ésta y realizando el acceso desde el interior de la extrusión, tal y como proponen Filipe Balestra \& Sara Göransson en la Incremental Housing Strategy para India del 2009 (The Society for the Promotion of Area Resource Centers (SPARC), 2008).
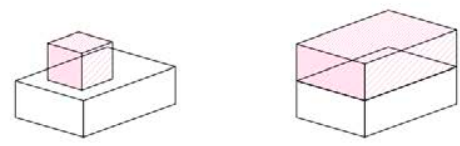

Figura 12. Adición vertical por colonización de cubierta y extrusión.

En último lugar dentro de las adiciones externas encontramos las adiciones por voladizo, resultado de recrecer la fachada o pegar un cuerpo construido a esta (Figura 13) como ocurre en las viviendas de Llanos y Mazzarri del conjunto habitacional peruano PREVI ya mencionado (García-Huidobro, Torres Torriti, \& Tugas, 2008) o como proponían en su proyecto inicial mediante sistemas prefabricado los holandeses UN_Studio en el Flexible housing in Almere del 200I. (Schneider \& Till, 2007).

\footnotetext{
${ }^{4}$ Del ingles: Adding-on en (Schneider \& Till, 2007).
} 


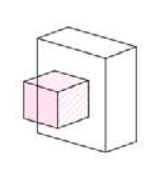

Figura 13. Adición por voladizo.

El tercero de los mecanismos por incremento de volumen que se pueden dar en la vivienda crecedera es el crecimiento por ocupación o slack space que se da en un espacio exterior a la vivienda y envuelto por esta. Esto quiere decir que la ampliación se da en "agujeros" dentro de la construcción que pueden ser ocupados por los usuarios a lo largo del tiempo. Más concretamente se trata de dos tipos de espacios ocupables, los vacíos horizontales (Figura 14) conformados por patios y jardines fácilmente apropiables, tales como los de las Extendible houses 't Hool de 1963 de van der Broek y Bakema (Schneider \& Till, 2007). Y los vacíos verticales (Figura 14) que consisten en grandes agujeros en la fachada que traspasan el edificio, como es el caso de las viviendas Quinta Monroy construidas en el 2003 por los chilenos ELEMENTAL (Aravena \& lacobelli, 2012). Estas dos estrategias a pesar de ser muy similares a la de delimitación, se diferencian de esta por su mayor complejidad, ya que en estas últimas es necesario levantar más de un paramento para delimitar el nuevo habitáculo haciendo relativamente más difícil el proceso.
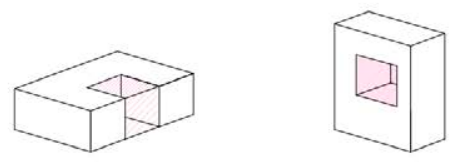

Figura 14. Ocupación de vacío horizontal y ocupación de vacío vertical.

El último mecanismo de ampliación que implica incremento de volumen, es la estrategia de expansión (Figura I5), un sistema de incremento reversible que aumenta el volumen de la vivienda temporalmente. Este procedimiento no se utiliza habitualmente debido a su complejidad constructiva y a su uso limitante, pero como se comentó al inició de la investigación ${ }^{5}$, es de destacada importancia ya que fue el más utilizado de los casos localizados en Estados Unidos durante los años 40 y 50. Ejemplos como los Urban sets de Ron Herron (Reyes González, 1998), la Casa Flexible de Masayuki Kurokawa (Rodríguez Cedillo, 2009) y las Zip-up enclosure número I y 2 de Richard Rogers \& Su Rogers de 1968 (Reyes González, 1998) dejan patente que lo habitual en este mecanismo basado en la prefabricación es ser utilizado en viviendas experimentales o de lujo, donde la habitabilidad está resuelta y los bajos recursos se dejan de lado apostando por la exploración proyectual del espacio.

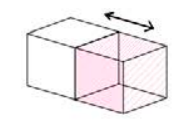

Figura 15. Ampliación por expansión.

Todos los casos que se han explicado hasta el momento han sido formas de crecimiento puras. Sin embargo, lo más habitual en la construcción residencial es que se produzcan sistemas combinados de crecimiento donde se

\footnotetext{
${ }^{5}$ Ver apartado de la tesis I.a. Objeto de estudio y estado de la cuestión.
} 
utilizan distintas formas de ampliación de manera simultánea. Dentro de estos crecimientos combinados podemos encontrar dos subtipos según la complejidad de sus ampliaciones, el crecimiento orgánico y el crecimiento de entrada múltiple. En el crecimiento orgánico (Figura 16), la vivienda semilla permite la combinación simultánea de crecimientos internos y crecimientos externos como ocurre en los prototipos para PREVI propuestos por Aldo van Eyck en 1979 (García-Huidobro, Torres Torriti, \& Tugas, 2008). Este es uno de los mecanismo más utilizados para la auto construcción de vivienda popular ya que es el sistema que permite mayor libertad organizativa a los habitantes. Por otro lado, el crecimiento de entrada múltiple (Figura 16), facilita igualmente la posibilidad de que la vivienda sea ampliada por crecimientos internos y externos, pero de manera que a su vez estos crecimientos estén preparados para sufrir otras ampliaciones externas o internas a partir de ellos mismos, provocando el anidamiento dentro de las ampliaciones iniciales. Este es el crecimiento más complejo de todos conceptualmente, ya que está asociado a crecimientos evolutivos a partir de fractales, y en él podemos ubicar a la homónima casa evolutiva de Renzo Piano de 1978 (Piano, 1978).
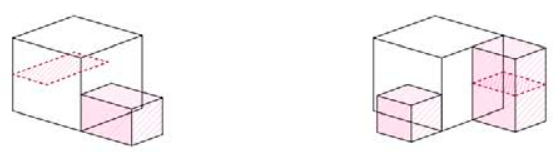

Figura 16. Crecimiento orgánico y crecimiento por entrada múltiple.

Queda claro que con tal repertorio de mecanismos para la ampliación es lógico que se vean distintas intensidades de crecimiento dependiendo del tipo de sistema que se utilice en cada momento. Como veremos en el siguiente apartado ${ }^{6}$ estas distintas formas de ampliación que varían en función de los ingresos de la familia, de la densidad urbana, del tamaño y disposición del solar, etc., son las que junto a estos factores delimitarán el crecimiento futuro de la casa y condicionarán la intensidad de crecimiento de la vivienda que afecta de forma directa a la forma del tejido urbano.

Es cierto que en los países en vías de desarrollo este tipo de vivienda se usa mayoritariamente porque es un sistema constructivo que se adapta a los escasos recursos económicos de sus habitantes sin condicionarlos en el futuro con grandes hipotecas impagables. Pero también se utiliza porque el tipo se adapta a sus necesidades espaciales en función de las variaciones de su núcleo familiar, tanto si este crece, como si este disminuye. Y porque además se adapta a sus necesidades temporales ya que es flexible con los tiempos y ciclos de la familia. Todas estas características llevan a los usuarios a pensar que su casa crecedera es la casa ideal en potencia porque inicia de una manera pero les da la oportunidad de soñar cuán grande quieren que sea esta brindándoles de verdad esta posibilidad de mejorar.

Todo esto hace que estas viviendas sean adecuadas no sólo para las familias de bajos recursos, si no para numerosas familias de cualquier condición y país, que igualmente estén interesadas en poder disfrutar de una vivienda que se adapte a sus tiempos, variaciones familiares y ahorros. Tal y como dice la multipremiada arquitecta india Anupama Kundoo "El diseño no es solo para gente con recursos, y no creo que las situaciones

\footnotetext{
${ }^{6}$ Ver apartado de la Tesis: 4.a Recopilación de casos y resultados estadísticos globales.
} 
low cost deban ser solo para los que no los tienen, conseguir más por menos es una cuestión de eficiencia en el diseño". (Fernández Rubio, 2014).

Es por ello que se ha decidido investigar sobre la vivienda crecedera y sus distintos mecanismos de crecimiento, para tratar de optimizar el proceso tanto en los casos en los que se busque una exploración desde la flexibilidad, como en los que se requiera una respuesta a una situación económica precaria. 
Volúmen constante / Crecimiento aditivo

\begin{tabular}{|c|c|c|c|}
\hline $\begin{array}{l}\mathbf{a}_{1} \text { Mesa habitable / Raw structure } \\
\text { /Principio del botellero }\end{array}$ & a & / adding-in & $\mathbf{a}_{3}$ Unión / joining together \\
\hline & $\mathbf{a}_{2.1}$ Ocupación bajo cubierta & 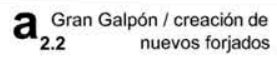 & \\
\hline
\end{tabular}

b

Crecimiento cristalográfico / Incremento de volúmen

\begin{tabular}{|l|l|l|l|}
\hline $\mathbf{b}_{1}$ Delimitación & \multicolumn{2}{|c|}{$\mathbf{b}_{2}^{\text {Ocupación / Slack Space }}$} & $\mathbf{b}_{3}$ Expansión \\
\hline & $\mathbf{b}_{2.1}^{\text {Horizontal }}$ & $\mathbf{b}_{2.2}^{\text {Vertical }}$ \\
\hline
\end{tabular}

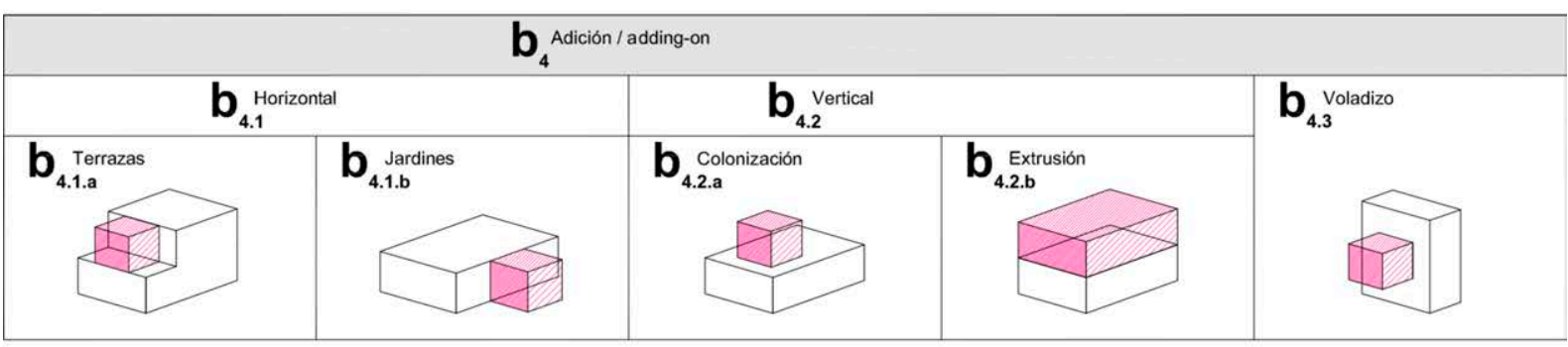

C

Crecimiento combinado

\begin{tabular}{|l|l|}
\hline $\mathbf{C}_{1}$ Crecimiento orgánico / crecimientos \\
internos + crecimientos externos
\end{tabular}

Constructivamente hay que tener en cuenta si las estructuras son:

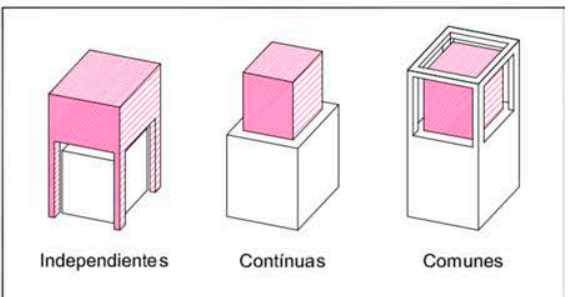

Tabla 05. Mecanismos de ampliación de la vivienda contemporánea. 
2. La ampliación en la vivienda contemporánea 


\section{2.b. Preselección de mecanismos de ampliación.}

Una vez identificados los distintos mecanismos de ampliación posibles y teniendo en cuenta la compilación de 214 casos realizada en el capítulo 4. Casos de estudio, se ha elaborado la (Tabla 06). En esta tabla se pueden observar diversas características que se conocen desde el inicio del proyecto (localización del proyecto, tipo de sistema constructivo que se va a utilizar, las condiciones del solar o el tipo de agrupación de viviendas que va a ser, etc.) que se han vinculado con determinados mecanismos de ampliación de manera sintética y operativa proyectualmente. Los datos utilizados para la elaboración de esta tabla han sido del tipo cuantitativo y cualitativo. Es decir, de los casos localizados se han extraído los mecanismos que estadísticamente más cumplen una característica determinada y se ha comprobando igualmente que cumpliera ese requisito de la forma más adecuada y con la mejor calidad posible. Gracias a esto, se ha podido relacionar con cada una de las características iniciales el tipo o tipos de mecanismos de ampliación que se adaptan mejor a cada una de estas circunstancias. De esta manera y conociendo estas características iniciales fácilmente identificables o medibles, se podrá realizar una primera preselección de sistemas de crecimiento de entre los 15 mecanismos de ampliación detectados. Esta preselección nos permitirá como proyectistas diseñar diversos prototipos de viviendas crecederas específicos para la evolución de una unidad de convivencia concreta que habite la casa en una ubicación determinada. Posteriormente estos prototipos podrán ser comparados según sus patrones evolutivos, lo que permitirá elegir el ejemplo óptimo para la unidad de convivencia determinada. 


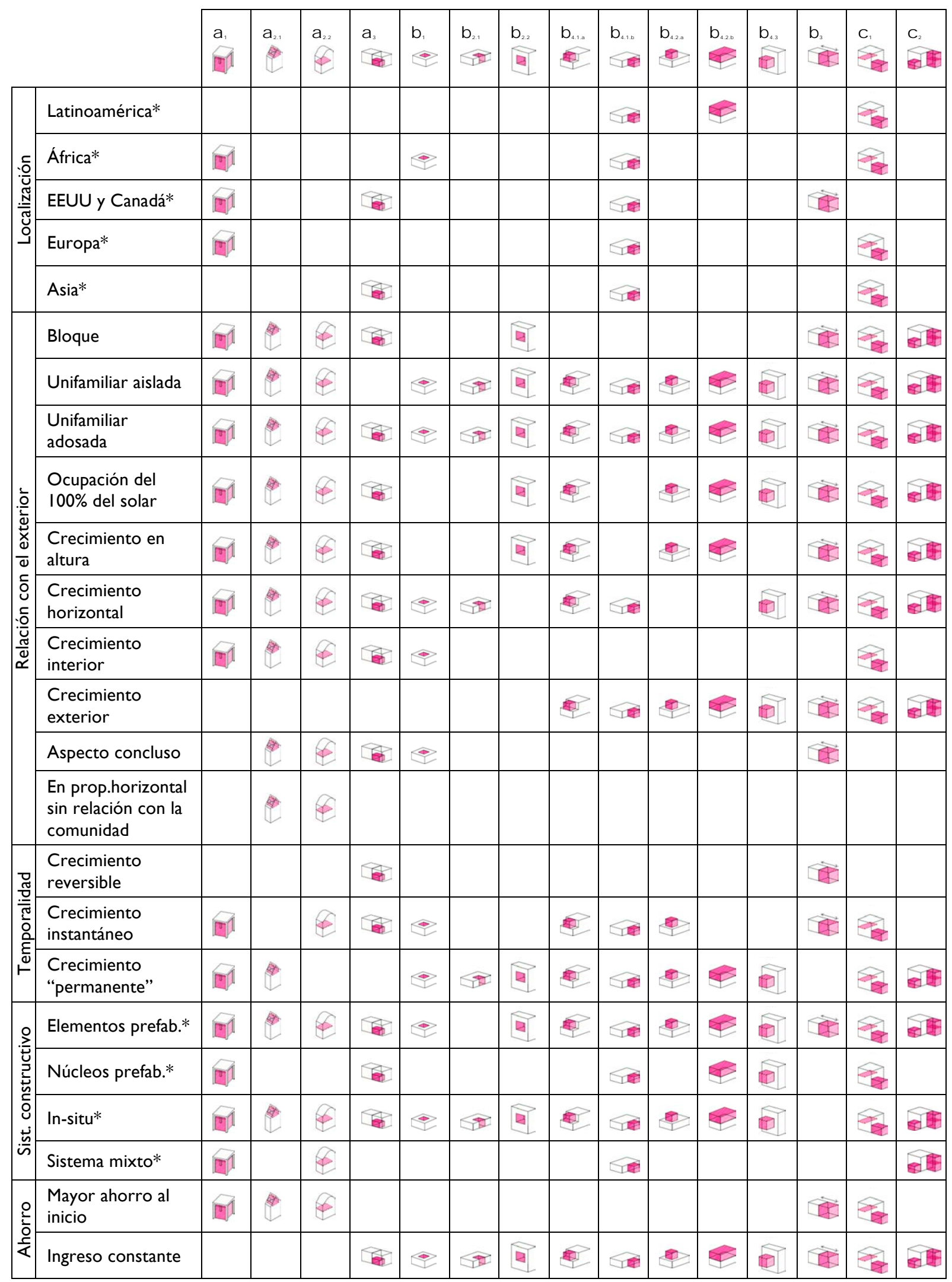

* Mecanismos de ampliación más utilizados estadísticamente para este condicionante inicial.

Tabla 06. Tabla de preselección de mecanismos de ampliación de acuerdo a los condicionantes iniciales. 

crecedera.

El proceso de transformación de la vivienda crecedera ha de ser adaptable y flexible, no lineal, permitiendo variaciones en el transcurso del tiempo y facilitando el mayor número de puntas de crecimiento en todas las fases para que el árbol de evolución espacial sea lo más amplio posible. A su vez, ha de permitir grandes transformaciones de forma sencilla y abierta (en diseño, disposición y material) para hacer el proceso económico y fácil. Y se ha de adaptar a la variabilidad imprevisible de las unidades de convivencia, incluyendo al usuario en el proceso de diseño y construcción de su hábitat, lo que reducirá los problemas de territorialidad en caso de núcleos familiares extendidos y minimizará los problemas de holgura en caso de unidades de convivencia de varios componentes. Además de todo lo anterior, la planificación del proceso de transformación tanto a nivel espacial como a nivel constructivo ha de permitir que la vivienda se habite mientras se construye transformándolo en un proceso más dinámico.

Tras analizar los casos localizados en esta investigación se han identificado nueves estrategias (espaciales o constructivas) que facilitan una evolución flexible y adaptable de la vivienda crecedera de acuerdo a las características que se acaban de mencionar. Estas nueve estrategias (la unión de estancias contiguas, la habitación polivalente, la hipercasa, la sección ocupable, los paramentos móviles o desmontables, los sobredimensionamientos, la separación soporte cerramiento, las células auto-portantes, y los sistemas constructivos en espera) son el soporte espacial de cada uno de los mecanismos de ampliación.

La identificación de estas estrategias proporcionan infinidad de posibilidades de diseño entorno a la vivienda crecedera ya que su combinación o su uso aislado permite distintas intensidades de crecimiento vinculadas a los mecanismos de ampliación.

\section{Unión de estancias contiguas.}

La estrategia de unión de estancias contiguas es del tipo espacial. Se produce al conectar los espacios interiores de dos habitáculos inmediatamente consecutivos, bien sea a través de aberturas en sus paramentos verticales o en sus paramentos horizontales. (Figura 17). 
Este es el procedimiento básico de crecimiento en caso de que se quiera habitar la vivienda mientras que se construye ya que las estancias se conectan únicamente en el momento en el que la obra está finalizada y el espacio se puede habitar sin alterar la vida diaria de la vivienda existente. Debido a esta característica, la unión se puede dar tanto si los habitáculos son de la misma propiedad como si son de propiedades distintas.

Esta estrategia es la base de prácticamente todos los mecanismos de ampliación estudiados (ocupación bajo cubierta; unión; delimitación: ocupación horizontal y vertical; expansión; adición horizontal, vertical y por voladizo; crecimientos combinados y crecimientos de entrada múltiple). Para obtener cada uno de ellos se varía la disposición en la que se realiza la unión de estancias contiguas y se combina en algunos casos con otro tipo de estrategias que añade complejidad al mecanismo de ampliación en cuestión.
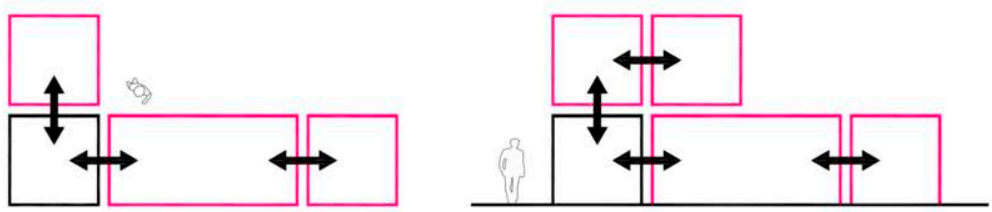

Figura 17. Unión de estancias contiguas.

Esta estrategia se puede apreciar en múltiples de los casos localizados como son el conjunto Battery Housing de Cedric Price (1964-66), las AA-System Houses de Alvar Aalto (194I), las Extendible Houses de J. Van den Broek y J. Bakema (1963), el conjunto Villa la Reina de Fernando del Castillo (1966), las Diagoon Houses de Herman Hertzberger (1969), o el conjunto Quinta da Malagueira de Alvaro Siza (1972).

\section{Habitación polivalente.}

Esta estrategia es del tipo espacial y en este caso lo importante no es cómo se unen los espacios si no cómo son estos en sí mismos. Para la estrategia de la habitación polivalente, todos los habitáculos que se añaden o sustraen de la vivienda tienen la misma superficie y proporción, de tal manera que cada cuarto se puede utilizar de manera alternativa para cualquier uso si se desea (estar, dormir, trabajar, comer...). Según el estándar observado en los casos localizados, la habitación polivalente es generalmente cuadrada, tiene una superficie aproximada de $14 \mathrm{~m}^{2}$ y posee una ventana y una puerta de acceso. (Figura 18).

Gracias a este sistema los usos de la vivienda se pueden trasladar fácilmente de una estancia a otra lo que aporta una mayor flexibilidad y adaptabilidad a la casa.

La habitación polivalente se ha localizado en todos los casos con mecanismo de ampliación por unión. También está presente en ejemplos ampliados por adición horizontal, adición vertical, delimitación, ocupación horizontal y estructura cruda o mesa habitable. 


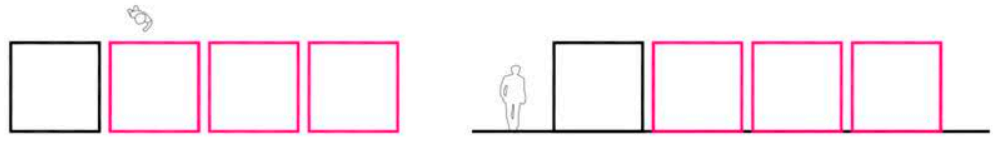

Figura 18. Habitación polivalente.

Algunos de los ejemplos en los que se puede identificar claramente la estrategia son: las viviendas sociales de desarrollo progresivo tipo B2 de Edwin Haramoto (1987), el Expansiva Housing System de Jorn Utzon (1969), el espace habitable modulé, extensible transportable de Jon D. Vredevoogd (1970), las viviendas Verdemonte de Luigi Snozzi (1974) y el prototipo para PREVI de Toivo Korhonen (1978).

\section{Hipercasa.}

Es la estrategia de gestión espacial que permite transformar la casa en un hábitat productivo o artefacto de renta. Esto significa que gracias a una adecuada disposición de las estancias respecto de los accesos y la calle, es posible transformar parte de estas en un comercio, taller o similar donde los habitantes puedan desarrollar actividades económicas (hábitat productivo). O si no, cabe la posibilidad de que estos espacios se renten y que otras personas, o bien desarrollen actividades económicas poniendo su propio negocio, o que utilicen las estancias como vivienda, transformándose de esta manera la casa en un artefacto de renta. (Figura 19).

Esta es una de las soluciones más efectivas y rentables económicamente como respuesta a la variabilidad de la vivienda y el número de componentes de la unidad de convivencia, ya que esta transformación hace más fáciles las épocas económicamente malas y propone un uso alternativo en la casa cuando se reduce el número de componentes de la familia.

La hipercasa es una estrategia que se desarrolla simultáneamente con los mecanismos de adición horizontal y vertical, y con los crecimientos combinados.
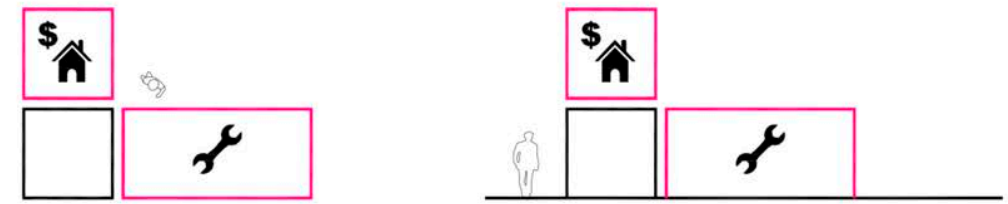

Figura 19. Hipercasa.

Este fenómeno se puede observar en las viviendas de la ciudadela Aranya diseñada por B. V. Doshi (1989), en el prototipo para el conjunto limeño PREVI de Charles Correa (1979) o en el prototipo 7xI7 INVITAB de Carlos González Lobo de (1985), entre otros. 


\section{Sección ocupable.}

La estrategia de sección ocupable es del tipo espacial. Las viviendas que tienen este tipo de corte vertical son aquellas que poseen dobles alturas, alturas expandidas, espacios comodín en vertical, altillos o bajo cubiertas. Es decir, todos aquellos espacios interiores que están preparados constructivamente para ser ocupados después de que la vivienda semilla sea habitada. (Figura 20). Esta ocupación posterior se realizará con pequeñas operaciones constructivas, a poder ser en seco, para no interrumpir el día a día de la casa. Este principio es el máximo representante del binomio habitar-construir mencionado en el apartado de la Problemática de la vivienda crecedera.

La sección ocupable es característica del crecimiento aditivo, la ocupación vertical y los sistemas de crecimiento combinado.
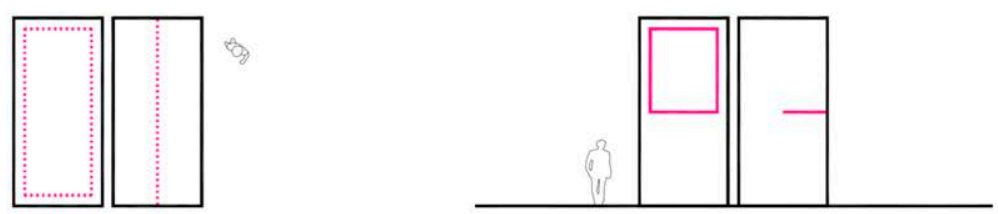

Figura 20. Sección ocupable.

Este tipo de corte se puede observar claramente, entre otros muchos proyectos, en las casas del conjunto de vivienda obrera nacional de Juan O'Gorman (1929), en el bloque de viviendas del proyecto Mkalles de Caminos y Goethert (1985), en las viviendas del conjunto Comunidad Andalucía de Fernando del Castillo (1990) o las viviendas en la Renca de ELEMENTAL (2002). Dónde la estrategia se aplica independientemente de si se trata de vivienda unifamiliar o un bloque de vivienda colectiva.

\section{Los paramentos móviles o desmontables.}

Estos paramentos móviles o desmontables son, tanto cerramientos exteriores, como particiones interiores, horizontales y verticales. Son aquellos que se pueden desplazar o desmontar de modo que transformen los espacios, sus usos y que incluso alteren el volumen construido y la superficie de la vivienda. (Figura 21). Estos forman parte de las estrategias de tipo constructivo.

Esta estrategia para la flexibilidad y la adaptabilidad es característica de los sistemas de crecimiento vinculados a la reversibilidad y a la instantaneidad, tales como la expansión y la unión. Aunque también es utilizado en estructuras crudas, adiciones horizontales, adiciones verticales y crecimientos combinados.

Su aplicación es especialmente común cuando se utilizan sistemas constructivos prefabricados para el crecimiento, independientemente de si estos son industrializados o si están fabricados artesanalmente con materiales tradicionales. Los paramentos suelen estar configurados por paneles auto-portantes o la combinación de elementos portantes y paneles vinculados estructuralmente a estos. 


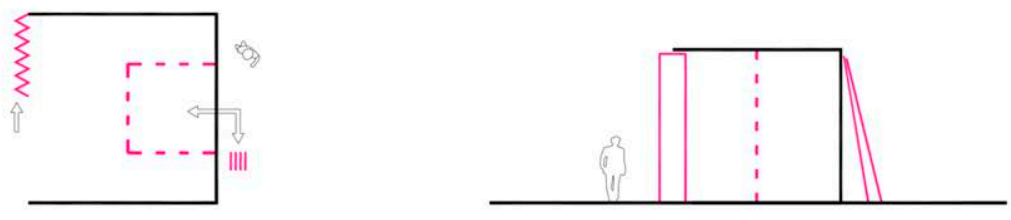

Figura 21. Parámetros móviles o desmontables.

Algunos ejemplos de paramentos móviles o desmontables se encuentran en la Prefabricated House de Carl Koch (1950), en el Moduli 225 de Kristian Gullichsen \& Juhani Pallasmaa (1968), en el sistema normalizado en guadua y madera de J. Mogollón y G. Díaz (1987) o en los Urban Sets de Ron Herron (198I) entre otros muchos de los localizados.

\section{Sobredimensionamientos.}

Esta estrategia se centra en términos estructurales y de instalaciones. Es importante, dado que las viviendas crecederas están diseñadas para ampliarse con el paso del tiempo, tener en cuenta que las cargas que sufra la estructura de la vivienda semilla en un inicio se verán alteradas en un futuro debido a las posteriores ampliaciones, al igual que se requerirá mayor capacidad en instalaciones y servicios por la misma cuestión. Por ello se ha de contar con un sobre dimensionamiento estructural, de instalaciones y de servicios, diseñando todos estos sistemas para la demanda de la vivienda ampliada en su máxima versión y no tanto de acuerdo a los requerimientos de la vivienda semilla, ya que esta decisión facilitará enormemente la flexibilidad durante el proceso de crecimiento y minimizará la problemática del traslado de instalaciones. (Figura 22).

En el caso de las instalaciones y los servicios es igualmente importante que se dispongan de forma racional, agrupada y accesible para que pueda haber una fácil conexión con los futuros crecimientos.

Los sobredimensionamientos, especialmente los estructurales, son necesarios cuando se hace uso de mecanismos de crecimiento vertical bien sea por ocupación o por adición, cuando se añaden cuerpos en voladizo, o cuando el crecimiento aditivo es hacia el interior. Igualmente, los sistemas combinados tendrán que practicar esta estrategia para maximizar su adaptabilidad y su transformabilidad a la hora de hacer modificaciones espaciales.

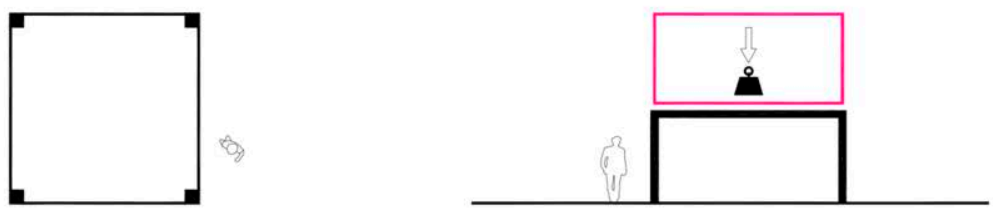

Figura 22. Sobredimensionamientos.

Se practican sobredimensionamientos de forma claramente identificable en el Square L-type System de J. Van den Broek y J. Bakema (1967), en el prototipo para PREVI de James Stirling (1978) o en la Incremental Housing Strategy de Filipe Balestra \& Sara Göransson (2009) donde la estructura está dimensionada inicialmente para soportar no sólo las cargas de la vivienda semilla si no también las cargas de las futuras ampliaciones, sin que 
exista la necesidad de construir nuevas estructuras o reforzar las existentes. En el caso del conjunto Quinta Monroy de ELEMENTAL (2004) el sobredimensionamientos se observa no sólo estructuralmente, si no también en términos de instalaciones, ya que ubican una serie de tomas de instalaciones estratégicamente para poder servir adecuadamente a los paulatinos crecimientos sin realizar grandes intervenciones en los sistemas de agua y saneamiento.

\section{Separación soporte - cerramiento.}

La separación entre estructura y cerramiento es la estrategia constructivo estructural que permite transformar libremente los espacios tanto en planta como en sección debido a que las particiones interiores y los cerramientos exteriores son únicamente divisiones espaciales y no tienen una función estructural. Esta estrategia, que empezó a difundirse en $19 / 4$ con la Maison Dom-ino de Le Corbusier, es el principio esencial en el que se basan los Open Building y es básica a la hora de aplicar mecanismos de crecimiento aditivo. Igualmente, es uno de los sistemas más apropiados cuando se trabaja con viviendas crecederas en bloque ya que generalmente se aplican mecanismos de crecimiento con volumen constante. (Figura 23).

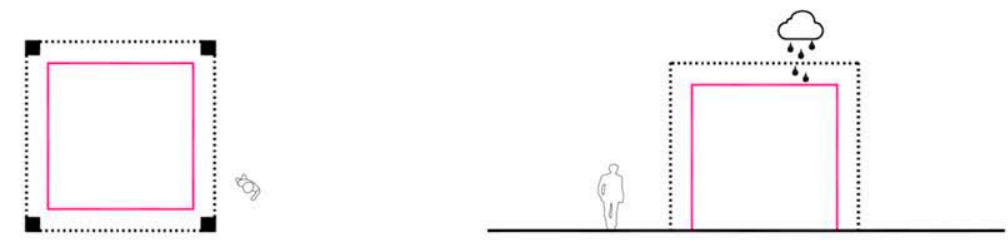

Figura 13. Separación soporte cerramiento.

Se puede observar la estrategia de separación entre soporte y cerramiento en el caso Squatter Inspired de lan Donadl y Robert Herz (1968), en el conjunto Wohnanlage Genter Strasse de Otto Steidle \& Partners (I96975), en el bloque de viviendas Metastadt de Richard Dietrich (1974), así como en el edificio Mod 10 ELEMENTAL de S-AR (2003), entre otros muchos de los 214 casos localizados.

\section{Células auto-portantes.}

En este caso se combinan aspectos estructurales, constructivos y espaciales simultáneamente en una sola acción. En ella se utilizan elementos auto-portantes que generalmente constituyen por si mismos un habitáculo estructural y constructivamente independiente del resto de la vivienda. Estos habitáculos o células se pueden añadir en seco y de forma instantánea al resto de la edificación quedando comunicados con la vivienda semilla mediante al menos uno de sus paramentos. (Figura 24).

Esta estrategia es característica de todos los sistemas de adición tanto horizontal y vertical, como en voladizo. Generalmente está vinculada a sistemas prefabricados, concretamente a sistemas industrializados, haciendo énfasis en la exploración de nuevos materiales para la construcción (fibras de vidrio, polímeros, etc). 


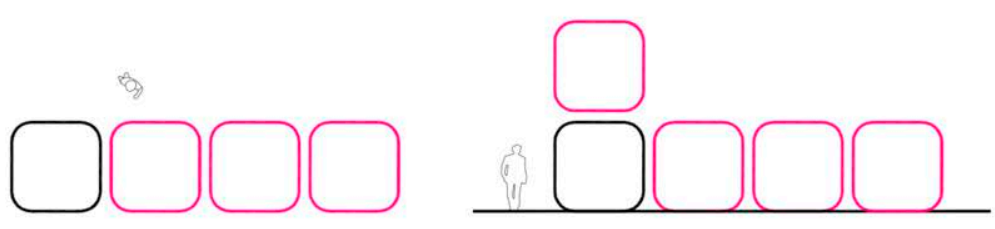

Figura 24. Células auto-portantes.

Se pueden identificar fácilmente células auto-portantes en la Unidad de habitación extensible de Arthuur Quarmby (1962), en el conjunto Steel Housing de Raymond Wilson (1967) y en L'Hexacube de Candilis y Blomstedt (1972), entre otros.

\section{Sistemas constructivos en espera.}

Es esencial tener en consideración esta estrategia de tipo constructivo para evitar problemas derivados de una inadecuada ejecución de las uniones entre la vivienda semilla y la ampliación de esta. Los sistemas constructivos en espera son aquellos que desde el inicio de proyecto están diseñados previendo una futura ampliación del elemento constructivo o estructural y que por tanto, debido a su configuración o disposición, facilitarán la construcción del elemento ampliado, formando una junta o "costura" estructuralmente solidaria y estable, y que sea continua impidiendo filtraciones.

Son básicamente sistemas constructivos abiertos, que permiten construir en cualquier orden eliminando fases restrictivas o fases llave.

Las juntas de estos sistemas constructivos varían dependiendo de si los sistemas son prefabricados o construidos en sitio, o si son industrializados o construidos artesanalmente, siendo más o menos sofisticadas. A continuación se muestran tres ejemplos de juntas estructurales para las viviendas Vjr-0 del proyecto Muros Habitables de Carlos González Lobo proyectado en México en 1987. Estas juntas desarrolladas en un sistema constructivo de muy bajo costo basado en muros de ladrillo cerámico y losas de hormigón es el sistema utilizado habitualmente para la construcción de vivienda social en México.

En el caso de la cimentación, por ejemplo, la zapata de la vivienda semilla está diseñada para que con una operación muy simple de desdoblado de los redondos se pueda continuar con la losa estructural de piso de forma solidaria. (Figura 25). Este tipo de sistemas están pensados para que el proceso de construcción sea fácil, rápido y económico, de modo que incluso se posibilite la autoconstrucción de las fases consecutivas por parte de los habitantes. 


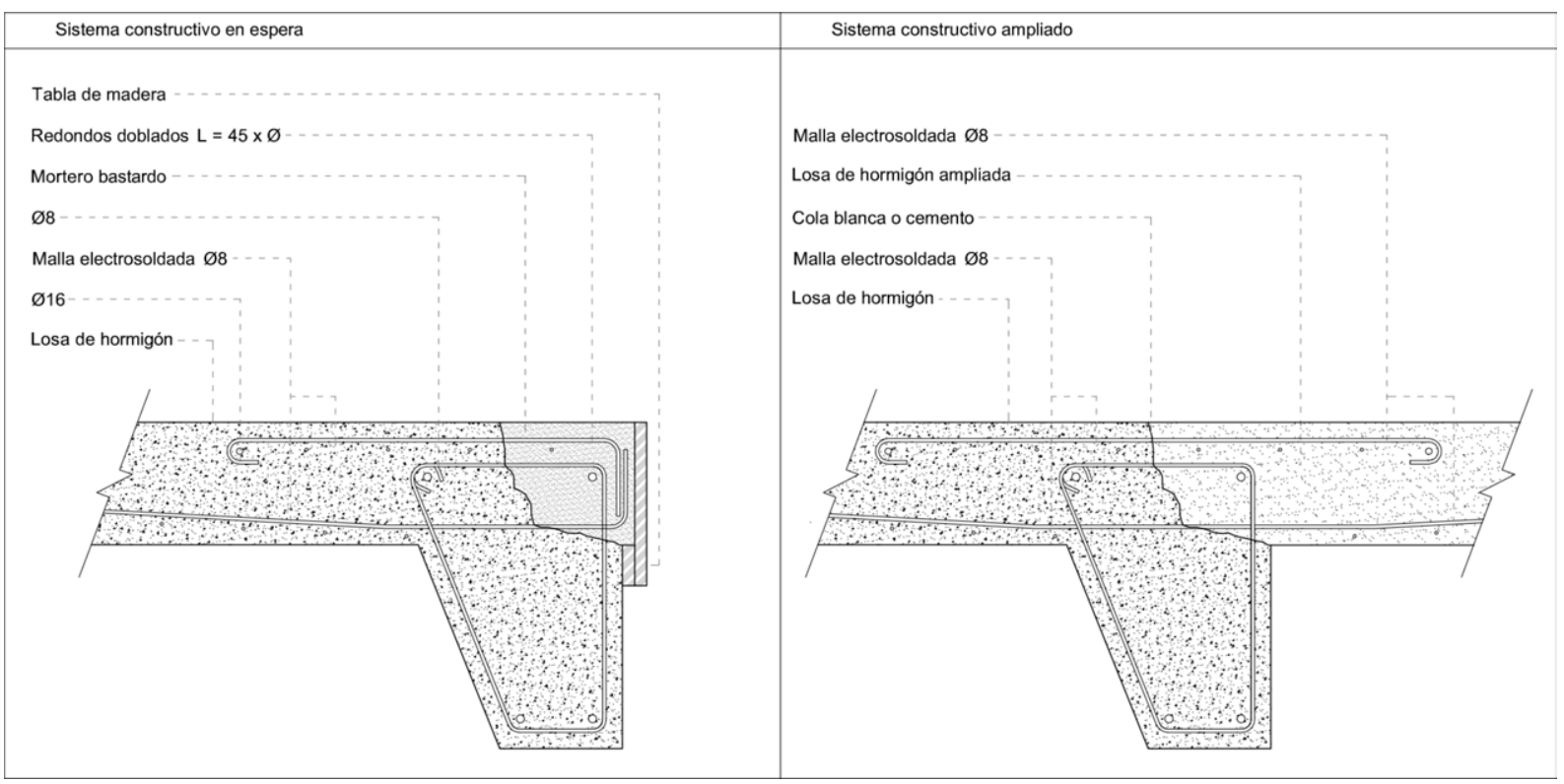

Figura 25. Sistemas constructivos en espera. Losa de cimentación.

El ejemplo más visible de este tipo de sistemas constructivos en espera son los llamados "hierros de la esperanza", conocidos por este nombre en numerosos países latinoamericanos porque representan la posibilidad de que en un futuro la familia prospere pudiendo ampliar su vivienda. (Figura 26).

Estos "hierros de la esperanza" consisten en embeber un armado extra en los pilares de la vivienda semilla de manera que estos sobresalgan de la losa quedando a la espera de ser utilizados en un futuro. Con esta actuación el pilar de la nueva planta trabajará de forma continua con la estructura inicial, sin requerir elementos estructuralmente más caros y complejos y sin necesidad de demoler parcialmente el hormigón del pilar inicial para introducir nuevos elementos que den continuidad a la estructura.

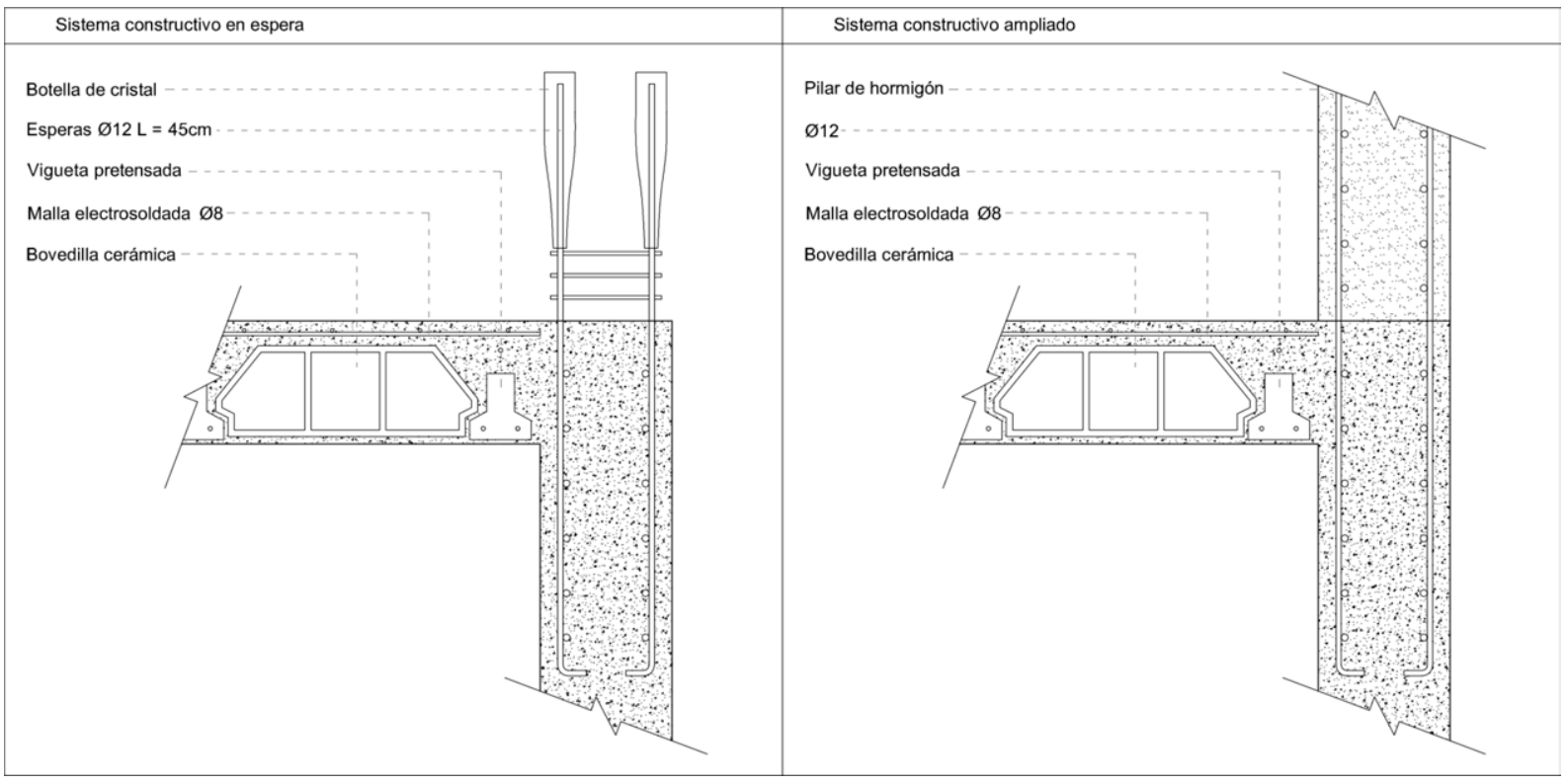

Figura 26. Sistemas constructivos en espera. Pilar con "hierros de la esperanza". 
Sin embargo, en las últimas décadas los "hierros de la esperanza" están adquiriendo una nueva dimensión dentro del imaginario de la ciudad. Cuando después de un tiempo determinado estos "hierros" continúan existiendo en la vivienda, la imagen de estos pasa de ser de esperanza a reflejar el fracaso de la familia, ya que evidencia ante su comunidad que no han sido capaces de mejorar de manera suficiente como para ampliar su vivienda. Es por ello, que se están desarrollando otros sistemas en espera igual de económicos que el anterior pero que al doblar los redondos y no dejarlos a la vista, no sólo impide que el hierro se oxide por el paso del tiempo, si no que evita esta situación negativa si no se alcanzan las expectativas esperadas después de un tiempo. (Figura 27).

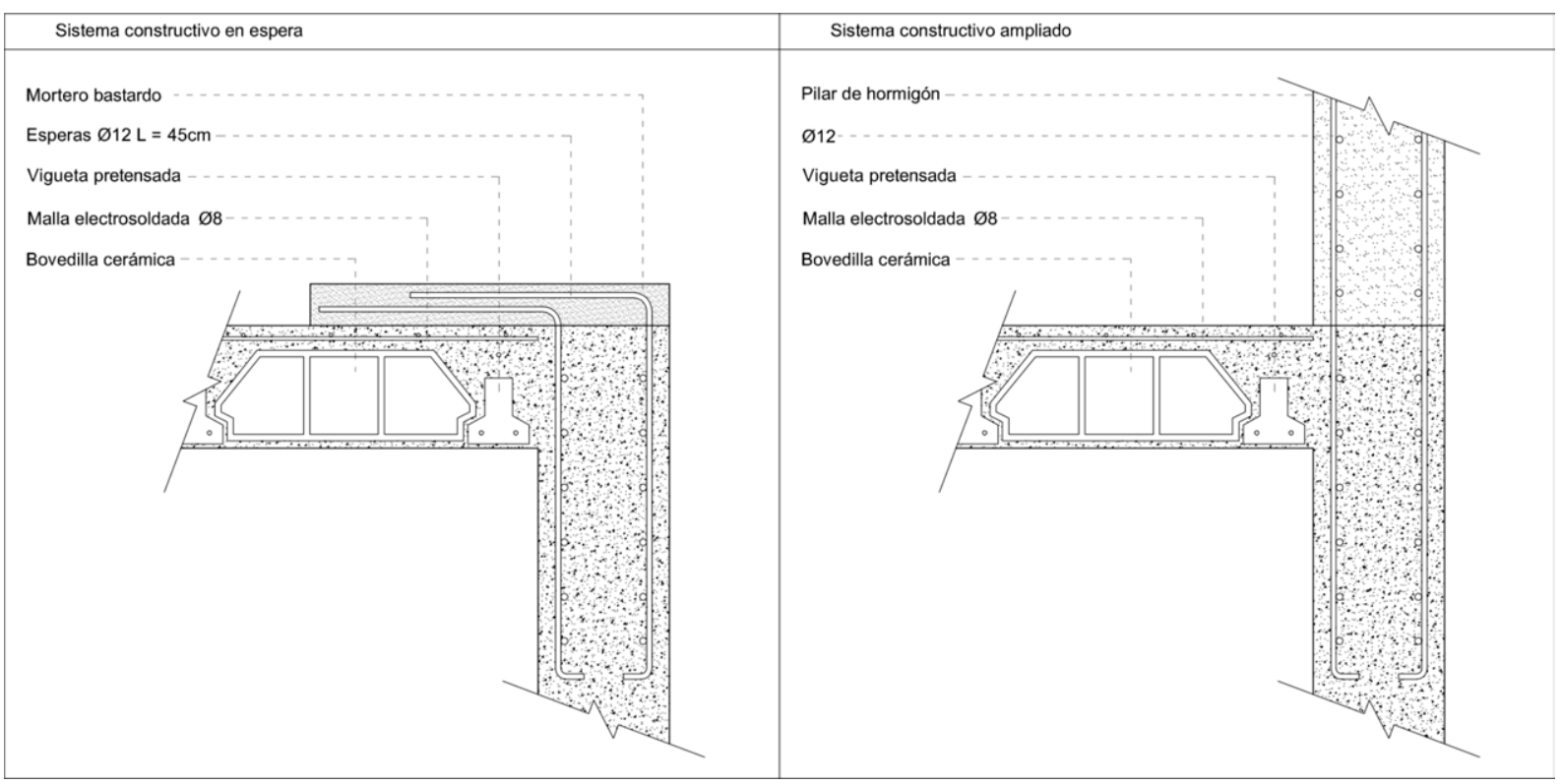

Figura 27. Sistemas constructivos en espera. Pilar con esperas dobladas.

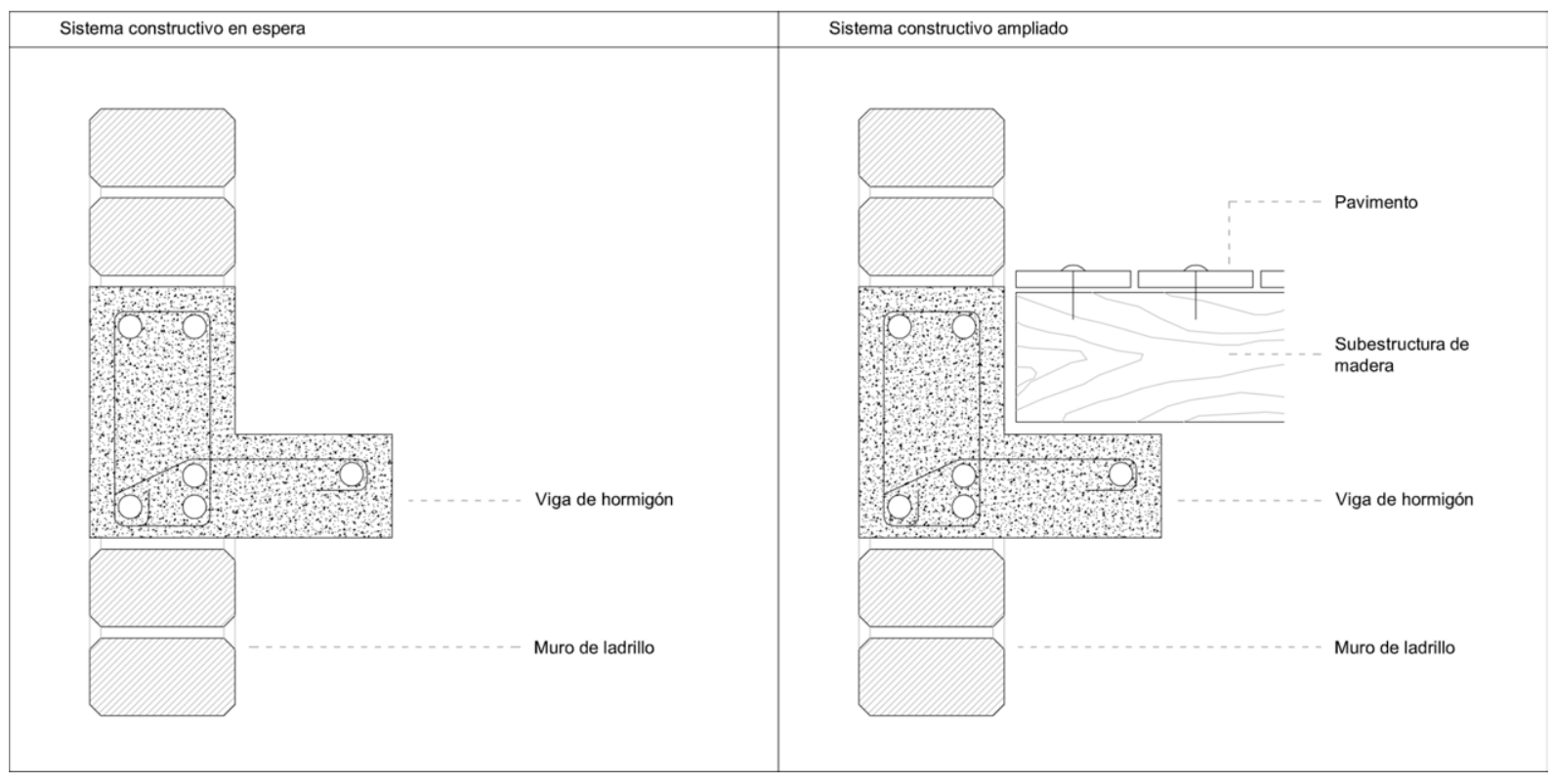

Figura 28. Sistemas constructivos en espera. Losa de piso intermedio. 
Como último ejemplo de "costura", se adjunta el caso de una ampliación interior donde se añade una losa de piso interior. (Figura 28).

En esta ocasión, la estructura en espera es una viga perimetral en $L$ de hormigón armado que permitirá la colocación de una subestructura que sostenga el nuevo pavimento. La nueva subestructura se construirá en seco trabajando únicamente por peso y facilitando una construcción rápida que no interfiera en el día de los habitantes.

Todos los sistemas de bajo costo mencionados se pueden igualmente producir a través de procesos industrializados y prefabricados menos económicos, pero que de la misma manera facilitan y simplifican enormemente el proceso de construcción siempre que sean sistemas abiertos.

Las habitations industrialis'ees par elements modul'es en bois de Jean Fatosme y Aloïs Bachmann (1968) y los prototipos para II Rigo Quarter de Renzo Piano (1978) son dos ejemplos de sistemas constructivos en espera prefabricados e industrializados, mientras que las ya mencionadas viviendas de Carlos González Lobo utilizan estos sistemas de bajo costo realizados in-situ. Estos son algunos de los muchos casos que sean localizado y que están dotados de sistemas constructivos en espera para facilitar la flexibilidad y la adaptabilidad de la vivienda potenciando la posibilidad del crecimiento. 
3. PATRONES EVOLUTIVOS y PARÁmEtros.

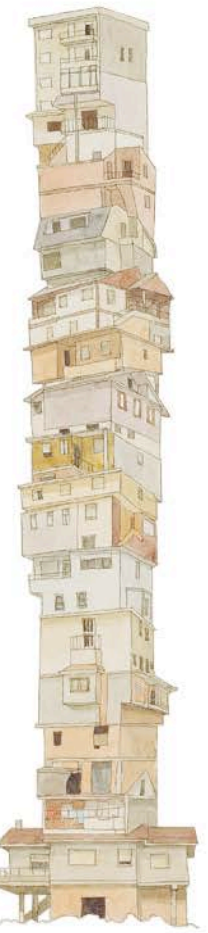





\section{3.a. Patrones y categorías.}

Para poder comparar cada uno de los mecanismos de ampliación de la forma más objetiva posible se ha decido evaluar cada uno de los casos de acuerdo a una serie de parámetros medibles que han facilitado la objetividad del trabajo. Para ello se ha tenido en cuenta como condicionante esencial que el proceso de crecimiento es una evolución en el tiempo y que por tanto los parámetros han de responder a esa variación. Debido a esta hipótesis, el estudio de la casa crecedera se hará por tanto tomando la vivienda como un proceso y no sólo como si fuese un objeto. Es por esto, y basado en el texto de Viviendas progresivas de Jan Bazant, que se optó por transformar los mencionados parámetros de estudio en lo que Bazant llama patrones evolutivos. Dichos patrones muestran la variación en el tiempo de las características parametrizadas de las viviendas reflejando así el carácter de proceso.

Según (Bazant, 2003, p. 16) existen tres patrones o procesos evolutivos, tendencias de transformación o crecimiento en el tiempo, que caracterizan las viviendas crecederas. Estos describen la historia familiar en dicha vivienda desde que los habitantes llegaron y se asentaron en su lote hasta que mejoraron económicamente y realizaron sus ampliaciones. Estas tendencias son el patrón de dinámica familiar, el patrón de crecimiento económico de las familias y el patrón de construcción progresiva. Estos tres patrones evolutivos propuestos por Bazant son de carácter eminentemente socioeconómico y dejan al margen otras características ineludibles del proceso de crecimiento en la vivienda que se tratarán más adelante. Por ello, partiendo de su propuesta y tomándola como ejemplo, se decidió complementar el análisis añadiendo parámetros propuestos por otros autores, también especializados en el estudio del fenómeno del crecimiento de la vivienda, tales como Francisco Vergara y Montserrat Palmer, García Huidobro, Torres y Tugas, Edwin Haramoto o Jorge Andrade. A su vez se ha complementado el análisis con índices que evalúen la calidad arquitectónica provenientes de las teorías de Christopher Alexander y Alexander Klein, entre otros. Para poder complementar el estudio del fenómeno del crecimiento, se analizaron estos parámetros e índices heredados de otras teorías a lo largo del tiempo extrayendo el patrón característico.

Gracias a esta combinación de patrones, se permite un estudio del fenómeno del crecimiento desde un punto de vista más complejo ya que la investigación no se centra exclusivamente en las tendencias socio-económicas del crecimiento, si no que abarca distintas categorías que incluyen la calidad arquitectónica del objeto. 
Estas categorías, que se han utilizado para clasificar los patrones o tendencias de crecimiento, parten de las tres propuestas en la teoría de Bazant (social, económica y morfológica) y se complementan con la categoría espacial y la legal, obteniendo la siguiente relación entre categorías y patrones evolutivos. (Tabla 07).

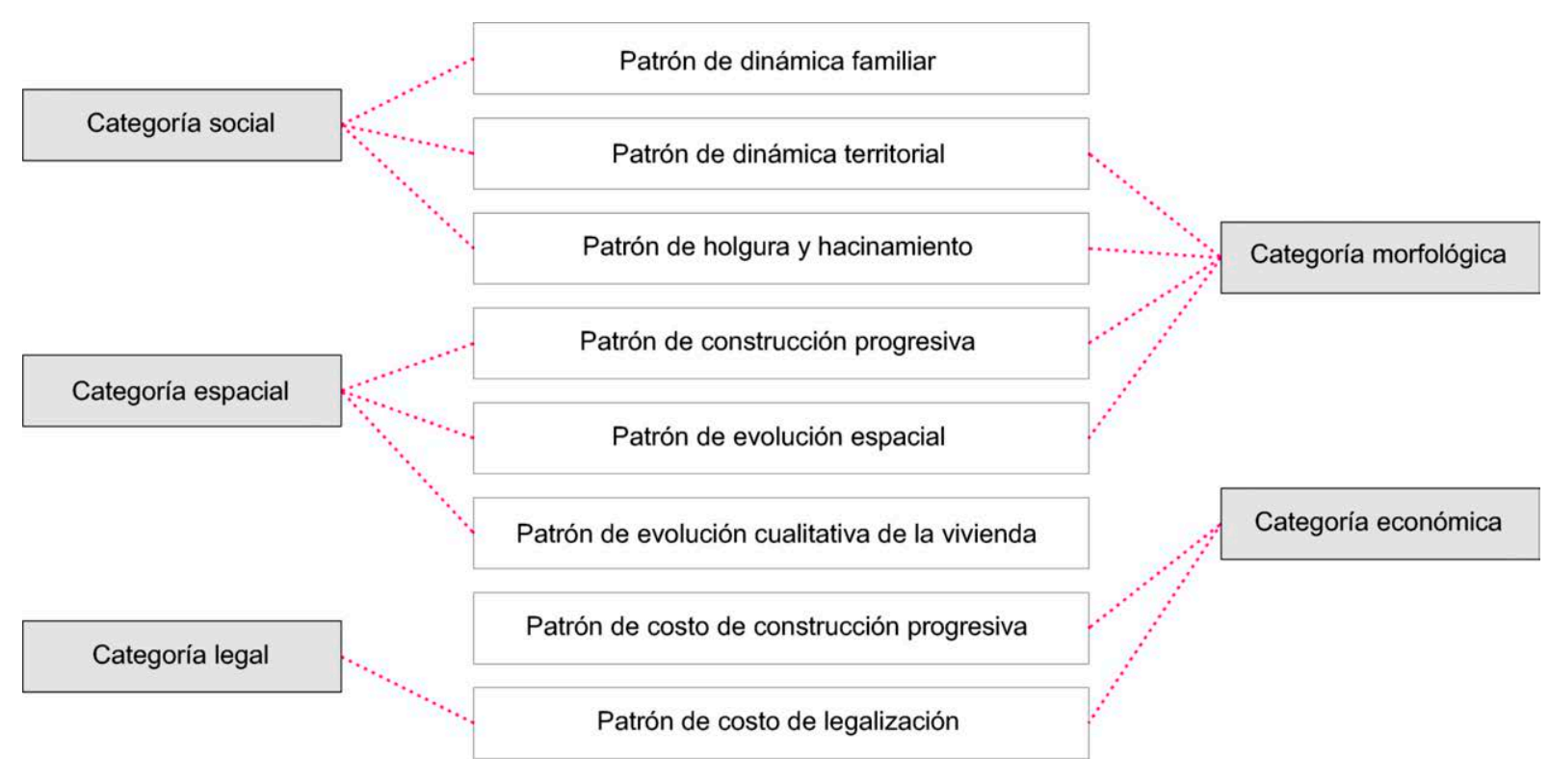

Tabla 07. Relación entre categorías de análisis y patrones evolutivos.

Cada patrón evolutivo es característico de una vivienda o una familia y se obtiene de una realidad existente que se mide según parámetros que se describirán más adelante. Por tanto en el caso en el que se haga una conjetura de cómo podría evolucionar un patrón en el futuro, este patrón será exclusivamente una tendencia hipotética, en función de la historia analizada y las aspiraciones de la familia, que permitirá proyectar lo que ocurrirá con posterioridad. 


\section{3.b. Patrón de dinámica familiar.}

Englobado dentro de la categoría social, este patrón se utiliza para analizar el proceso de crecimiento de la familia (tamaño, composición, edades, ritmo de crecimiento y relaciones). Definido por Jan Bazant como patrón de dinámica familiar, también ha sido estudiado por Jorge Andrade (Andrade Narváez, 1999) bajo el nombre de transformación del grupo social. Ambos investigadores toman como parámetro de análisis de primer orden el número de familiares por lote, reflejando la relación de parentesco entre los miembros y dejando patente cada tipo de unidad de convivencia que habita el lote.

De acuerdo a las investigaciones anteriores obtenemos la siguiente clasificación de tipos de unidades de convivencia, que utilizaremos igualmente como referente a lo largo de esta investigación:

- Familias nucleares: aquellas familias unipersonales o familias donde sólo existe una pareja o una pareja con algún hijo. (Considerada por Jorge Andrade como núcleo doméstico).

- Familias extendidas: familias nucleares a las que llega a vivir un pariente.

- Núcleo familiar extendido: aquel constituido por varias familias de parientes. Por ejemplo, el caso en el que el pariente que llegó a la familia extendida traiga a su propia familia.

- Familias desintegradas: familias donde la figura que traía mayor sustento al hogar ha desaparecido o no ejerce como tal. Este tipo de familias suele tener mayores problemas para realizar mejoras y ampliaciones en su vivienda debido a la irregularidad en los ingresos o a la falta de ellos.

- Grupo no familiar: cuando en el lote o en la vivienda existen, además de la familia inicial, inquilinos que pagan un alquiler y no forman parte de la unidad familiar.

- Grupo mixto: Caso en el que en la vivienda existan varias familias, algunas con relación de parentesco con la familia inicial (núcleo familiar extendido) y otros inquilinos sin relación familiar.

El sistema de representación utilizado para dibujar el patrón se ha heredado de las investigaciones de (GarcíaHuidobro, Torres Torriti, \& Tugas, 2008, p. 131). En el patrón de evolución familiar propuesto por los chilenos se combina el tiempo en el eje de abscisas con los metros cuadrados de la vivienda en el eje de ordenadas. 
Mientras que en el patrón propuesto por Bazant se combina el tiempo con el número de habitantes que ocupan el lote en cada momento, dejando el cálculo de los metros cuadrados para patrones de tipo morfológico. Para la tesis se utilizará el patrón de Bazant ya que se considera que esa separación entre lo morfológico y lo social es importante para clarificar el proceso. En cada una de las fases de crecimiento se indicará, además del número de habitantes en ese momento, la composición familiar mediante un icono similar al utilizado por García- Huidobro, Torres y Tugas. Gracias a este icono se podrá entender mejor la relación social entre cada uno de los miembros existentes y/o nuevos de la familia. (Tabla 08).

$(1$ Familias nucleares Familias extendidas

Tabla 08. Icono según tipos de unidades de convivencia.

El icono consta de una serie de círculos que representan los progenitores de cada una de las familias. Cada una de las líneas radiales dentro de estos representan los hijos de la familia. En el caso de que haya más de una familia con parentesco (familia extendida), como puede ser el caso de un pariente que viene de fuera trayendo a su familia a la casa, se representará como un círculo concéntrico respecto a la primera familia. Mientras en el caso de la llegada de una familia sin lazos de parentesco, como podrían ser unos inquilinos que paguen una renta, el círculo será dibujará ajeno al de la familia inicial.

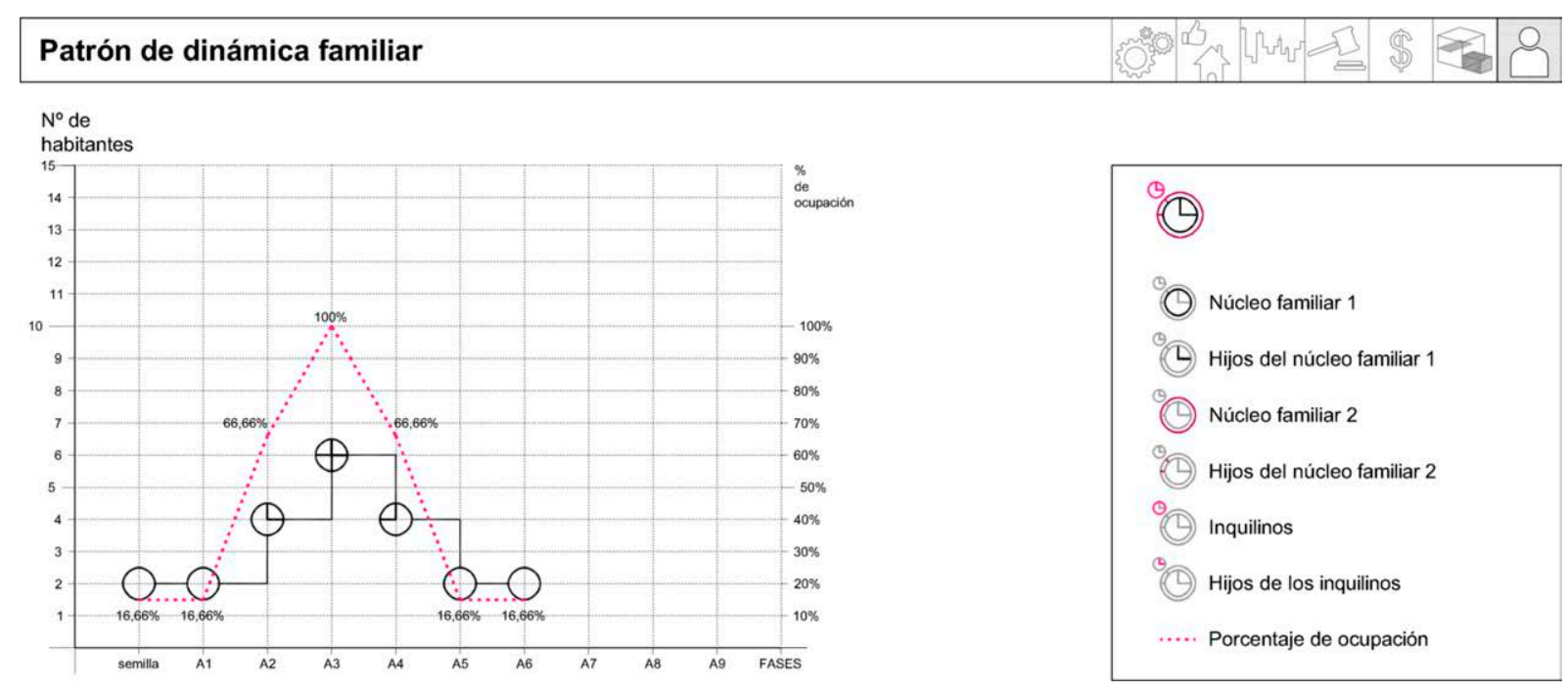

Gráfica 0I. Ejemplo de patrón de dinámica familiar.

Para obtener nuevos datos y conclusiones, se puede superponer este patrón sobre la gráfica de lo que propone teóricamente el arquitecto en términos de crecimiento de espacio, el patrón de construcción progresiva. De esta manera se extrae la relación entre los metros cuadrados de superficie construida por habitante y las variaciones de miembros de la familia, lo que permite averiguar en que momentos hay holgura o presión espacial en la vivienda. Observación que se podrá verificar en el patrón de holgura y hacinamiento. 
Los datos que se necesitan para obtener el patrón de dinámica familiar son: número de miembros de la familia, relaciones de parentesco entre miembros, tipo de familia y variación de miembros de la familia en el tiempo.

En el patrón se dibuja el parámetro que se está representando, en el tiempo y en su unidad característica (número de habitantes en este caso). Y a su vez, se representa superpuesta una línea porcentual que indica la variación relativa del parámetro en función de los valores de la vivienda semilla. De esta manera se considera que será mucho más fácil poder comparar distintos casos gracias a la comparación de las variaciones porcentuales y no tanto al valor absoluto de estas. En este caso, el 100\% del valor de variación porcentual se referirá al número máximo de habitantes que se ha dado de manera simultánea en alguna de las fases de crecimiento o decrecimiento de la vivienda, independientemente de si este valor se ha dado al inicio, al final o en el medio del proceso. 
3.Patrones evolutivos y parámetros 


\section{3.c. Patrón de dinámica territorial.}

Este patrón se ubica dentro de dos categorías, la categoría social y la categoría morfológica, ya que estudia la relación entre el espacio de la vivienda y como este afecta a las relaciones sociales. Más concretamente, este patrón analiza las tendencias de ocupación de cada una de las familias para identificar los territorios que puedan producir determinados conflictos dentro de la convivencia al ser espacios compartidos por diferentes familias (Andrade Narváez, 1999).

Estos territorios son identificados por Jorge Andrade, tal y como se indica a continuación:

- Territorio privado, es aquella área de la vivienda que ocupa únicamente una familia y que no se comparte con otros a no ser que sean invitados de manera temporal.

- Territorio compartido familiar, es la superficie de la casa que comparten dos familias con lazos de parentesco. Este territorio puede variar desde compartir espacios de comunicación como pueden ser el acceso, o la escalera, a compartir espacios de estancia como el patio o el estar. O como ocurre muy a menudo, compartir los espacios de servicio como cocina y baño ya que al ser los que tienen instalaciones son los más caros de construir.

- Territorio compartido no familiar, es el espacio compartido por varias familias que no tienen lazos de parentesco, como es el caso de los inquilinos. Estos espacios suelen corresponder con las zonas de comunicación como son el acceso, o la escalera.

A la hora de representar dicho patrón se ha utilizado el sistema de representación de Jorge Andrade quien indica con distintas tramas sobre las plantas de cada fase de que tipo de territorio se trata. De esta manera se puede ver si estos territorios evolucionan a lo largo del tiempo o no, y sobre todo es útil para identificar las áreas problemáticas. Una vez localizadas será más fácil solucionarlas, bien sea reduciendo la cantidad de territorios compartidos o bien transformándolos para que estos interfieran lo menos posible en la vida cotidiana de las familias. Para completar el patrón de dinámica territorial propuesto por Andrade se incorporó una tabla porcentual con la cantidad de cada uno de los territorios por vivienda en cada fase, lo que facilita la comparación entre fases y entre casos en términos absolutos. 
Para el trazado del patrón se han necesitado los planos de la vivienda, la propuesta de crecimiento por parte del arquitecto, el tipo de familia y el número de integrantes que habitan la casa, para que extrayendo los usos de los planos se puedan localizar los territorios comunes y de que tipo de territorio se trata en cada caso.

\section{Patrón de dinámica territorial}

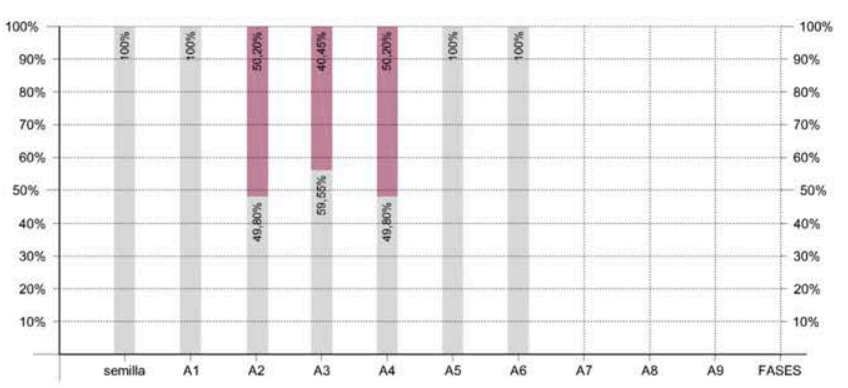

Tipos de territorios

Territorio privado

Territorio compartido familiar

Territorio compartido no familiar

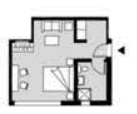

Vivienda semilla

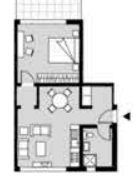

Ampliación 01

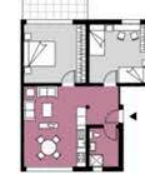

Ampliación 02

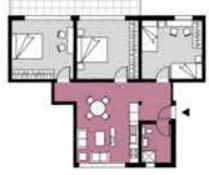

Ampliación 03

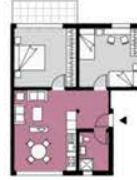

Ampliación 04

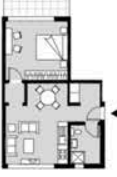

Ampliación 05

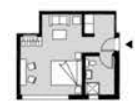

Ampliación 06

Gráfica 02. Ejemplo de patrón de dinámica territorial. 


\section{3.d. Patrón de holgura y hacinamiento.}

Como se ha comentado en apartados anteriores, en los últimos años las actividades de ocio y de trabajo remunerado se han ampliado en tiempo y en requerimientos de espacio en la vivienda. Es importante por tanto para este análisis señalar la proporción óptima entre espacio útil de la vivienda y el número de personas que viven en ella, para poder anticipar futuras ampliaciones de la vivienda en función de las posibles evoluciones de la familia.

¿Pero cuál es el valor óptimo de confort de una vivienda en función del número de personas que la habitan?, ¿Es posible, independientemente de los factores culturales y económicos de las familias, establecer dicho valor óptimo de forma universal? ¿Y cuál es el indicador más adecuado para evaluar ese confort'?

En el caso de España, el espacio medio por habitante en la actualidad es de aproximadamente $35 \mathrm{~m}^{2}$ por persona $^{2}$, frente a los $25,39 \mathrm{~m}^{2}$ del promedio europeo y los $14,52 \mathrm{~m}^{2}$ por persona del promedio mundial según datos de la ONU-Hábitat entre 1995 y 1997 (UN-Habitat, 2000). A pesar de que esta media mundial de holgura en vivienda ${ }^{3}$ (14,52 $\mathrm{m}^{2}$ útiles por persona) se acerca mucho a la cifra óptima de $15 \mathrm{~m}^{2}$ por persona propuesta por muchos autores e incluso por la legislación española ${ }^{4}$, si aplicáramos esta proporción en muchas de las viviendas, no solo de países sub desarrollados o en vías de desarrollo si no incluso en países desarrollados, encontraríamos que de acuerdo este baremo una enorme cantidad de hogares estarían por debajo del umbral óptimo, formando parte del registro de viviendas sobreocupadas o hacinadas.

Es por esto, que simultáneamente al indicador de la holgura se utiliza un indicador que evalúa el hacinamiento en función del número de personas por cuarto. Para este indicador de hacinamiento, UN-Hábitat considera que hay un déficit cualitativo en la vivienda cuando habitan más de tres personas por cuarto, mientras que si

\footnotetext{
' La ONU-Hábitat propone algunos de los siguientes indicadores para evaluar la sobrepoblación en la vivienda: Metros cuadrados útiles por persona, número de hogares por superficie, número de habitantes por cuarto, número de personas por cama y número de niños menores de cinco años por habitación. (UN-Habitat, 2009).

${ }^{2}$ Datos de CommSec, RBA, UN, US Census para el 2009.

${ }^{3}$ Se considerará el indicador de la holgura como metros cuadrados útiles por persona en una vivienda.

${ }^{4}$ El Plan Estatal de Vivienda y Rehabilitación 2009-2012 de España establece las superficies máximas y mínimas de las viviendas protegidas (viviendas sociales) en las que la superficie mínima de 30 metros cuadrados útiles podrá estar ocupada por un máximo de dos habitantes. (Ministerio de Vivienda, 2008).
} 
conviven cinco o más personas por habitación, independientemente de la superficie de esta, se considera que existe un hacinamiento no mitigable (Freire Delgado, 2009).

Si de acuerdo al barómetro de hacinamiento adoptado por UN-Hábitat analizamos el caso de la ciudad europea de Ámsterdam obtendríamos, según datos del Netherlands Department for Housing, que menos del I\% de los hogares de la ciudad están hacinados. Pero, sin embargo, si analizáramos los mismos hogares desde el criterio de los estándares para vivienda en Ámsterdam donde las casas con más de una persona por cuarto son consideradas como sobrepobladas, obtendríamos que más del $26,2 \%$ de los hogares de Ámsterdam están hacinados (UN-Habitat, 2006).

Es aquí donde entra la problemática de los estándares culturales y sociales que anunciábamos anteriormente. ¿Es posible independientemente de los factores culturales y económicos de las familias establecer un valor óptimo y universal en la relación entre el número de habitantes de una vivienda y su superficie útil?.

Para esta investigación se utilizarán tanto el indicador de la holgura (metros cuadrados útiles por persona) como el de el hacinamiento (número de personas por cuarto) y se tomarán como referencia los valores óptimos de $15 \mathrm{~m}^{2}$ por persona y 3 personas por cuarto respectivamente para evaluar el confort a nivel de densidad de habitantes de la vivienda independientemente de la procedencia de la unidad de convivencia. Esta decisión se ha tomado con base en el artículo "Not Enough Room: Overcrowding in Urban Households" donde establecen dichos rangos como valores óptimos de densidad independiente de la cultura y la etnicidad de los habitantes.

\section{Patrón de holgura y hacinamiento}
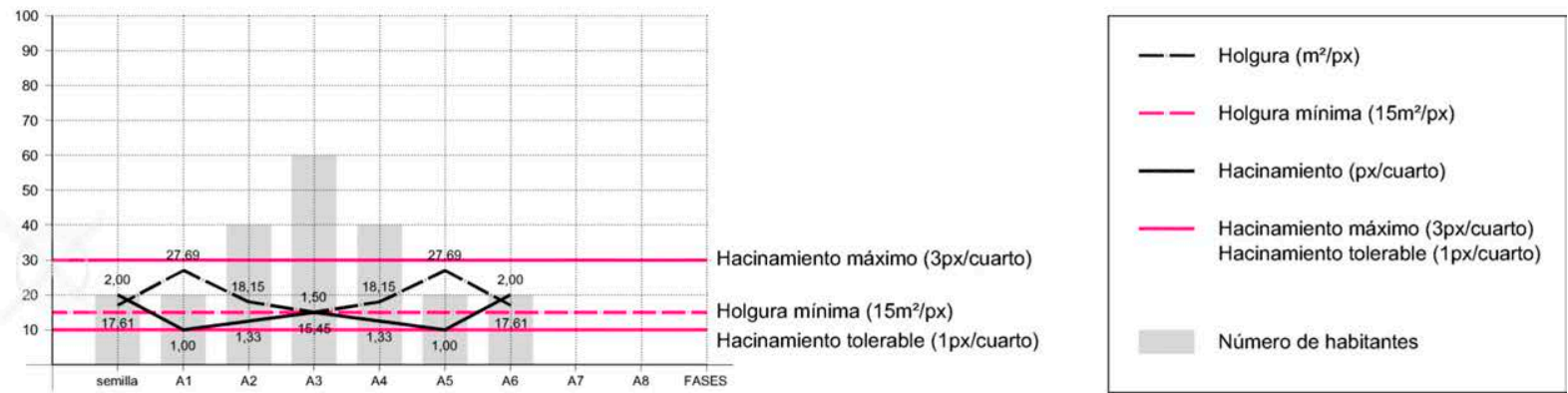

Gráfica 03. Ejemplo de patrón de holgura y hacinamiento.

En la representación del patrón de hacinamiento se ha necesitado calcular el número de habitantes de la vivienda y su disposición respecto de las habitaciones de esta. Mientras que para la holgura se han calculado los metros cuadrados útiles de la casa y se han puesto en relación con los habitantes. Para no perder de vista los valores óptimos extraídos anteriormente, se marcarán las cifras de referencia en el patrón para identificar claramente en que ocasiones se cumplen los estándares y en que ocasiones no. (Gráfica 03). 


\section{3.e. Patrón de construcción progresiva.}

El patrón de construcción progresiva se encuentra dentro de las categorías morfológica y arquitectónica, ya que está asociado a la superficie de la vivienda y a la distribución física de los espacios y sus relaciones por yuxtaposición. Se centra por tanto en la variación del tamaño de la casa indicando la relación que tiene el nuevo espacio ampliado con el resto de las estancias de la vivienda.

Jorge Andrade también analiza este patrón denominándolo transformación del sistema formal (Andrade Narváez, 2003) y en él estudia el número y tipo de espacios incrementados en el proceso de evolución de la vivienda.

\section{Patrón de construcción progresiva}
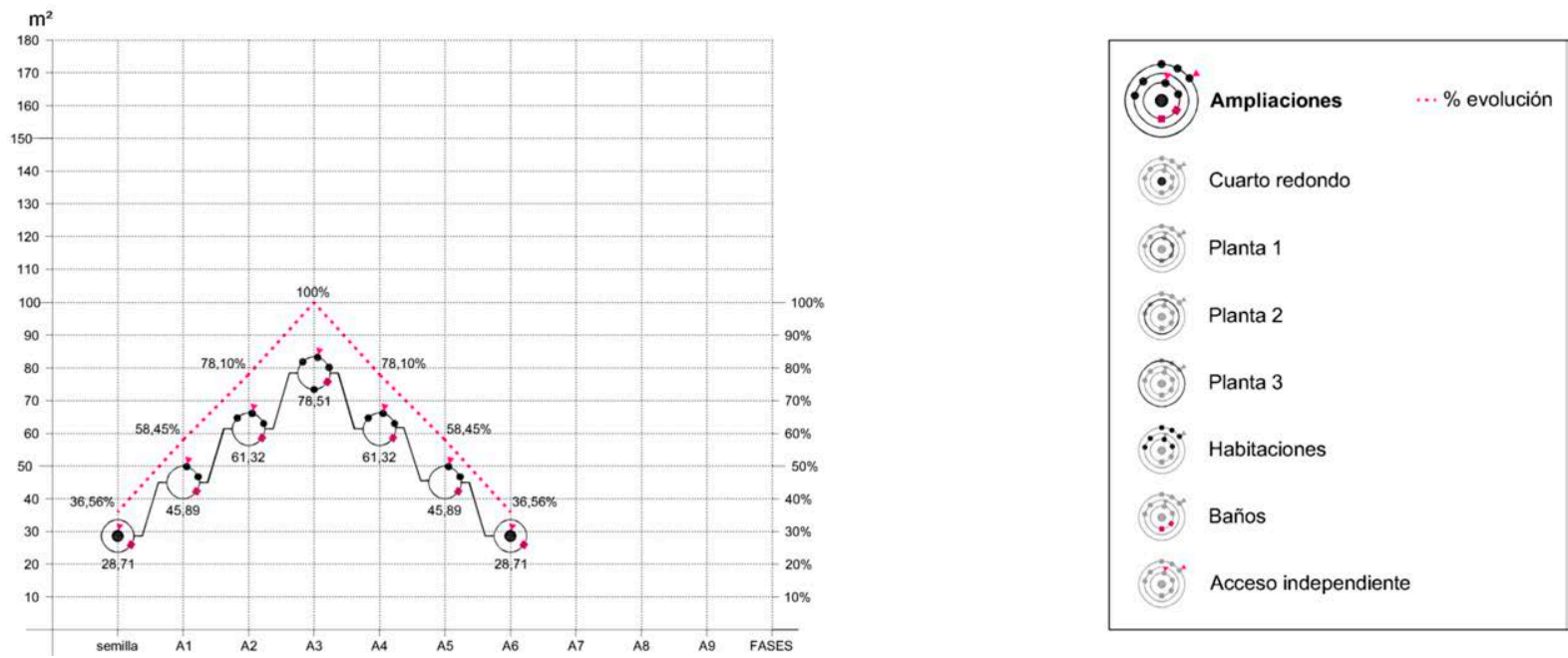

Gráfica 04. Ejemplo del patrón de construcción progresiva.

Para este patrón se ubica en el eje de ordenadas el tiempo (constante común en todos los patrones que tracemos) y en el eje de abscisas se encontrarán los metros cuadrados útiles construidos. De esta manera se podrá analizar como se va ampliando la superficie efectiva de la vivienda. Para completar el análisis e inspirado en la representación de la dinámica familiar de (García-Huidobro, Torres Torriti, \& Tugas, 2008, p. I3I) se ha utilizado un icono que muestra la posición relativa de cada una de las estancias iniciales y sus ampliaciones. De 
esta manera se podrá identificar si las ampliaciones son en planta baja, en primer piso, o en segundo, si hay un solo acceso o si hay varios y donde se encuentran y cual es el número de habitaciones (entendiendo por habitaciones y únicamente en este caso, cualquier estancia de la casa. Estar, comedor, dormitorio o cocina).

Para estudiar esta tendencia de evolución es necesario extraer los metros cuadrados útiles construidos en el inicio, los metros cuadrados útiles ampliados en cada fase, así como el número de cuartos iniciales y el número de cuartos que se han ido ampliando en cada fase. Lo que se completará con la localización de los cuartos ampliados y los accesos.

Para hacer la información más fácilmente comparable con la de otros casos se representa superpuesta la línea porcentual que indica la variación relativa del parámetro en función de la superficie incrementada. Para ello se tomará como valor máximo la superficie útil máxima que alcance la vivienda siendo esta el valor $100 \%$ de la escala. (Gráfica 04). 


\section{3.f. Patrón de evolución espacial.}

Dentro de la categoría de patrones que atienden a la morfología del crecimiento encontramos también el patrón de evolución espacial. Este patrón, extraído de las teorías de Carlos González Lobo (González Lobo, 1999) quien lo describe como puntas de crecimiento, es similar a un árbol genealógico del crecimiento de la casa en el que se muestran los posibles crecimientos que se podrían hacer en cada una de las fases basándonos en el resultado final de la vivienda. De esta manera se puede identificar la flexibilidad de la vivienda propuesta y cual es la fase que potencialmente permite más posibilidades distintas de ampliación (ramas de crecimiento) de manera que la familia pueda escoger la que más le convenga. También se puede identificar cual es la fase más restrictiva, es decir, aquella que una vez construida no permite que se continúe el crecimiento debido a su disposición. Como por ejemplo, podría ser aquella ampliación que no previese adecuadamente la futura habitabilidad de la vivienda y que no permitiese construir más porque si no la vivienda se quedaría sin iluminación y ventilación. Es por esto que también pertenece a la categoría espacial, ya que la decisión de si un crecimiento toma una rama $u$ otra en muchos casos se hará en función de la calidad espacial resultante. Este análisis de la evolución espacial también permite identificar las fases llave, que son aquellas que si no se hacen impiden que se continúe ampliando la vivienda, como podría ser la colocación de una escalera para seguir creciendo en planta alta. Y puede llegar a mostrar la rama más rica, es decir el camino de ampliación que tiene más variaciones espaciales posibles a lo largo de todo el proceso de construcción.

A la hora de representar este patrón se ha tratado de construir el árbol que muestre el proceso evolutivo de cada una de las viviendas que se podrían obtener a partir de una misma vivienda semilla. En este se indica tanto si el proceso de evolución se ha producido por adición de un espacio o por la reducción de este y señala mediante un índice las posibles alternativas de crecimiento que hay en cada fase.

Para poder elaborar este gráfico se han requerido los planos de la vivienda semilla y la propuesta de crecimiento por parte del arquitecto. Tras ellos se ha realizado una conceptualización de las fases del proceso proponiendo cuales serían las posibles combinaciones de ampliación de los espacios en cada uno de los casos. En ningún momento se han sugerido espacios que no estuvieran propuestos anteriormente en los planos de los arquitectos por lo que se ha trabajado únicamente con los espacios existentes combinándolos entre sí. (Gráfica 05). 


\section{Patrón de evolución espacial}

10
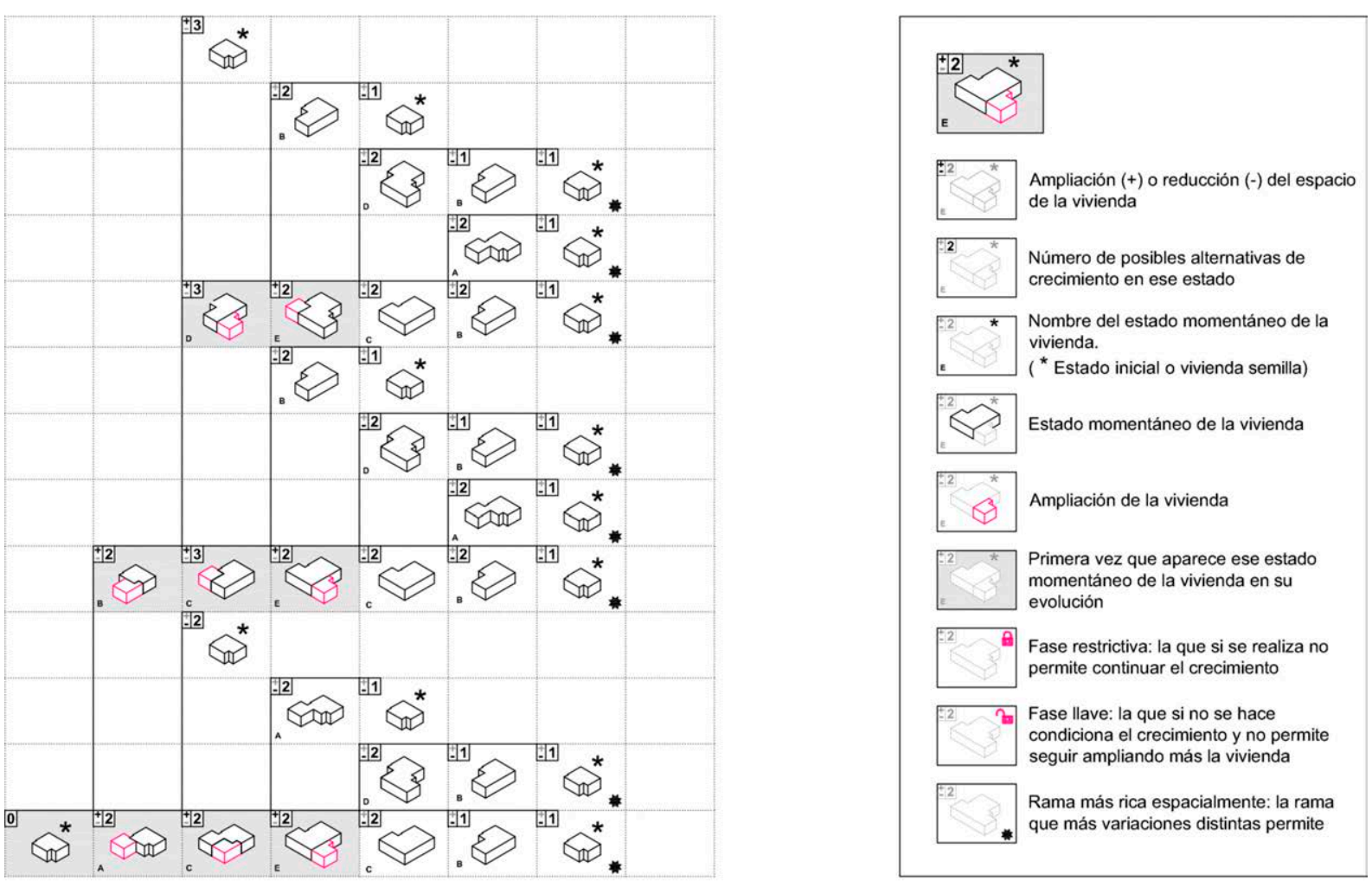

\section{$\overbrace{\text { Nümero maximo de fases conseculivas }}^{*} 7$}

Número máximo de fases consecutivas

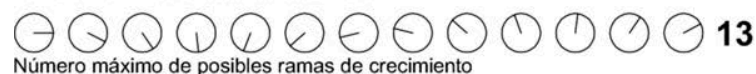

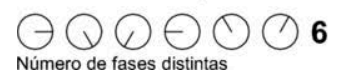

Gráfica 05. Ejemplo de patrón de evolución espacial. 


\section{3.g. Patrón de evolución cualitativa de la vivienda.}

Este patrón se ubica dentro de la categoría espacial que evalúa la calidad del proyecto. Para elaborar este patrón se han creado una serie de indicadores extraídos de los textos de distintos autores expertos en la evaluación de viviendas mínimas y/o sociales y se ha hecho un compendio de sus parámetros que vinculados al tiempo han permitido evaluar la calidad de la vivienda crecedera.

Debido a que esta tesis se enmarca dentro del Departamento de Proyectos de la Universidad Politécnica de Madrid, se ha considerado indispensable no sólo evaluar si los proyectos de viviendas crecederas analizados responde a unas necesidades sociales, económicas, constructivas y espaciales adecuadas. Si no que es fundamental que las respuestas tengan la suficiente calidad arquitectónica.

En 198I se entendía por calidad en las viviendas a la habitabilidad de éstas, es decir, la capacidad de dar satisfacción a las exigencias de los usuarios. Según Xavier Sust (Sust, Borrell, Paricio, \& Ramón, 198I), "esta satisfacción se valoraba en función de la durabilidad, el confort ambiental y la funcionalidad. Una durabilidad que garantizara la solidez y facilidad de conservación. Un confort ambiental que creara en el interior de la vivienda un medio adecuado al cuerpo humano, refiriéndose básicamente a la temperatura, la iluminación natural, el soleamiento, la ventilación, el ruido y la humedad. $Y$ una funcionalidad que posibilitara las actividades propias de una vivienda dentro de las condiciones más cómodas teniendo en cuenta aspectos físicos como la accesibilidad, aspectos psíquicos como la intimidad, aspectos utilitarios como la comodidad y aspectos simbólicos como la expresión del estatus social". Sin embargo hoy en día, y asociado a los cambios tecnológicos, sociales y medioambientales urge proponer otros principios de análisis tal y como hace Tania Magro Huertas en su investigación "Nuevos parámetros de calidad en la vivienda contemporánea" (Magro Huertas, 2006-2007). En esta propone frente a los cambios medioambientales, la economía de medios que evite el derroche energético. Frente a los cambios sociales, espacios indeterminados que permitan una adaptación de estos a diversas funciones y distintas agrupaciones familiares a lo largo del tiempo. $Y$ frente a los avances tecnológicos, espacios que no estén totalmente acabados y que se puedan ir completando conforme a las futuras y cambiantes necesidades. 
Por tanto partiendo de los estudios de autores de primera línea en el análisis de la vivienda como Klein o Habraken y combinando estos con las revisiones de investigadores actuales como Sust, Monteys, Magro, etc... Se sugirien los siguientes parámetros para la evaluación de la calidad de las viviendas estudiadas en este documento.

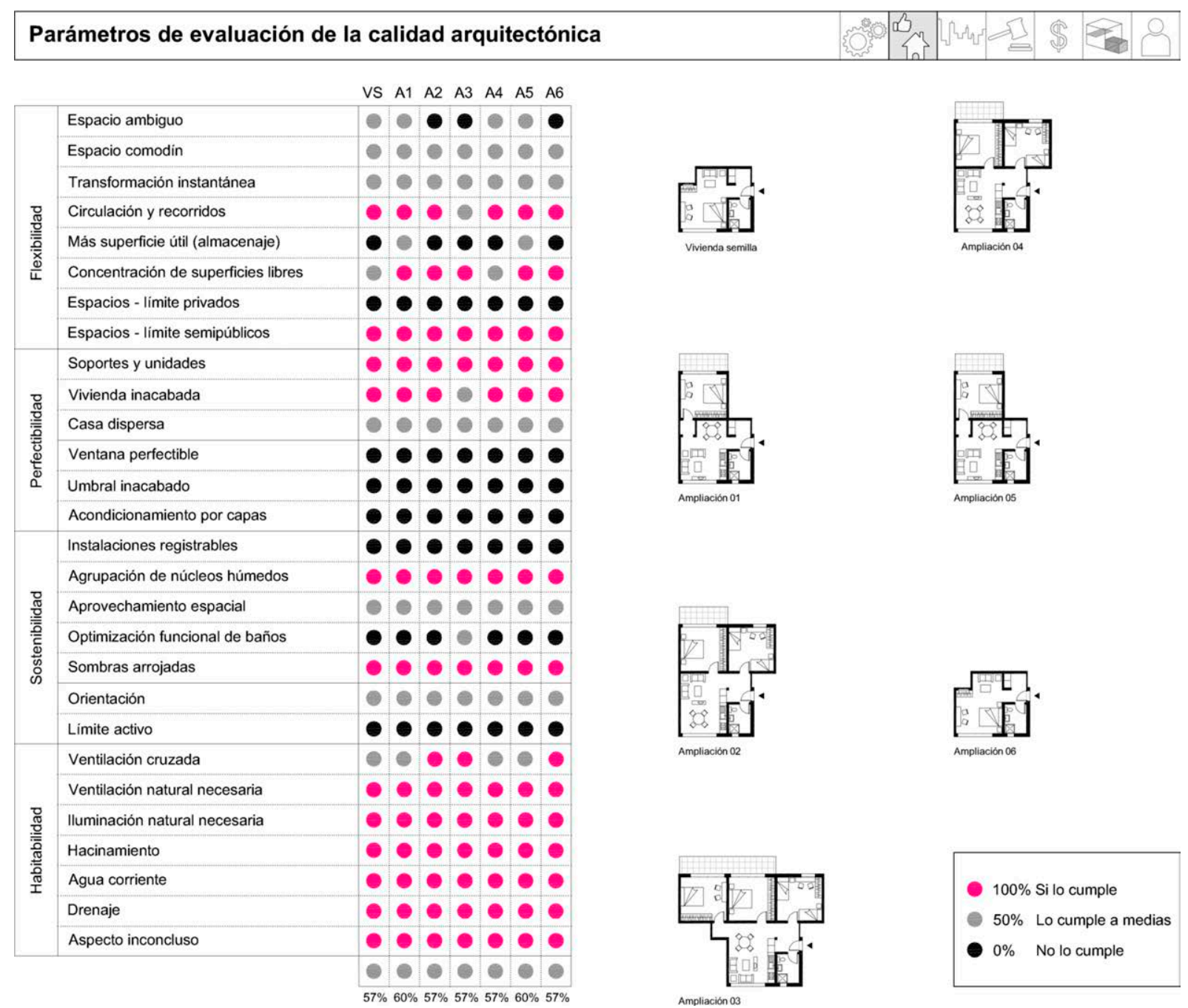

Gráfica 06. Ejemplo de patrón de evolución cualitativa de la vivienda.

OI Espacio ambiguo: Espacio que al no estar definido funcionalmente puede ser potencialmente utilizado de diversas maneras a la vez o en tiempos distintos. "Un espacio que abre una posibilidad a lo potencial, lo imprevisto y lo no planificado. Un espacio sin programa alguno pero, por ello mismo, con un potencial de posibilidades que, casi siempre, desarrollan los propios habitantes mediante el proceso de habitarlo". (Goulet, 2010, p. 144).

02 Espacio comodín: Aquel que teniendo o no un uso determinado se puede vincular a otro espacio para dotarlo de nuevas posibilidades. Permite agrandar el espacio y alargar las visuales dando otras situaciones diferentes. (Magro Huertas, 2006-2007, p. 45). 
03 Transformación instantánea: Modificación espacial que se logra gracias a elementos móviles o desplazables que con operaciones sencillas de traslado logran dotar al espacio de cualidades distintas, ya sean visuales, espaciales o funcionales (Magro Huertas, 2006-2007, p. 47).

04 Circulación y recorridos: El recorrido de las circulaciones debe de seguir una organización racional y sencilla posibilitando la simultaneidad en relación al ahorro de energías puramente físicas (Klein, 1980, p. 125).

05 Más superficie útil: Todas aquellas superficies extras no computables (alturas menos de 2,10 m) denominadas como altillos, entrepisos o tapancos que se pueden usar para trabajar, dormir, almacenar, etc. (Magro Huertas, 2006-2007, p. 49).

06 Concentración de superficies libres: De este concepto depende según Klein la espaciosidad y comodidad de la vivienda e indica la cantidad de superficie libre que está agrupada. A mayor concentración, mayor percepción de espaciosidad y mayor libertad de movimiento. (Klein, 1980).

07 Espacios- límite privados: Aquellos espacios situados en la franja perimetral de la vivienda (balcones, terrazas, galerías, logias, atrios, etc.) que pueden funcionar generando dobles circulaciones, aportando un espacio extra o que permitan dar varios usos alargando el interior hacia el exterior. (Magro Huertas, 2006-2007, p. 63).

08 Espacios- límite semipúblicos: Los que permiten acceder a la vivienda (pasillos, corredores, rellanos, etc.) y donde podrían ocurrir otras muchas cosas. (Magro Huertas, 2006-2007, p. 65).

09 Soportes y unidades: Las viviendas están compuestas por soportes y unidades separables, de tal manera que los soportes serían aquellos elementos inamovibles y definidos por el proyectista y las unidades separables podrían variar respecto de las necesidades de los usuarios. Se pretende construir un conjunto de reglas que gobiernen las posibles variaciones, y que sean lo suficientemente simples como para permitir al residente visualizar todas las opciones posibles de cambio abiertas a él. (Habraken, 1987).

10 La vivienda inacabada: Aquella que se adquiere con sus elementos básicos para ser habitada, pero con posibilidades de ser completada a lo largo del tiempo. Es un soporte básico al que poder ir agregándole diferentes elementos que mejoren sus condiciones y completen sus posibilidades. (Magro Huertas, 2006-2007, p. 53)

II La casa dispersa: Las unidades habitables están pensadas como viviendas mínimas a las que ir agregando otras unidades que la completarán y que podrían colocarse de forma discontinua y dispersa por el soporte. (Monteys \& Fuertes, 1987, p. 144).

12 Ventana perfectible: Ventana personalizable cuyo marco sirve como bastidor y a la que se le pueden incorporar con el tiempo una serie de capas (contraventana, persiana, toldo...). Con esta ventana crecedera la vivienda será más económica inicialmente. (Magro Huertas, 2006-2007, p. 69).

13 Umbral inacabado: Espacio intermedio entre interior y exterior que con el tiempo puede ser modificado por el usuario añadiendo elementos que cambien la relación interior de la vivienda con el exterior. (Magro Huertas, 2006-2007, p. 7I). 
14 Acondicionamiento por capas: El cerramiento entero de la vivienda está compuesto por capas que podrán cambiarse y completarse conforme a las necesidades del usuario a modo de pieles de la vivienda. $Y$ se conseguirían distintos resultados interiores a nivel de climatización, iluminación, aislamiento, protección y vistas. (Magro Huertas, 2006-2007, p. 7I).

15 Instalaciones registrables y accesibles: permite que las instalaciones puedan ser ampliadas, consultadas y reparadas por cualquiera sin entrar a la vivienda y sin necesidad de obras (Magro Huertas, 2006-2007, p. 59).

I6 Agrupación de núcleos húmedos: La agrupación de zonas húmedas hace más eficientes las instalaciones minimizando los conductos y facilitando la reparación (Magro Huertas, 2006-2007, p. 59).

17 Aprovechamiento del espacio: mediante mobiliario polifuncional, almacenamiento que ocupe zonas residuales de la vivienda, zonas de paso sobredimensionadas para albergar otros usos, etc. (Magro Huertas, 2006-2007, p. 6I).

18 Optimización funcional de los baños: plantear baños disociados permite no tener que duplicar funciones que no sean realmente necesarias ahorrando espacio (Magro Huertas, 2006-2007, p. 59).

19 Sombras arrojadas: según Klein las sombras arrojadas por los antepechos de ventanas, muebles, etc. pueden llegar a producir efectos psíquicos y ópticos desagradables, por lo que considera que es imprescindible evaluar este aspecto a la hora de indicar la calidad de la vivienda. (Klein, 1980).

20 Orientación: El edificio deberá de estar bien orientado y tener dos fachadas muy distintas funcional y formalmente que creen protecciones o captaciones solares según se requiera. (Magro Huertas, 2006-2007, p. 73)

2 I Límite activo: Es el ámbito formado entre el interior y el exterior (galerías, balcones, miradores, logias, patios, fachadas ventiladas, fachadas verdes, etc.) que puede ser energéticamente activo en la medida en que utilicemos todos los recursos de control del microclima de que dispongamos. (Magro Huertas, 2006-2007, p. 75).

22 Ventilación cruzada: Ventilación que se consigue generando el paso del viento a través de una habitación debido a la abertura de dos huecos.

23 Ventilación natural necesaria: Renovación de aire suficiente para asegurar la salubridad del aire y el acondicionamiento térmico de la vivienda.

24 Iluminación natural necesaria: Uso suficiente de aperturas para conseguir una iluminación interior eficaz que permita maximizar el confort visual y reducir el uso de energía eléctrica.

25 Hacinamiento: Número de habitantes que duermen en una habitación. Este parámetros se extraerá del patrón de holgura de hacinamiento y se utiliza nuevamente en este patrón ya que se considera esencial a la hora de evaluar la calidad de una vivienda.

26 Agua corriente: Acceso a la red pública de agua potable. 
27 Drenaje: Acceso al sistema de drenaje público para retirada de aguas.

28 Aspecto inconcluso: Cuando la vivienda crecedera, debido al carácter procesual y no de objeto terminado, posee una apariencia de construcción no terminada. (Haramoto, 1987)

A la hora de trazar el patrón de calidad a lo largo del tiempo se ha decidido evaluar cada uno de los parámetros anteriores en una escala del cero al cien donde cero significa que la vivienda no cumple con las características de dicho parámetros, cincuenta significa que lo cumple más o menos, y cien significa que lo cumple totalmente. Según esto, para obtener la calidad global de la vivienda se sumarán los valores de todos los parámetros descritos adquiriendo un número sobre cien que indica el valor de la calidad arquitectónica de la vivienda seleccionada. De esta manera se podrá evaluar si a medida que la vivienda crece adquiere una mayor calidad o si el proyecto empeora. Y además se facilitará la posibilidad de comparar la calidad de los diferentes casos de estudio.

Para la obtención de los datos de cálculo de los anteriores parámetros se ha requerido tanto los planos de la vivienda semilla como los de la propuesta de crecimiento por parte de los arquitectos. 
3.Patrones evolutivos y parámetros 


\section{3.h. Patrón de costo de construcción progresiva.}

Este patrón está vinculado a la categoría económica y estudia concretamente el costo de construcción de la vivienda en cada una de las fases de crecimiento, desglosado en estructura y cerramiento, por un lado, y acabados, por el otro. Dentro de los cálculos, se considerará el costo de la mano de obra aunque quepa la posibilidad, sobre todo en casos como los latinoamericanos, de que la construcción de la vivienda se realice por parte de los propios habitantes o familiares allegados con lo que desaparecería este gasto.

\section{Patrón de costo de construcción progresiva}

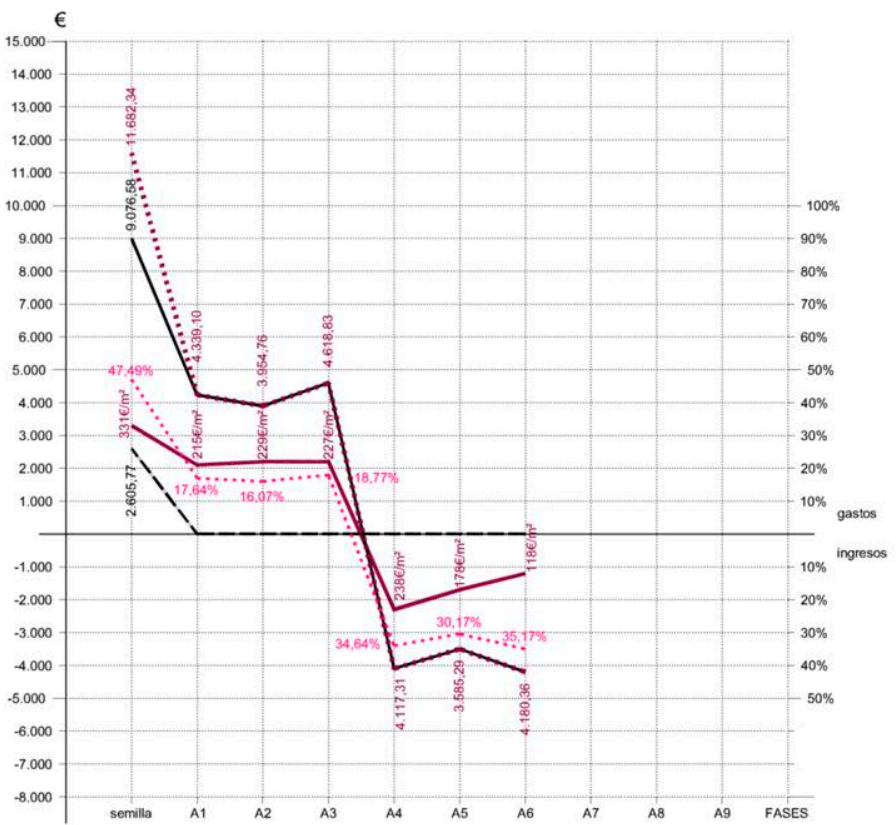

\begin{tabular}{|rr}
\hline $11.682 €\left(331 € / \mathrm{m}^{2}\right)$ & Gasto viv. semilla \\
$4.339 €\left(215 € / \mathrm{m}^{2}\right)$ & Gasto ampliación 1 \\
$3.954 €\left(229 € / \mathrm{m}^{2}\right)$ & Gasto ampliación 2 \\
$4.618 €\left(227 € / \mathrm{m}^{2}\right)$ & Gasto ampliación 3 \\
$-4.117 €\left(238 € / \mathrm{m}^{2}\right)$ & Gasto decrecimiento 1 \\
$-3.585 €\left(178 € / \mathrm{m}^{2}\right)$ & Gasto decrecimiento 2 \\
$-4.180 €\left(118 € / \mathrm{m}^{2}\right)$ & Gasto decrecimiento 3 \\
\hline
\end{tabular}

$24.595 €\left(264 € / \mathrm{m}^{2}\right)$ Gasto total por ampliación $11.882 €\left(317 € / \mathrm{m}^{2}\right)$ Ingreso por decrecimiento

$12.712,07 €\left(360 € / \mathrm{m}^{2}\right) \quad$ Inversión total

\begin{tabular}{|c|c|}
\hline & Gasto en estructura y cerramiento \\
\hline--- & Gasto en acabados \\
\hline ?...... & $\begin{array}{l}\text { Patrón de costo total de } \\
\text { construcción progresiva }\end{array}$ \\
\hline ….... & $\begin{array}{l}\text { Evolución porcentual del costo } \\
\text { total de construcción progresiva }\end{array}$ \\
\hline & Gasto total por metro cuadrado \\
\hline
\end{tabular}

Gráfica 07. Ejemplo de patrón de costo de construcción progresiva.

Queda claro que no es lo mismo, a nivel de costos y de disponibilidad de mano de obra especializada, construir, por ejemplo, en acero en Estados Unidos, que en México o en España. Al igual que algunos sistemas son inviables en otras localizaciones por temas de climatología o por falta de ese material en la zona, como 
podría ser el caso de construcciones en bambú. Sin embargo y a pesar de poder ser una operación excesivamente reduccionista, se tratará de unificar costos bajo los precios de una única localización concreta para poder hacer más comparable el fenómeno, en este caso los precios de Granada, en España. En futuras investigaciones se podrá realizar la misma operación tomando los precios de otros lugares, lo que probablemente haga que este parámetro varíe notablemente.

Para poder trazar este patrón se ha necesitado averiguar los materiales empleados en cada una de las fases del proyecto, se ha estipulado un precio general de cada partida tomando como referencia la base de precios CYPE Ingenieros en su versión española (CYPE Ingenieros, 2014) ya que se ha decidido que los cálculos se harán para una posible vivienda que se construiría en España dado que la tesis se presenta en este país y el tribunal estará más relacionado con los precios españoles. La utilización de esta moneda como unidad de medida facilitará la interrelación de datos entre este patrón y el de costo de legalización al estar en las mismas unidades. Una vez obtenidos estos datos y gracias a los planos de las fases, se extraerán las mediciones de cada partida de cada material y se calculará el costo material de la construcción. En el caso de que la vivienda crezca se tendrá un gasto al ampliar materialmente el espacio, mientras que en el caso de decrecimientos del espacio lo que se obtendrá es la diferencia entre el gasto que materialmente implica reducir el espacio y el ingreso que implica el cederle ese espacio a otra persona, en caso de que sea un decrecimiento por cesión a otro usuario (como es el caso de los procesos de decrecimiento por unión, en este caso sustracción). En este último caso, el ingreso correspondería únicamente al costo material de lo construido. No se incluirían en este caso ningún otro gasto derivado del precio del suelo (dado que no se está considerando en ningún momento), ni se añadirán costos por el proceso legal de cesión, ya que estos costos se asumen el patrón de costo de legalización. (Gráfica 07).

Hay que tener en cuenta que a la hora de calcular el costo de la construcción no se ha calculado el costo total de esta y únicamente se han considerado los elementos que condicionan la espacialidad interna de la vivienda dejando fuera del cálculo las instalaciones (sin excluir las instalaciones sanitarias) y la cimentación (debido a que a igualdad de cargas y superficie esta varía principalmente por el terreno en el que se construyen y no tanto las pequeñas variaciones de la solución espacial adoptada).

En cuanto a su representación gráfica, a la línea de gasto en estructura y cerramiento y a la de gasto en acabados, se le añadirá la línea de gasto total que es la suma de las anteriores. Y se completará el patrón, al igual que los casos anteriores, con el cálculo la línea porcentual que indica la variación relativa del parámetro en función del gasto total. En este caso se tomará como valor máximo la suma de los gastos parciales hasta alcanzar el gasto total que será el valor $100 \%$ de la escala. No se tendrán en cuenta las ganancias obtenidas por el decrecimiento puesto que este dato desvirtuaría la compresión del patrón, ya que se podría malinterpretar que el gasto total para obtener el crecimiento máximo de la vivienda es menor. Y se considera que la familia ha de ser consciente del costo total de la construcción ya que esto implica ahorrar una cantidad de dinero determinada, que aunque en parte sea devuelta posteriormente tendrán que ahorrarla de todas maneras porque existe la posibilidad de que la vivienda alcance su crecimiento máximo y que luego no decrezca nunca, de manera que los usuarios no reciban la diferencia de dinero producida por el decrecimiento. 


\section{3.i. Patrón de costo de legalización.}

El segundo de los patrones que responde a la categoría económica es el patrón de costo de legalización que también se engloba en la categoría legal e indica lo que cuesta legalizar cada una de las fases de crecimiento de la vivienda.

En el caso de México, y según el arquitecto Luis García Galiano miembro de "Espacio máximo costo mínimo", hay que señalar que tanto si la vivienda semilla consta de menos de $60 \mathrm{~m}^{2}$, como si las ampliaciones posteriores son menores de $45 \mathrm{~m}^{2}$ no se requiere la tramitación de un visado. Es por ello que la vivienda crecedera tiene tanto éxito a nivel unifamiliar en países con una legislación como la de México, ya que los trámites burocráticos son mucho menores, lo que reduce costes y tiempo de espera para la construcción.

Sin embrago, a la hora de calcular el costo de legalización se tomarán como referencia los costos en España, concretamente los derivados de la legislación del Ayuntamientos de Granada ya que es el ayuntamiento que tiene las normativas más actualizadas respecto a este tema ${ }^{5}$.

A continuación se adjunta un ejemplo desglosado del método de cálculo aplicado en esta investigación para obtener el costo de legalización de una ampliación de $25 \mathrm{~m}^{2}$ en Granada. Para calcular dicho precio se ha desglosado por un lado el coste material de construcción y por otro el valor de los trámites y de los honorarios de los arquitectos considerando como coste de legalización la suma de los dos últimos. (Tabla 09).

Los costos derivados de la legalización de la ampliación proceden de los siguientes trámites: Tasa por la expedición de consulta previa o informe de la ficha urbanística, estudios topográfico y geotécnico, redacción de proyecto básico y de ejecución por parte de un técnico especializado, aval de garantía indispensable para solicitar la licencia de obras (tanto en la Ordenanza de Granada, como en la de Sevilla se considera el proceso de ampliación como una obra mayor que tendrá que obtener la licencia de obras pertinente), impuesto sobre construcciones, instalaciones y obras, tasa por licencia urbanística, dirección de obra de arquitecto y aparejador, tasa por licencias urbanísticas de primera ocupación, minuta del notario, gestoría, impuesto sobre actos jurídicos documentados, y finalmente, aranceles del registro de la propiedad.

\footnotetext{
${ }^{5}$ Ordenanza de la edificación del Ayuntamiento de Granda actualizada a I de enero de 2014.
} 
CÁLCULO DE COSTOS DE LEGALIZACIÓN PARA AMPLIAR 25 M2
$\mathrm{m} 2$ vivienda
$25 \mathrm{~m} 2$
precio $\mathrm{m} 2$ construido
$600 € / \mathrm{m} 2$

PRESUPUESTO DE OBRA DE CONSTRUCCIÓN DE LA VIVIENDA

\begin{tabular}{|c|c|c|}
\hline Presupuesto de ejecución material (PEM) & $15000 €$ & \multirow{9}{*}{$\begin{array}{l}\text { PRECIOS DE CTE } \\
\text { PRECIOS DE CTE } \\
\text { PRECIOS DE CTE }\end{array}$} \\
\hline Control de calidad & $700 \mid €$ & \\
\hline Gestion de residuos & $2300 €$ & \\
\hline Seguridad y salud & $1200 €$ & \\
\hline Gastos generales $13 \%$ del PEM & $1950 €$ & \\
\hline Beneficio industrial $6 \%$ del PEM & $900 €$ & \\
\hline Total ejecución por contrata & $17850 €$ & \\
\hline IVA (21\%) & $3748.5 €$ & \\
\hline Total ejecución por contrata con IVA & $21598.5 €$ & \\
\hline
\end{tabular}

Total ejecución por contrata con IVA

TASA POR LA EXPEDICIÓN DE CONSULTA PREVIA O INFORME-FICHA URBANÍSTICO

\begin{tabular}{|l|r|}
\hline Tasa de licencia de obras (1,12\% PEM) & 168 \\
\hline Consulta previa (10\% de la tasa) & 16.8 \\
\hline Informe ficha & 111.21 \\
\hline
\end{tabular}

Informe ficha

ESTUDIOS TOPOGRÁFICO Y GEOTÉCNICO
\begin{tabular}{|l|r|}
\hline Estudio topográfico & 300 \\
\hline IVA (21\%) & 63 \\
\hline Total estudio topográfico & 363 \\
\hline & 900 \\
\hline Estudio Geotécnico & 189 \\
\hline IVA (21\%) & 1089 \\
\hline Total estudio geotécnico & \\
\hline \multicolumn{2}{|l|}{ REDACCIÓN DE PROYECTO BÁSICO Y DE EJECUCIÓN } \\
\hline Coste (4\% PEM) & 600 \\
\hline IVA (21\%) & 126 \\
\hline Total redacción PB y PE & 726 \\
\hline
\end{tabular}

Tanto en la Ordenanza de Granada como en la de Sevilla se considera el proceso de ampliación como una obra mayor que tendrá que obtener la licencia de obras pertinente

AVAL DE GARANTIA (INDISPENSABLE PARA SOLICITAR LA LICENCIA DE OBRA

\begin{tabular}{|l|r|}
\hline Estudio (0,5\%) mínimo 70€ & 70 \\
\hline Formalización (0,5\%) mínimo 75€ & 75 \\
\hline Riesgo trimestral (0,5\%) mínimo 50€ & 250 \\
\hline Coste total estimado del aval & 395 \\
\hline \multicolumn{2}{|l|}{ IMPUESTO SOBRE CONSTRUCCIONES, INSTALACIONES Y OBRAS } \\
\hline Impuesto (4\% PEM sin CC, R y SS) \\
\hline TASA POR LICENCIA URBANISTICA \\
\hline Licencia de obra mayor (1.12\%PEM) \\
\hline DIRECCIÓN DE OBRA DE ARQUITECTO Y APAREJADOR \\
\hline Dirección de obra arquitecto (4\% PEM) \\
\hline IVA (21\%) \\
\hline total dirección obra arquitecto & 600 \\
\hline \multicolumn{2}{|l|}{168} \\
\hline Dirección obra aparejador (2.85\% PEM) & 726 \\
\hline IVA (21\%) & 427.5 \\
\hline total dirección obra aparejador & 89.775 \\
\hline
\end{tabular}

\begin{tabular}{|r|r|}
\hline total dirección obra aparejador & 517.275 \\
\hline
\end{tabular}

TASA POR LICENCIAS URBANISTICAS DE PRIMERA OCUPACIÓN

\begin{tabular}{|l|r|}
\hline Licencia primera ocupación (1.12\% PEM) & 168 \\
\hline
\end{tabular}

MINUTA DEL NOTARIO
\begin{tabular}{|l|r|}
\hline COSte & 483.31 \\
\hline GESTORIA & 200 \\
\hline Factura & 225 \\
\hline IMPUESTO SOBRE ACTOS JURIDICOS DOCUMENTADOS \\
\hline COSte (1,5\% PEM) \\
\hline ARANCELES REGRISTO DE LA PROPIEDAD \\
\hline Coste & 154.83 segủn tablas \\
\hline
\end{tabular}

COSTE TOTAL PARA REALIZAR LA AMPLIACIÓN LEC 27357.125

${ }^{*}$ No se tiene en cuenta el seguro decenal por considerar que no enajenaremos la vivienda

\begin{tabular}{|lrr|}
\hline COSTE MATERIAL & 15000 & $60.10 \%$ \\
COSTE DE LEGALIZACIÓN (TRAMITES Y TÉCNICOS) & 9958.625 & $39.90 \%$ \\
\hline
\end{tabular}

Tabla 09. Cálculo de costos de legalización para ampliar $25 \mathrm{~m}^{2}$. 
En este caso se puede observar que el costo material de la ampliación sería aproximadamente de I5.000 euros tomando como precio base del metro cuadrado construido $600 € / \mathrm{m}^{2}$. Mientras que el costo de la legalización sería de $9.958,62 €$. Esto implica que el costo total para ampliar y legalizar $25 \mathrm{~m}^{2}$ de una vivienda sería de 24.958,62 €, a lo que se podría en último caso descontar el costo de la mano de obra, puesto que como ya hemos señalado antes se considera la posibilidad de que la familia pueda autoconstruir su casa. Con estos datos se obtiene que el $60.10 \%$ de este costo total sería de material para la construcción y el resto (39.90 \%) equivaldría a los gastos anteriormente indicados para la legalización de esta ampliación. Esta proporción casi de 40 - 60 hace que la mayoría de las veces la gente que realiza ampliaciones en su hogar en España no lo haga de forma legal, es decir, no lo notifique al Ayuntamiento correspondiente ya que de esta manera únicamente realizarían el $60 \%$ del gasto. Esta costumbre que a corto plazo es muy beneficiosa para los habitantes, ya que no sólo se ahorran el costo de legalización si no el incremento en los subsecuentes recibos para el pago del Impuesto de bienes inmuebles, a la larga trae numerosos problemas. Por ejemplo, en el momento en el que se quisiera vender, traspasar o subdividir la vivienda de forma legal ya que habría que realizar las legalizaciones pertinentes que no se hicieron en su momento.

\section{Patrón de costo de legalización}
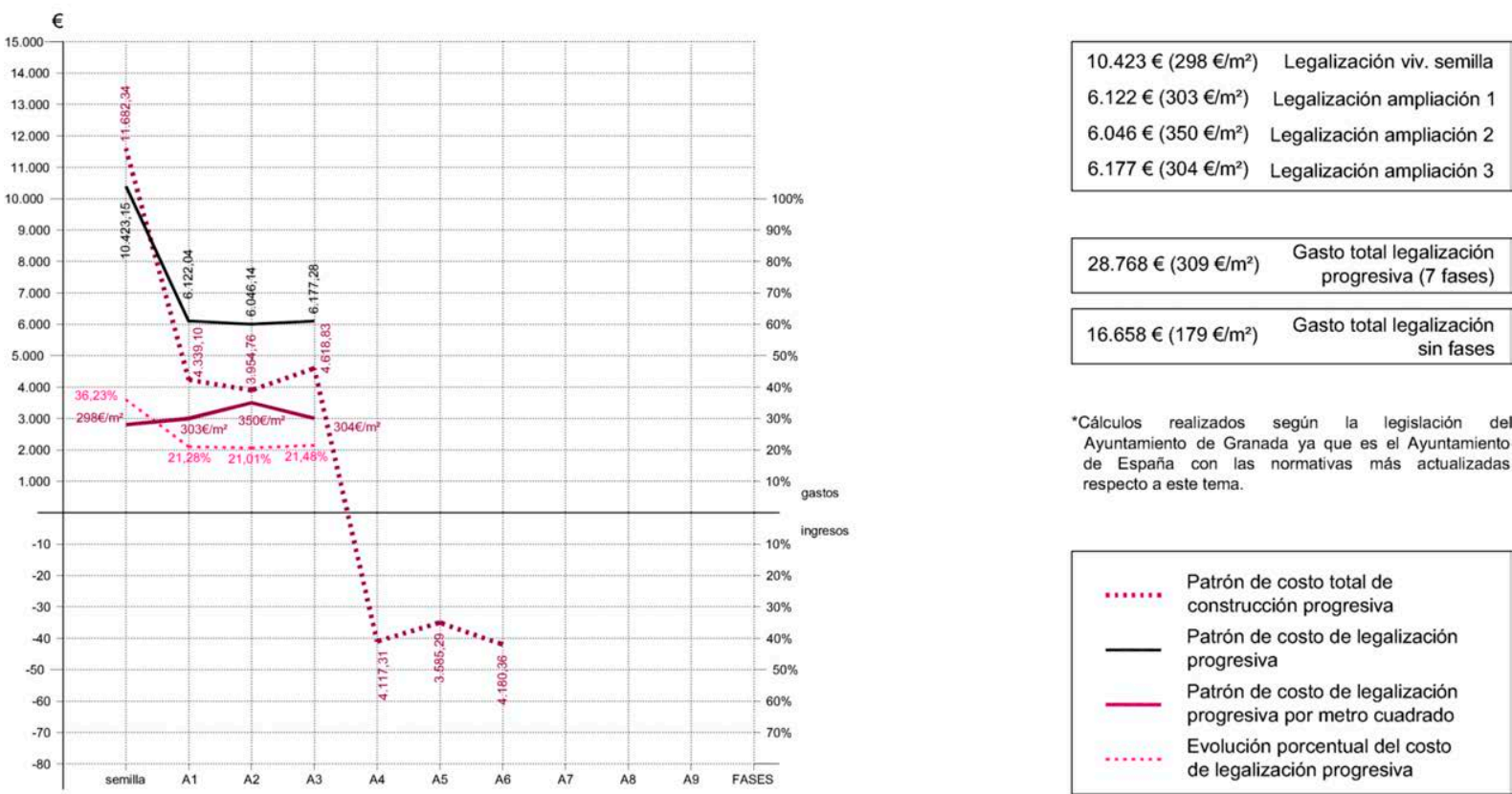

Gráfica 08. Ejemplo de patrón de costo de legalización.

Para trazar el patrón de costo de legalización, se ubicarán sobre la línea de tiempo otras tres líneas. La del costo de legalización de la vivienda en cada fase. La que representa el costo total de la construcción progresiva, para que de esta manera se pueda comparar la relación entre costo material total y costo de legalización. Y finalmente, la línea de evolución porcentual del costo de legalización que servirá para hacer más fácilmente comparable el proceso entre distintos casos.

Para extraer los datos que permiten dibujar el patrón se ha partido de los metros cuadrados iniciales de la vivienda, los metros cuadrados ampliados y el costo material de cada una de las fases. 
3.Patrones evolutivos y parámetros 


\section{3.j. Otros parámetros analizados.}

Además de los patrones de crecimiento se han propuesto una serie de indicadores complementarios que representan otras características generales del proceso de crecimiento y que se localizan en las fichas de descripción de cada uno de los casos de estudio. Además de indicar los mecanismos de ampliación utilizados en cada vivienda analizada, estos especifican las siguientes características:

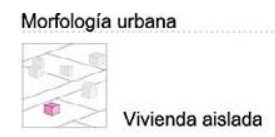

Modalidades de uso

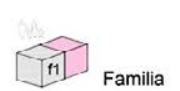

Categoría constructiva

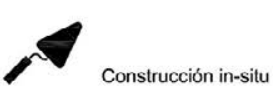

Construcción in-situ

Autoconstrucción

Flexibilidad
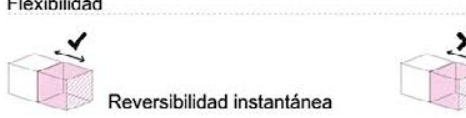

Realización

$\oplus$

Proyecto

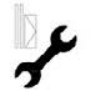

Elementos prefabricados

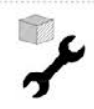

Célula prefabricada

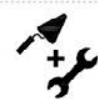

Sistema mixto (in-situ + prefab.)

Sistema mixto

Semilla construida por terceros

Construcción por terceros

Ampliación autoconstercero

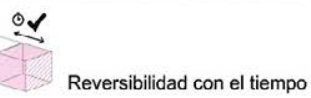

Reversibilidad con el tiempo

Tipo de desarrollo

Pequeño desarrollo de gestión privada

\section{Gran desarrollo de} gestión privada
Desarrollo de gestión pública

Tabla 10. Otros parámetros analizados.

- Morfología urbana: De acuerdo a si la vivienda es aislada, si se encuentra dentro de una agrupación de viviendas unifamiliares (en este caso se considera como vivienda unifamiliar aquella que al principio estuvo considerada como tal, o que aún siendo una familia extendida o un grupo no familiar compuesto por una familia y sus 
inquilinos, conservase inicialmente la estructura de vivienda unifamiliar y no de vivienda colectiva). $O$ si es un bloque conformado por varias viviendas.

- Modalidades de uso: De acuerdo al uso previsto para la futura ampliación. Ya sea nuevo espacio para la propia familia, que la familia sea extendida por la llegada de un nuevo miembro, que la vivienda se convierta en un artefacto de renta al alquilar parte de esta a inquilinos que aporten nuevos ingresos (la llamada casa habitación según (Vergara Dávila \& Palmer Trias, 1988, p. 77)), o que la vivienda sea una hipercasa (García-Huidobro, Torres Torriti, \& Tugas, 2008) porque tenga un negocio o un taller en ella y que al igual que en el artefacto de renta produzca ingresos para la familia.

-Categoría constructiva: La vivienda puede responder dentro de este parámetro a dos categorías más.

Por un lado en función de cual sea el agente que realice la construcción la vivienda podrá ser autoconstruida por los propios habitantes; o por los habitantes guiados por un técnico especializado que les aconseje; o podrá estar construida por terceras personas; o también se podrán dar sistemas mixtos en los que una parte de la vivienda se dé mediante un sistema y la otra por otro.

Por otro lado está la categoría vinculada a la construcción material que indica si la vivienda está realizada por construcción in-situ, por elementos prefabricados, por células prefabricadas, o si es un sistema mixto que combine construcción prefabricada y construcción in-situ. Este índice se refiere al material dominante en el total de la construcción (Vergara Dávila \& Palmer Trias, 1988, p. 78).

-Flexibilidad: Con este parámetro se indica si la ampliación es irreversible (es decir es definitiva) o si puede desmantelarse fácilmente. Si estamos en casos como los de la expansión donde las modificaciones se pueden realizar en cuestión de horas, nos encontraremos en el caso de reversibilidad instantánea. En otros casos donde el proceso dure más porque estén pensadas como intervenciones definitivas a medio plazo se considerará reversibilidad en el tiempo ya que se pueden deshacer empleando algo más de tiempo que en el caso anterior.

-Realización: Indicará si el proyecto ha sido construido o no.

-Tipo de desarrollo: En función de si es un pequeño desarrollo de gestión privada (como puede ser una vivienda unifamiliar); un gran desarrollo de gestión privada; o un desarrollo de gestión pública. 
4. casos de estudio.

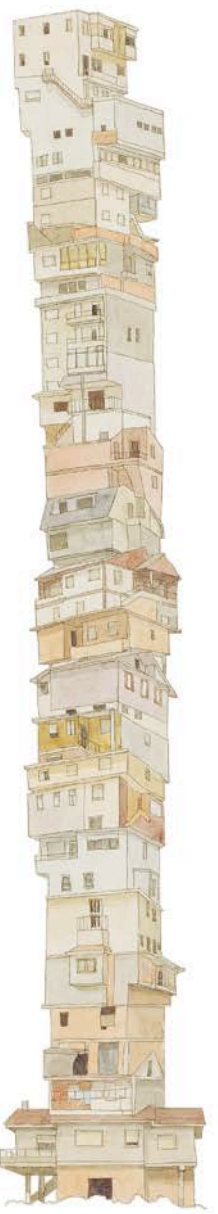





\section{4.a. Recopilación de casos y resultados estadísticos globales.}

\section{Recopilación de casos.}

Para este estudio se han seleccionado únicamente casas crecederas concebidas como tales desde el inicio del proyecto. A la hora de elegir cada caso se tuvo en cuenta que cada vivienda cumpliera las siguientes características:

- El proyecto ha de contar al menos con un tipo de mecanismo de ampliación significativo y se han de dar diversas ampliaciones en el tiempo hasta alcanzar su desarrollo máximo óptimo.

-La vivienda ha de incluirse en un conjunto urbano reconocible sobre el cual se puede evaluar la variación de la densidad de habitantes en el tiempo. Es independiente de la elección si el conjunto urbano es propuesto a exnovo por el arquitecto o si existe con anterioridad.

- El proyecto ha de ser ideado desde el principio hasta el final por un técnico y han de existir planos de esta evolución de la vivienda. Se trata por tanto en todos los casos de un crecimiento programado.

- El proyecto puede haber sido construido o no. Al no tener unos condicionantes tan estrictos como los casos reales (cliente, presupuesto, lugar, normativas, etc.), se considera que las propuestas teóricas complementan las mesuradas propuestas reales, ya que tienen un carácter propositivo mucho mayor al poder investigar conceptos, materiales y disposiciones más innovadoras y arriesgadas. Sin embargo, y aunque para la recopilación general de casos no es requisito que sea un ejemplo construido, para el análisis pormenorizado de los casos seleccionados si se requerirá el que la vivienda se haya construido para comprobar la viabilidad real de la propuesta.

- Los casos serán exclusivamente de arquitectura residencial (unifamiliar o colectiva). Se considerará siempre la vivienda como unidad mínima de estudio de las estrategias de ampliación, obviando las ampliaciones fuera de esta unidad (como podrían ser las ampliaciones de zonas comunes dentro de un bloque).

- Se dejará fuera de la selección de casos aquellos que, aun habiendo sido pensados para sufrir ampliaciones, pertenezcan a la vivienda de lujo o a la vivienda ilegal por pertenecer a situaciones extremas dentro del fenómeno.

- Todos los casos seleccionados han de haber sido publicados en algún libro o revista especializado sobre el tema de al menos tirada nacional. Ya que se ha considerando su divulgación como el filtro para la calidad arquitectónica. 
- Debido a que este control previo desde el inicio del proyecto es un requisito para el objeto de estudio, se dejarán al margen de esta investigación aquellas edificaciones que sufran la acción y efecto de extenderse mediante prótesis arquitectónicas', ya que se trata de dispositivos ajenos a la vivienda inicial, insertados a posteriori y que no forman un todo con la vivienda semilla.

El estudio se centra en la arquitectura residencial de los siglos $X X$ y $X X I$ y delimita dos marcos temporales de estudio. Uno, acotado entre la actualidad y el año 1914, momento en el que Le Corbusier diseña la Maison Domino. Proyecto que marcó un antes y un después en la concepción de la vivienda moderna ya que abrió el camino a la flexibilidad y a distintos tipos ampliación gracias a la separación entre cerramiento y estructura y a la industrialización de esta última. Y otro segundo marco, entre la actualidad y los años 50 y 60 , momento en el que comienza la crítica a la construcción en masa, la seriación y la deshumanización, fruto de la reconstrucción tras la Segunda Guerra Mundial, que propició el desarrollo de una serie de proyectos idealistas y utópicos, dentro de los cuales se ubicaban de una forma más tangible los proyectos de ampliación.

Dentro del marco temporal más amplio (19/4-2014) se han recopilado 214 proyectos residenciales en los que se producen uno o varios procesos de ampliación simultáneos. En cada una de estas 214 viviendas se ha evaluado el lugar geográfico, el momento de realización y las diferentes estrategias que se han llevado a cabo para ampliar cada propuesta. Para facilitar la lectura de dicha de información se ha ordenado cronológicamente en una tabla según mecanismos conceptuales de ampliación que resume los 214 casos localizados. (Tabla I2). Esta masa crítica se ha considerado suficiente para poder extraer el mayor número de sistemas de ampliación diferentes y observar de forma detallada y contrastada el funcionamiento de cada uno de ellos pudiendo elaborar unas estadísticas del fenómeno de la vivienda crecedera a nivel global que se encuentran en el siguiente apartado, Resultados estadísticos globales.

De esta masa crítica se ha realizado una selección de ocho casos en los que se analiza la relación del fenómeno del crecimiento de la vivienda con la ciudad. En esta selección se ha diferenciado a su vez entre arquitectura residencia colectiva y arquitectura residencial multifamiliar, tal y como se explica en el apartado de Casos de estudio general. Los casos que conforman esta selección son:

En arquitectura residencial colectiva:

- Square L-type System de J. Van den Broek y J. Bakema.

- Viviendas Quinta Monroy de ELEMENTAL.

- Überbauung Brahmshof de Kuhn \& Fischer und Partner.

-Multifamiliar que crece de Pedro Ramírez Vázquez.

\footnotetext{
' Manuel Gausa en el Diccionario metápolis de arquitectura avanzada, define las prótesis arquitectónicas como "un suplemento receptivo y activo, a la vez extraño y a la vez sensible a lo particular, capaz de regirse por sí mismo y, al mismo tiempo, de reestructurar, reimpulsar y potenciar al anfitrión a fin de trascenderlo más allá de sus propios límites". (VV.AA., 2000). A pesar de que esta definición contemple la posibilidad de que la ampliación transforme al anfitrión, no se considerará este tipo de proyecto en el estudio.
} 
Y en arquitectura residencial multifamiliar:

- Población Rene Schneider de Percy Díaz.

- Expansiva Housing System de Jorn Utzon.

- Il Rigo Quarter de Renzo Piano.

-Vivienda para el conjunto PREVI de Toivo Korhonen.

Posteriormente se ha realizado una sub-selección en la que se estudia cada ejemplo de forma pormenorizada. Esta segunda discriminación parte de los criterios de legibilidad y calidad, ya que los proyectos adoptados son los que muestran de forma más explícita un tipo de ampliación concreto y tienen una reconocida calidad arquitectónica. Los casos que componen esta sub-selección son:

- Überbauung Brahmshof de Kuhn \& Fischer und Partner.

- Viviendas Quinta Monroy de ELEMENTAL.

- Il Rigo Quarter de Renzo Piano.

- Población Rene Schneider de Percy Díaz.

Para elegir estos ejemplos se ha tratado de que estuvieran reflejados todos los tipos de crecimientos mencionados en el apartado 2.a. Mecanismos de ampliación. También se ha valorado que la muestra fuera lo más heterogénea posible eligiendo dos casos latinoamericanos y dos europeos, dos construidos por terceros y otros dos autoconstruidos, y que hubiera ejemplos prefabricados, construidos in-situ, unifamiliares y plurifamiliares, tal y como se refleja en la siguiente tabla (Tabla II).

\begin{tabular}{|l|c|c|c|c|}
\hline \multicolumn{1}{|c|}{ Proyecto } & $\begin{array}{c}\text { Überbauung } \\
\text { Brahmshof }\end{array}$ & $\begin{array}{c}\text { Viviendas Quinta } \\
\text { Monroy }\end{array}$ & II Rigo Quarter & $\begin{array}{c}\text { Población Rene } \\
\text { Schneider }\end{array}$ \\
\hline Procedencia & Europa (Austria) & Latinoamérica (Chile) & Europa (Italia) & Latinoamérica (Chile) \\
\hline $\begin{array}{l}\text { Gestión de la } \\
\text { construcción }\end{array}$ & Por terceros & $\begin{array}{c}\text { Por terceros + } \\
\text { autoconstrucción }\end{array}$ & Por terceros & Por terceros + \\
\hline Tipo residencial & Multifamiliar & Multifamiliar & Unifamiliar adosada & Unifamiliar adosada \\
\hline Tipo de \\
construcción
\end{tabular}

Tabla II. Características de los casos sub-seleccionados

Debido a las limitaciones temporales de este estudio se consideró imposible la realización de un sondeo a mayor escala que tuviera una representatividad estadística. Es por ello que se ha decidido estudiar casos 
característicos de cada uno de los mecanismos de ampliación reconocidos. De esta manera, aunque el estudio no tiene valor estadístico en términos cuantitativos, si lo tiene en términos cualitativos por la representatividad de cada uno de estos procesos de ampliación.

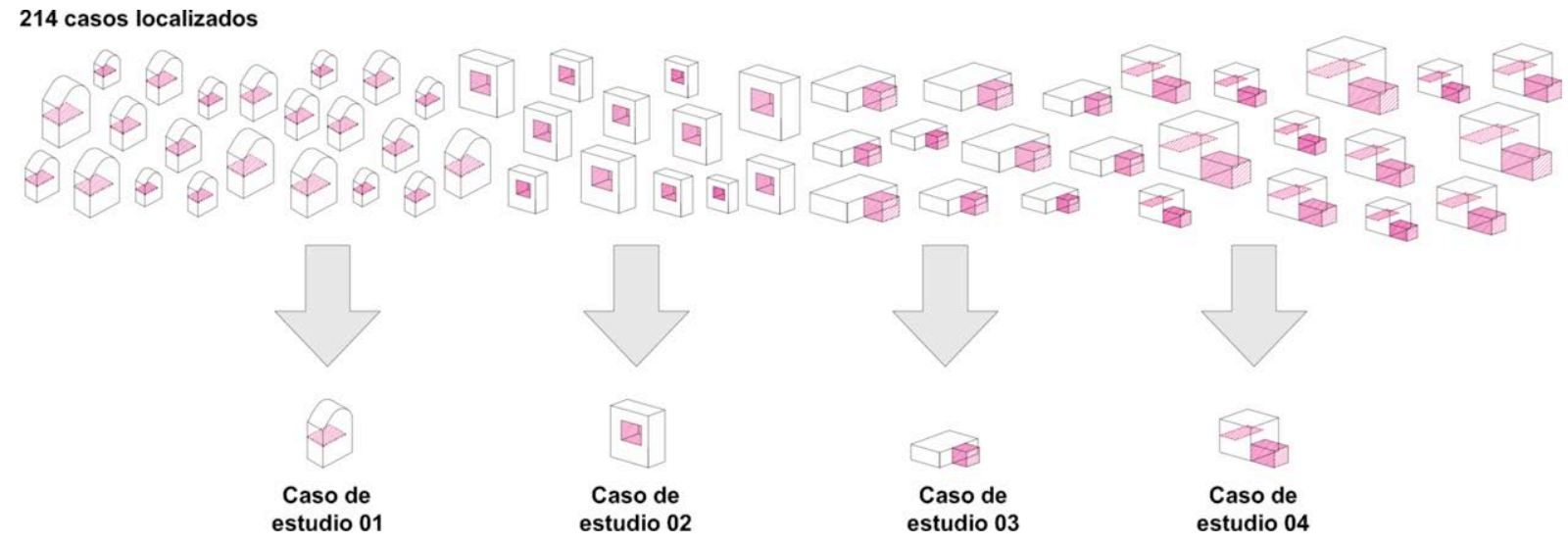

Figura 29. Selección de casos.

Para resumir y aclarar el proceso de recopilación de casos (Figura 29) se repasará de nuevo brevemente el método empleado. En primer lugar, se han seleccionado 214 casos ejemplares entre 1914 y 2014 para identificar los mecanismos conceptuales de ampliación (Tabla 12). De este grupo se han elegido cuatro casos ejemplares construidos que se han tomado como paradigmas de las estrategias de crecimiento. Para a continuación analizarlos de acuerdo a los parámetros descritos en el capítulo 3. Patrones evolutivos y parámetros. 


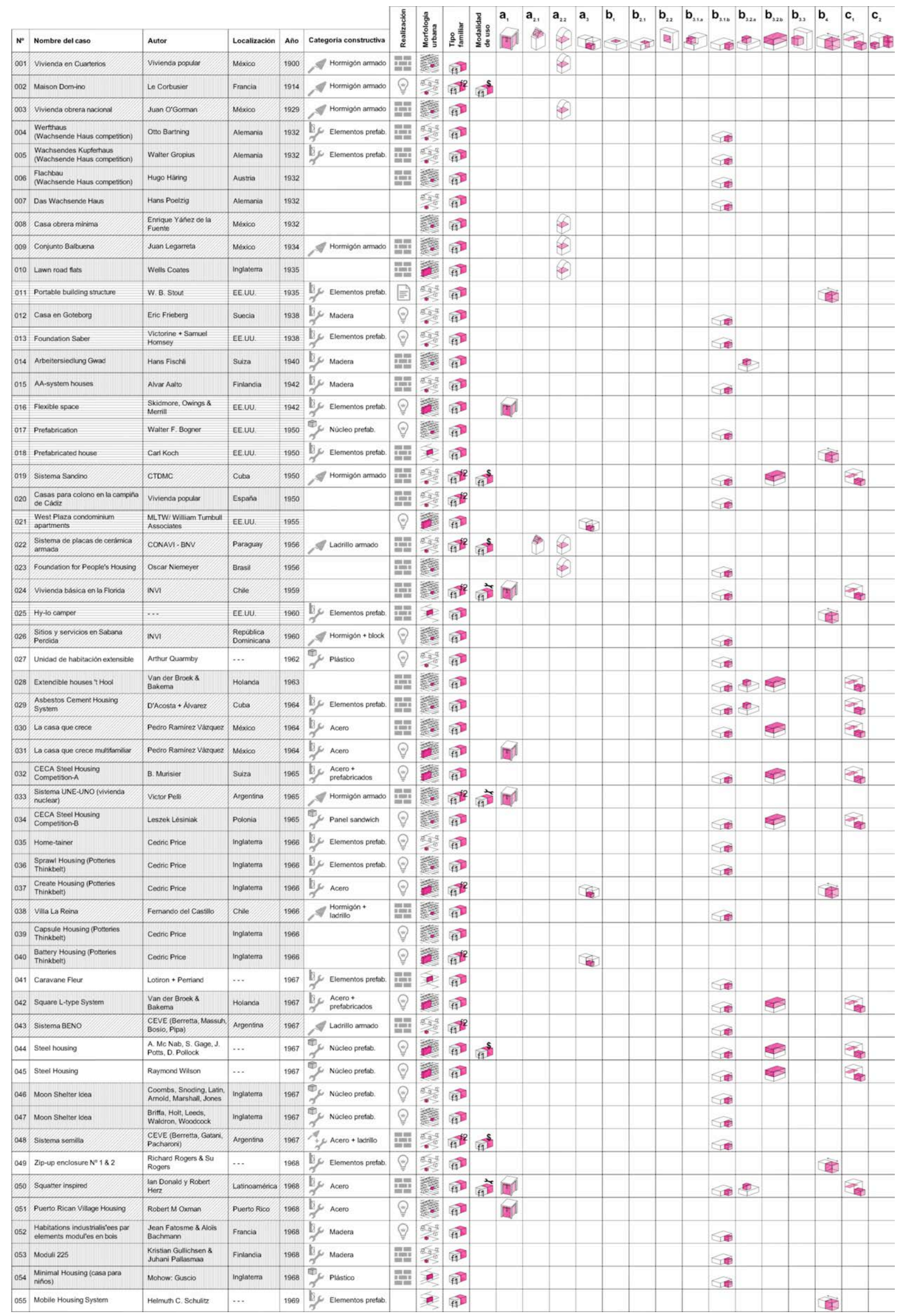

Tabla 12. Selección de 214 casos de viviendas crecederas. (Continúa). 


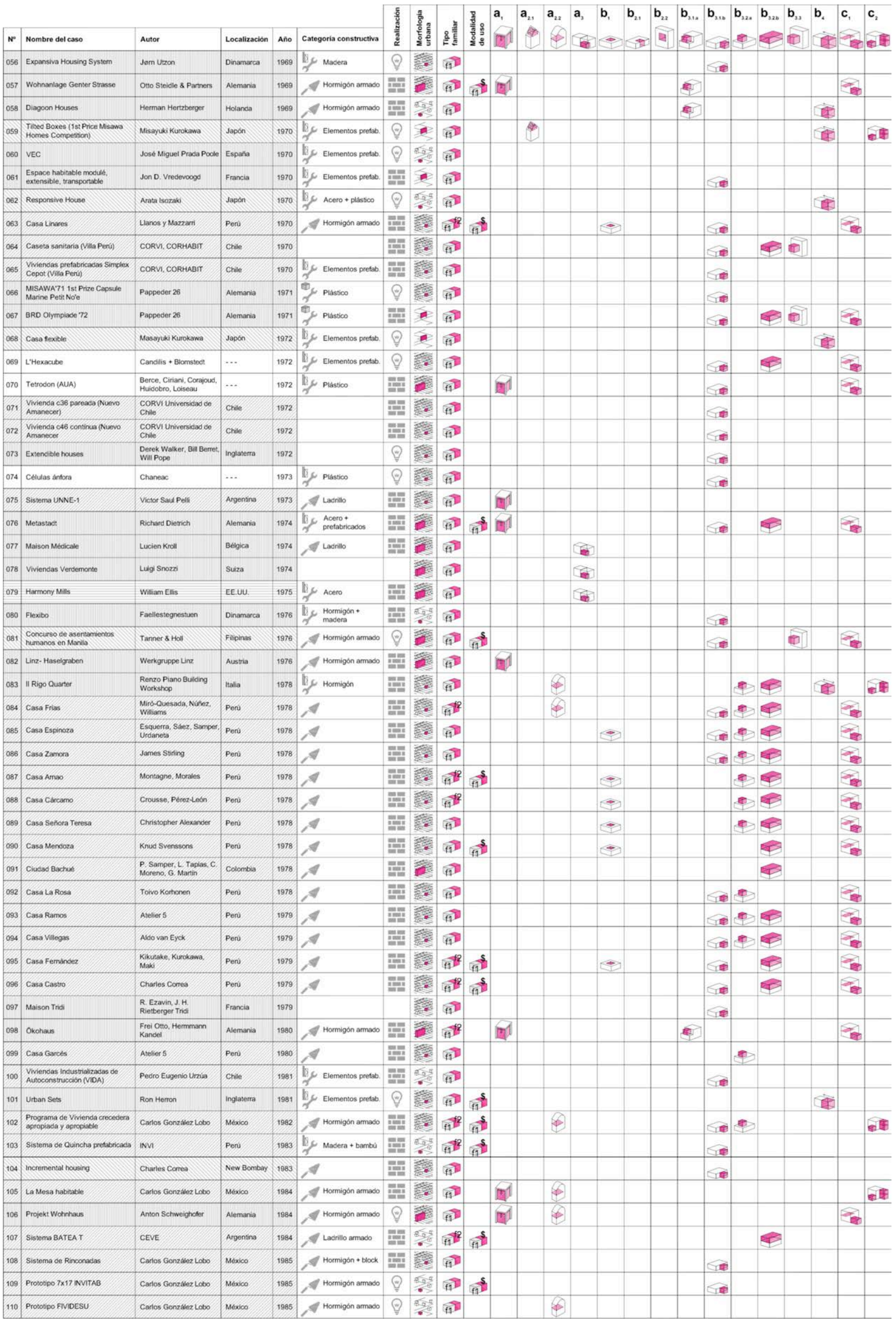

Tabla 12. Selección de $2 / 4$ casos de viviendas crecederas. (Continúa). 


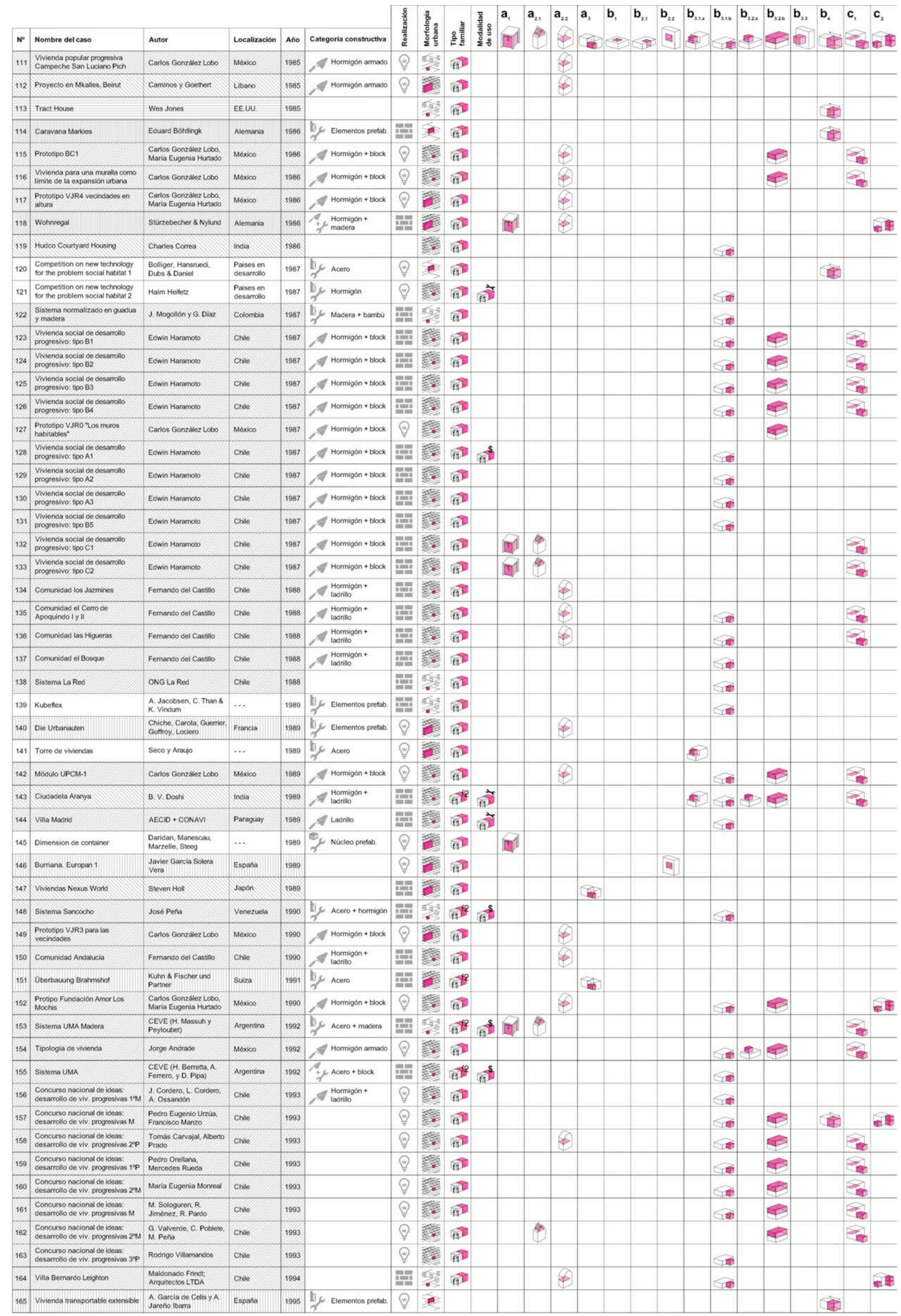

Tabla 12. Selección de 2/4 casos de viviendas crecederas. (Continúa). 


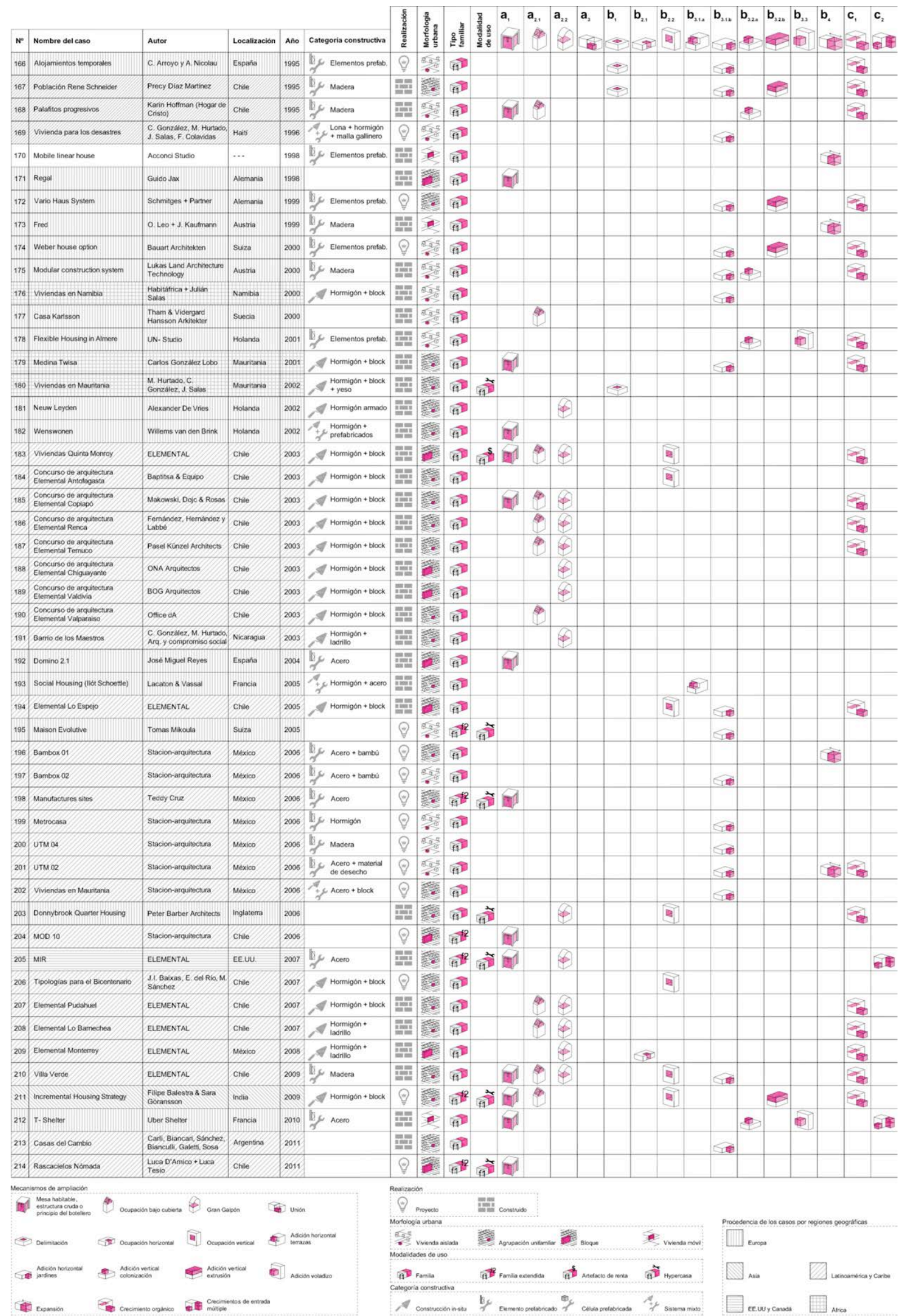

Tabla 12. Selección de 2/4 casos de viviendas crecederas. 


\section{Resultados estadísticos globales.}

Para tratar de entender mejor el fenómeno, se ha realizado una serie de comparaciones entre los datos globales obtenidos en el marco de estudio más amplio obteniendo los siguientes resultados:

\section{$4,8 \%$}

EE.UU. y Canadá 10 casos

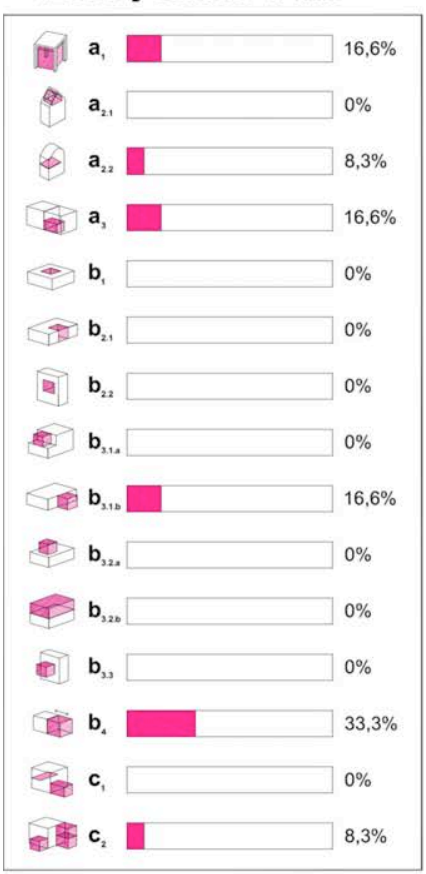

$56 \%$

Latinoamérica 117 casos

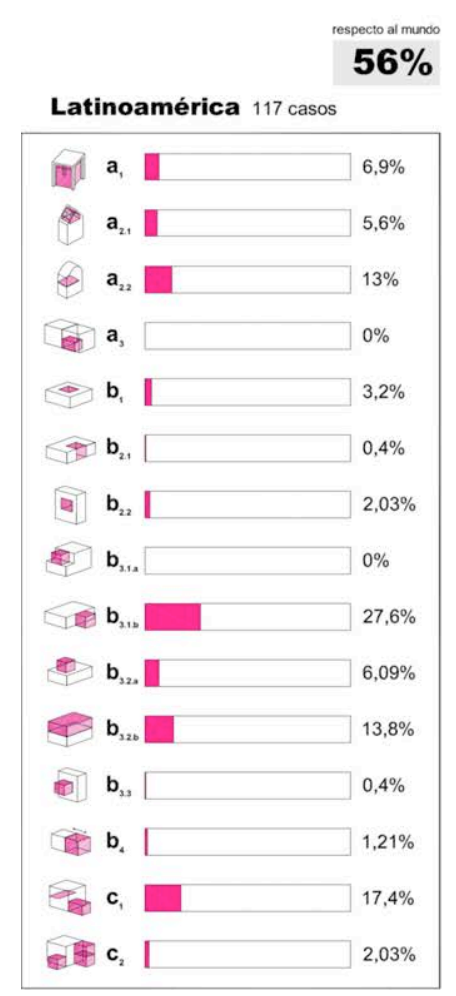

$\mathbf{3 1 \%}$

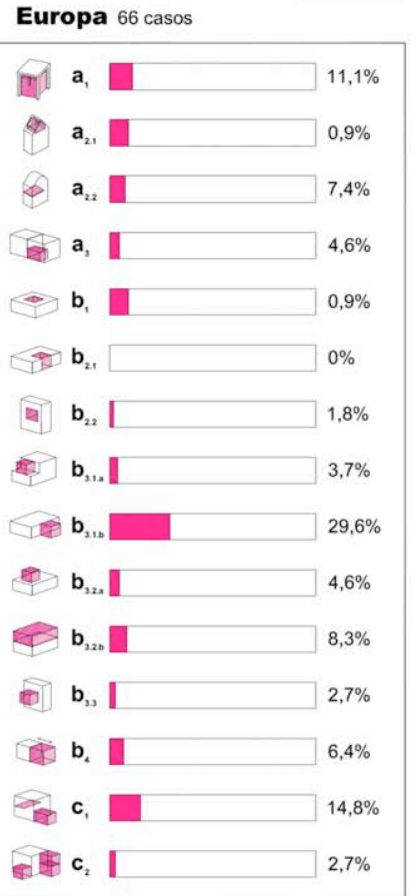

$5,2 \%$

\begin{tabular}{|c|c|}
\hline 01 a, & $4,3 \%$ \\
\hline (2) $\mathrm{a}_{21}$ & $8,6 \%$ \\
\hline (4) $a_{22}$ & $4,3 \%$ \\
\hline (a) $a_{\text {, }}$ & $4,3 \%$ \\
\hline$\Leftrightarrow b_{1}$ & $0 \%$ \\
\hline$\approx \mathbf{b}_{21}$ & $0 \%$ \\
\hline (a) $\mathbf{b}_{22}$ & $4,3 \%$ \\
\hline (201) $b_{2,1}$ & $4,3 \%$ \\
\hline$\rightarrow \mathbf{b}_{21 b}$ & $21,7 \%$ \\
\hline (1) $b_{32}$ & $4,3 \%$ \\
\hline$\Leftrightarrow b_{22 b}$ & $8,6 \%$ \\
\hline (10) $b_{2}$. & $4,3 \%$ \\
\hline (18) $b_{4}$ & $13,04 \%$ \\
\hline \&c & $13,04 \%$ \\
\hline 서용 $c_{2}$ & $4,3 \%$ \\
\hline
\end{tabular}

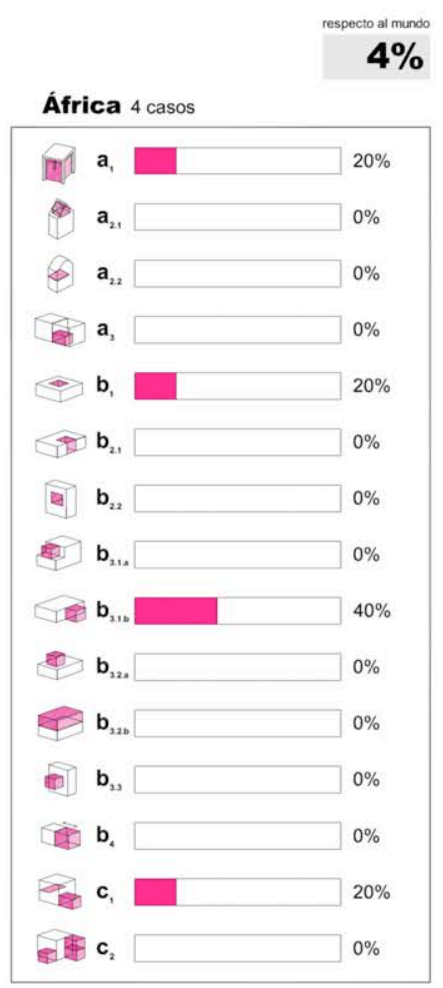

En el Mundo 208 casos

\begin{tabular}{|c|c|}
\hline$m$ a & $8,3 \%$ \\
\hline$\otimes a_{2}$ & $4,9 \%$ \\
\hline (b) $\mathrm{a}_{22}$ & $10,6 \%$ \\
\hline (a) $a_{3}$ & $2,03 \%$ \\
\hline$\Leftrightarrow b_{1}$ & $2,5 \%$ \\
\hline \&17 $\mathbf{b}_{21}$ & $0,25 \%$ \\
\hline [4] $\mathbf{b}_{22}$ I & $2,03 \%$ \\
\hline (11) $b_{2.1}$. & $1,26 \%$ \\
\hline$\leqslant \mathbf{b}_{2+1}$ & $27,6 \%$ \\
\hline$b_{32 .}$ & $5,32 \%$ \\
\hline$\notin b_{32 b}$ & $11,4 \%$ \\
\hline (d]) $\mathbf{b}_{3,}$ & $1,26 \%$ \\
\hline \& $b_{4}$ & $4,3 \%$ \\
\hline$\Leftrightarrow c_{1}$ & $15,9 \%$ \\
\hline 새 $18 \mathrm{c}_{2}$ & $2,5 \%$ \\
\hline
\end{tabular}

Tabla 13. Mecanismos de ampliación más utilizados por región geográfica. 
Del análisis de los 214 casos seleccionados, se ha obtenido que el 65,2\% de estos se dan países en vías de desarrollo de las regiones de Latinoamérica, Asia y África (56\%, 5,2\% y 4\% respectivamente) mientras que en Estados Unidos y Europa se encuentran el $35,8 \%$ de los casos (4,8\% y $31 \%$ cada uno). (Tabla I3).

Un $27,6 \%$ de los casos ejemplares seleccionados utilizan la adición horizontal en jardines como mecanismo de ampliación, siendo el más utilizado. El segundo mecanismo más usado es el de el crecimiento orgánico, con un 15,90\% de los casos. Mientras que los sistemas de ampliación por voladizo y por ocupación horizontal son los menos usados puesto que no se utilizan de forma aislada si no que siempre se utiliza dentro de un crecimiento combinado como es el crecimiento orgánico o el crecimiento de entrada múltiple. (Tabla I3).

En el caso de EE.UU. y Canadá la gran mayoría de los ejemplos identificados (33,3\%) amplían su superficie mediante el mecanismo de expansión, un sistema caracterizado por su instantánea reversibilidad. El segundo sistema de crecimiento mayoritario es la unión (16,6\%) que de igual manera es fácilmente reversible y se realiza en el interior de los edificios, siendo inapreciable esta transformación desde el exterior, por lo que en ambos casos la imagen urbana a penas se ve alterada en el tiempo (Tabla 13). Principalmente se utilizan estos sistemas por dos razones. Uno, porque la presión espacial interior se vincula más a un crecimiento puntual del programa (una breve visita, un evento, un cambio de estación del año, etc.) y no tanto a una demanda continua de mayor superficie como ocurre en otras regiones del mundo. $Y$ dos, también se utilizan porque el gran aparato burocrático y legislativo que estos países poseen hace muy complejo y costoso en tiempo y dinero el realizar dichas ampliaciones de forma permanente.

Sin embargo, por otro lado, en regiones como la latinoamericana o la africana la situación cambia. Debido a que la presión demográfica es muy alta y que los metros cuadrados por persona en una vivienda son ínfimos, es necesario que el espacio se amplíe de forma permanente, al menos en un período de tiempo lo suficientemente largo como para que el número de miembros del núcleo familiar se reduzca. De esta manera aparecen otros mecanismos de ampliación. En el caso de Latinoamérica y Caribe la mayoría de los casos analizados (27,6\%) crecen mediante mecanismos de adición horizontal y el segundo sistema más utilizado es el crecimiento orgánico (17,4\% de los casos), mientras que en el caso de África la cifra de casos realizados por adición horizontal asciende hasta el $40 \%$ (Tabla 13). Estos sistemas de crecimiento con aumento de volumen, son la mayoría de las veces, mucho más sencillos de construir y mucho más baratos que los sistemas reversibles anteriormente citados, por lo que se pueden repetir mucho más fácilmente por cualquiera. De esta manera y debido a la gran demanda de espacio habitacional que existe en las regiones del sur, cuando surge la necesidad de ampliación y se tienen los medios, se amplía el espacio de alguna de estas dos maneras mencionadas, que son claramente perceptibles desde el exterior. 
EE.UU. y Canadá

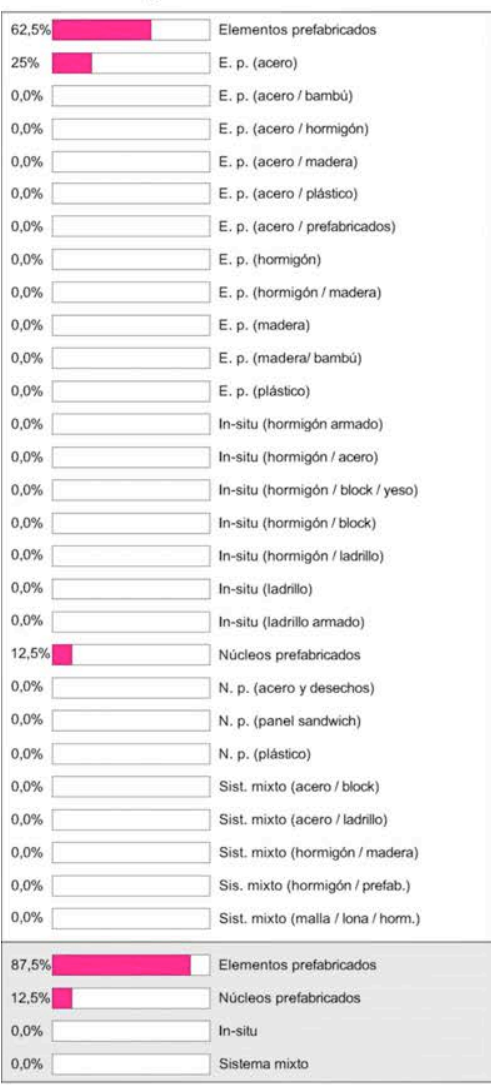

\section{Latinoamérica}

\begin{tabular}{|c|c|}
\hline $2,4 \%$ [ & Elementos prefabricados \\
\hline $2,4 \%$ ए & E. p. (acero) \\
\hline $1,2 \%$ & E. p. (acero / bambü) \\
\hline $1,2 \%$ & E. p. (acero / hormigón) \\
\hline $0,0 \% \square$ & E. p. (acero / madera) \\
\hline $1.2 \%$ & E. p. (acero / plástico) \\
\hline $6,0 \%$ & E. p. (acero / prefabricados) \\
\hline $0,0 \%$ & E. p. (hormigón) \\
\hline $1,2 \%$ & E. p. (hormigón / madera) \\
\hline $2,4 \%$ ए & E. p. (madera) \\
\hline $4.8 \%$ & E. p. (madera/ bambü) \\
\hline $0.0 \%$ & E. p. (plástio) \\
\hline $0,0 \%$ & In-situ (hormigón armado) \\
\hline $0.0 \%$ & | In-situ (hormigón / acero) \\
\hline $36,5 \% \square$ & | In-situ (hormigón / block / yeso) \\
\hline $12,1 \% \square$ & In-situ (hormigon / block) \\
\hline 14,6\%巨 & | In-situ (hormigón / ladanllo) \\
\hline $3,6 \%$ I & In-situ (ladrilio) \\
\hline $2,4 \%$ ए & In-situ (Iadrillo ammado) \\
\hline $2,4 \%$ ए & Núcleos prefabricados \\
\hline $1,2 \% \square$ & N. p. (acero y desechos) \\
\hline $0,0 \% \square$ & N.p. (panel sandwich) \\
\hline $0,0 \%$ & N.p. (plástico) \\
\hline $1,2 \%$ & Sist, mixto (acero / block) \\
\hline $1,2 \%$ & | Sist. mixto (acero / ladrillo) \\
\hline $0,0 \%$ & Sist. mixto (hormigón / madera) \\
\hline $0,0 \%$ [ & Sis. mixto (hormigón / prefab.) \\
\hline $1,2 \% \square$ & Sist. mixto (malla / lona / horm.) \\
\hline 23,1\% & Elementos prefabricados \\
\hline $3,6 \%$ 工 & Núcleos prefabricados \\
\hline $69.5 \%$ & In-situ \\
\hline $3,6 \%$ I & Sistema mixto \\
\hline
\end{tabular}

\section{Europa}

\begin{tabular}{|c|c|}
\hline $32 \%$ & Elementos prefabricados \\
\hline $0,0 \%$ & E.p. (acero) \\
\hline $0.0 \%$ & E. p. (acero/bambü) \\
\hline $0,0 \%$ & E. p. (acero / hormigón) \\
\hline $0.0 \%$ & E. p. (acero / madera) \\
\hline $4.0 \%$ & E. p. (acero / plástico) \\
\hline $8,0 \%$ & E. p. (acero / prefabricados) \\
\hline $2,0 \% \square$ & E. p. (hormigon) \\
\hline $4,0 \%$ I & E. p. (hormigón / madera) \\
\hline $0,0 \%$ & E. p. (madera) \\
\hline $16 \% \square$ & E. p. (madera/ bambü) \\
\hline $2,0 \%$ ए & E. p. (plástioo) \\
\hline $2,0 \% \square$ & In-situ (hormigón armado) \\
\hline $0,0 \%$ & In-situ (hormigon / acero) \\
\hline $0.0 \%$ & | In-situ (hormigón / block / yeso) \\
\hline $0,0 \%$ [ & In-situ (hormigón / block) \\
\hline $16 \% \square$ & | In-situ (hormigón / ladrillo) \\
\hline $0,0 \%$ & In-situ (ladrilio) \\
\hline $2,0 \%$ ए & | In-situ (ladrillo amado) \\
\hline $2.0 \% \square$ & Núcleos prefabricados \\
\hline $0,0 \%$ & N. p. (acero y desechos) \\
\hline $2,0 \%[$ & N. p. (panel sandwich) \\
\hline $4.0 \%$ I & N. p. (plástico) \\
\hline $0.0 \%$ & | Sist. mixto (acero / block) \\
\hline $0.0 \%$ & | Sist. mixto (acero / ladrillo) \\
\hline $2,0 \%[$ & Sist. mixto (hormigon / madera) \\
\hline $2,0 \%[$ & Sis. mixto (hormigon / prefab.) \\
\hline $0.0 \%$ & Sist. mixto (malla / lona / horm.) \\
\hline $68 \%$ & Elementos prefabricados \\
\hline $8 \%$ & Núcleos prefabricados \\
\hline $20 \% \square$ & In-situ \\
\hline $4 \%$ I & Sistema mixto \\
\hline
\end{tabular}

\section{África}

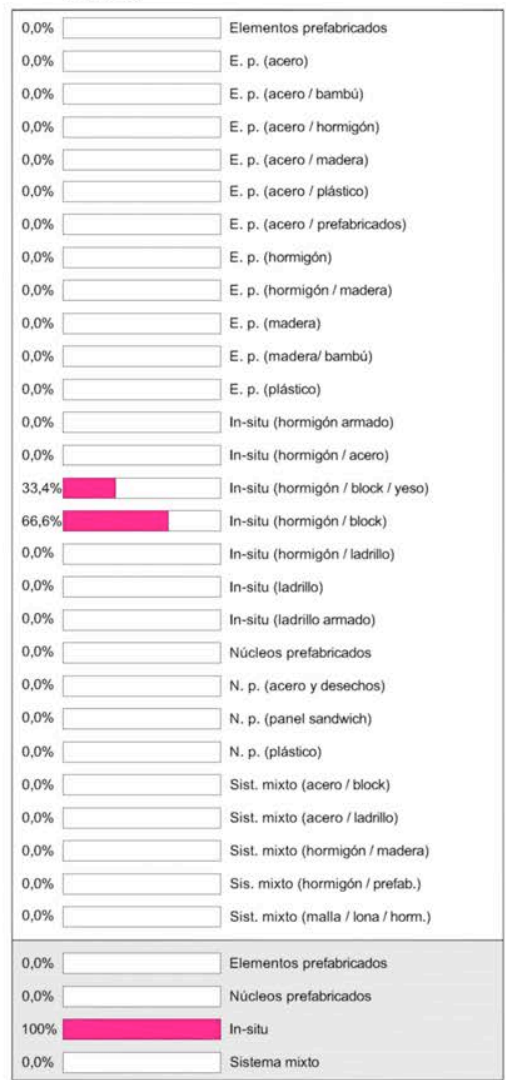

Asia

\begin{tabular}{|c|c|}
\hline $25 \%$ & Elementos prefabricados \\
\hline $0,0 \%$ & E. p. (acero) \\
\hline $0.0 \%$ & E. p. (acero/ bambü) \\
\hline $0,0 \%$ & E. p. (acero / hormigón) \\
\hline $0,0 \%$ & E. p. (acero / madera) \\
\hline $12,5 \%$ & E. p. (acero / plastico) \\
\hline $0,0 \%$ & E. p. (acero / prefabricados) \\
\hline $0,0 \%$ & E. p. (hormigon) \\
\hline $0,0 \%$ & E. p. (hormigón / madera) \\
\hline $0.0 \%$ & E. p. (madera) \\
\hline $0,0 \%$ & E. p. (madera/ bambü) \\
\hline $0,0 \%$ & E.p. (plástico) \\
\hline $25 \%$ & In-situ (hormigon armado) \\
\hline $0,0 \%$ & In-situ (hormigón / acero) \\
\hline $0.0 \%$ & In-situ (hormigón / block / yeso) \\
\hline $12,5 \%$ & In-situ (hormigón / block) \\
\hline $12,5 \%$ & In-situ (hormigón / ladnillo) \\
\hline $0,0 \%$ & In-situ (ladrillo) \\
\hline $0.0 \%$ & In-situ (ladrillo armado) \\
\hline 12,5\%ם & Núcleos prefabricados \\
\hline $0,0 \%$ & N. p. (acero y desechos) \\
\hline $0,0 \%$ & N. p. (panel sandwich) \\
\hline $0.0 \%$ & N. p. (plástico) \\
\hline $0.0 \%$ & Sist. mixto (acero / block) \\
\hline $0,0 \%$ & Sist. mixto (acero / ladnillo) \\
\hline $0,0 \%$ & Sist. mixto (hormigón / madera) \\
\hline $0,0 \%$ & Sis. mixto (hormigón / prefab.) \\
\hline $0.0 \%$ & Sist. mixto (malla / lona / horm.) \\
\hline $37.5 \%$ [ & Elementos prefabricados \\
\hline $12,5 \%$ & Núcleos prefabricados \\
\hline $50 \%$ & In-situ \\
\hline $0 \%$ & Sistema mixto \\
\hline
\end{tabular}

\section{En el Mundo}

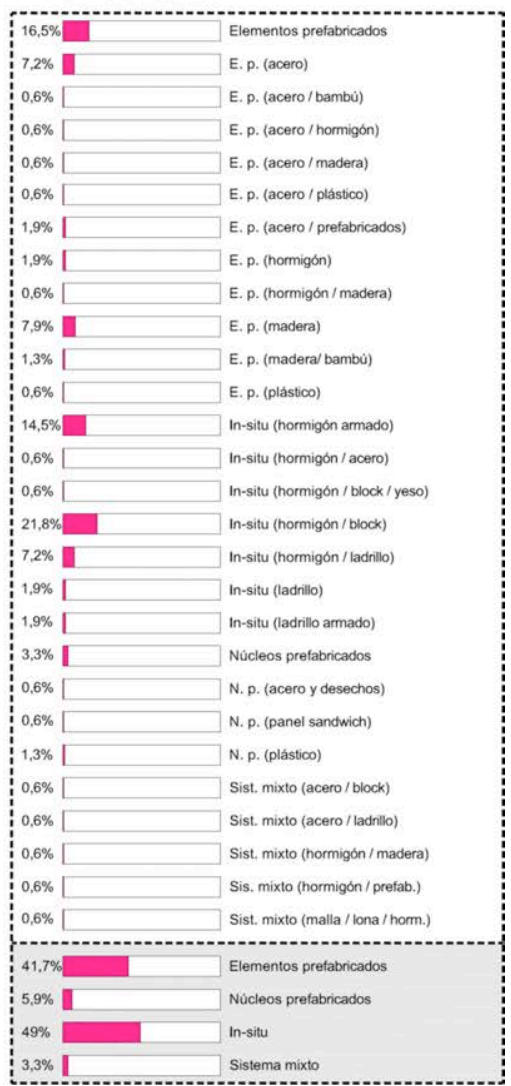

Tabla 14. Sistemas constructivos más usados por región para la ampliación de la vivienda. 
En cuanto a los sistemas constructivos empleados en las viviendas crecederas localizadas, se han detectado cuatro grandes grupos: los casos que utilizan elementos discretos prefabricados (tales como tablones y escuadrías de madera, perfiles de acero, paneles prefabricados, etc.), los que están conformados por núcleos o células prefabricadas (carcasas plásticas, núcleos de acero prefabricado, etc.), los sistemas que se construyen insitu (como los bloques de hormigón, el ladrillo, etc.) y los sistemas mixtos (como la estructura de acero con cerramiento de ladrillo o la estructura de hormigón armado con paneles prefabricados).

El fenómeno de la casa crecedera se debate entre dos de estos grandes grupos, la construcción in-situ con un $49 \%$ de los casos detectados y la construcción por elementos prefabricado con un 4I,70\% de los casos. El sistema constructivo más utilizado es el sistema in-situ de estructura de hormigón armado con cerramiento de bloque de hormigón (21,80\% de los casos). Seguido de cerca por la construcción total en hormigón armado ( $14,50 \%$ de los casos) y la construcción con elementos prefabricados (I6,50\% de los casos). (Tabla I4).

En el caso de Latinoamérica los sistemas más utilizados son los englobados dentro del grupo de la construcción in-situ $(69,5 \%$ de los casos localizados) al igual que en África (100\% de los casos) y más concretamente el sistema más utilizado es el de la estructura de hormigón armado con cerramiento de blocks. Mientras tanto en Europa (68\%) y en Estados Unidos y Canadá (87,5\%) los sistemas más utilizados son los pertenecientes al grupo de los elementos prefabricados, destacando en Estados Unidos y Canadá el uso de los paneles prefabricados en general y Europa la construcción en madera o con paneles prefabricados. (Tabla 14).

En el caso de Asia, la construcción predominante de las casas crecederas localizadas se realiza por sistemas Insitu (50\%) siendo el hormigón armado el material predominante $(25 \%)$. Cabe destacar la diferencia existente entre el caso de Estados Unidos y Canadá, y el caso de África, donde el primero se caracteriza por el uso de un $100 \%$ de sistemas prefabricados, mientras que en África el $100 \%$ de los casos son construidos in-situ. El $87,5 \%$ de los casos norteamericanos se construyen con sistemas por elementos prefabricados mientras que el $12.5 \%$ restante son núcleos prefabricados completos. Mientras que. en la región africana, el $100 \%$ de los casos estudiados son construidos in-situ con estructuras de hormigón armado y cerramiento de blocks de hormigón. (Tabla 14). Esta diferencia en los sistemas constructivos hace que los mecanismos de ampliación sean diametralmente distintos, como ya hemos comentado. En Estados Unidos y Canadá el 74,83\% de los casos se amplían por sistemas sin incremento de volumen y que posibilitan la opción de la reversibilidad. Mientras que en África el $60 \%$ de los casos implican un aumento de volumen edificatorio irreversible (Tabla 13).

Centrándonos más concretamente en cada uno de los mecanismos de ampliación podemos observar que la reversibilidad va estrechamente vinculada a los sistemas constructivos que se utilizan. En sistemas reversibles como son la expansión y la unión se utilizan mayoritariamente sistemas de construcción basados en la prefabricación.

En el caso de la expansión todos los casos son prefabricados. El 94,2\% de ellos utilizan elementos prefabricados como las combinaciones de acero y bambú, o de acero y plástico, o únicamente madera, entre otros materiales. $Y$ el 5,8\% restante se construye mediante células prefabricadas, concretamente de acero. Igualmente, en el mecanismo de la unión el $75 \%$ de los casos localizados se construyen mediante sistemas 
constructivos prefabricados de acero. Sin embargo en el resto de sistemas no hay una tendencia tan clara en el uso de la prefabricación. (Tabla I5).

En los casos en los que no hay incremento de volumen se utiliza mayoritariamente construcción in-situ. El $25,8 \%$ de los casos que crecen según el principio del botellero utilizan hormigón armado, al igual que el $25 \%$ de los casos de crecimiento por delimitación. La mayoría de los casos localizados de ocupación bajo cubierta (60\%) y de ampliación por gran galpón (37,8\%) sin embargo están construidos con una combinación de hormigón armado y bloque de hormigón. (Tabla I5).

Igualmente, en la mayoría de los casos localizados en los que el crecimiento es por incremento de volumen se usan sistemas de construcción in-situ. Este es el caso de la ocupación vertical donde el 100\% de los casos detectados se construyen con ladrillo, o el caso de la ocupación horizontal o la extrusión donde el 83,4\% y el $36,3 \%$ de los casos respectivamente crecen con estructura de hormigón armado y bloques de hormigón, mientras que el $50 \%$ de los ejemplos de crecimiento mediante adición horizontal en terrazas son de hormigón armado, al igual que el $40 \%$ de los casos que se amplían por voladizo. Sin embargo, en el caso de la ampliación por colonización los sistemas constructivos cambian obteniendo un $70 \%$ de los casos que crecen mediante sistemas basados en elementos prefabricados. (Tabla I5).

En el caso de la adición horizontal en jardines, al ser el tipo que se da en más lugares y con mayor número de casos encontramos todo tipo de ejemplos con distintos sistemas constructivos (utiliza hasta 22 materiales o sistemas constructivos distintos de los 28 detectados) esto implica que sumando todos estos distintos sistemas el $58,75 \%$ de los casos sean prefabricados (45\% por elementos prefabricados y $13,75 \%$ por núcleos prefabricados). A pesar de que el sistema constructivo más utilizado en este tipo sea la estructura de hormigón armado con cerramiento de blocks de hormigón (I8,75\% de los casos localizados). (Tabla I5).

En lo referido al uso de la vivienda crecedera a lo largo de la historia, se ha obtenido que el $22,4 \%$ de los casos seleccionados se proyectaron en la década de los 70, seguido del $21,4 \%$ de los ejemplos de los ochentas y el 19,5\% construidos entre el 2000 y el 2010 . (Tabla 16). 


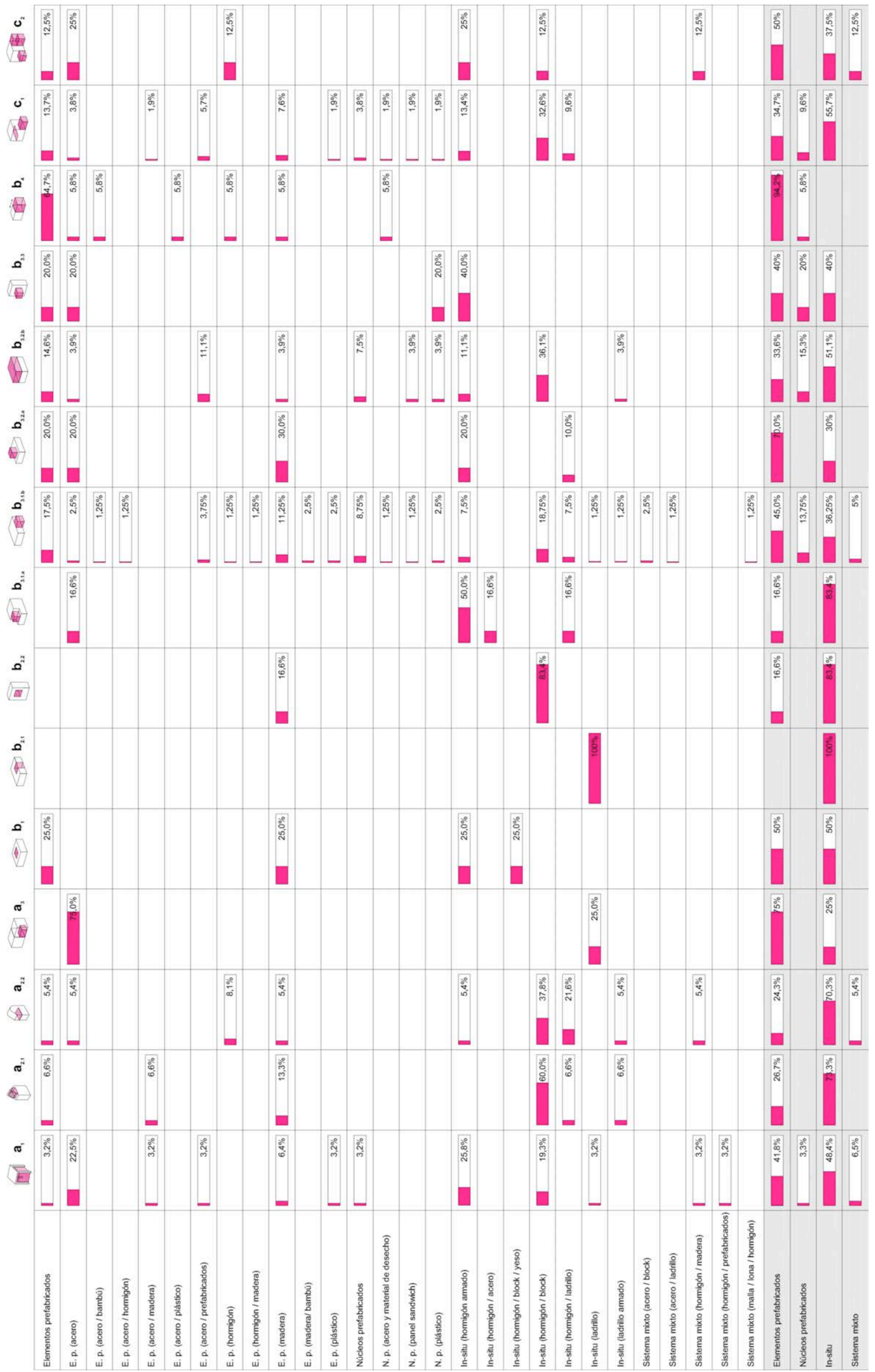

Tabla I5. Sistemas constructivos más usados por mecanismo de ampliación. 
En las dos primeras décadas del siglo $X X$ los mecanismos de ampliación utilizados se basaban en no incrementar el volumen de la vivienda (principio del botellero y ocupación bajo cubierta). Hasta que a partir de 1930 comienzan a utilizarse métodos con incremento de volumen (adición horizontal en jardines). Entre la década de los 30 y los 40 la proporción de viviendas proyectadas con aumento de volumen aumenta más de un $10 \%$ siendo el tipo predominante la adición horizontal en jardines, que se mantendrá como el mecanismo de ampliación más utilizado hasta la actualidad. En la década de los 40 comienza a haber más diversidad de tipos obteniendo un $33,2 \%$ de los casos sin incremento de volumen frente al $66,8 \%$ de los casos que si que aumentan. A partir de los años 60 la tendencia cambia y comienza a predominar el uso de sistemas con incremento de volumen (86\%) probablemente asociado al cambio de la región predominante ya que desde 1900 hasta aproximadamente finales de la década de los 60 la mayoría de los casos localizados se encontraban en Europa, mientras que a partir de la década de los 70 la región donde comienzan a localizarse más ejemplos es Latinoamérica (Tabla 17).

Entre las décadas de los 70 y los 90 se da la mayor variedad de mecanismos de ampliación, fruto de la búsqueda teórico práctica de la flexibilidad en la vivienda comentada en el apartado I.a. Objeto de estudio y estado de la cuestión del documento. En la primera década del siglo $\mathrm{XXI}$ es en la que se dan todos los tipos de ampliación identificados excepto el de la expansión. (Tabla 16).

Con todos estos datos se observa que el fenómeno del crecimiento es heterogéneo y que no se aplica exclusivamente en viviendas en casos de alta pobreza y marginalidad como se ha considerado en numerosas ocasiones.

Es cierto que en los países en vías de desarrollo este tipo de vivienda progresiva se usa mayoritariamente porque es un sistema constructivo que se adapta a los escasos recursos económicos de sus habitantes sin condicionarlos en el futuro con grandes hipotecas impagables. Pero también lo hacen porque el tipo se adapta a las necesidades espaciales derivadas de las variaciones de su núcleo familiar, tanto si este crece, como si este disminuye. Es también usado porque es flexible con los tiempos y ciclos de la familia, lo que lleva a pensar a los usuarios en muchas ocasiones que su casa crecedera es la casa ideal en potencia porque inicia de una manera pero les da la oportunidad de soñar cuán grande quieren que esta sea, brindándoles de verdad esta posibilidad de mejorar.

Todo esto hace que estas viviendas sean adecuadas no sólo para las familias de bajos recursos, si no para numerosas familias de cualquier condición y país, que igualmente estén interesadas en poder disfrutar de una vivienda que se adapte a sus tiempos, variaciones familiares y ahorros. 


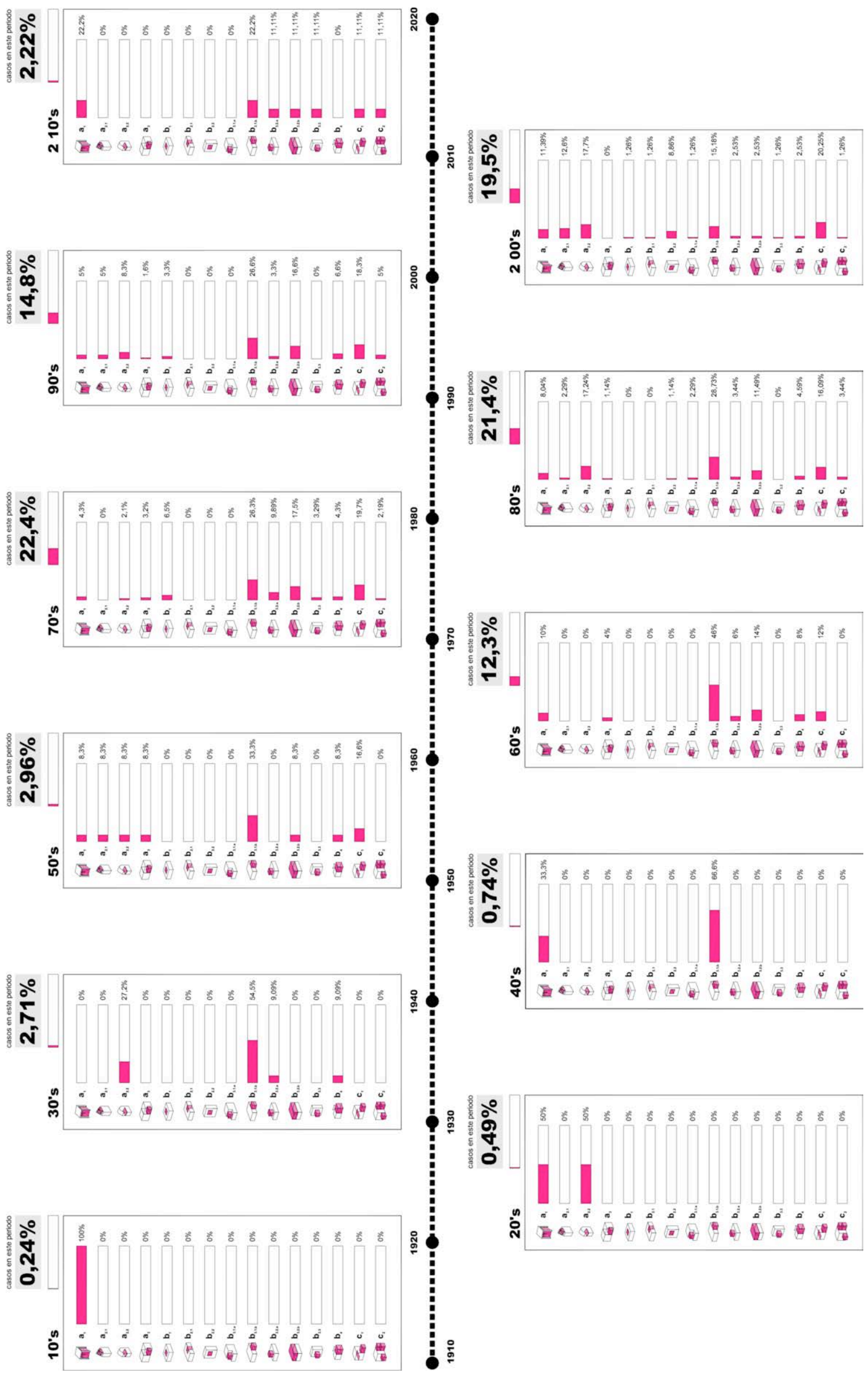

Tabla 16. Mecanismos de ampliación más utilizados en cada época. 


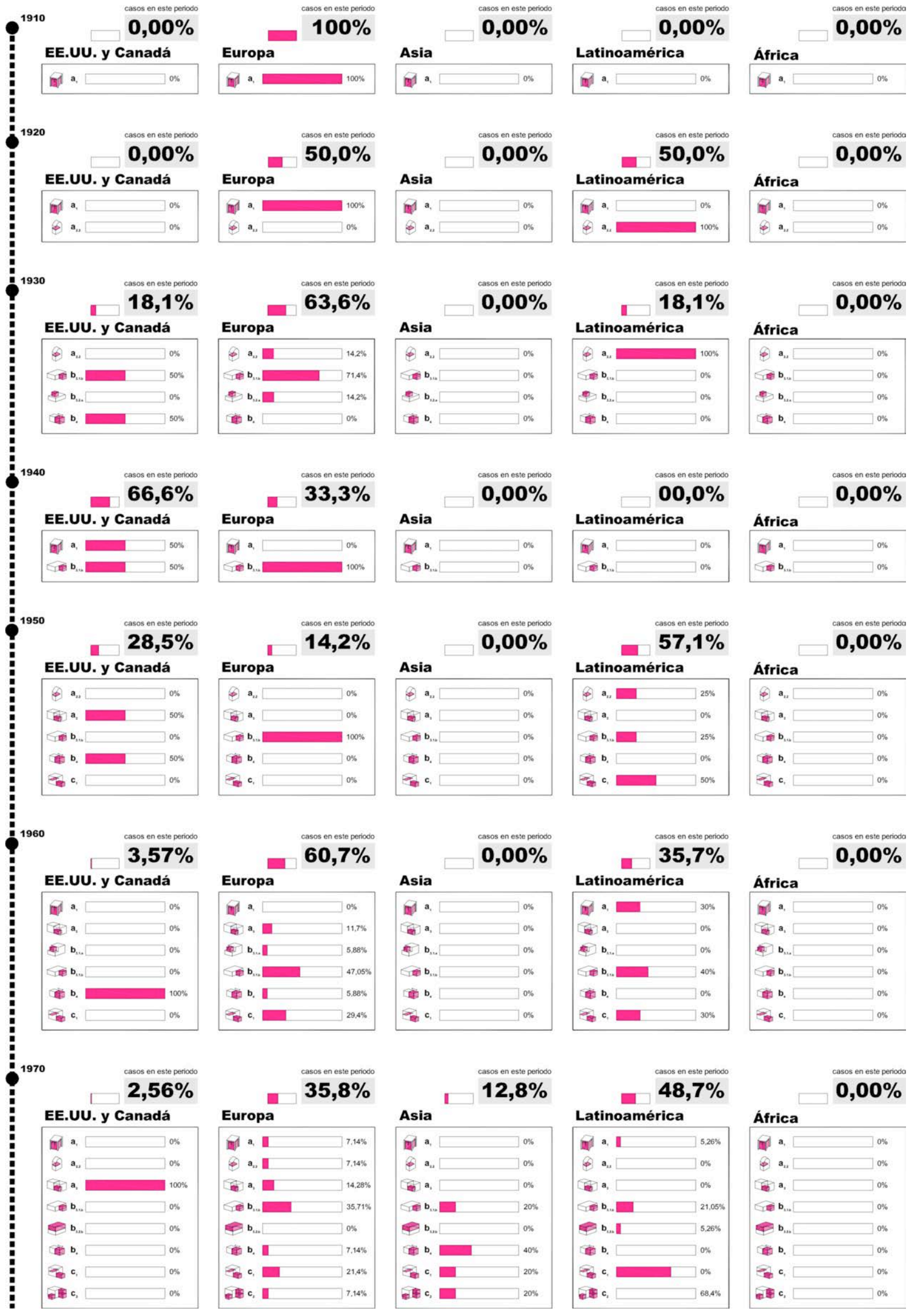

Tabla 17. Mecanismos de ampliación más utilizados por región en una época determinada. (Continúa) 


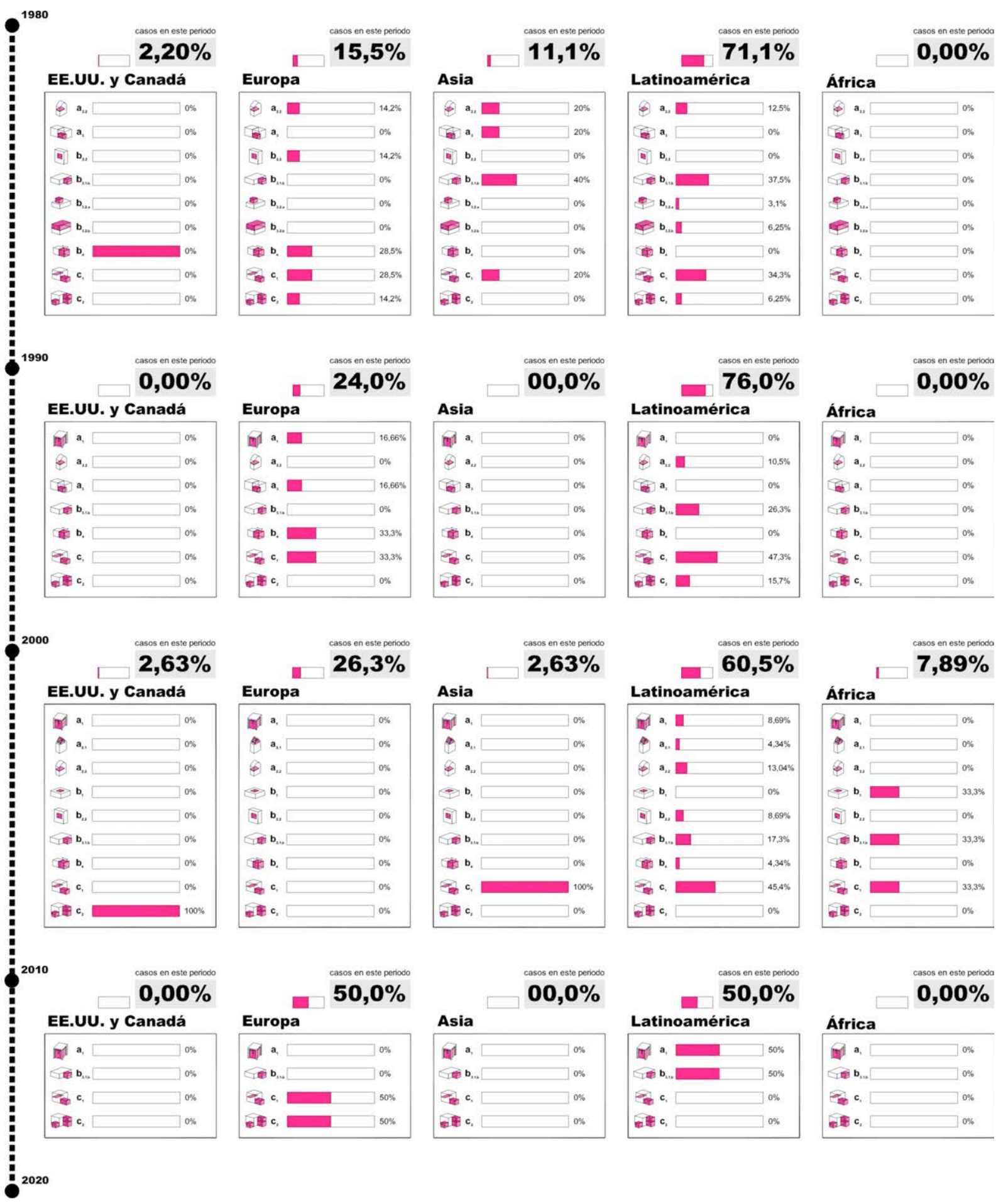

Tabla 17. Mecanismos de ampliación más utilizados por región en una época determinada. 


\section{4.b. Casos de estudio general.}

Para entender adecuadamente la complejidad del fenómeno del crecimiento en la vivienda ampliable, se ha decidido estudiar, en un primer lugar y de manera general, como afecta este proceso al tejido urbano. Para ello se han seleccionado ocho casos de estudio de los 214 localizados en todo el mundo, de acuerdo a dos categorías: arquitectura residencial colectiva y arquitectura residencial multifamiliar.

Esta diferenciación entre arquitectura residencial colectiva y multifamiliar se basa en la agrupación de las viviendas, donde en la arquitectura residencial colectiva las viviendas se asocian verticalmente y horizontalmente de manera simultánea. Mientras que en el caso de arquitectura residencial multifamiliar, la agregación y repetición de viviendas se realiza únicamente de manera horizontal formando un conjunto'.

Tal y como se ha empezado a enunciar en los apartados anteriores, estas diferentes formas de agrupación de las viviendas afectan directamente en la selección de los mecanismos de ampliación que se utilizan en cada caso, ya que las posibles puntas de crecimiento están determinadas por las relaciones topológicas entre las unidades que conforman el conjunto. Por esta razón, en la discriminación de estos ocho casos se ha tratado elegir ejemplos con diferentes mecanismos, analizando la relación entre la morfología del crecimiento de la vivienda basada en los mecanismos de ampliación y cuatro factores urbanos que se han considerado de especial interés: la densidad de viviendas (viv/ha), la densidad de población (px/ha), la compacidad (\%) y la ocupación (\%).

Para el estudio de los ocho casos se han dibujado una serie de fichas de análisis donde se comparan por un lado los conjuntos residenciales propuestos por los arquitectos como primera etapa (las viviendas semillas insertas en la ciudad), con, por otro lado, la vivienda ampliada en su máxima expresión inserta en el mismo conjunto. De modo que se puede analizar tanto en volumen como en sección, la morfología y evolución del crecimiento y los anteriormente mencionados factores urbanos.

Los casos escogidos para su estudio general son los ocho siguientes:

\footnotetext{
I No se han considerado de forma independiente dentro de esta clasificación las viviendas unifamiliares aisladas, debido a que según los textos de Jorge Andrade, se sostiene que la vivienda unifamiliar, con el tiempo, acaba transformándose en una agrupación horizontal progresiva de viviendas. Lo que en el caso de esta investigación se ha catalogado como arquitectura residencial multifamiliar. (Andrade Narváez, 1999, 62).
} 
Dentro de la arquitectura residencial colectiva.

-Square L-type System de J. Van den Broek y J. Bakema (1967) Holanda.

-Viviendas Quinta Monroy de ELEMENTAL (2003) Chile.

-Überbauung Brahmshof de Kuhn Fischer und Partner (1991) Suiza.

-Multifamiliar que crece de Pedro Ramírez Vázquez (1960) México.

Y en la arquitectura residencial multifamiliar.

-Población René Schneider de Percy Díaz Martínez (1995-96) Chile.

-Expansiva housing system de Jorn Utzon (1969) Francia.

-II Rigo Quarter de Renzo Piano Building Workshop (1978) Italia.

-Vivienda para el conjunto PREVI de Toivo Korhonen (1978) Perú. 


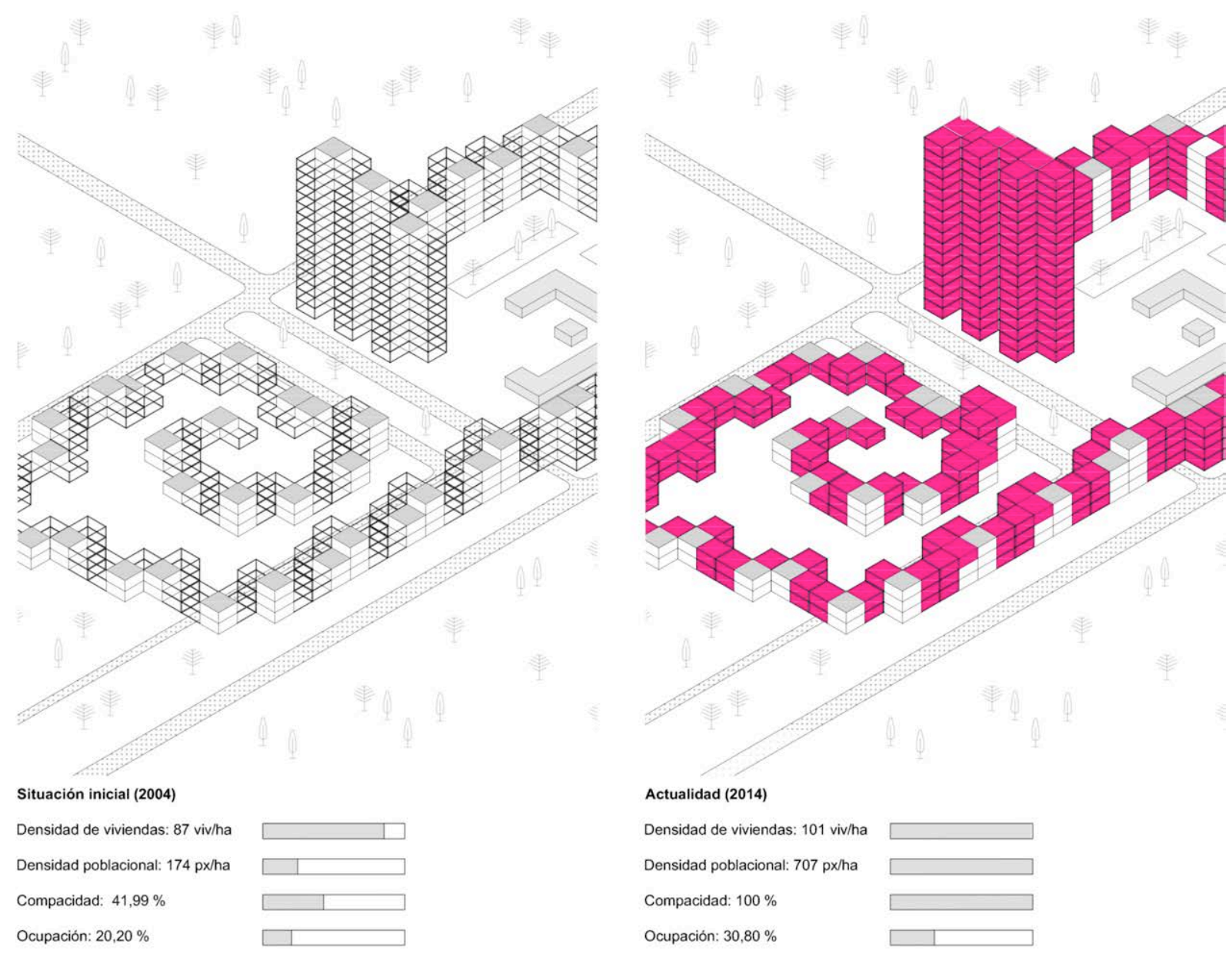
(1) Calle vehicular
(4) Plaza pública
(7) Espacio natural
(2) Jardin privado
(5) Equipamiento
(8) Plaza semipública
(3) Paseo peatonal
6) Jardin público
(9) Plaza privada

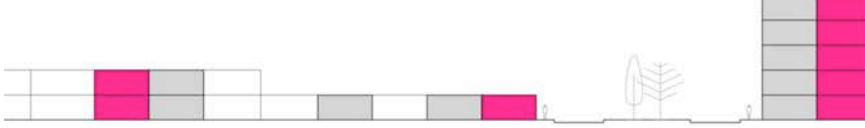

(2)

(2)

(2)

(2) (1) (6) 1
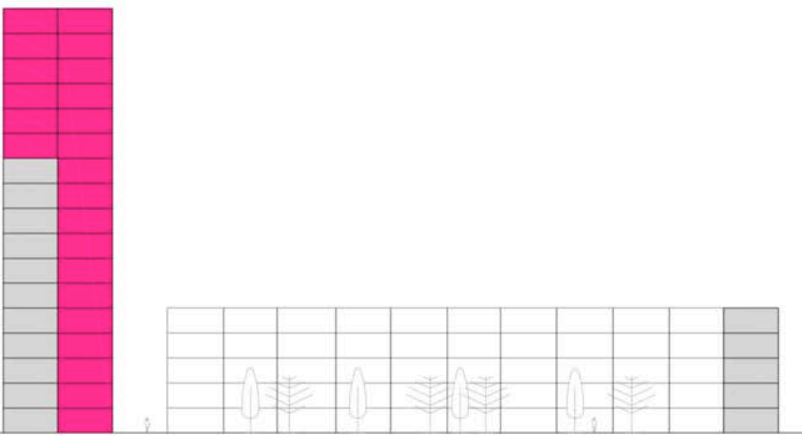

(1)

(2)

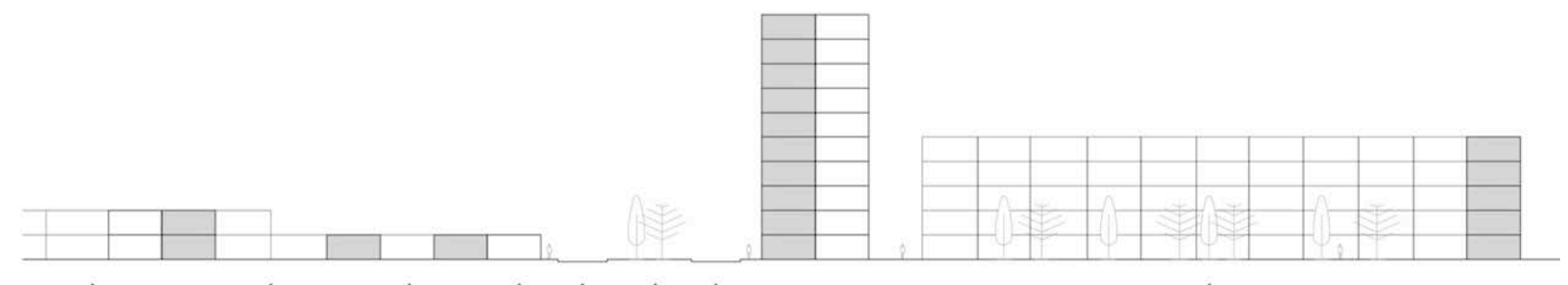

(2)

(2)

(2)

(2) 1

(6) 1

(2) 


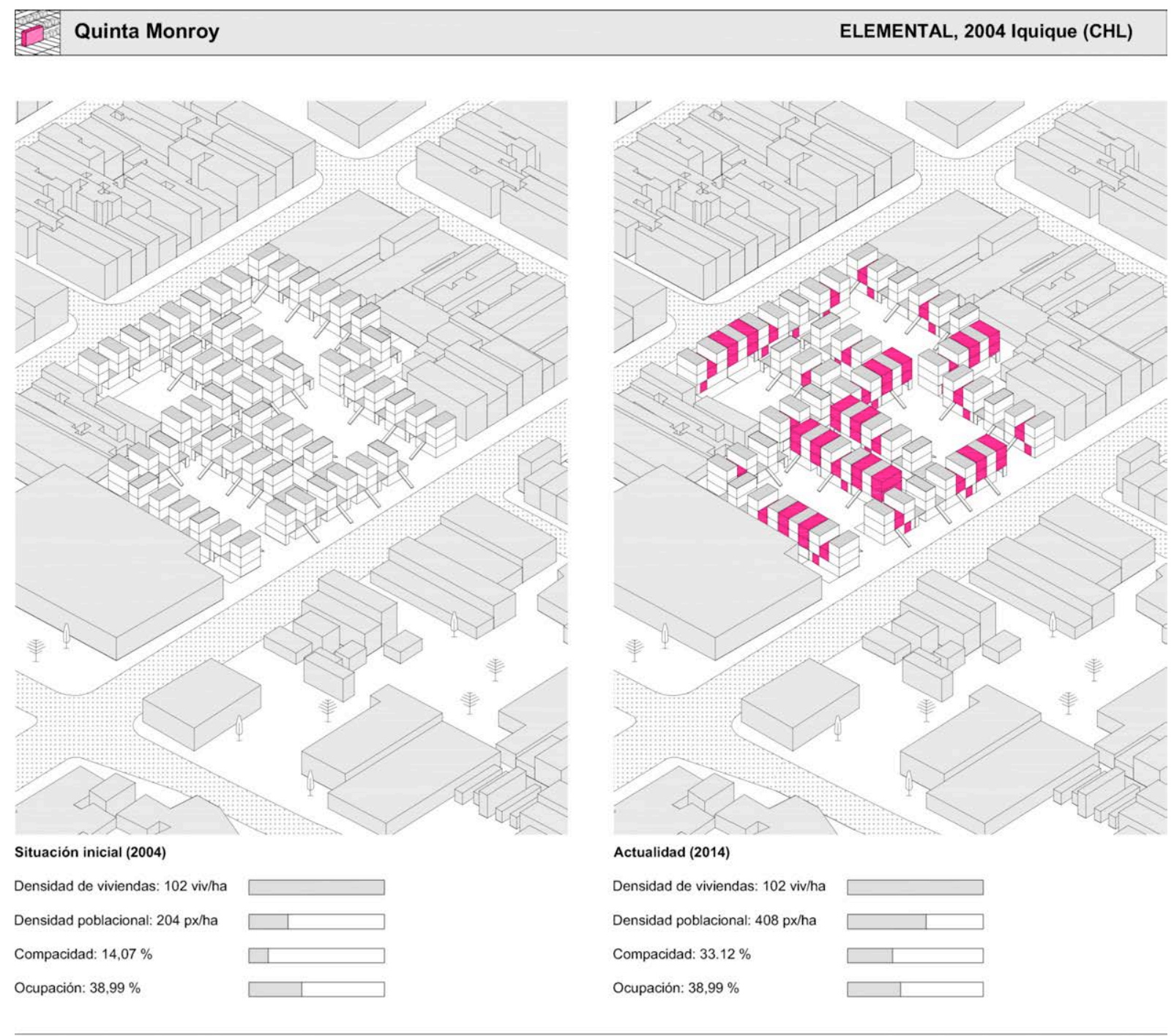
(1) Calle vehicular
(4) Plaza pública
(7) Espacio natural
(2) Jardin privado
(5) Equipamiento
(8) Plaza semipública
(3) Paseo peatonal
6) Jardin público
(9) Plaza privada

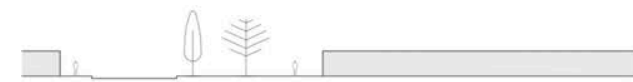

(1) (4)

(2)

(8)

(2)

(8)

(2)

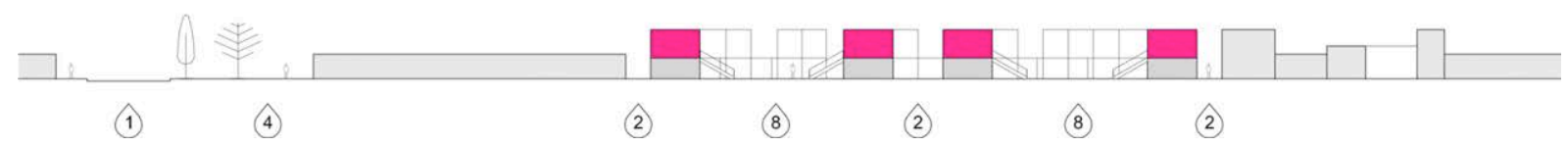




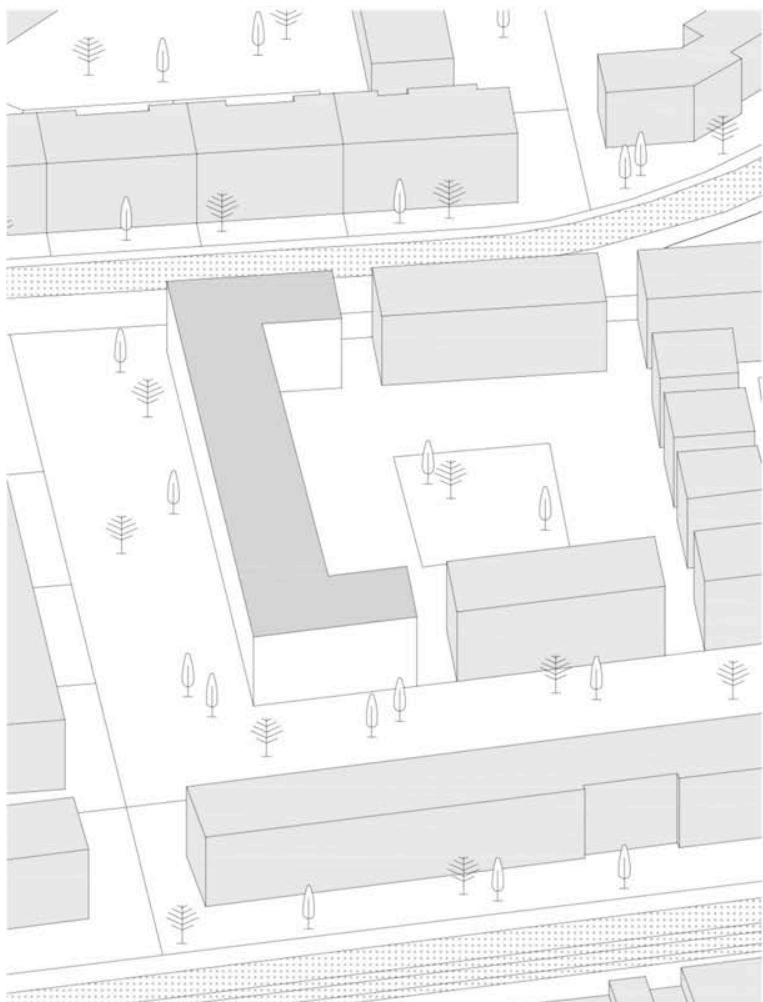

Situación inicial (1991)

Densidad de viviendas: 72 viv/ha

Densidad poblacional: 288 px/ha

Compacidad: $100 \%$

Ocupación: $34,95 \%$

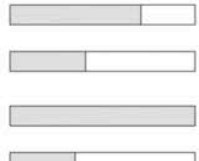

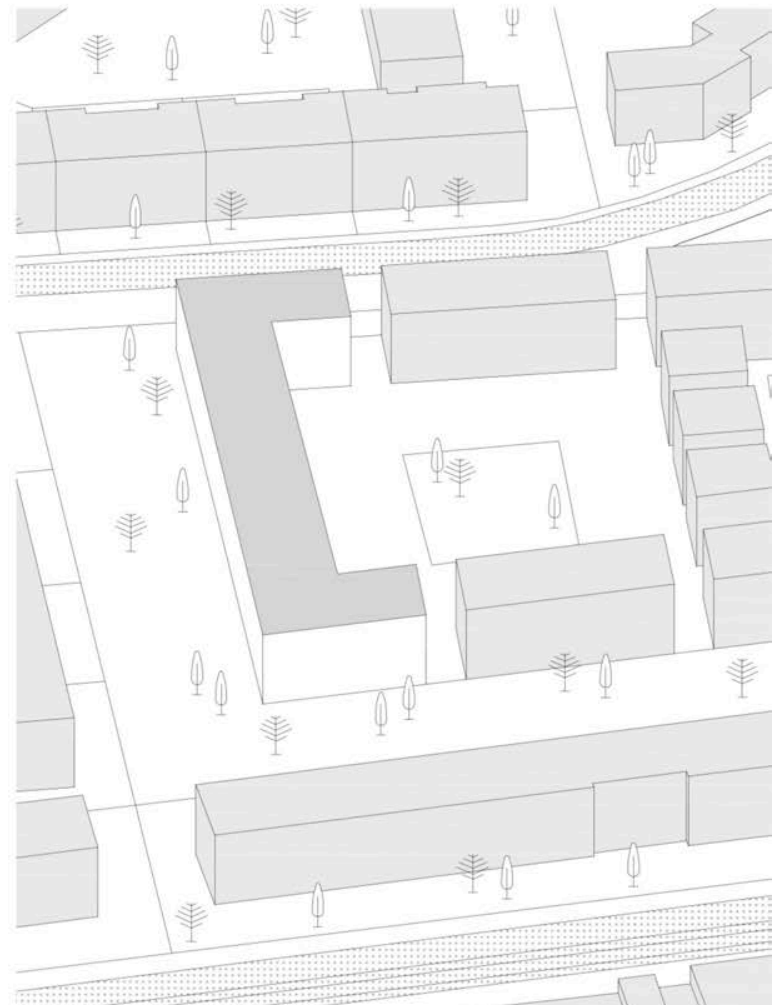

Actualidad (2014)

Densidad de viviendas: 72 viv/ha

Densidad poblacional: $288 \mathrm{px} / \mathrm{ha}$

Compacidad: $100 \%$

Ocupación: $34,95 \%$
(1) Calle vehicular
(4) Plaza pública
(7) Espacio natural
(2) Jardín privado
(5) Equipamiento
(8) Plaza semipública
(3) Paseo peatonal
6) Jardin público
(9) Plaza privada

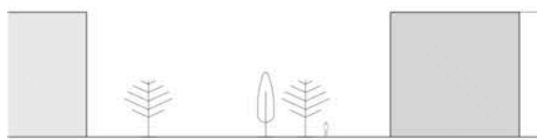

(2)

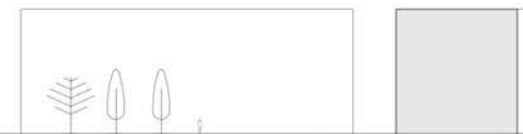

(2)

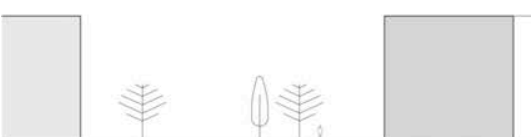

(2) 


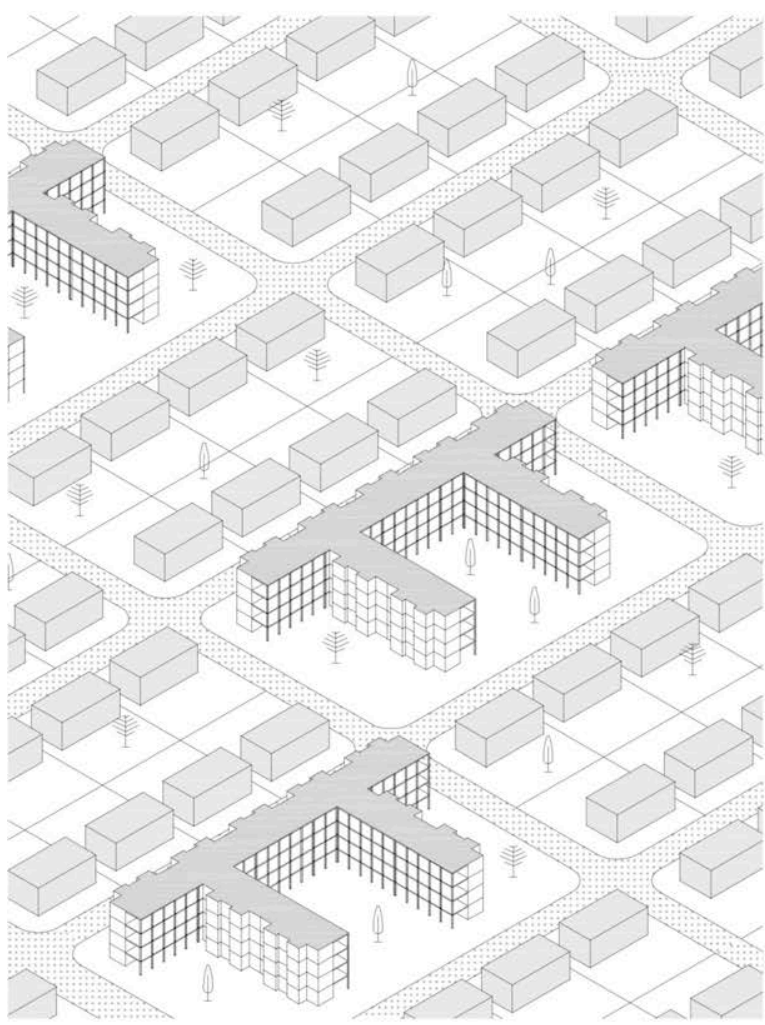

Situación inicial (1960)

Densidad de viviendas: 80 viv/ha Densidad poblacional: $160 \mathrm{px} / \mathrm{ha}$ Compacidad: $14,08 \%$

Ocupación: 20,14 \%

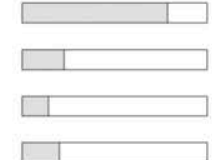

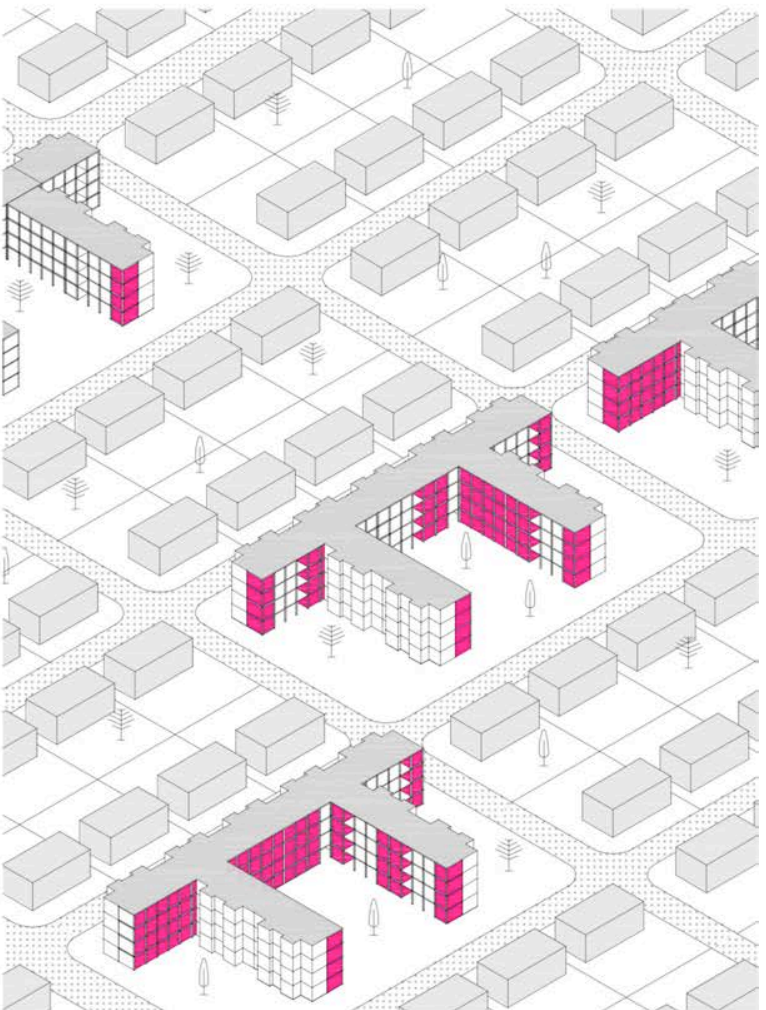

Actualidad (hipótesis de máximo crecimiento)

Densidad de viviendas: 80 viv/ha

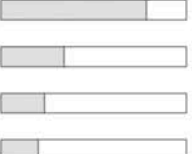
(1) Calle vehicular
(4) Plaza pública
(7) Espacio natural
(2) Jardin privado
(5) Equipamiento
(8) Plaza semipública
(3) Paseo peatonal
6) Jardin público
(9) Plaza privada

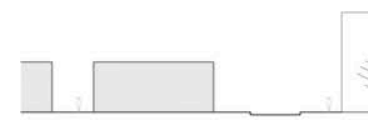

(2)

(1)

8

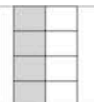

8

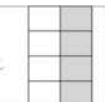

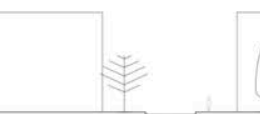

(8)

(1)

8

(9)

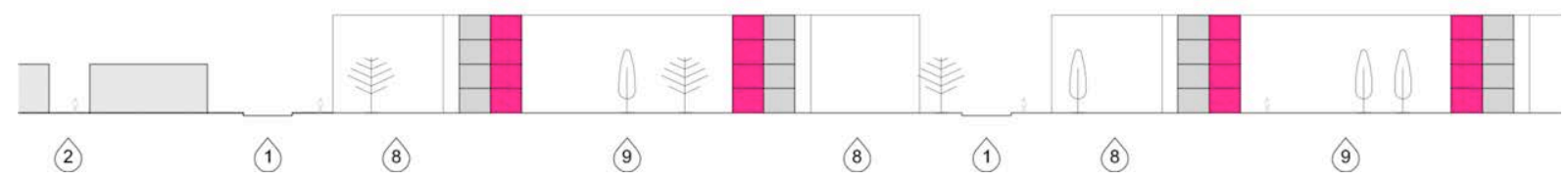




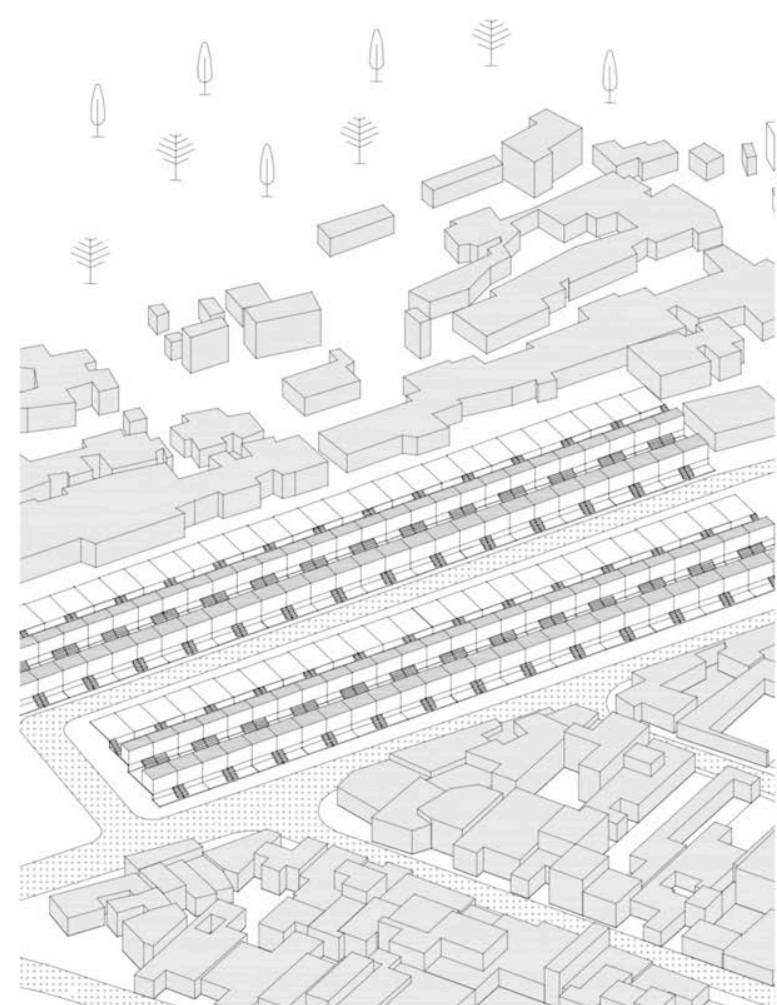

Situación inicial (1996)

Densidad de viviendas: 69 viv/ha Densidad poblacional: $138 \mathrm{px} / \mathrm{ha}$ Compacidad: $10,56 \%$

Ocupación: $31,38 \%$

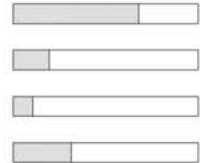

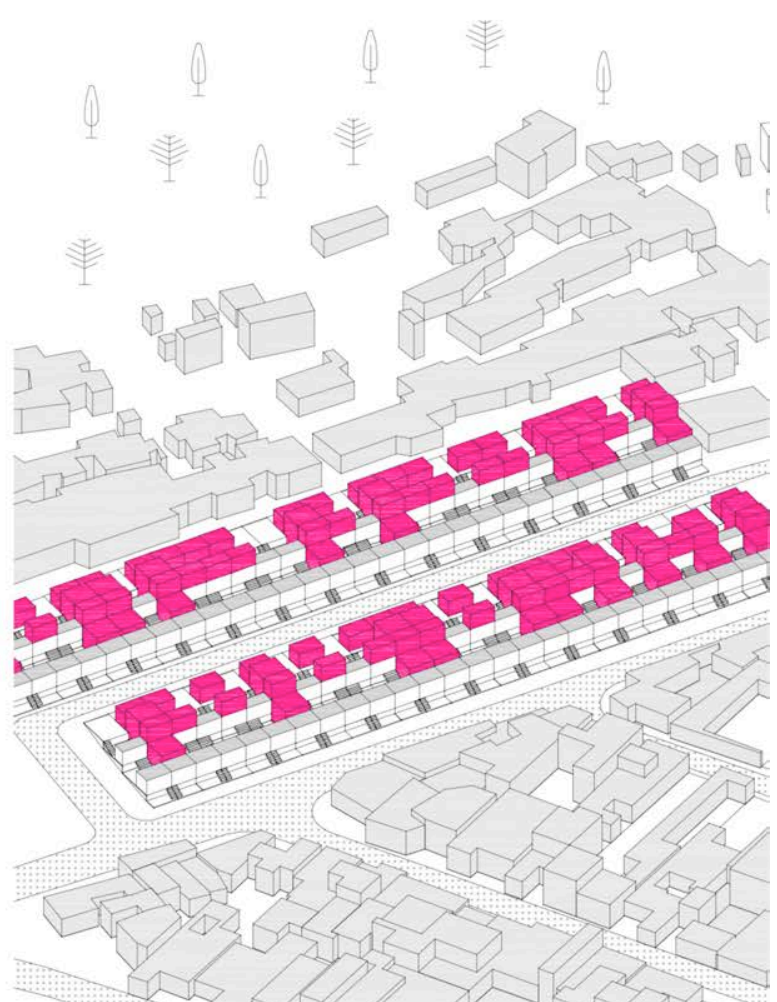

Actualidad (2014)

Densidad de viviendas: 69 viv/ha

Densidad poblacional: $276 \mathrm{px} / \mathrm{ha}$

Compacidad: $50,27 \%$

Ocupación: $54,50 \%$
(1) Calle vehicular
(4) Plaza pública
(7) Espacio natural
(2) Jardin privado
(5) Equipamiento
(8) Plaza semipública
(3) Paseo peatonal
6) Jardin público
(9) Plaza privada
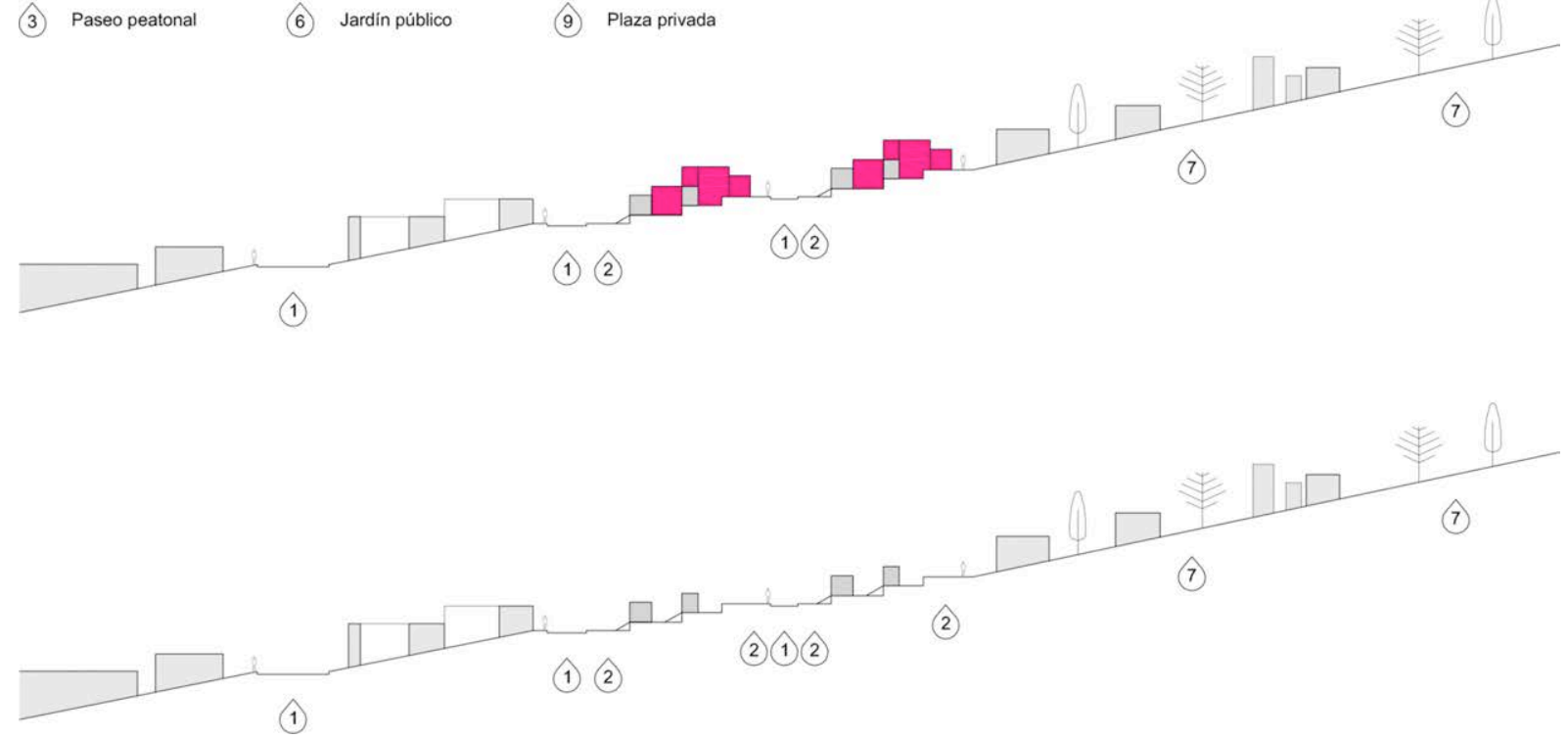


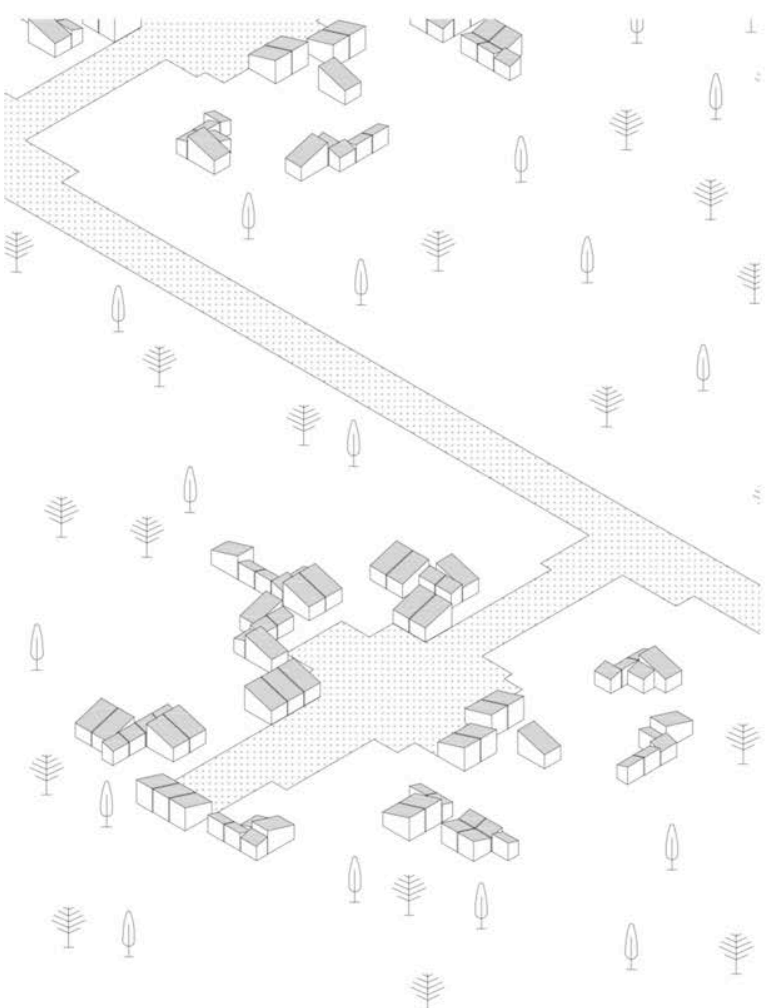

Situación inicial (1969)

Densidad de viviendas: 9 viv/ha Densidad poblacional: $12 \mathrm{px} / \mathrm{ha}$ Compacidad: $29,60 \%$

Ocupación: $15,92 \%$

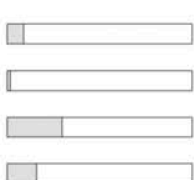

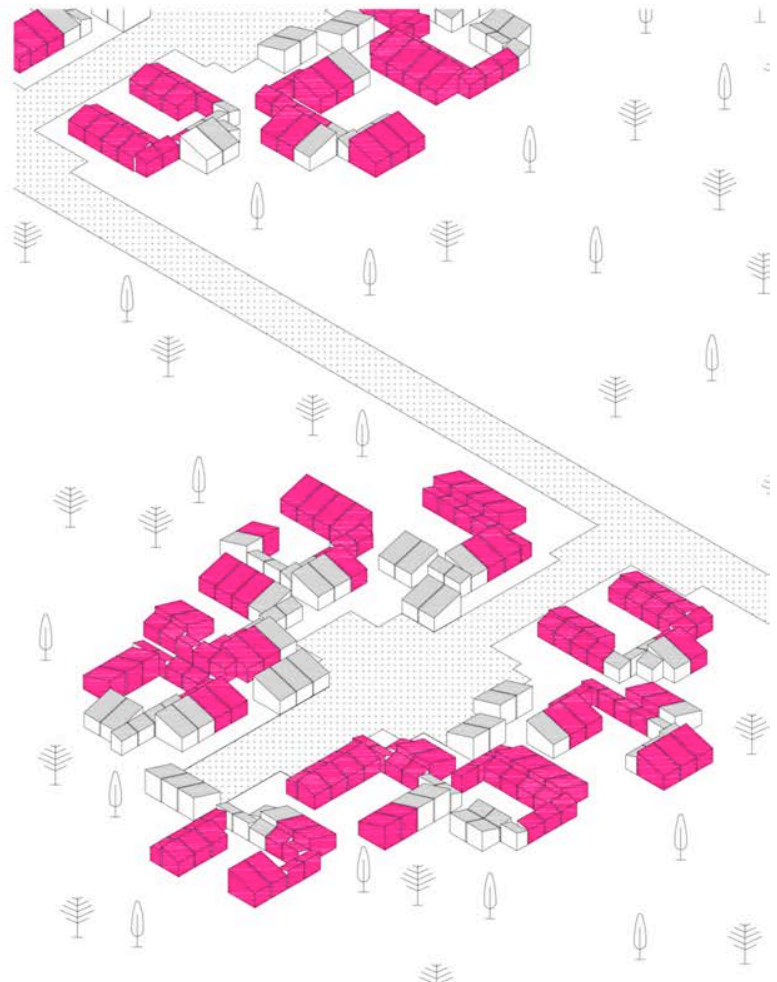

Actualidad (2014)

Densidad de viviendas: 9 viv/ha

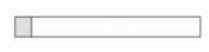

Densidad poblacional: $40 \mathrm{px} / \mathrm{ha}$

Compacidad: $53,66 \%$

Ocupación: $44,09 \%$

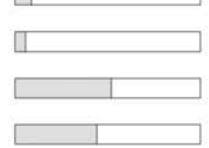
(1) Calle vehicular
(4) Plaza pública
(7) Espacio natural
(2) Jardin privado
(5) Equipamiento
(8) Plaza semipública
(3) Paseo peatonal
6) Jardin público
9) Plaza privada

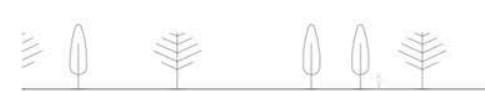

(7)
(2)

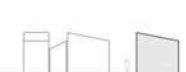

(5) 1 


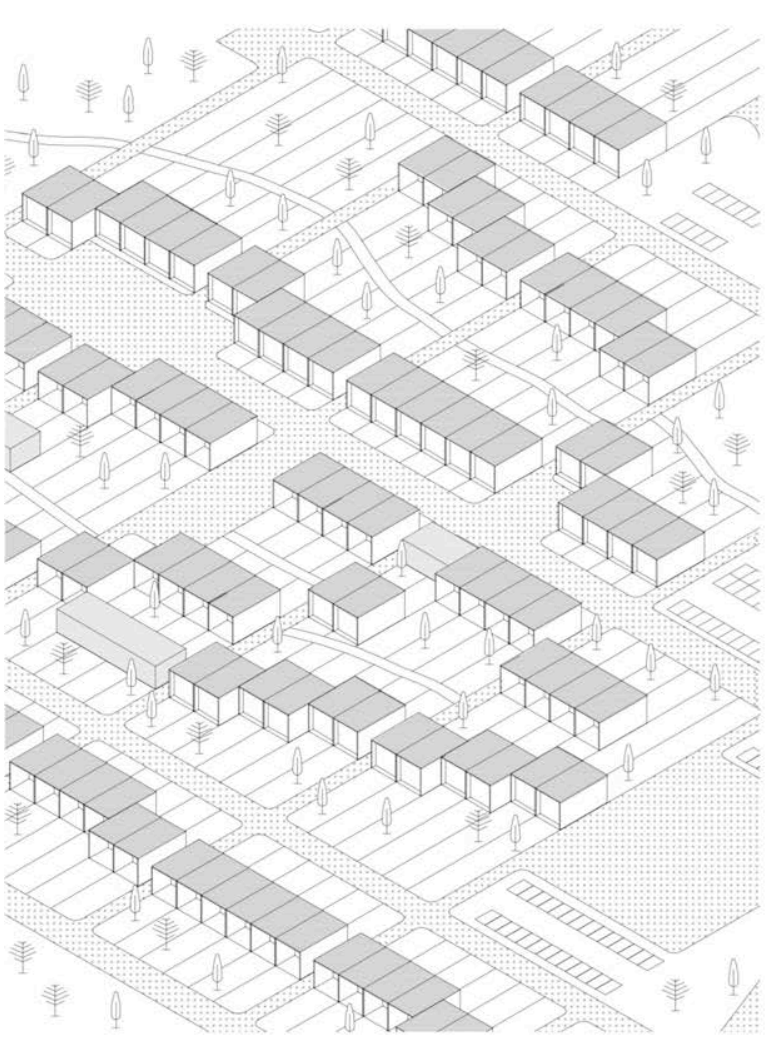

Situación inicial (1982)

Densidad de viviendas: 25 viv/ha

Densidad poblacional: $50 \mathrm{px} / \mathrm{ha}$

Compacidad: $24,14 \%$

Ocupación: $29,91 \%$

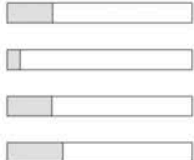

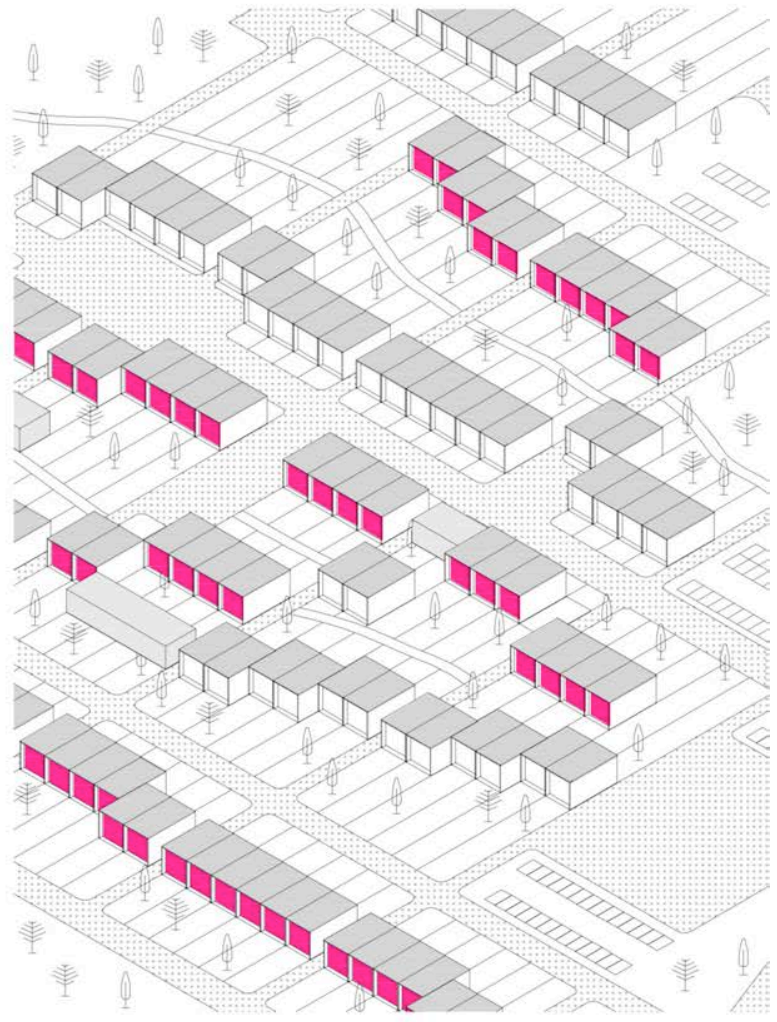

Actualidad (2014)

Densidad de viviendas: 25 viv/ha

Densidad poblacional: $150 \mathrm{px} / \mathrm{ha}$

Compacidad: $39,93 \%$

Ocupación: $29,91 \%$

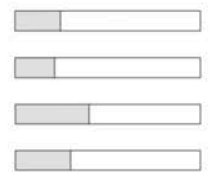
(1) Calle vehicular
(4) Plaza pública
(7) Espacio natural
(2) Jardin privado
(5) Equipamiento
(8) Plaza semipública
(3) Paseo peatonal
6) Jardin público
(9) Plaza privada

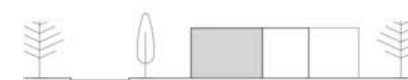

(1)
(2)

(3)
(2)

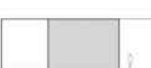

)
(4) 

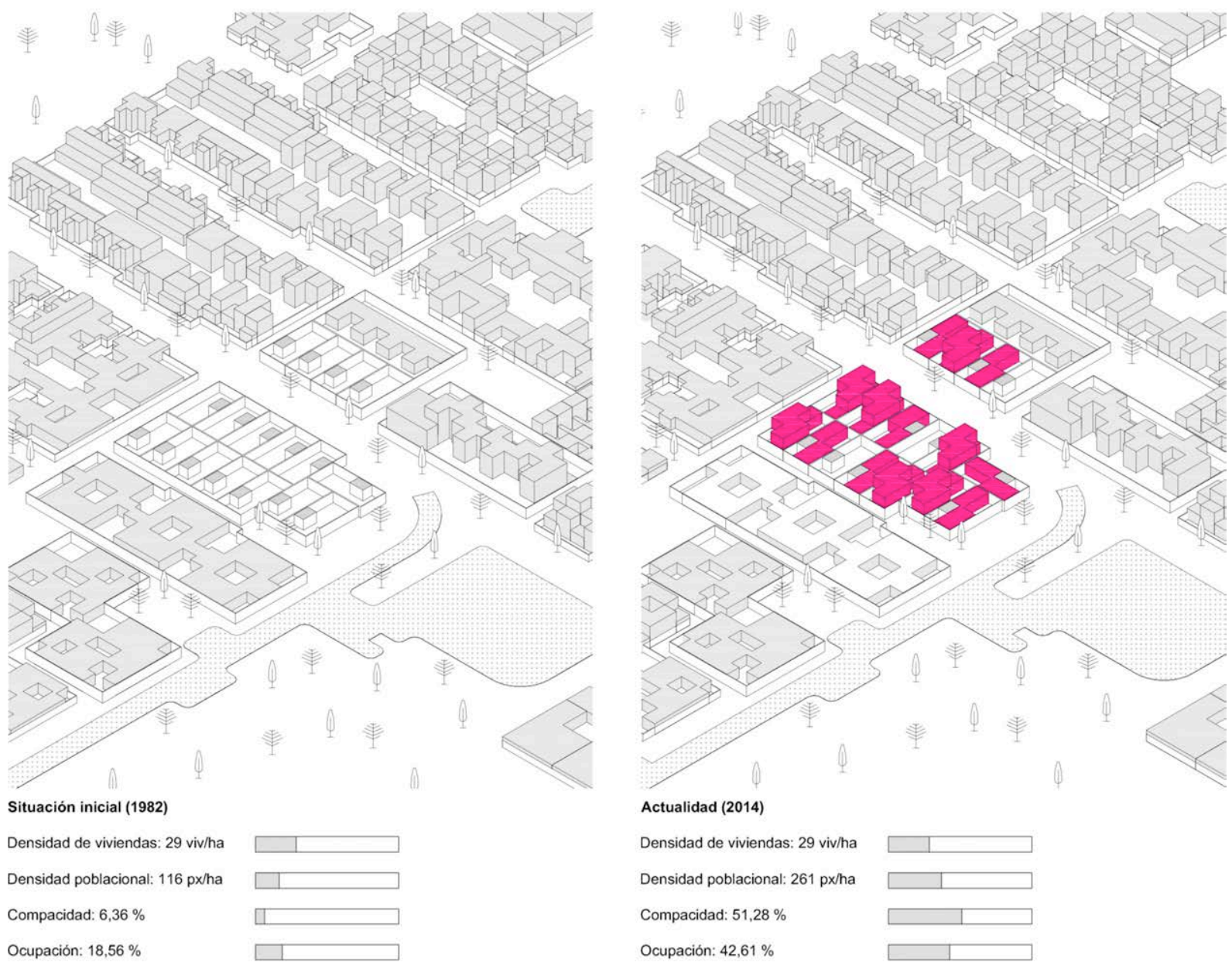
(1) Calle vehicular
(4) Plaza pública
(7) Espacio natural
(2) Jardin privado
(5) Equipamiento
(8) Plaza semipública
(3) Paseo peatonal
6) Jardin público
(9) Plaza privada

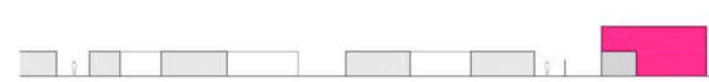

(3)

(2) (3)

(3) (2)

(2)

(3)

(2)

(3)

(2)

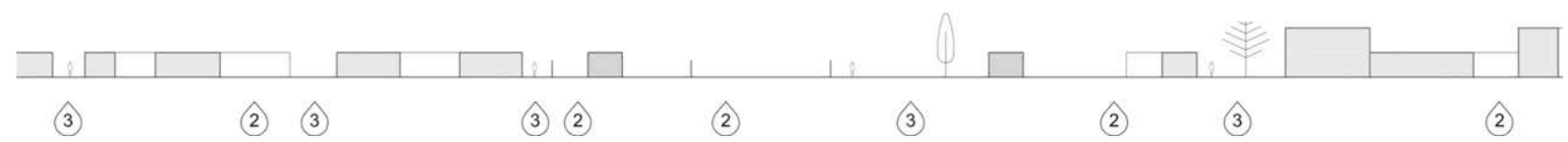


Como ya se ha anunciado, para el análisis de la relación entre el crecimiento de la vivienda y su entrono urbano se han graficado en las fichas cuatro factores considerados de especial interés: Densidad de viviendas, densidad poblacional, compacidad y ocupación.

Para este estudio se ha considerado como densidad de viviendas al número de hogares que se localizan dentro de la unidad de superficie hectárea.

\begin{tabular}{|c|c|}
\hline Square L-type system & $87 \mathrm{viv} / \mathrm{ha}$ \\
\hline Quinta Monroy & 102 viv/ha \\
\hline Überbauung Brahmshof & $72 \mathrm{viv} / \mathrm{ha}$ \\
\hline Multifamiliar que crece & 80 viv/ha \\
\hline Población René Schneider & 69 viv/ha \\
\hline Sectional housing system Espansiva & $9 \mathrm{viv} / \mathrm{ha}$ \\
\hline ॥ Rigo Quarter & $25 \mathrm{viv} / \mathrm{ha}$ \\
\hline Viviendas para PREVI & $29 \mathrm{viv} / \mathrm{ha}$ \\
\hline
\end{tabular}

\begin{tabular}{|c|c|}
\hline Square L-type system & 101 viv/ha \\
\hline Quinta Monroy & 102 viv/ha \\
\hline Überbauung Brahmshof & 72 viv/ha \\
\hline Multifamiliar que crece & $80 \mathrm{viv} / \mathrm{ha}$ \\
\hline Población René Schneider & $69 \mathrm{viv} / \mathrm{ha}$ \\
\hline Sectional housing system Espansiva & 9 viv/ha \\
\hline || Rigo Quarter & 25 viv/ha \\
\hline Viviendas para PREVI & $29 \mathrm{viv} / \mathrm{ha}$ \\
\hline
\end{tabular}

Tabla 18. Densidad de viviendas (viv/ha) de los ocho casos de estudio. Vivienda semilla y fase extendida.

De los ocho casos analizados (Tabla 18) se puede observar que las viviendas agrupadas dentro de la categoría de arquitectura colectiva tienen una mayor densidad de viviendas en las dos etapas. Eso se debe, evidentemente, a que a pesar de que en ambas categorías se manejan ocupaciones de suelo similares (Tabla 2l), las agrupaciones colectivas se desarrollan más en altura, posibilitando por la acumulación vertical el desarrollo de un mayor número de viviendas por hectárea.

A su vez, todos los casos estudiados (salvo el ejemplo del Square L-type System) mantienen a lo largo de todo su desarrollo, desde la fase inicial con viviendas semillas hasta la última fase con casas expandidas, un número de viviendas por hectárea constante. Sin embargo, en el caso del Square L-type System hay un aumento de las viviendas entre la primera y la última fase debido a que con el tiempo se produce una adición de unidades habitacionales en el bloque. Es decir, el crecimiento progresivo y programado en este caso no se produce únicamente en términos de la unidad (vivienda), si no también en términos de su agrupación (el bloque), lo que permite obtener mayores variaciones en términos de densidad.

Otra posibilidad en la que se puede observar una variación en el número de viviendas por hectárea sin que la agrupación crezca, es el caso en el que las casas del conjunto fueran artefactos de renta o dieran servicio a unidades de convivencia que con el paso del tiempo se transformaran en núcleos extendidos no familiares. De esta manera, parte de la vivienda inicial se transforma para ser rentada o compartida por otros grupos familiares que hacen que aumente el número de viviendas por hectárea (ya que para el análisis se ha asociado el concepto de vivienda a la idea del hogar) sin necesidad de construir nuevas casas.

Así mismo, en el estudio de la vivienda crecedera es esencial el análisis de la densidad confrontando el indicador de viviendas por hectárea ya estudiado con el de personas por hectárea que se describe a continuación.

De esta manera se encuentra la densidad de población, definida como el número de individuos de la misma especie que viven en una unidad de superficie, en este caso personas por hectárea. 
Debido a la complejidad de las unidades de convivencia actuales, es necesario diferenciar entre los factores anteriores (densidad de población y densidad de viviendas) ya que en una misma casa crecedera se pueden tener, con el tiempo, dos hogares diferentes. De modo que, sin alterar la densidad poblacional, es decir, manteniendo el número de habitantes por hectárea y transformando únicamente la composición familiar, se puede llegar a alcanzar una mayor complejidad y densidad de relaciones sociales que como pueden derivar en la propuesta de nuevos usos y asociaciones locales, afectan de manera indirecta al tejido urbano, tal y como indica en sus estudios Teddy Cruz (Cruz, 20I2).

Concretamente en el caso de los ejemplos analizados podemos observar que en todos hay una tendencia a la densificación. (Tabla 19). En la fase inicial se detecta una notoria diferencia entre la densidad poblacional de la arquitectura colectiva y la multifamiliar, siendo la de la primera más elevada. Sin embargo, una vez que se llega a la fase expandida, dos de los casos de vivienda multifamiliar, la Población René Schneider (con sistemas de ampliación por delimitación, extrusión y adición horizontal en jardines) y las viviendas para PREVI (con los mismos sistemas de ampliación por extrusión y delimitación) sobrepasan la densidad poblacional de algunos de los casos de vivienda colectiva. Esto se debe a que los modelos aplicados en estas agrupaciones multifamiliares de tipo social están diseñados para albergar más habitantes por vivienda que el resto de casos gracias a su distribución inicial, de forma que a pesar de que no aumenta el número de viviendas, el número de personas por hectárea puede aumentar notablemente.

\section{Densidad poblacional}

\begin{tabular}{|l|c|}
\hline Square L-type system & $174 \mathrm{px} / \mathrm{ha}$ \\
Quinta Monroy & $204 \mathrm{px} / \mathrm{ha}$ \\
Öberbauung Brahmshof & $288 \mathrm{px} / \mathrm{ha}$ \\
\hline Multifamiliar que crece & $160 \mathrm{px} / \mathrm{ha}$ \\
\hline Población René Schneider & $138 \mathrm{px} / \mathrm{ha}$ \\
\hline Sectional housing system Espansiva & $12 \mathrm{px} / \mathrm{ha}$ \\
\hline II Rigo Quarter & $50 \mathrm{px} / \mathrm{ha}$ \\
Viviendas para PREVI & $116 \mathrm{px} / \mathrm{ha}$ \\
\hline
\end{tabular}

\begin{tabular}{|c|c|}
\hline Square L-type system & $707 \mathrm{px} / \mathrm{ha}$ \\
\hline Quinta Monroy & $408 \mathrm{px} / \mathrm{ha}$ \\
\hline Überbauung Brahmshof & $288 \mathrm{px} / \mathrm{ha}$ \\
\hline Multifamiliar que crece & $240 \mathrm{px} / \mathrm{ha}$ \\
\hline Población René Schneider & $276 \mathrm{px} / \mathrm{ha}$ \\
\hline Sectional housing system Espansiva & $40 \mathrm{px} / \mathrm{ha}$ \\
\hline || Rigo Quarter & $150 \mathrm{px} / \mathrm{ha}$ \\
\hline Viviendas para PREVI & $261 \mathrm{px} / \mathrm{ha}$ \\
\hline
\end{tabular}

Tabla 19. Densidad poblacional (px/ha) de los ocho casos de estudio. Vivienda semilla y fase extendida.

El mayor incremento de densidad poblacional en agrupaciones colectivas de vivienda se da en aquellos casos que utilizan mecanismos de ampliación basados en el incremento de volumen, como es el caso de Quinta Monroy. Y especialmente se puede identificar cuando aparece la ampliación por extrusión, como se observa en el ejemplo del Square L-type System. Sucede de igual manera en las agrupaciones multifamiliares, donde la variación más significativa de densidad poblacional se da en los ejemplos que combinan la extrusión y la delimitación, la Población René Schneider y las Viviendas para PREVI.

Otro de los indicadores analizados es la compacidad (\%), que es la cualidad de compacto o condensado y se refiere a aquellos cuerpos que tienen una textura o estructura apretada y poco porosa. Aplicado a este análisis urbano, el concepto se refiere a la porosidad del tejido urbano vinculado a la morfología de las viviendas. 
Se mide en sección y relaciona la posibilidad máxima de construcción permitida por normativa, con la edificación levantada hasta el momento de estudio. Obteniéndose el 100\% de la porosidad cuando el espacio en sección se encuentra colmatado u ocupado totalmente de acuerdo a lo establecido por la legislación.

Se pueden identificar dos situaciones distintas, el caso en el que la compacidad va aumentando en el tiempo y en el que dicha compacidad es constante, porque por ejemplo se ha alcanzado el $100 \%$ de su valor en la primera fase, como se observa en el caso Überbauung Brahmshof. (Tabla 20).

El fenómeno está directamente asociado al tipo de mecanismo de ampliación utilizado, ya sea que se utilice un crecimiento con incremento de volumen o uno con volumen constante.

Se puede observar en el caso de Square L-type System, que inicia con un 4I,99\% de compacidad y llega al $100 \%$, que no sólo se aumenta este indicador gracias a los crecimientos de las viviendas mediante mecanismos de ampliación con incremento de volumen por adición horizontal en jardines, si no también por la adición de nuevas casas en horizontal, pero sobre todo en vertical compactando al máximo el grupo.

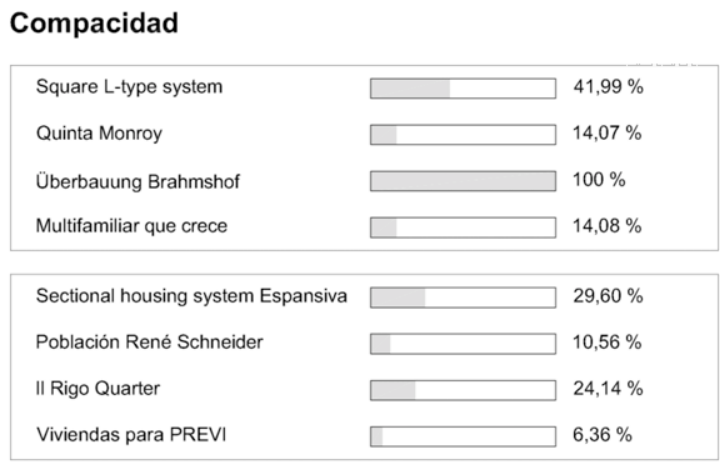

\begin{tabular}{|l|l|}
\hline Square L-type system & $100 \%$ \\
Quinta Monroy & $33.12 \%$ \\
Uberbauung Brahmshof & $100 \%$ \\
Multifamiliar que crece & $23,41 \%$ \\
\hline Sectional housing system Espansiva & \multicolumn{2}{|}{$53,66 \%$} \\
Población René Schneider & $50,27 \%$ \\
II Rigo Quarter & $39,93 \%$ \\
Viviendas para PREVI & $51,28 \%$ \\
\hline
\end{tabular}

Tabla 20. Compacidad (\%) de los ocho casos de estudio. Vivienda semilla y fase extendida.

Cabe destacar la notoria transformación de los casos de la Población René Schneider y las Viviendas PREVI, que pasan a aumentar hasta cinco veces su compacidad. Esto se debe a principalmente a que son los dos casos que utilizan el mecanismo de ampliación por delimitación, con el que se cubren los patios o huecos existentes en planta baja o alta, y que posteriormente se combinan con extrusiones, compactando notablemente la sección.

El último de los factores comparados en este análisis general de casos es el de la ocupación (\%).

La ocupación, entendida como acción o efecto de ocupar se refiere a la toma de posesión de un territorio o de un lugar al instalarse en él. Este indicador analiza en términos urbanos la proporción de suelo construido por vivienda, relacionando los metros cuadrados construidos en planta con la superficie total del lote. Analiza por tanto la porosidad del tejido urbano al igual que el indicador de la compacidad, pero mientras que el primero la analiza en corte este indicador la estudia en planta.

Los rangos de ocupación de suelo son similares tanto en el caso de agrupaciones colectivas como multifamiliares, existiendo dos casos multifamiliares (Sectional Housing System Expansiva y las Viviendas para PREVI) que ocupan menos porcentaje de suelo que los casos de vivienda colectiva. (Tabla 21 ). 
Se ha considerado que mediante la combinación de los resultados del estudio de la ocupación y la compacidad se podrá identificar el tipo de ampliación que se esté utilizando.

Por ejemplo, en el caso de Quinta Monroy y debido a que las viviendas eran para la reubicación de familias que vivían en el mismo lugar hacinadas y con problemas de habitabilidad, seguridad y diferenciación de propiedades. El proyecto buscaba un conjunto denso pero con grandes espacios comunes que permitieran el control general de la unidad y el paso del aire y la luz a las viviendas gracias a la permeabilidad obtenida con la disposición de estas. De manera que la reducida ocupación del 38,99\% permanece constante de la primera a la última fase indicando que no se usan crecimientos con incremento de volumen como son la adición horizontal en jardines, la adición en voladizos, la expansión, la delimitación o la ocupación horizontal. Sin embargo y debido a la variación en la compacidad a casi el doble de la primera a la última fase, se podría considerar la posibilidad de la existencia de crecimientos del tipo adición vertical en terrazas, ocupación vertical y adición vertical (siendo los dos últimos los que efectivamente se dan en este caso de estudio).

\section{Ocupación}

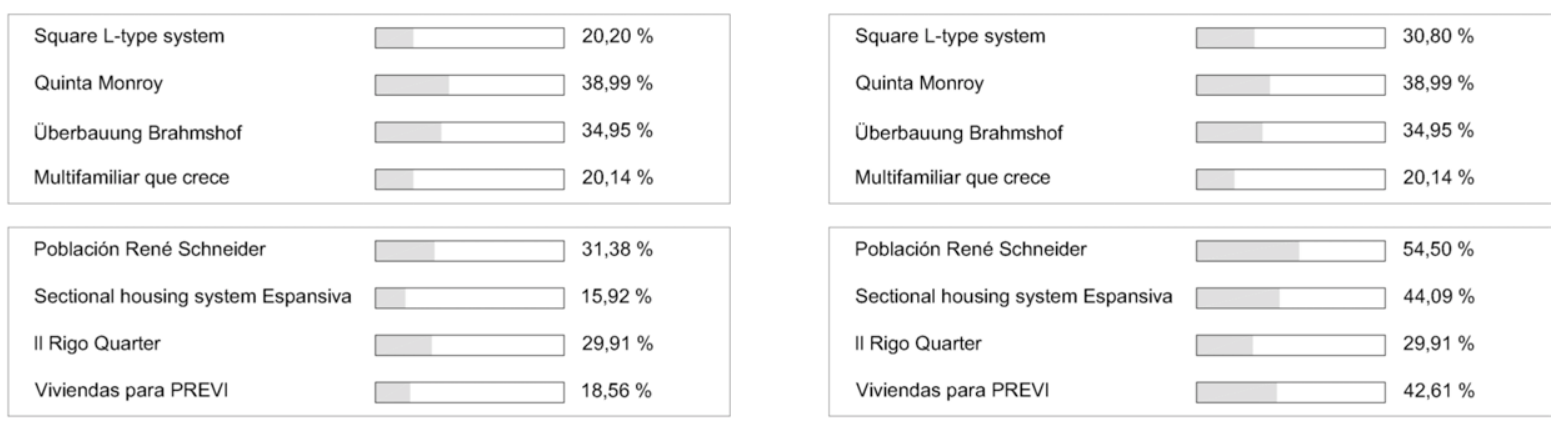

Tabla 2I. Ocupación (\%) de los ocho casos de estudio. Vivienda semilla y fase extendida.

Al igual que en caso de la compacidad, la ocupación lógicamente no varía, en los casos en los que se utilizan mecanismos de ampliación sin incremento de volumen (Überbauung Brahmshof, Multifamiliar que crece e II Rigo Quarter). Mientras que en los casos en los que se utilizan crecimientos por delimitación o adición horizontal en jardines el aumento de la ocupación es notable.

Las posibilidades que da el uso de vivienda crecedera en conjuntos arquitectónicos colectivos o multifamiliares para la transformación de la ciudad en términos de variaciones de densidad, compacidad y ocupación son numerosas y de acuerdo a los mecanismos de ampliación utilizados las transformaciones se podrán percibir en el paisaje urbano a simple vista (en el caso de crecimientos con incremento de volumen) o suceder de manera sumergida sin ser apreciado visualmente en el día a día del habitante de la ciudad (como ocurre al utilizar mecanismos sin incremento de volumen).

La utilización de este tipo de viviendas transformables en el tiempo como grano de la ciudad permite, de acuerdo a un adecuado pre-diseño del espacio y programación de la evolución, que no solo se produzca un aumento de los factores anteriormente analizados, si no que en los casos que se requiera se pueda conseguir la reversibilidad de estos procesos reduciendo los factores estudiados de acuerdo a las necesidades del habitante y a las presiones sociales, demográficas, ecológicas, económicas, etc. del entorno urbano. 
4.c. Casos de estudio particular.

A continuación se analizarán exhaustivamente cada uno de los cuatro casos seleccionados en el apartado anterior:

\section{- Überbauung Brahmshof de Kuhn \& Fischer und Partner.}

\section{- Viviendas Quinta Monroy de ELEMENTAL.}

- II Rigo Quarter de Renzo Piano.

\section{- Población Rene Schneider de Percy Díaz.}

Para ello se han realizado una serie de fichas comparativas en las que se ilustran las fases de crecimiento de cada propuesta con sus plantas y axonometrías, detallando a mayor escala la vivienda semilla y la fase final. Tras estas fichas para la comprensión arquitectónica, se ha realizado otra serie de cuatro formatos dedicado a los patrones evolutivos. En ambos casos se ha analizado la propuesta de los arquitectos en términos espaciales y sociales. Y se ha interpretado, de acuerdo al mobiliario dibujado por los arquitectos en los planos de cada fase, que el número de habitantes de la unidad de convivencia está directamente relacionado con el número de camas de la casa.

Para complementar las fichas, estas se acompañan de un texto descriptivo del proyecto y un texto analítico sobre los patrones evolutivos de cada caso.

Todas las fichas se han realizado a la misma escala para que la comparación entre casos sea más sencilla y evidente. 
4.Casos de estudio 


\section{Überbauung Brahmshof de Kuhn \& Fischer und Partner.}

El proyecto se ubica en Suiza en la ciudad de Zúrich en un área residencial relativamente cercana al centro de la ciudad y bien comunicada con este mediante transporte público (tranvía y autobuses). En el año de su construcción por Kuhn \& Fisher, 199I, la densidad de la zona era de II8,69 viviendas por hectárea, mientras que en la actualidad la densidad ha aumentado a 121,68 viviendas por hectárea.

La propuesta a estudiar se encuentra en Brahmsstrasse números 22 y 24 y se trata de un bloque que tiene 10 viviendas por cada núcleo de escalera con una superficie total de I.52I,74 $\mathrm{m}^{2}$. El bloque se organiza en torno a un patio (Brahmshof) y mezcla distintos tipos de vivienda en función de su acceso. En la planta baja se encuentran los servicios comunitarios, el aparcamiento y la escalera común exterior que sirve a las galerías de las plantas impares. En la primera planta el acceso a las viviendas se realiza mediante una galería de dos metros de ancho que hace al mismo tiempo las veces de estancia y área de juegos. Desde ella se accede también a una serie de escaleras que dan paso a las viviendas pareadas de la segunda planta. Mientras que a la tercera planta se accede por una galería que se separa de la fachada de las casas en las zonas de servicio y sirve a cuatro viviendas dúplex. (Brahmshof Zürich, 1993).

La superficie media de las viviendas es de $80 \mathrm{~m}^{2}$ y constan en su versión básica de dos habitaciones, una de ellas con terraza, una sala de estar-comedor-cocina con terraza, un baño completo y un pequeño recibidor. Solo el acceso, el baño y la cocina son fijos y el resto de habitaciones, todas cuadradas y de $14 \mathrm{~m}^{2}$ son espacios indefinidos. Al no tener una función predeterminada se permite que cualquier espacio tenga cualquier uso. Además, y gracias a la construcción prefabricada mediante paneles de hormigón verticales, se permite la conexión horizontal y vertical entre los departamentos adyacentes, lo que permite una gran flexibilidad en el uso. (Schneider \& Till, 2007).

Las viviendas están orientadas noreste-suroeste y tienen ventilación cruzada, permitiendo que todas las estancias tengan ventilación e iluminación natural.

En cuanto al sistema de crecimiento previsto por los arquitectos, las viviendas se amplían de forma reversible mediante el procedimiento de la unión (joining together para Schneider \& Till). Partiendo de una vivienda semilla de $28,71 \mathrm{~m}^{2}$ que consta de un cuarto redondo que hace las veces de comedor, cocina, dormitorio y sala de estar, un baño, el acceso y una terraza. La vivienda puede llegar a crecer hasta ocupar 78,51 $\mathrm{m}^{2}$ mediante tres ampliaciones de 17,18 $\mathrm{m}^{2}, 15,43 \mathrm{~m}^{2}$ y $17,19 \mathrm{~m}^{2}$. Cada una de estas ampliaciones se realizan mediante una sencilla apertura en uno de los tabiques de yeso añadiendo una nueva habitación de $14 \mathrm{~m}^{2}$ a la vivienda. Este sistema al ser reversible da la posibilidad de que la vivienda crezca, pero que también esta se reduzca de tamaño. Por lo que una vez ampliada se puede regresar al estado inmediatamente anterior únicamente cerrando el hueco abierto anteriormente. Las ampliaciones están destinadas para una misma familia que requiere de este crecimiento por un déficit de espacio. Bien sea porque ha aumentado en número de miembros de la familia o porque esta requieren de más lugar de almacenaje o nuevas áreas para desarrollar diversas actividades. 

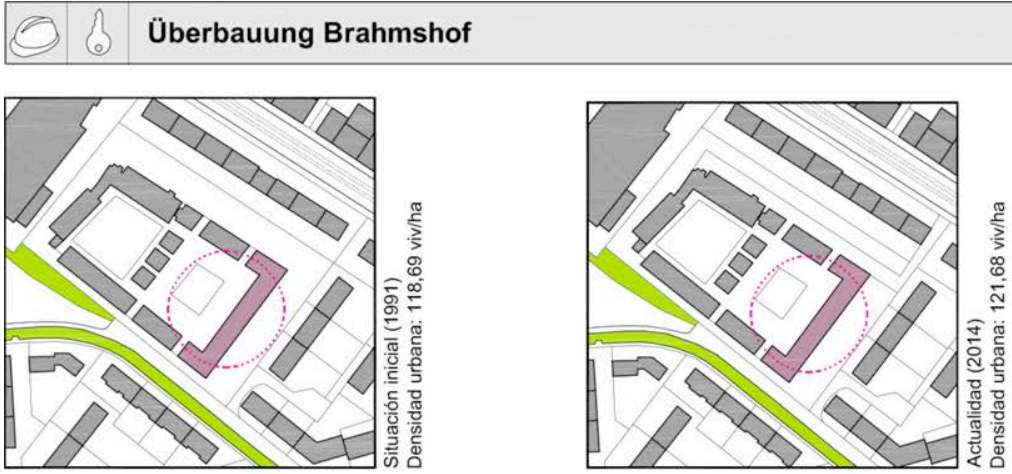

Kuhn \& Fisher, 1991 Suiza (EU)

Evolución de la vivienda en el tiempo

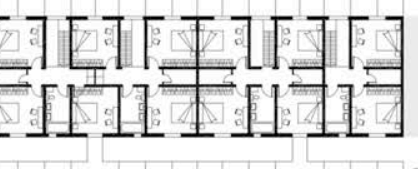

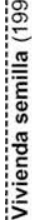

Fis]: [1]

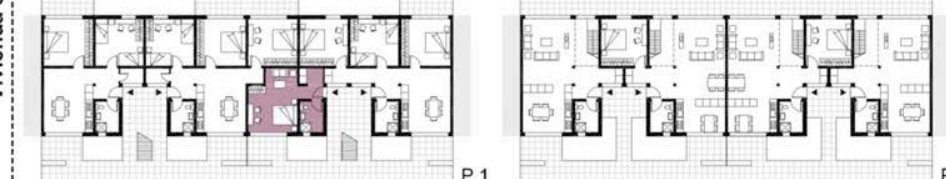

\section{P.2}
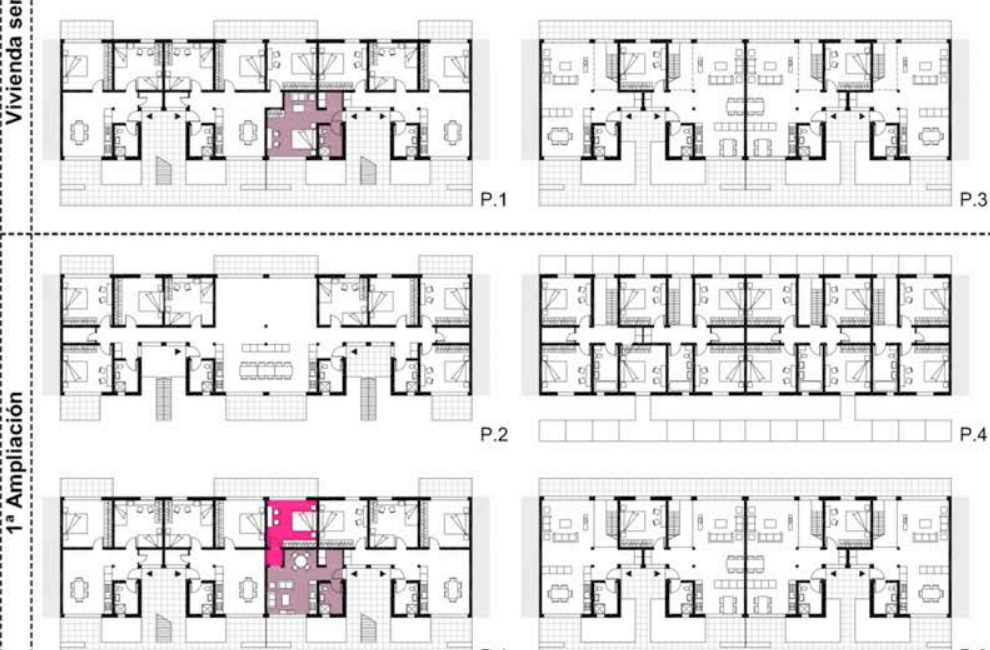

$\frac{0}{4}$

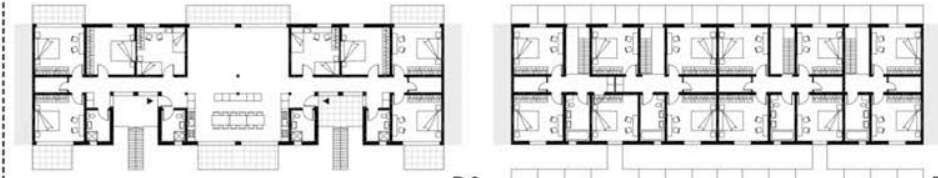

๙ P.

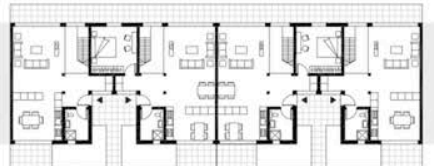

aj Li fulio

$$
\text { rj Litaj Lie }
$$

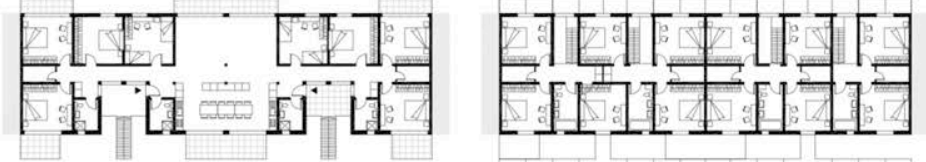

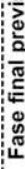
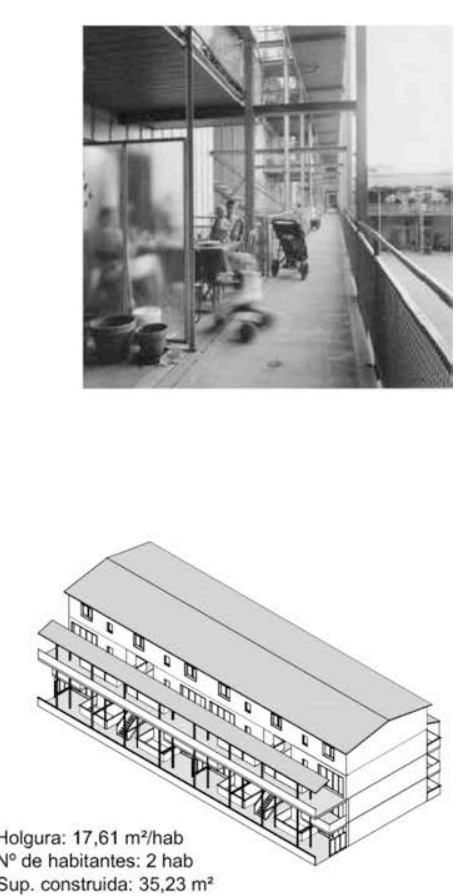

Sup. construida: $35,23 \mathrm{~m}$
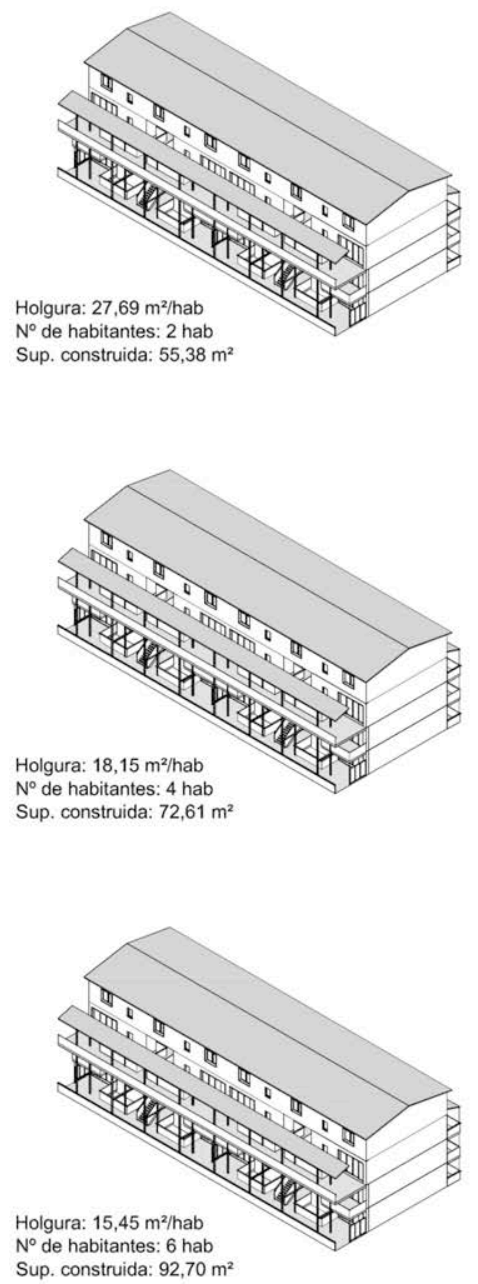

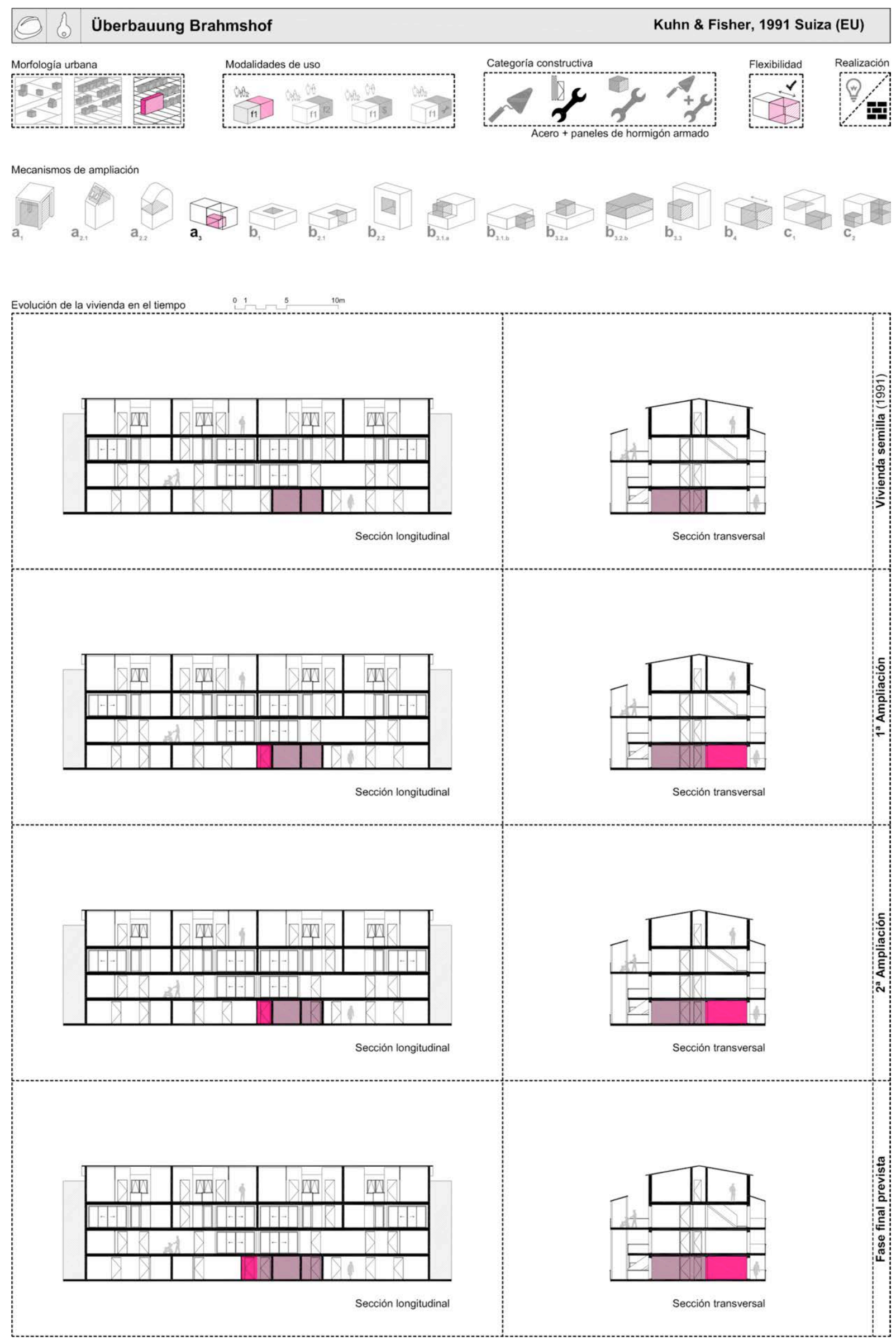

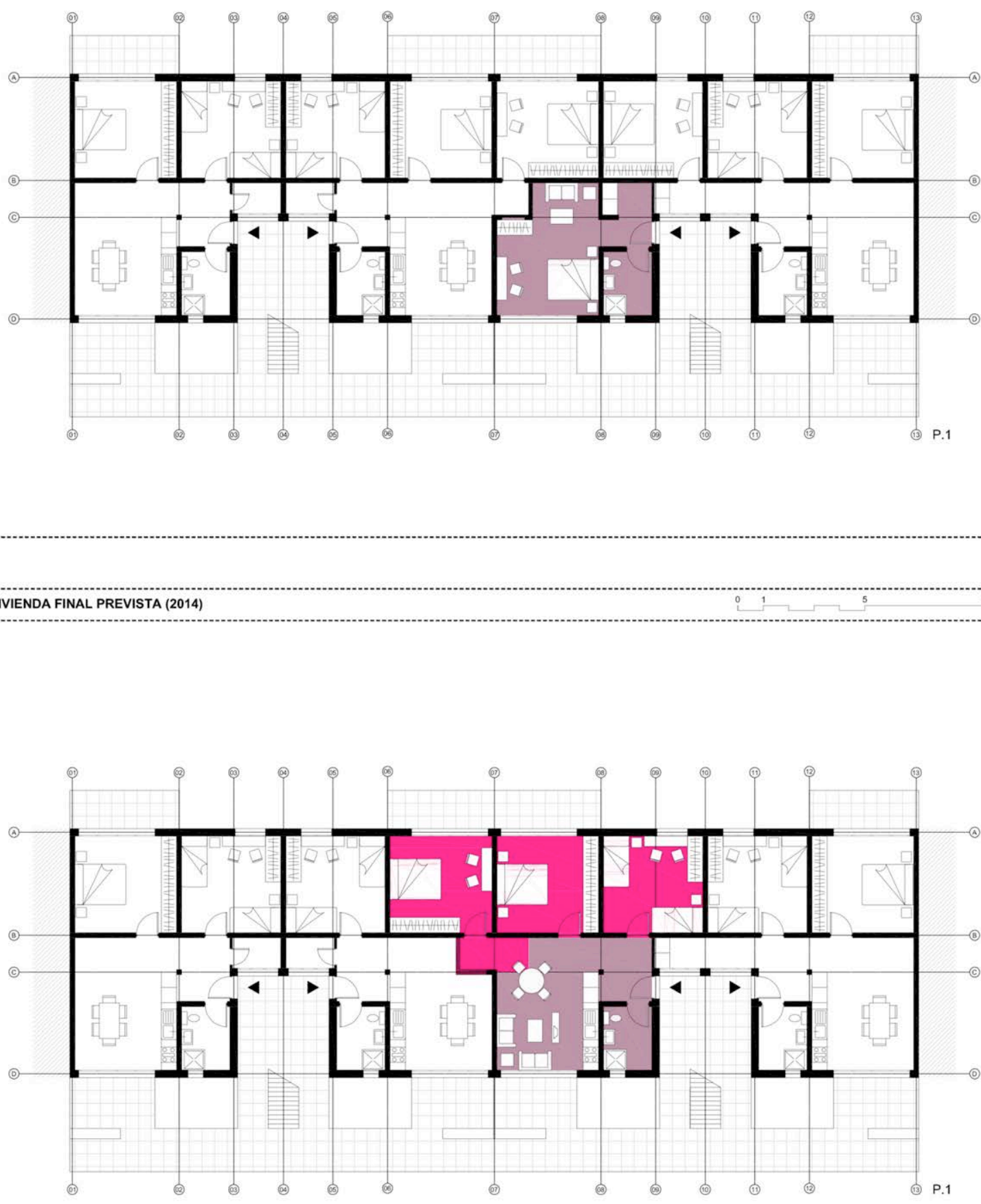


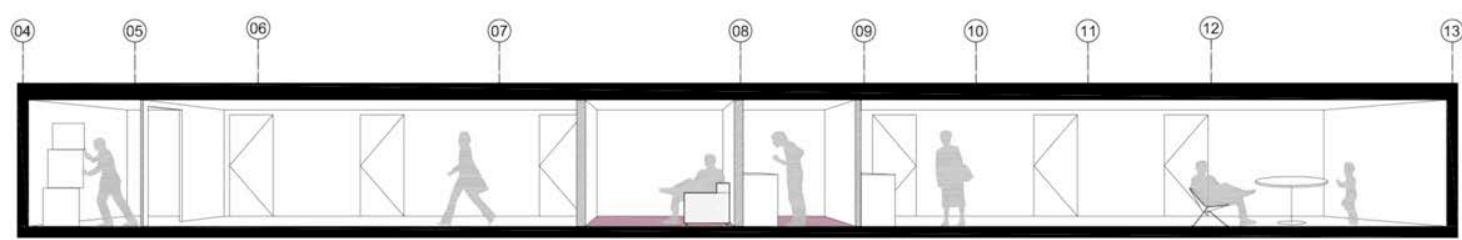

(B) (A) (C) (D)

vivienda 1

- vivienda 2

vivienda 3
A Unión de estancias contiguas
B Banda central para distribución de estancias
(C) Paramentos desmontables $y$ facilmente transformables
(D) Habitación polivalente, todas las estancias tienen la misma superficie y forma
(E) Paramentos que permiten abrir facilmente puertas en cualquier lugar

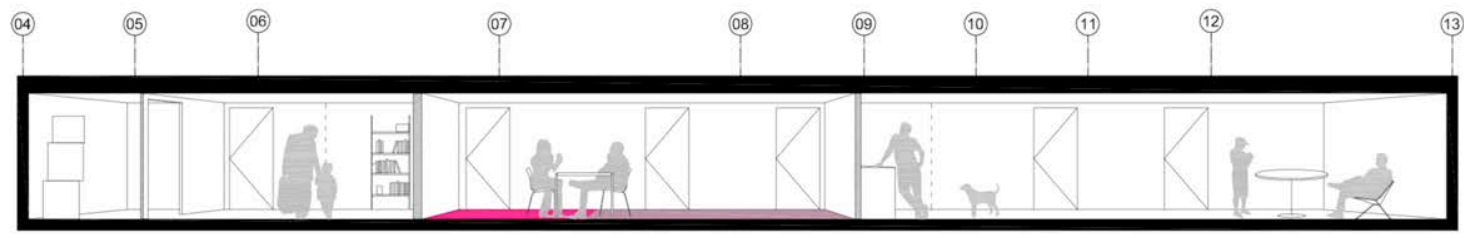

(C) (A) B

(E)

$\longleftarrow$ vivienda 1

- vivienda 2

vivienda 3
A Unión de estancias contiguas
B Banda central para distribución de estancias
(C) Paramentos desmontables $y$ facilmente transformables
(D) Habitación polivalente, todas las estancias tienen la misma superficie y forma
(E) Paramentos que permiten abrir facilmente puertas en cualquier lugar 

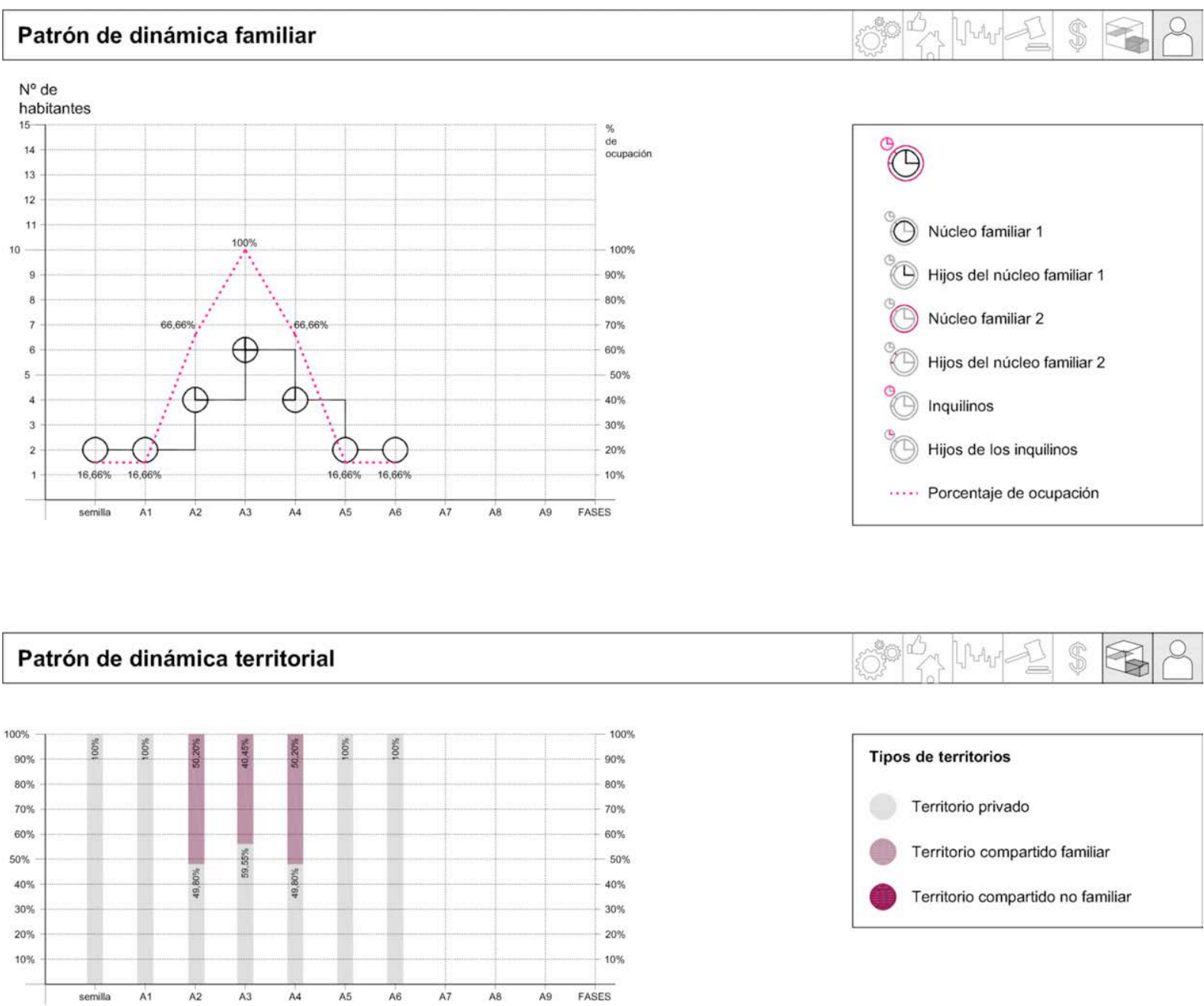

Tipos de territorios

Territorio privado

Territorio compartido familia

Territorio compartido no familiar

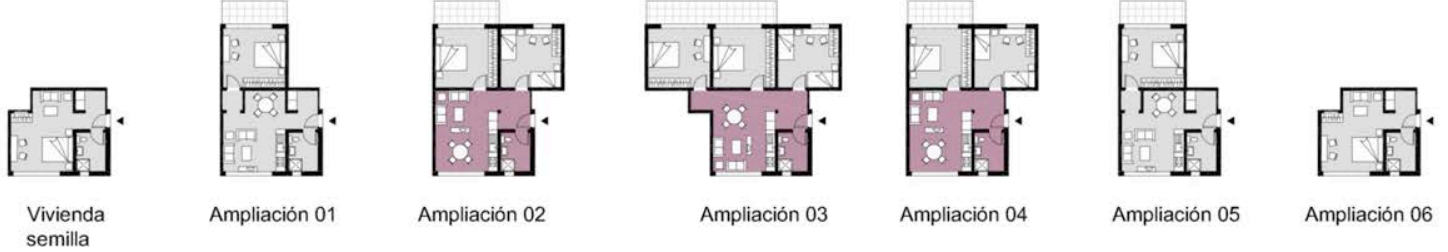

और

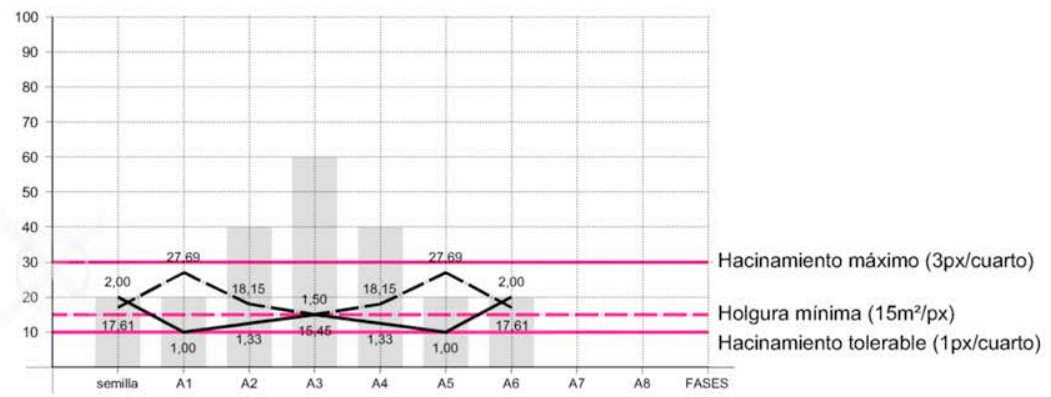

- Holgura $\left(\mathrm{m}^{2} / \mathrm{px}\right)$

- Holgura minima $\left(15 \mathrm{~m}^{2} / \mathrm{px}\right)$

— Hacinamiento (px/cuarto)

Hacinamiento máximo (3px/cuarto) Hacinamiento tolerable (1 px/cuarto)

Número de habitantes 


\section{Patrón de construcción progresiva}

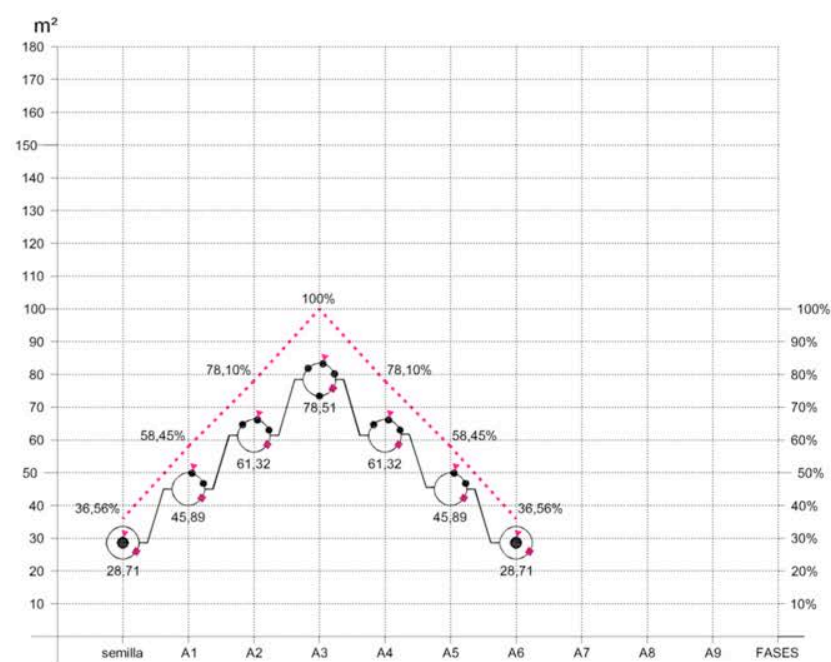

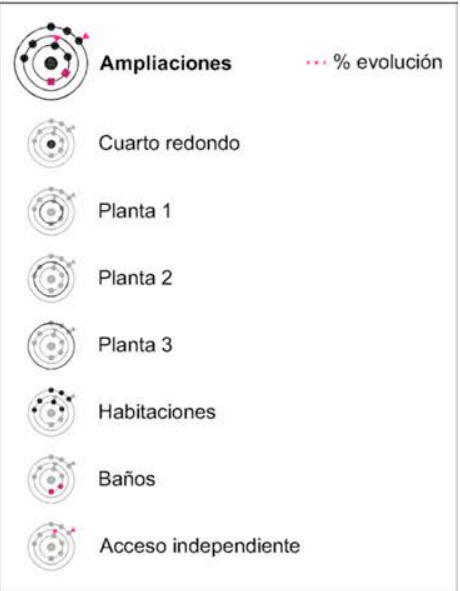

\section{Patrón de evolución espacial}
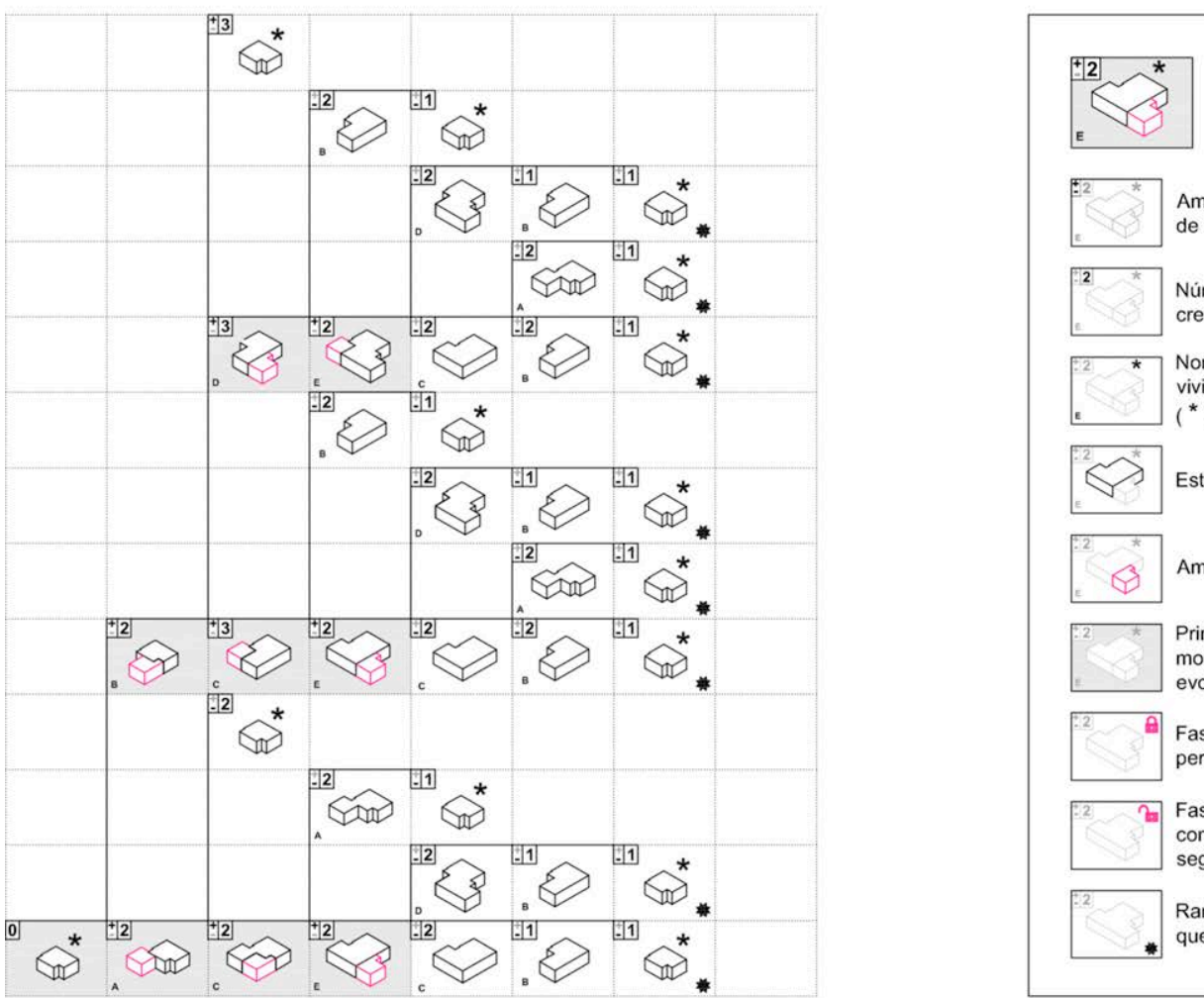

$2^{2} \quad$ Ampliación (+) o reducción (-) del espacio de la vivienda

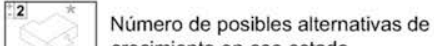
crecimiento en ese estado

2 * Nombre del estado momentáneo de la vivienda.

( ${ }^{*}$ Estado inicial o vivienda semilla)

Estado momentáneo de la vivienda

8. Ampliación de la vivienda

Primera vez que aparece ese estado momentáneo de la vivienda en su evolución

2 Fase restrictiva: la que si se realiza no permite continuar el crecimiento

Fase llave: la que si no se hace condiciona el crecimiento y no permite seguir ampliando más la vivienda

\section{$\bigodot_{\text {Número máximo de fases consecutivas }}^{*} \mathrm{~B}$}

$\rightarrow 0000000013$

Número máximo de posibles ramas de crecimiento 
Parámetros de evaluación de la calidad arquitectónica

$\begin{array}{llllllll}\text { VS } & \mathrm{A} 1 & \mathrm{~A} 2 & \mathrm{~A} 3 & \mathrm{~A} 4 & \mathrm{~A} 5 & \mathrm{~A} 6\end{array}$

\begin{tabular}{|c|c|c|c|c|c|c|c|c|}
\hline \multirow{8}{*}{ 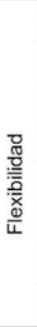 } & Espacio ambiguo & ? & ? & 중 & 숭 & ? & ? & - \\
\hline & Espacio comodin & ? & ? & ? & ? & ? & - & ○ \\
\hline & Transformación instantánea & ? & ? & ? & ? & ? & ? & - \\
\hline & Circulación y recorridos & - & ? & ? & ? & - & - & (2) \\
\hline & Más superficie útil (almacenaje) & - & ? & - & - & 20 & ? & 궁 \\
\hline & Concentración de superficies libres & ? & ? & 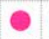 & ? & ? & - & O \\
\hline & Espacios - limite privados & - & ? & - & ? & 궁 & - & ? \\
\hline & Espacios - limite semipúblicos & ? & ? & ? & ? & ? & - & 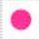 \\
\hline \multirow{6}{*}{ 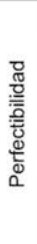 } & Soportes y unidades & ? & ? & - & - & ? & O & - \\
\hline & Vivienda inacabada & ? & - & - & ? & - & - & 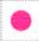 \\
\hline & Casa dispersa & ? & ? & - & ? & - & - & ? \\
\hline & Ventana perfectible & - & 당 & - & - & 중 & - & 웅 \\
\hline & Umbral inacabado & - & - & - & - & - & - & - \\
\hline & Acondicionamiento por capas & - & - & - & 숭 & - & - & - \\
\hline \multirow{7}{*}{ 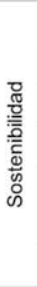 } & Instalaciones registrables & - & ? & ? & 숭 & 궁 & ? & - \\
\hline & Agrupación de núcleos húmedos & ? & ? & ? & - & ? & ? & (?) \\
\hline & Aprovechamiento espacial & ? & O & P & ? & P & ? & P \\
\hline & Optimización funcional de baños & ? & - & - & ? & - & - & - \\
\hline & Sombras arrojadas & ? & ? & ? & ? & (1) & ? & ? \\
\hline & Orientación & - & ? & O & 숭 & (2) & ? & O \\
\hline & Limite activo & - & - & - & - & - & - & 중 \\
\hline \multirow{7}{*}{ 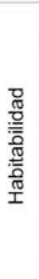 } & Ventilación cruzada & ? & ? & ? & ? & ? & ? & (2) \\
\hline & Ventilación natural necesaria & ? & ? & - & ? & - & - & ○ \\
\hline & Iluminación natural necesaria & - & ? & ? & ? & - & ? & ? \\
\hline & Hacinamiento & ? & ○ & ? & - & ? & ○ & O \\
\hline & Agua corriente & ? & ? & ? & - & - & ? & 0 \\
\hline & Drenaje & ? & ? & ? & ? & ? & ○ & (2) \\
\hline & Aspecto inconcluso & ? & ? & ? & ? & ? & ? & 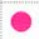 \\
\hline & & P & P & O & ? & ? & ? & O \\
\hline
\end{tabular}
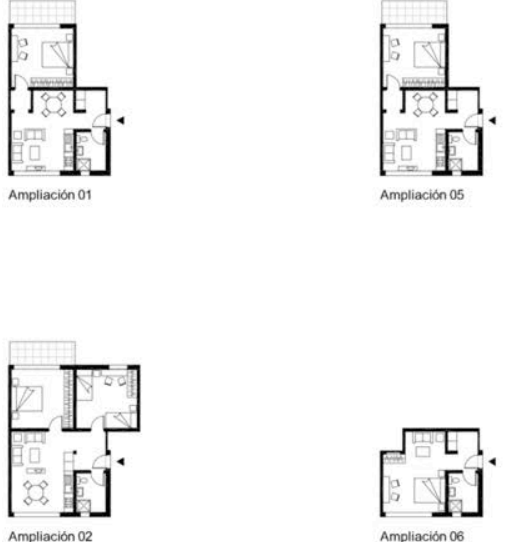

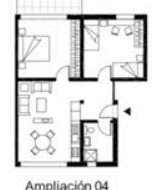<smiles></smiles>

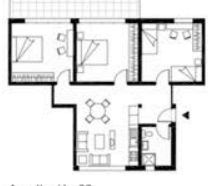

$50 \%$ Lo cumple a medias

$0 \%$ No lo cumple

Patio, escaleras y exterior del conjunto Überbauung Brahmshof.
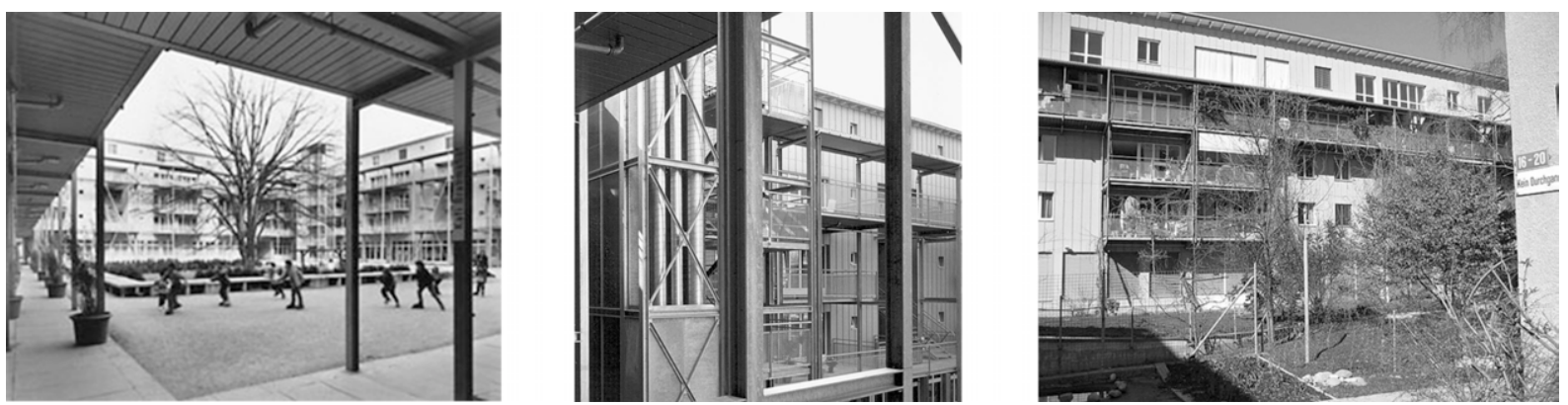


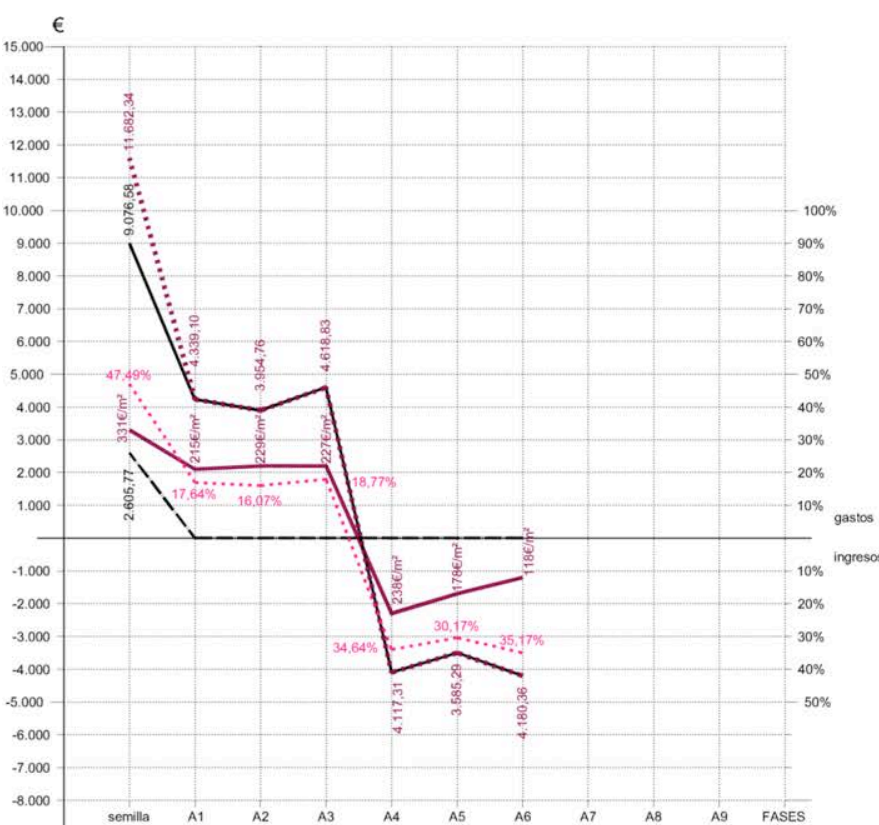

\begin{tabular}{lr}
\hline $11.682 €\left(331 € / \mathrm{m}^{2}\right)$ & Gasto viv. semilla \\
$4.339 €\left(215 € / \mathrm{m}^{2}\right)$ & Gasto ampliación 1 \\
$3.954 €\left(229 € / \mathrm{m}^{2}\right)$ & Gasto ampliación 2 \\
$4.618 €\left(227 € / \mathrm{m}^{2}\right)$ & Gasto ampliación 3 \\
$-4.117 €\left(238 € / \mathrm{m}^{2}\right)$ & Gasto decrecimiento 1 \\
$-3.585 €\left(178 € / \mathrm{m}^{2}\right)$ & Gasto decrecimiento 2 \\
$-4.180 €\left(118 € / \mathrm{m}^{2}\right)$ & Gasto decrecimiento 3
\end{tabular}

\begin{tabular}{|c|c|}
\hline $24.595 €\left(264 € / \mathrm{m}^{2}\right)$ & Gasto total por ampliación \\
\hline $11.882 €\left(317 € / \mathrm{m}^{2}\right)$ & Ingreso por decrecimiento \\
\hline
\end{tabular}

$\begin{array}{ll}\text { Gasto en estructura y cerramiento } \\ \ldots \ldots . . & \text { Gasto en acabados } \\ & \begin{array}{l}\text { Patrón de costo total de } \\ \text { construcción progresiva }\end{array} \\ \ldots . . . & \begin{array}{l}\text { Evolución porcentual del costo } \\ \text { total de construcción progresiva }\end{array} \\ & \text { Gasto total por metro cuadrado }\end{array}$
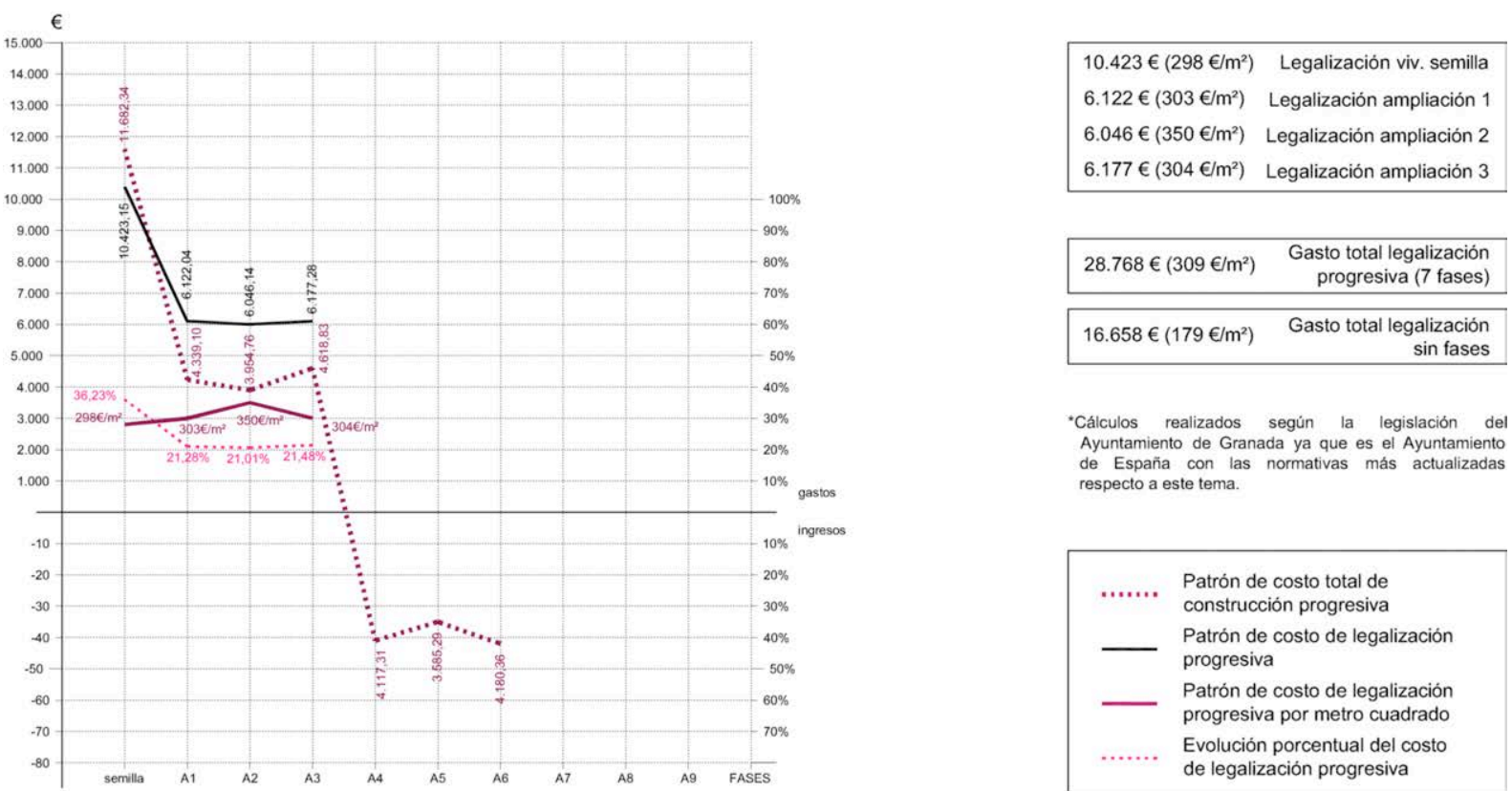

Patrón de costo total de construcción progresiva

Patrón de costo de legalización progresiva

Patrón de costo de legalización progresiva por metro cuadrado Evolución porcentual del costo de legalización progresiva 


\section{a. Patrón de dinámica familiar.}

El patrón de crecimiento que implícitamente proponen los arquitectos según los planos de Überbauung Brahmshof es un patrón piramidal sin excesivas complejidades. El crecimiento progresivo propone un aumento de hasta seis miembros en la unidad familiar, para que una vez alcanzado el máximo se vuelva a reducir el número de miembros hasta llegar a la situación inicial. Este tipo de crecimiento es característico de las unidades familiares europeas de las últimas décadas, en las que los núcleos iniciaban con una pareja, crecían, y gracias a su poder adquisitivo los hijos podían independizarse a edad temprana dejando a los padres solos en la vivienda familiar.

\section{b. Patrón de dinámica territorial.}

Debido a que la vivienda semilla, al igual que todas las futuras ampliaciones, está destinada a un único núcleo familiar, el espacio de ésta es esencialmente territorio privado. Con ello los problemas de territorialidad con otras familias o con la propia familia, en caso de que se diesen familias extendidas, se reducen únicamente a los espacios de comunicación que sirven para acceder a la vivienda. Para evitar posibles problemas de privacidad en estas áreas de territorio compartido no familiar, los arquitectos han retranqueado las pasarelas de circulación común respecto de los espacios que requieren más privacidad como es el caso de los baños y han colocado bancos para sentarse donde la pasarela se ensancha, evitando que los usuarios puedan acercarse a los ventanales de las salas de estar disminuyendo de esta manera los posibles problemas derivados estos territorios compartidos. Como ya se ha mencionado en cuanto a la territorialidad en el interior de la vivienda, los territorios son privados o compartidos por la misma familia. En todas las fases la relación territorio privadoterritorio compartido es aproximadamente del $50 \%$ en cada caso.

\section{c. Patrón de holgura y hacinamiento.}

En cuanto al hacinamiento, todas las fases propuestas por los arquitectos están lejos del límite de hacinamiento máximo propuesto por la ONU, 3 personas por cuarto. Sin embargo no respetan el hacinamiento tolerable requerido por los estándares europeos (menos de una persona por cuarto), y únicamente se alcanza esta cifra en la primera y la quinta ampliación. Por otro lado, los límites de la holgura mínima ( $15 \mathrm{~m}^{2}$ por persona), son respetados en todas las fases salvo en la de mayor número de habitantes (la tercera ampliación) donde el número de metros cuadrados por persona se encuentra por debajo de lo deseado.

\section{d. Patrón de construcción progresiva.}

En cuanto al patrón de construcción progresiva, este está directamente vinculado al de la dinámica familiar. La ampliación de la superficie construida es del orden del 21,89\% aproximadamente en cada fase.

El crecimiento lineal, organizado y constante que se da en los ámbitos de la dinámica familiar y de la construcción progresiva responde y se puede dar gracias al orden interno de la estructura del edificio. Al tratarse de un crecimiento sin incremento de volumen realizado a través del mecanismo de adición, las ampliaciones responden a los tamaños establecidos de las estancias existentes. Para ello los arquitectos modularon las habitaciones de manera que todas ellas fueran del mismo tamaño $\left(14 \mathrm{~m}^{2}\right)$ y que pudieran 
dedicarse indiferentemente a cualquiera de las funciones de la casa (dormitorio matrimonial, individual, estudio, estar, comedor...). Se puede observar que en un primer momento la vivienda funciona como un cuarto redondo donde en un único espacio se desarrollan las funciones de cocina, sala-comedor y dormitorio. Sin embargo y a medida que esta se amplía, las funciones se van descomprimiendo espacialmente trasladando el dormitorio a la nueva estancia. Cada nueva estancia, del mismo tamaño que la anterior da la posibilidad de albergar sin problemas tanto a dos camas individuales como una cama matrimonial y el proceso funciona perfectamente tanto en el sentido de la adición como en el de la sustracción de dichas habitaciones.

\section{e. Patrón de evolución espacial.}

El tipo propuesto por Kuhn \& Fisher es lo suficientemente adaptable como para permitir el crecimiento siguiendo 13 caminos (ramas) diferentes. No posee ni fases llave ni fases restrictivas, más allá de las fases que alcanzan el espacio máximo de ampliación. Esto da mucha libertad al posible crecimiento a pesar de parecer en un primer momento que la estructura y el hecho de ser un crecimiento por unión puedan condicionar altamente el proceso.

\section{f. Patrón de evolución cualitativa de la vivienda.}

La vivienda tiene en general una calidad arquitectónica aceptable a lo largo de todas sus fases. Su puntaje global es muy homogéneo destacando positivamente la primera fase de ampliación un 3\% respecto de las anteriores.

De todos los aspectos, los referidos a la optimización y la perfectibilidad interior de la vivienda destacan como sobresalientes con un puntaje del $83 \%$ en prácticamente todas las fases. Esto es debido a que el mecanismo de ampliación utilizado es el de la unión y este requiere de una potencial posibilidad de reorganización y ocupación interior no solo a nivel espacial, si no también a nivel constructivo, que permita realizar los procesos de modificación y división interior necesarios. Este énfasis en la transformabilidad del espacio interior a través de sistemas prefabricados proporciona como contrapunto una escasa relación del interior con el exterior a nivel de flexibilidad (con un puntaje del 33,33 sobre 100) y de perfectibilidad (0 sobre 100). Esa flexibilidad interior no se refleja en la fachada, que permanece invariable a pesar de los posibles cambios de uso interiores, a no ser que se añadan posteriormente otros elementos que permitan su variación (persianas, mosquiteras, cortinas...).

A nivel de sostenibilidad la propuesta es igualmente aceptable en cuanto a la optimización interior en todas sus fases $(50 \%)$. Gracias a la optimización de las instalaciones organizadas en núcleos húmedos que corresponden junto al acceso, la fachada y la estructura a las únicas partes fijas del edificio. Sin embargo, en cuanto a la relación interior-exterior el proyecto no es una respuesta involucrada en este aspecto ya que no atiende especialmente a las orientaciones lo que hace que el puntaje se reduzca.

\section{g. Patrón de costo de construcción progresiva.}

En lo referido a los costos de la construcción se puede observar que este patrón tiene dos momentos clave.

El correspondiente a la primera fase en el que se observa el mayor gasto en construcción (47,49\% del total). Que se debe a que el bloque de viviendas se completa desde un inicio incluyendo acabados. De manera que el costo se divide por metros cuadrados entre cada uno de los habitantes, pagando menor cantidad el que menos 
metros cuadrados utiliza. Por lo que una vez realizado el gran desembolso inicial, las ampliaciones posteriores serán proporcionalmente siempre más baratas dado que la operación de ampliación es muy básica (abrir un hueco en una pared prefabricada y preparada para ello sin necesidad de añadir acabados).

A pesar de que se contabilice en el gasto el precio de compra de los nuevos metros cuadrados (contando para ello únicamente el costo material de construcción), como los metros cuadrados añadidos son mucho menores que los adquiridos en la vivienda semilla el gasto será menor.

La segunda fase importante del proceso evolutivo de Überbauung Brahmshof en términos del costo de construcción progresiva, es el proceso de decrecimiento. En este momento, a pesar de las modificaciones espaciales y los gastos que esta obra conlleva, el hecho de tener una pérdida de espacio implica una ganancia de dinero por lo que en estas fases el costo de construcción progresiva acaba siendo una cifra negativa. Es decir, la familia gana dinero con el decrecimiento. En este caso, el gasto por ampliación total de la vivienda a estudiar es de 24.595,03 $€$, mientras que el ingreso por decrecimiento es de $1 \mathrm{I} .882,96 €$ quedándonos con una vivienda idéntica a la vivienda semilla. Esto implica que en el proceso global de evolución la inversión total sería de I2.7| $2,07 €$ un gasto $48 \%$ menor de lo que hubiera sido si no se hubieran empleado sistemas de decrecimiento que permiten recuperar dinero cuando parte de la vivienda se queda obsoleta.

\section{h. Patrón de costo de legalización.}

La evolución del patrón de costo de legalización tiene una tendencia similar al del costo de la construcción. Este inicia con una potente inversión del $36,23 \%$ de costo total para la legalización de toda la vivienda que es prácticamente igual que el costo de la construcción en esa fase $(10.423,15 €$ en concepto de legalización de la vivienda semilla frente a $1 \mathrm{I} .682,34 €$ en concepto de costo de construcción de la vivienda semilla). Una vez realizada esta operación el costo de legalización del resto de las fases se reduce un 15\%, pero en todos los casos este gasto acaba siendo superior al costo de la construcción progresiva $(6.122,04 €$ de costo de legalización en la segunda fase frente a 4.339,10 € de costo de la construcción) lo que podría hacer que los usuarios se plantearan si realizar las operaciones sin legalizarlas debido a la gran inversión que el proceso supone. 


\section{Viviendas Quinta Monroy de ELEMENTAL.}

La propuesta de Quinta Monroy fue un complejo trabajo de radicación de un asentamiento informal compuesto por 93 familias ubicadas en el mismo lugar desde hacía aproximadamente 40 años. La Quinta Monroy se encuentra en una localización privilegiada en el centro de la población de lquique, muy cerca de la playa, de servicios y del terminal agropecuario. Con una parcela de $5,025 \mathrm{~m}^{2}$ de superficie y una densidad de 657 habitantes por hectárea, los arquitectos se enfrentaban a la reubicación de las 93 familias en ese mismo sitio, preservando la identidad y las raíces de los habitantes y mejorando sensiblemente la habitabilidad y la seguridad de estos, a través de un proceso de diseño participativo junto a los habitantes del asentamiento. (Aravena \& lacobelli, 2012).

Se decidió agrupar las viviendas en torno a cuatro patios, con accesos independientes y únicos de manera que estas pequeñas agrupaciones estimularan la organización de los habitantes y permitieran controlar fácilmente quien entra y quien sale al conjunto. Los arquitectos trataron de que la distancia entre las fachadas fuera la mayor posible (20 metros) y que los paramentos verticales y horizontales que dividieran las propiedades fueran de material solido (hormigón armado) dando una mayor seguridad en términos estructurales, de privacidad y de tenencia. (ELEMENTAL, 2008).

La principal decisión de proyecto fue que con el escaso presupuesto con el que se contaba se pudiera no sólo comprar el suelo de la Quinta, si no también construir las 93 viviendas. Por lo que únicamente se les entregó a los habitantes el $50 \%$ de su vivienda, que abarcaba aquellas partes de la casa más difíciles de construir (escaleras, baños y cocinas). Al entregarles este $50 \%$ a todos por igual, se conseguía a nivel de conjunto una identidad y una armonía común, que aunque luego se alterara parcialmente de acuerdo a las ampliaciones realizadas por cada habitante, les obligaba a tomar conciencia de que forman parte de una comunidad mayor integrándose con el resto de la ciudad formal. (Aravena \& lacobelli, 20I2).

Gracias a la porosidad que posee el edificio, los arquitectos suponen que las ampliaciones se darán de la forma más fácil posible (adición vertical y estructura cruda), lo que hará que las familias puedan completarlo de forma intuitiva mediante los mecanismos de estructura cruda, creación de nuevos forjados y ocupación vertical.

El conjunto está formado por dos tipos de viviendas, una casa en planta baja de $26,29 \mathrm{~m}^{2}$ construidos que se puede ampliar mediante el mecanismo de estructura cruda hasta los 55,35 $\mathrm{m}^{2}$. Y un apartamento de dos pisos que se encuentra sobre la casa $y$ al que se accede desde el patio por una escalera independiente. El apartamento, parte de $26,29 \mathrm{~m}^{2}$ construidos en los dos pisos y mediante adición de forjados y crecimiento por ocupación vertical puede alcanzar en sucesivas fases hasta los $67,96 \mathrm{~m}^{2}$. En ambos casos el programa de la vivienda inicia con un baño completo, un cuarto que hace las veces de salón, comedor y dormitorio y una cocina abierta a este. En su fase más extendida la casa pueda alcanzar a tener un baño, cocina abierta, salóncomedor y hasta dos dormitorios. Mientras que el apartamento llegará a tener baño, cocina abierta, salóncomedor y hasta tres dormitorios totalmente independientes. En todas las fases ambas viviendas están perfectamente ventiladas e iluminadas gracias a su agrupación y distribución que permite la ventilación cruzada. 


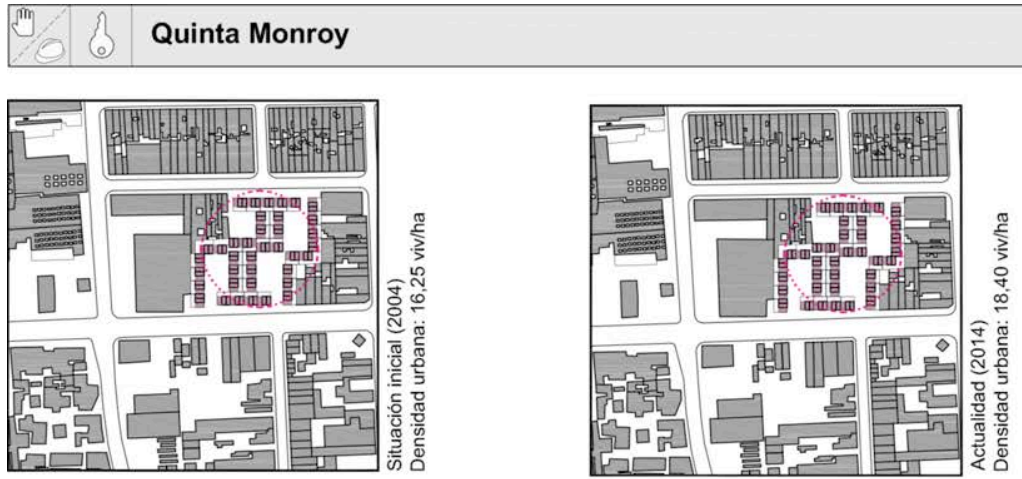

ELEMENTAL, 2004 Iquique (CHL)
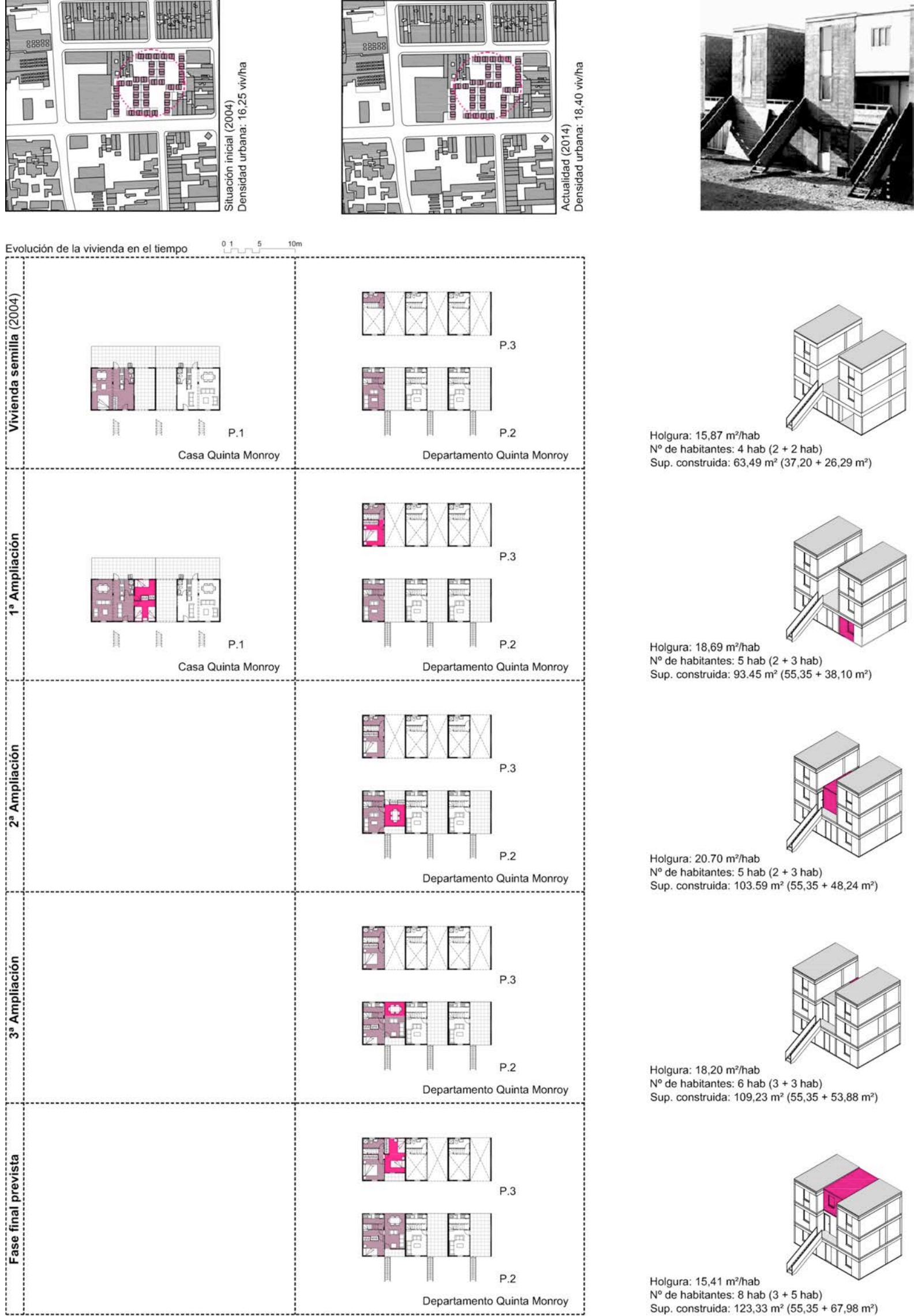

$N^{\circ}$ de habitantes: 4 hab $(2+2$ hab

Sup. construida: $63,49 \mathrm{~m}^{2}\left(37,20+26,29 \mathrm{~m}^{2}\right)$

Holgura: $18,69 \mathrm{~m}^{2} /$ hab

$N^{\circ}$ de habitantes: 5 hab $(2+3$ hab $)$

Sup. construida: $93.45 \mathrm{~m}^{2}\left(55,35+38,10 \mathrm{~m}^{2}\right)$

Holgura: $20.70 \mathrm{~m}^{2} / \mathrm{hab}$
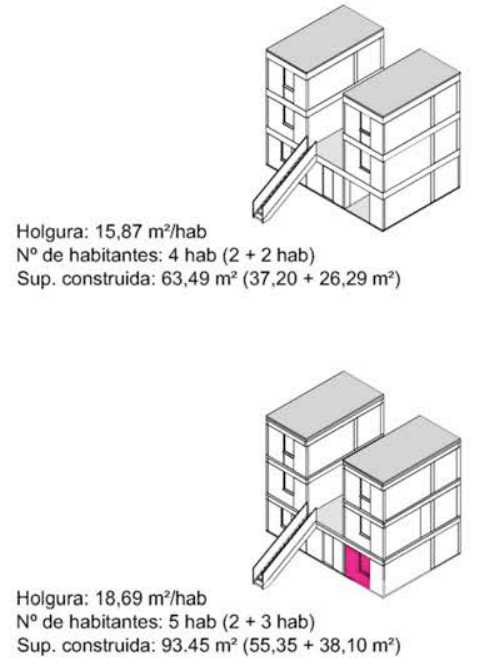

No de habitantes: 5 hab $(2+3$ hab $)$

Sup. construida: $103.59 \mathrm{~m}^{2}\left(55,35+48,24 \mathrm{~m}^{2}\right)$

Holgura: $18,20 \mathrm{~m}^{2} / \mathrm{hab}$

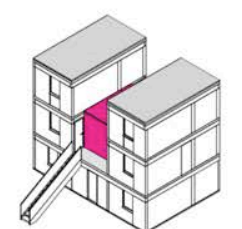

de habitantes: 6 hab $(3+3$ hab $)$

Sup. construida: $109,23 \mathrm{~m}^{2}\left(55,35+53,88 \mathrm{~m}^{2}\right)$

Holgura: $15,41 \mathrm{~m}^{2} / \mathrm{hab}$

$N^{\circ}$ de habitantes: 8 hab $(3+5$ hab $)$

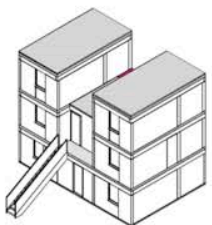

Sup. construida: $123,33 \mathrm{~m}^{2}\left(55,35+67,98 \mathrm{~m}^{2}\right)$

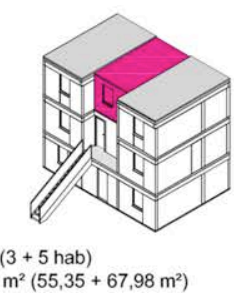




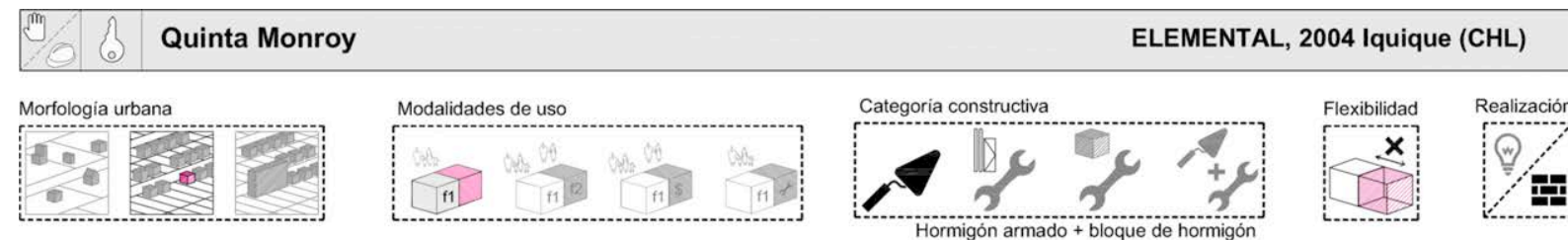
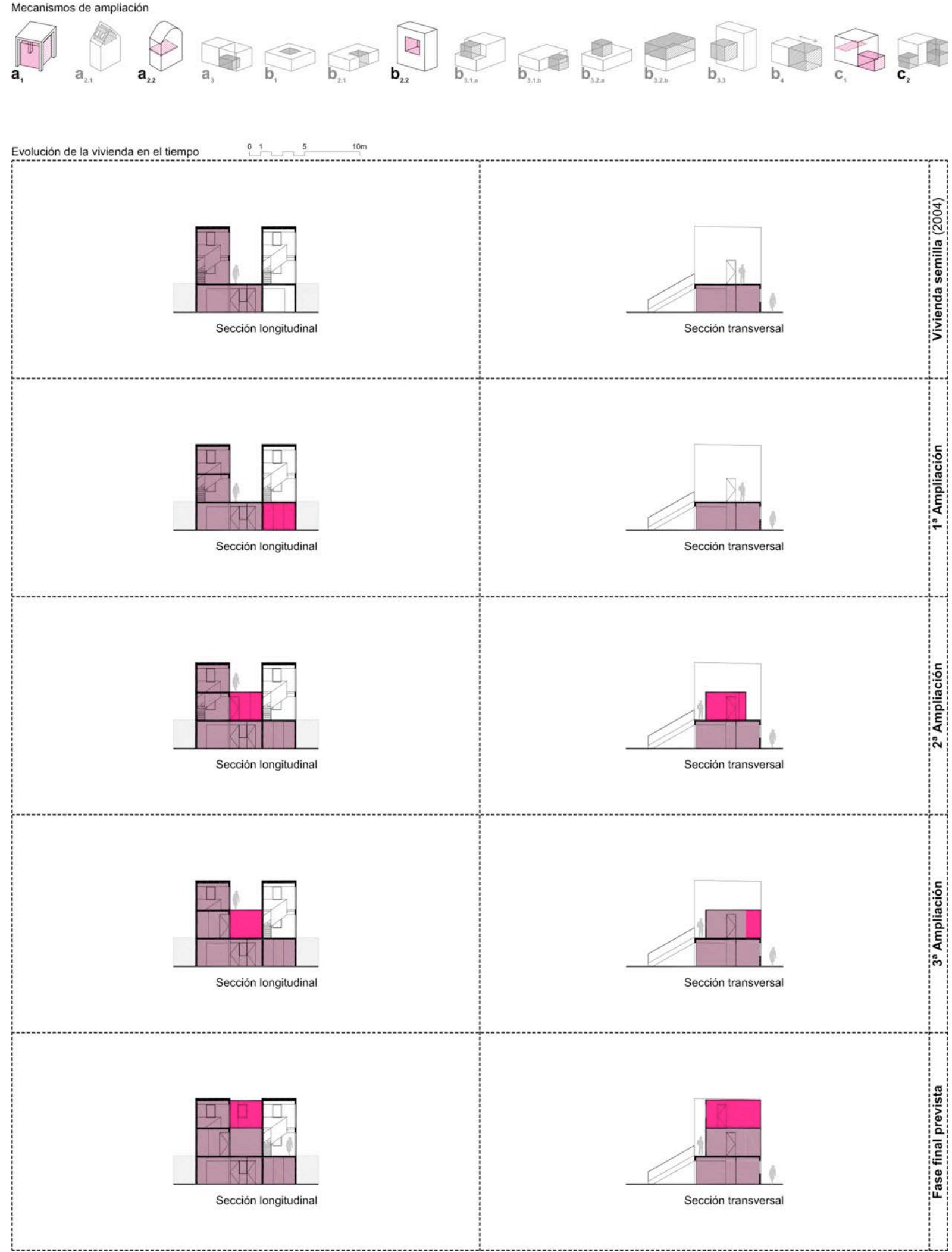

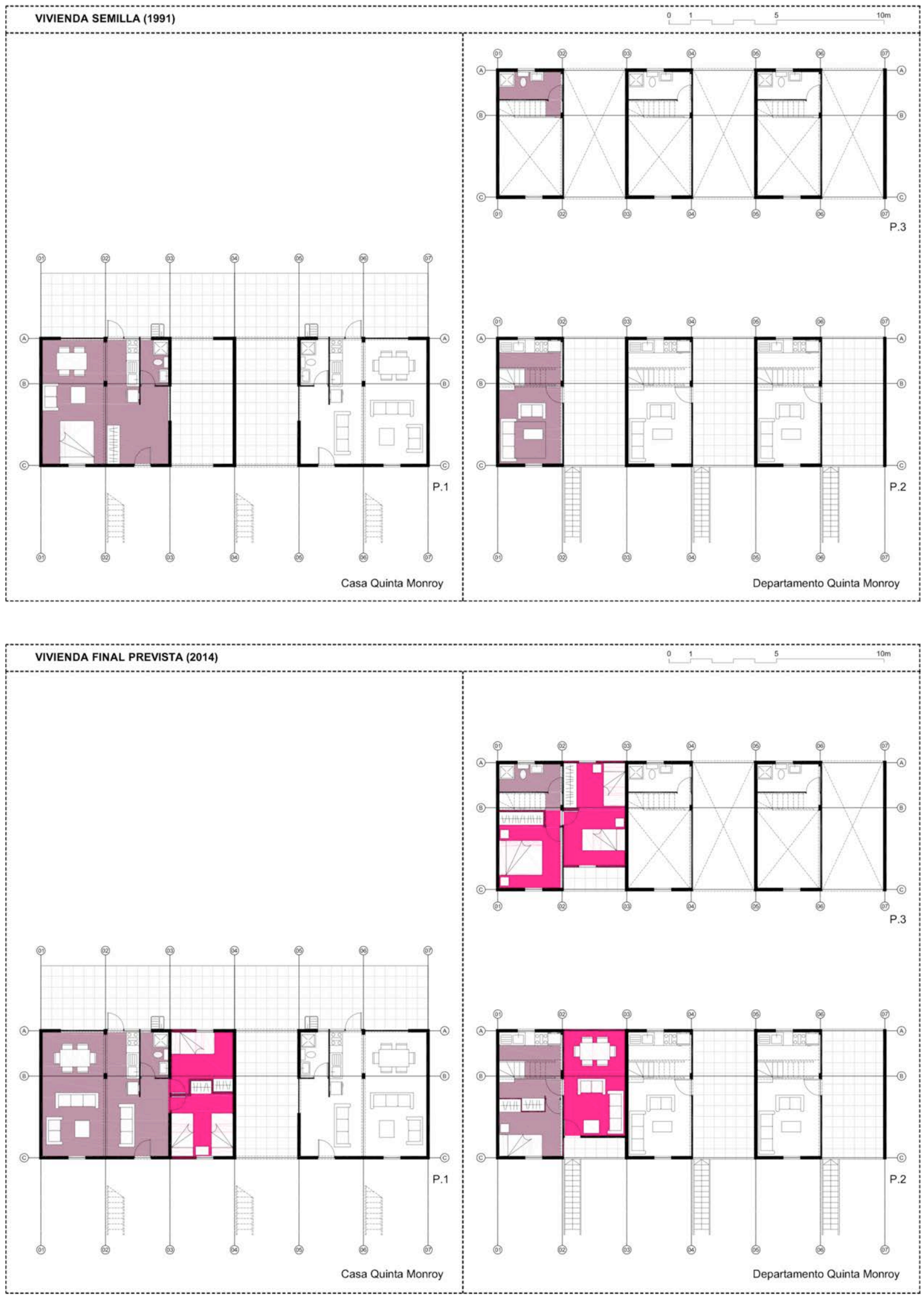


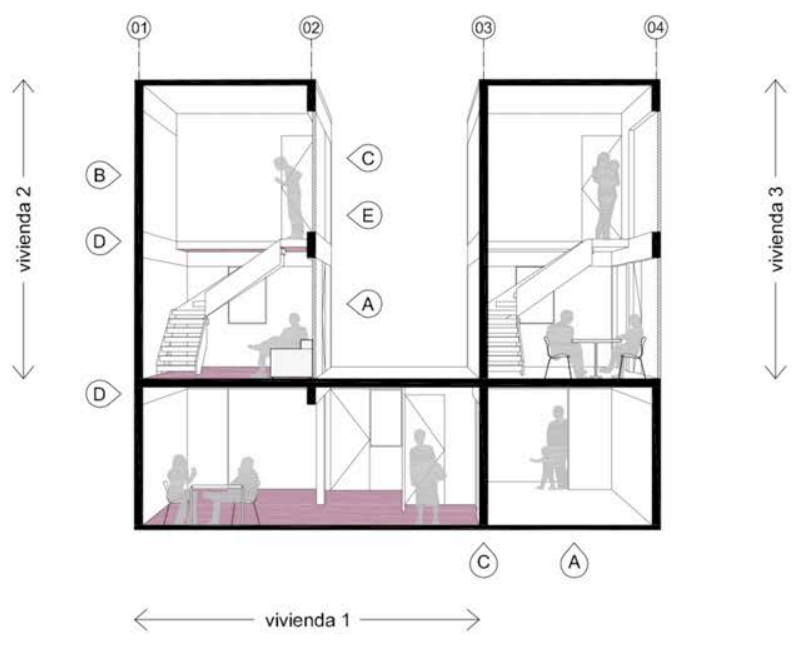
A Unión de estancias contiguas
(B) Sección ocupable
C Paramentos desmontables y facilmente transformables
(D) Sobredimensionamiento estructural
(E) Separación soporte cerramiento

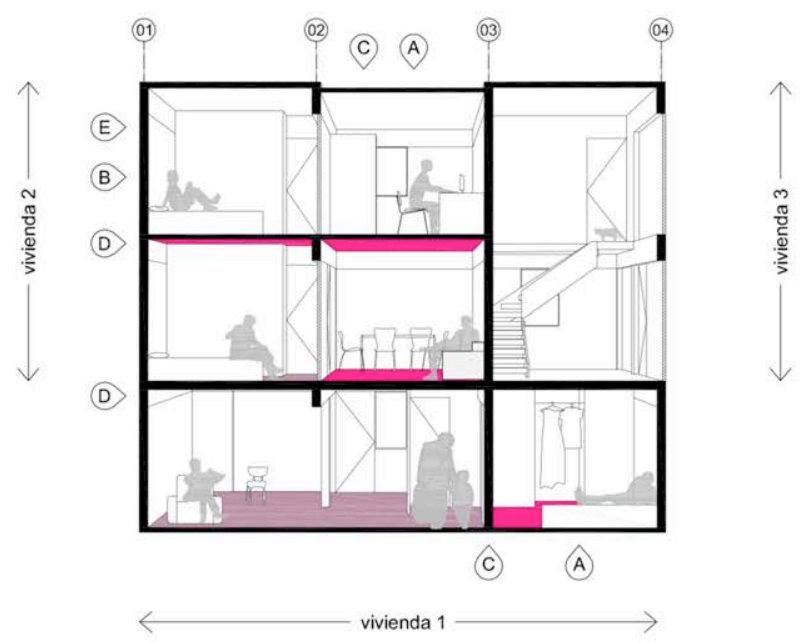
A Unión de estancias contiguas
(B) Sección ocupable
(C) Paramentos desmontables y facilmente transformables
(D) Sobredimensionamiento estructural
(E) Separación soporte cerramiento 


\begin{tabular}{|l|l|l|l|l|l|l|l|}
\hline Patrón de dinámica familiar & \\
\hline $\begin{array}{l}N^{\circ} \text { de } \\
\text { habitantes } \\
15 \\
14\end{array}$ \\
13
\end{tabular}

\section{Patrón de dinámica territorial}

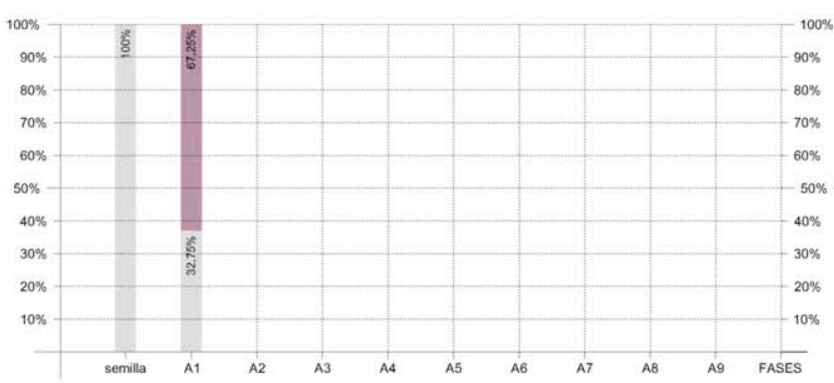

Tipos de territorios

Territorio privado

Territorio compartido familiar

Territorio compartido no familiar

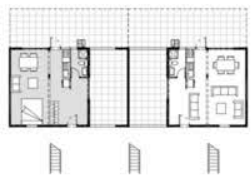

Vivienda semilla

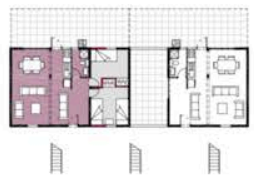

Ampliación 01

\section{Patrón de holgura y hacinamiento}

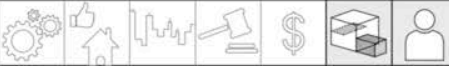

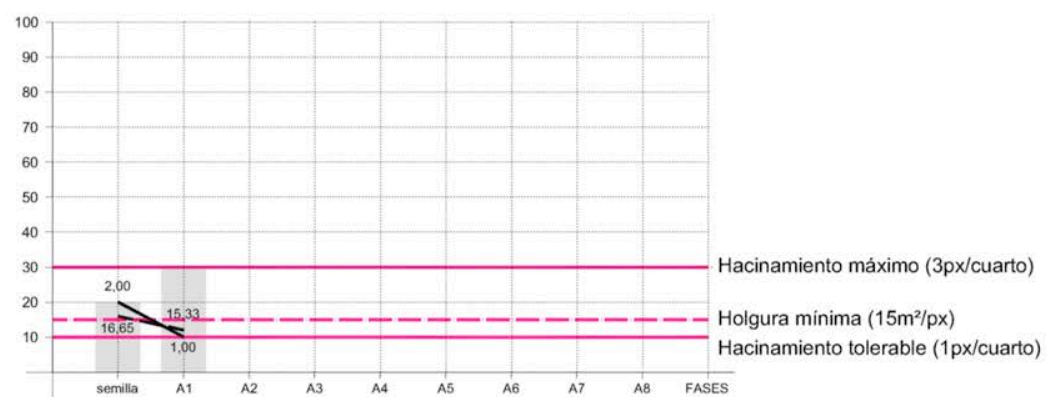

- Holgura $\left(\mathrm{m}^{2} / \mathrm{px}\right)$

- Holgura minima $\left(15 \mathrm{~m}^{2} / \mathrm{px}\right)$

— Hacinamiento ( $\mathrm{px} / \mathrm{cuarto})$

Hacinamiento máximo (3px/cuarto) Hacinamiento tolerable (1 px/cuarto)

Número de habitantes 


\section{Patrón de construcción progresiva}

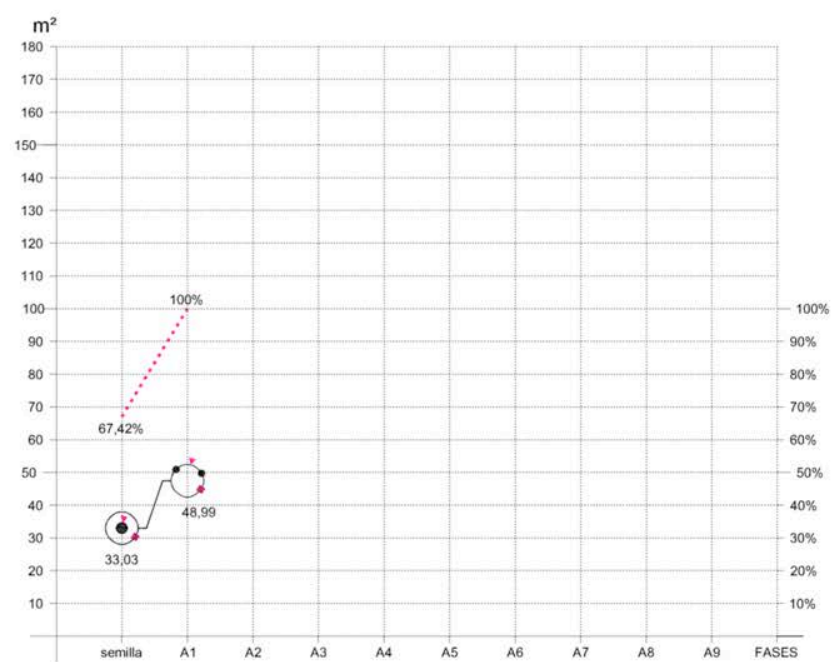

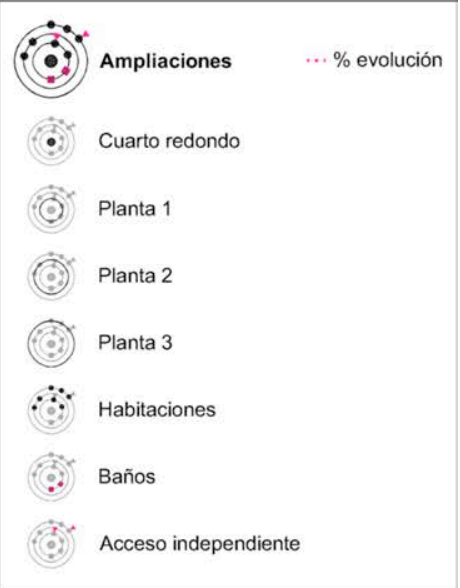

\section{Patrón de evolución espacial}
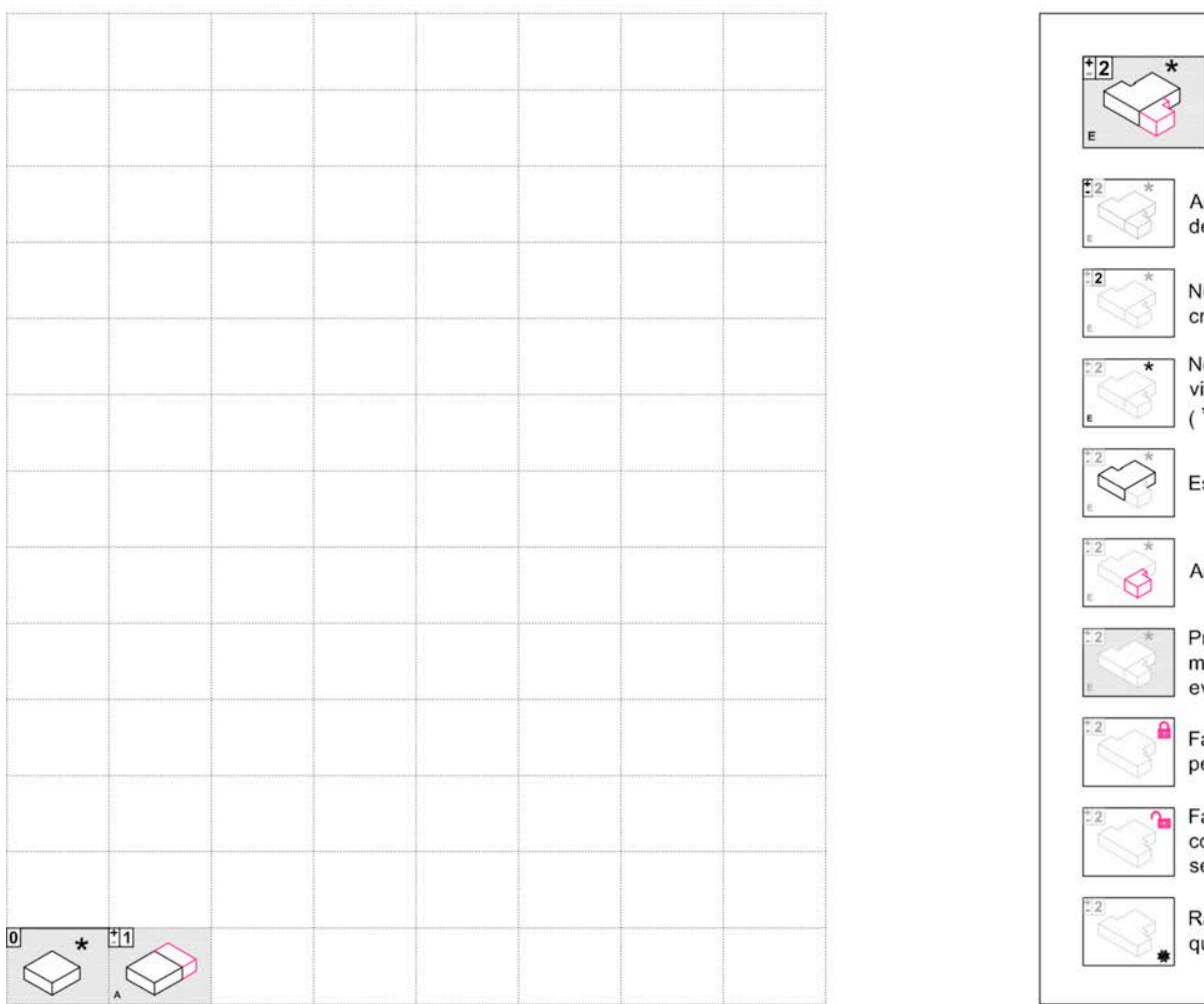

$\underbrace{*}_{2}$ Ampliación (+) o reducción (-) del espacio

$2{ }^{*}$ Número de posibles alternativas de crecimiento en ese estado

2 * Nombre del estado momentáneo de la vivienda.

E ( ${ }^{*}$ Estado inicial o vivienda semilla)

Estado momentáneo de la vivienda

Ampliación de la vivienda

* Primera vez que aparece ese estado momentáneo de la vivienda en su evolución

2 Fase restrictiva: la que si se realiza no permite continuar el crecimiento

Fase llave: la que si no se hace condiciona el crecimiento y no permite seguir ampliando más la vivienda

Rama más rica espacialmente: la rama * que más variaciones distintas permite

$+2$

Número máximo de fases consecutivas

$\ni 1$

Número máximo de posibles ramas de crecimiento

$\ominus \ominus 2$

Número de fases distintas 


\section{Parámetros de evaluación de la calidad arquitectónica}

\begin{tabular}{|c|c|c|c|}
\hline & & vS & A1 \\
\hline & Espacio ambiguo & ? & ? \\
\hline & Espacio comodin & ○ & ? \\
\hline & Transformación instantánea & ? & (2) \\
\hline శ్ర & Circulación y recorridos & ? & ? \\
\hline 言 & Más superficie útil (almacenaje) & - & ○ \\
\hline$\frac{\Phi}{4}$ & Concentración de superficies libres & ? & ? \\
\hline & Espacios - limite privados & ? & ? \\
\hline & Espacios - limite semipúblicos & ? & ? \\
\hline & Soportes y unidades & - & - \\
\hline & Vivienda inacabada & ? & ? \\
\hline 흘 & Casa dispersa & ○ & - \\
\hline 包 & Ventana perfectible & - & ? \\
\hline & Umbral inacabado & ? & - \\
\hline & Acondicionamiento por capas & - & - \\
\hline & Instalaciones registrables & ○ & ? \\
\hline & Agrupación de núcleos húmedos & - & ? \\
\hline 要 & Aprovechamiento espacial & P & O \\
\hline : & Optimización funcional de baños & - & - \\
\hline 峁 & Sombras arrojadas & ○ & ○ \\
\hline & Orientación & ? & ? \\
\hline & Limite activo & - & - \\
\hline & Ventilación cruzada & ? & ○ \\
\hline & Ventilación natural necesaria & ○ & 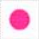 \\
\hline ?ृ & Iluminación natural necesaria & ? & ? \\
\hline 垔 & Hacinamiento & ○ & ? \\
\hline$\frac{\text { ती }}{\text { त्र }}$ & Agua corriente & ○ & - \\
\hline & Drenaje & - & ? \\
\hline & Aspecto inconcluso & P & ? \\
\hline & & ○ & ? \\
\hline
\end{tabular}

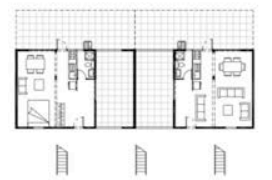

Vivienda semilla

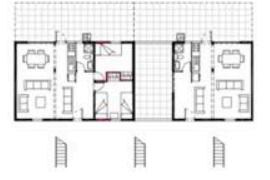

Ampliación 01
$100 \%$ Si lo cumple

$50 \%$ Lo cumple a medias

- $0 \%$ No lo cumple

Interior inicial, interior ocupado, exterior con ampliación de la Casa Quinta Monroy.
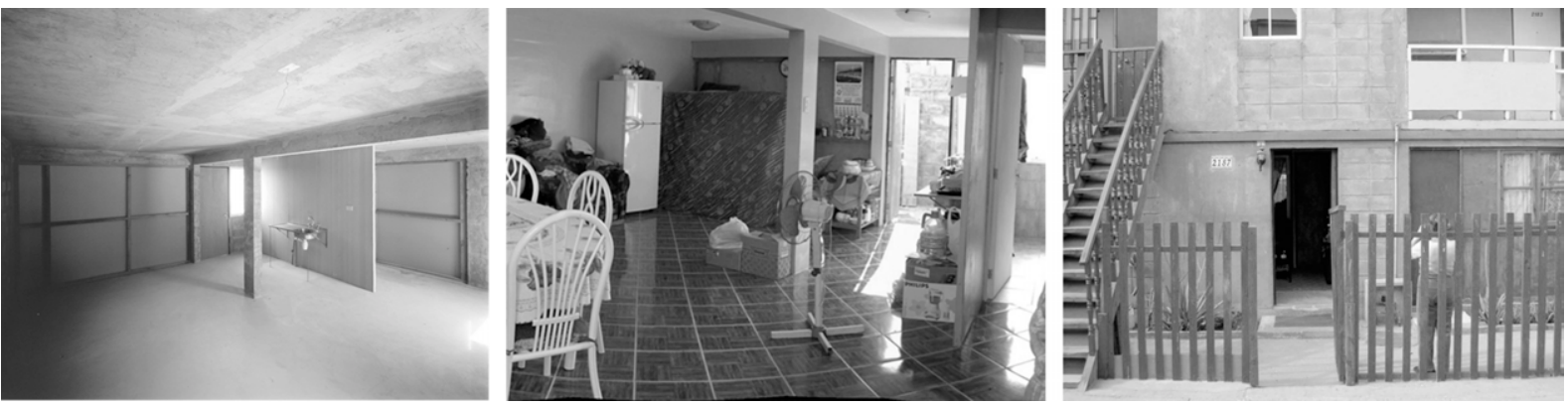


\section{Patrón de costo de construcción progresiva}

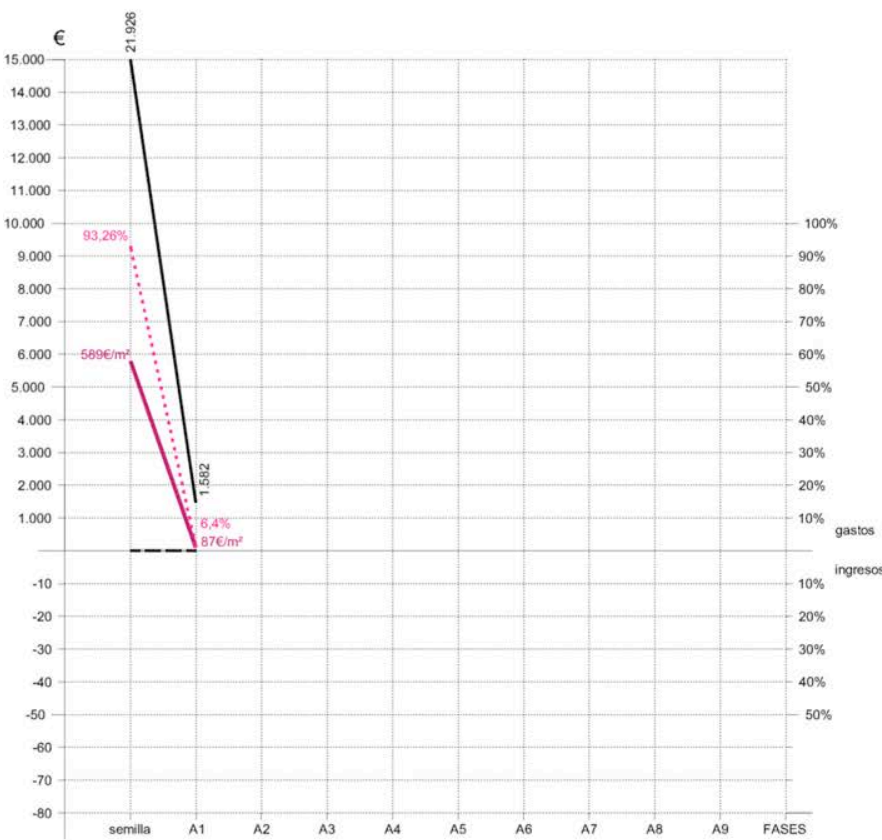

$21.926 €\left(589 € / \mathrm{m}^{2}\right) \quad$ Gasto vivienda semilla

$1.582 €\left(87.20 € / \mathrm{m}^{2}\right)$

Gasto ampliación 1

$23.509 €\left(424 € / \mathrm{m}^{2}\right)$ Gasto total por ampliación

$0 € \quad$ Ingreso por decrecimiento

$23.509 €\left(424 € / \mathrm{m}^{2}\right) \quad$ Inversión total

__ Gasto en estructura y cerramiento

Gasto en acabados

Patrón de costo total de construcción progresiva

Evolución porcentual del costo total de construcción progresiva Gasto total por metro cuadrado

\section{Patrón de costo de legalización}

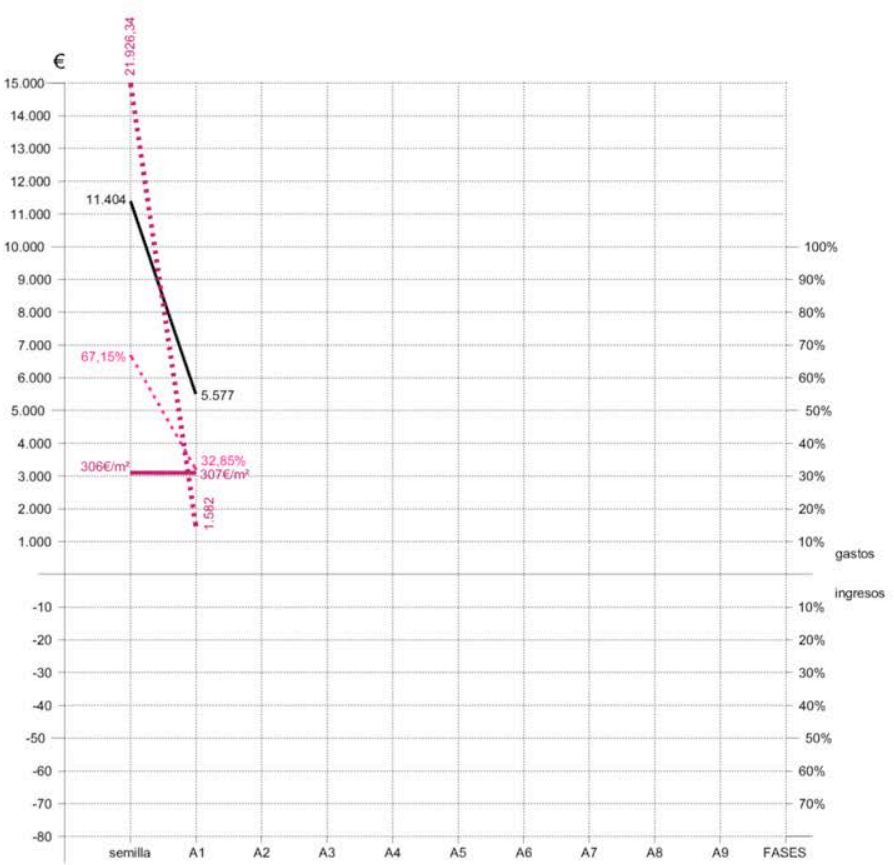

$11.404 €\left(306 € / \mathrm{m}^{2}\right) \quad$ Legalización viv. semilla $5.577 €\left(307 € / \mathrm{m}^{2}\right) \quad$ Legalización ampliación 1

\begin{tabular}{|c|c|}
\hline $16.981 €\left(306 € / \mathrm{m}^{2}\right)$ & $\begin{array}{r}\text { Gasto total legalización } \\
\text { progresiva ( } 2 \text { fases) }\end{array}$ \\
\hline $11.734 €\left(212 € / \mathrm{m}^{2}\right)$ & $\begin{array}{r}\text { Gasto total legalización } \\
\text { sin fases }\end{array}$ \\
\hline
\end{tabular}

Patrón de costo total de construcción progresiva

Patrón de costo de legalización progresiva

Patrón de costo de legalización

progresiva por metro cuadrado

Evolución porcentual del costo de legalización progresiva 


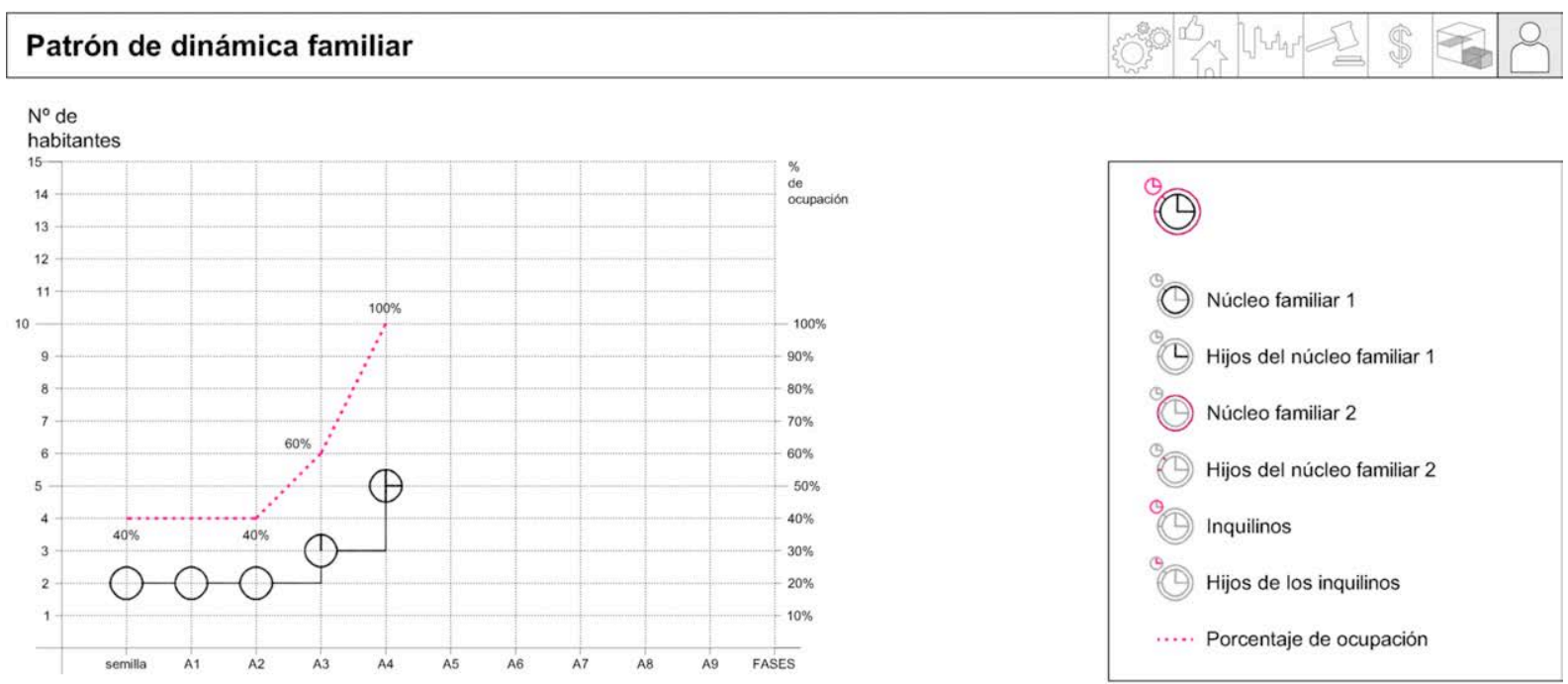

\section{Patrón de dinámica territorial}

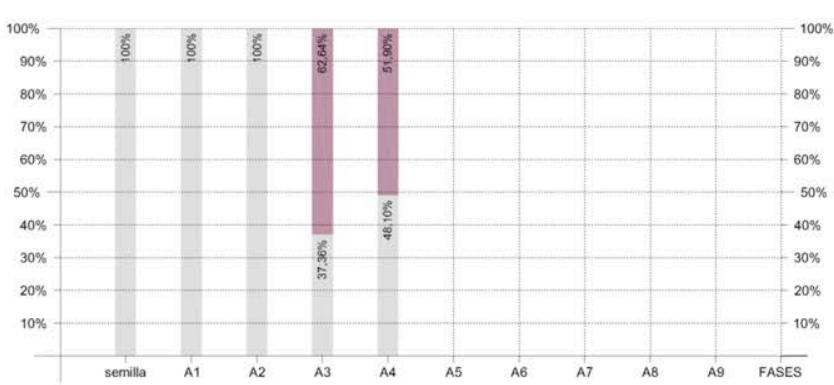

Tipos de territorios

Territorio privado

Territorio compartido familiar

Territorio compartido no familiar
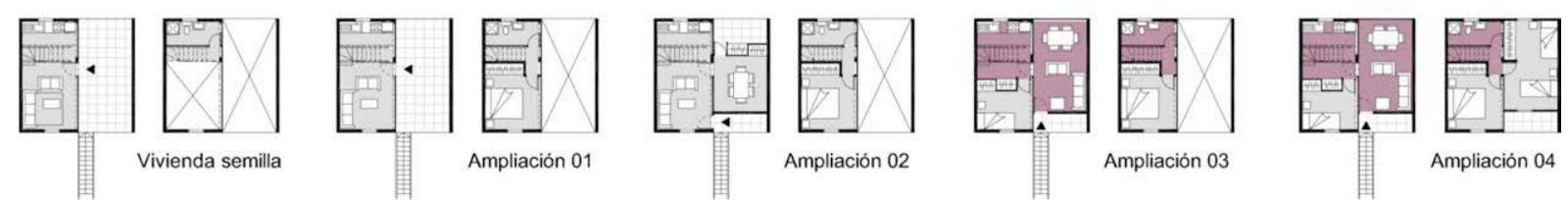

Patrón de holgura y hacinamiento

की
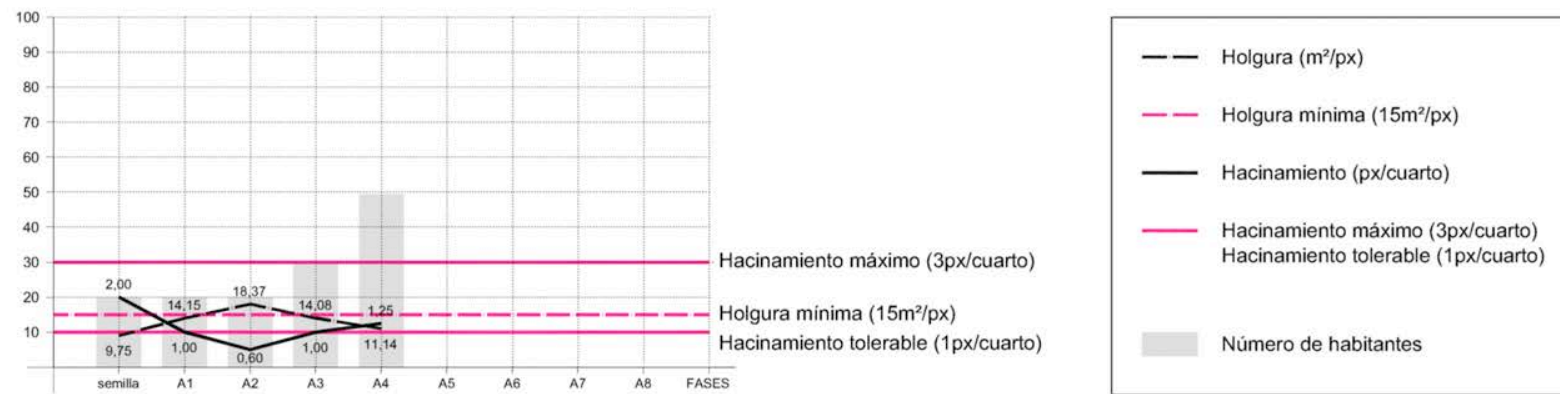


\section{Patrón de construcción progresiva}

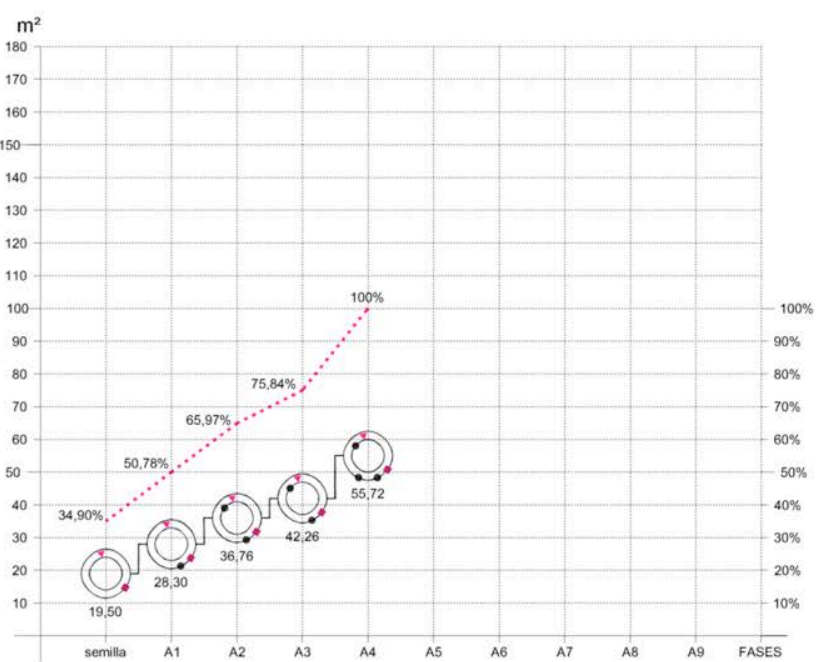

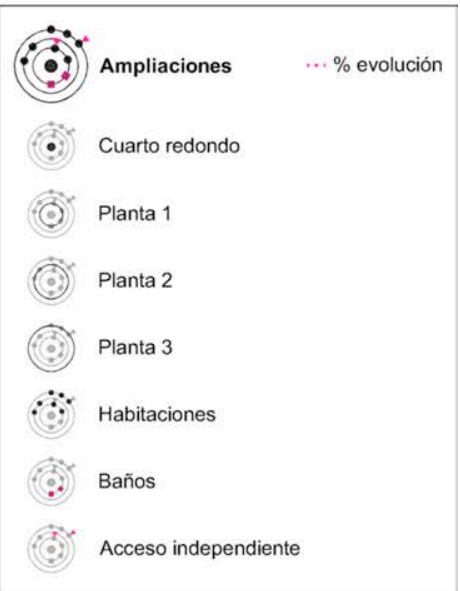

\section{Patrón de evolución espacial}

5oㅇ
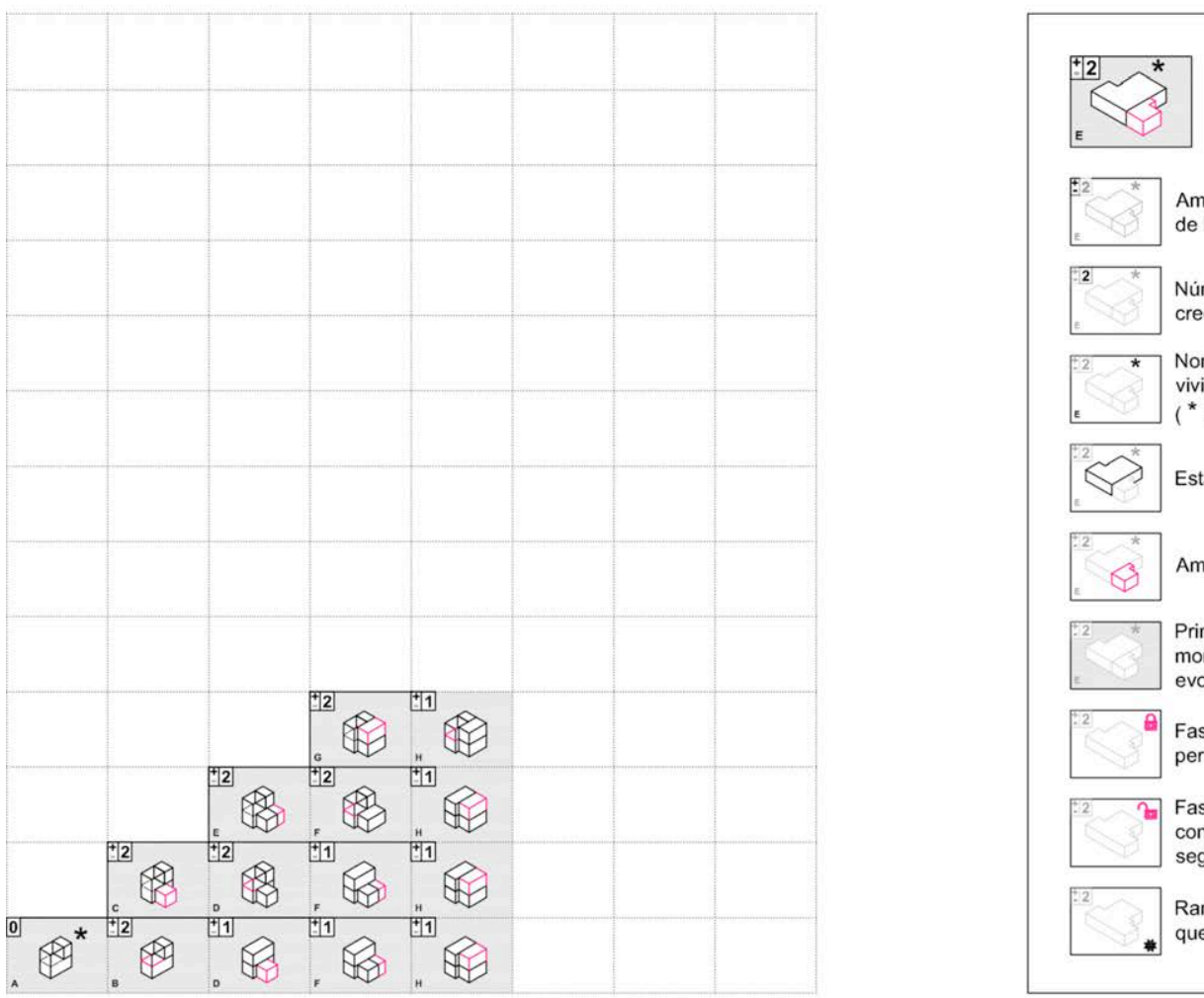

$F^{2} S^{*}$ Ampliación (+) o reducción (-) del espacio $\begin{array}{lll}2 & * & \begin{array}{l}\text { Número de posibles alternativas de } \\ \text { crecimiento en ese estado }\end{array}\end{array}$

2 * Nombre del estado momentáneo de la vivienda.

E ( ${ }^{*}$ Estado inicial o vivienda semilla)

Estado momentáneo de la vivienda

8 Ampliación de la vivienda

* Primera vez que aparece ese estado momentáneo de la vivienda en su evolución

2 Fase restrictiva: la que si se realiza no permite continuar el crecimiento

Fase llave: la que si no se hace condiciona el crecimiento y no permite seguir ampliando más la vivienda

Rama más rica espacialmente: la rama * que más variaciones distintas permite

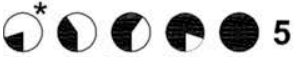

Número máximo de fases consecutivas

$\rightarrow \bigcirc \in 4$

Número máximo de posibles ramas de crecimiento

$\rightarrow \bigcirc \bigcirc 0 \in 000$

Número de fases distintas 


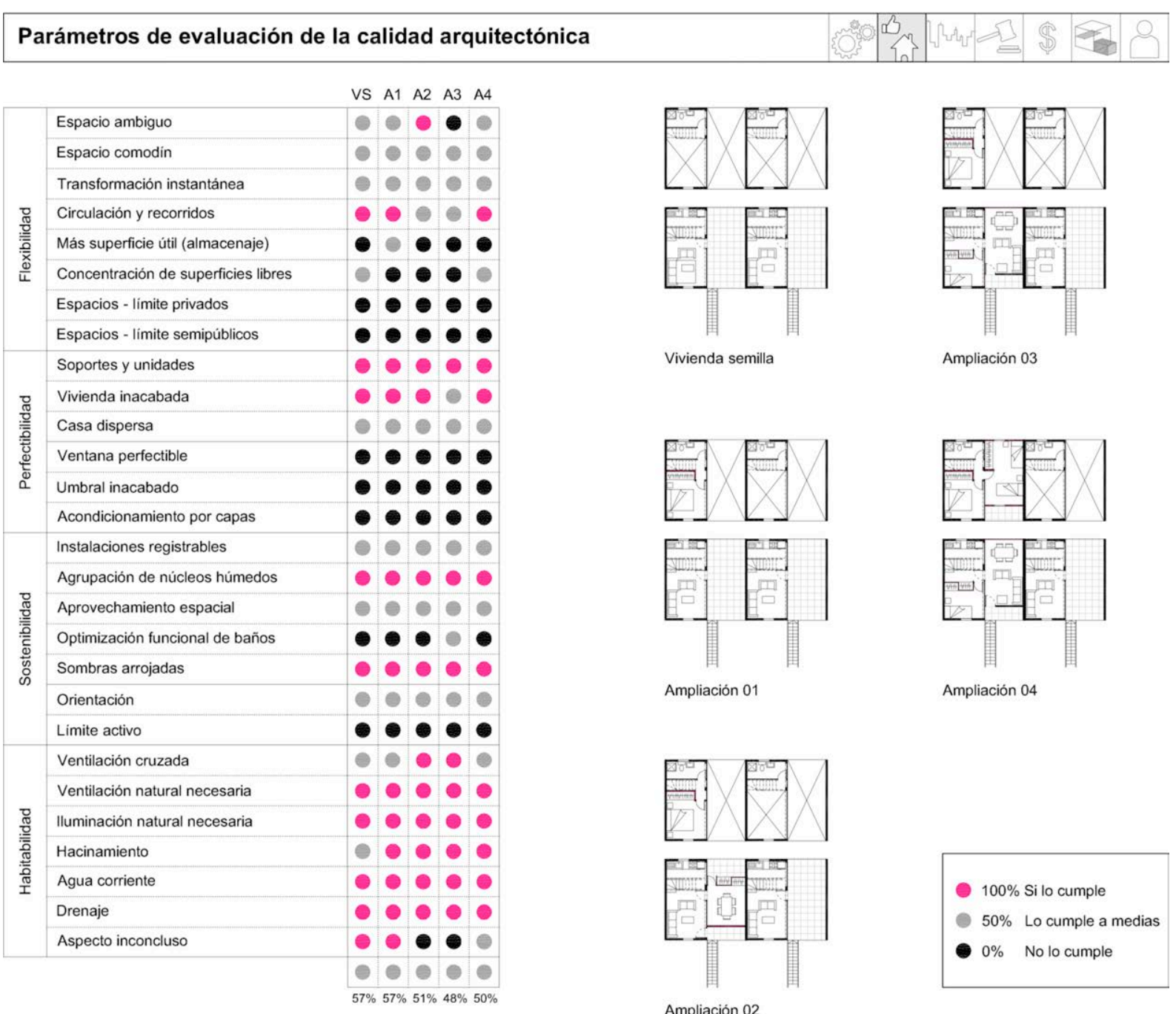

Vista desde el patio, vista de la calle, vista interior de la vivienda inicial y vista interior de la vivienda ampliada.
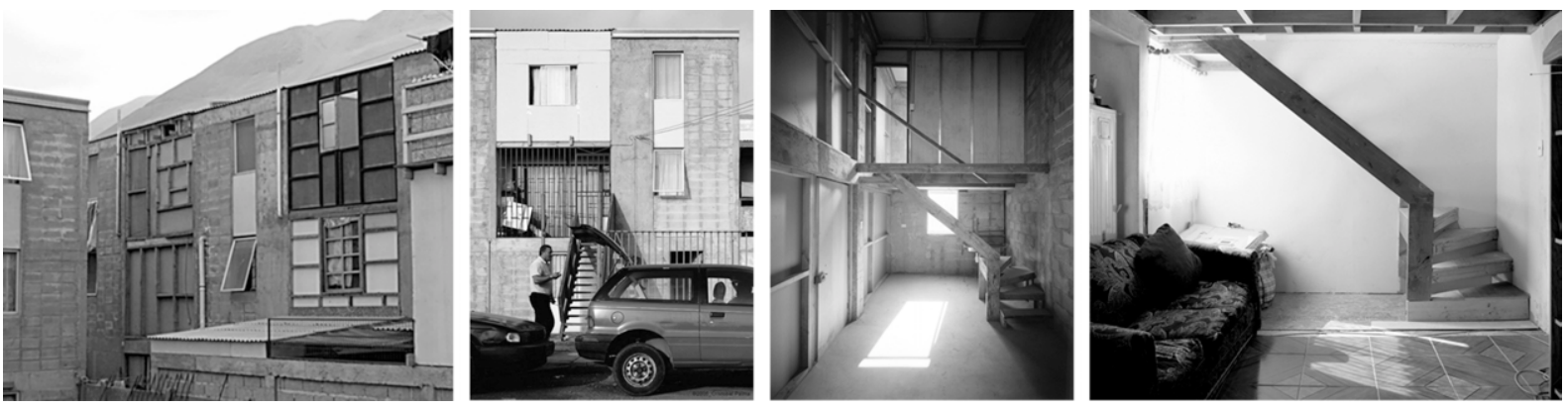


\section{Patrón de costo de construcción progresiva}

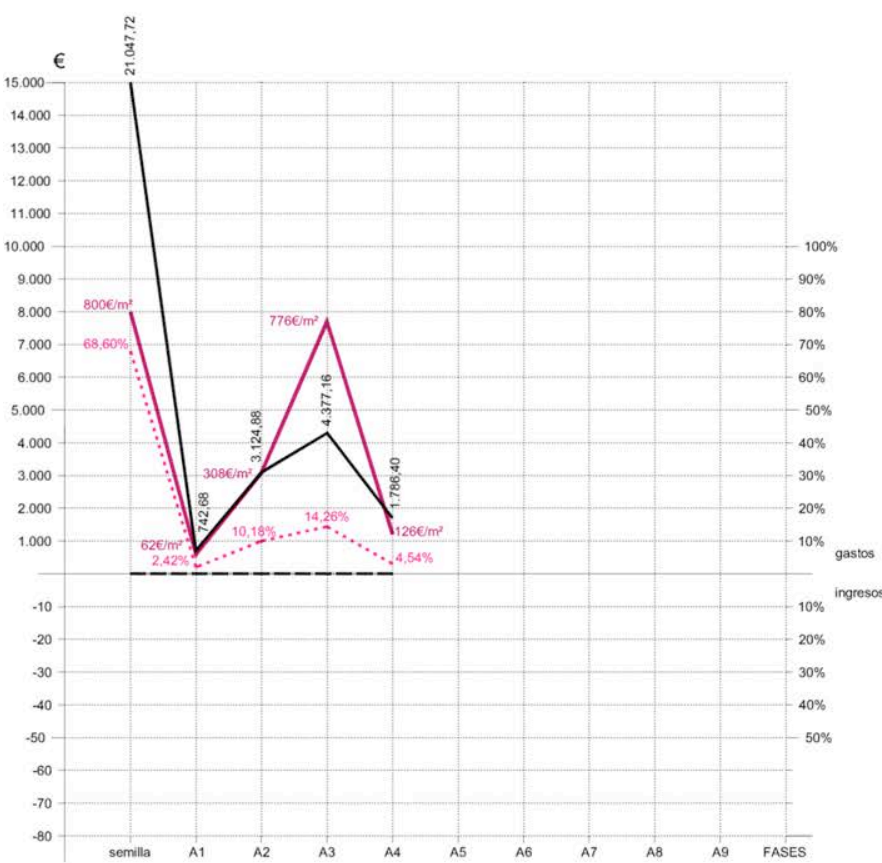

\begin{tabular}{lr}
$21.047 €\left(800 € / \mathrm{m}^{2}\right)$ & Gasto vivienda semilla \\
$742 €\left(62 € / \mathrm{m}^{2}\right)$ & Gasto ampliación 1 \\
$3.124 €\left(308 € / \mathrm{m}^{2}\right)$ & Gasto ampliación 2 \\
$4.377 €\left(776 € / \mathrm{m}^{2}\right)$ & Gasto ampliación 3 \\
$1.7861 €\left(126 € / \mathrm{m}^{2}\right)$ & Gasto ampliación 4 \\
& \\
\hline
\end{tabular}

$31.078 €\left(454 € / \mathrm{m}^{2}\right)$ Gasto total por ampliación

$0 € \quad$ Ingreso total por decrecimiento

$31.078 €\left(454 € / \mathrm{m}^{2}\right) \quad$ Inversión total

\section{_ Gasto en estructura y cerramiento \\ Gasto en acabados \\ Patrón de costo total de construcción progresiva \\ Evolución porcentual del costo total de construcción progresiva Gasto total por metro cuadrado}

\section{Patrón de costo de legalización}

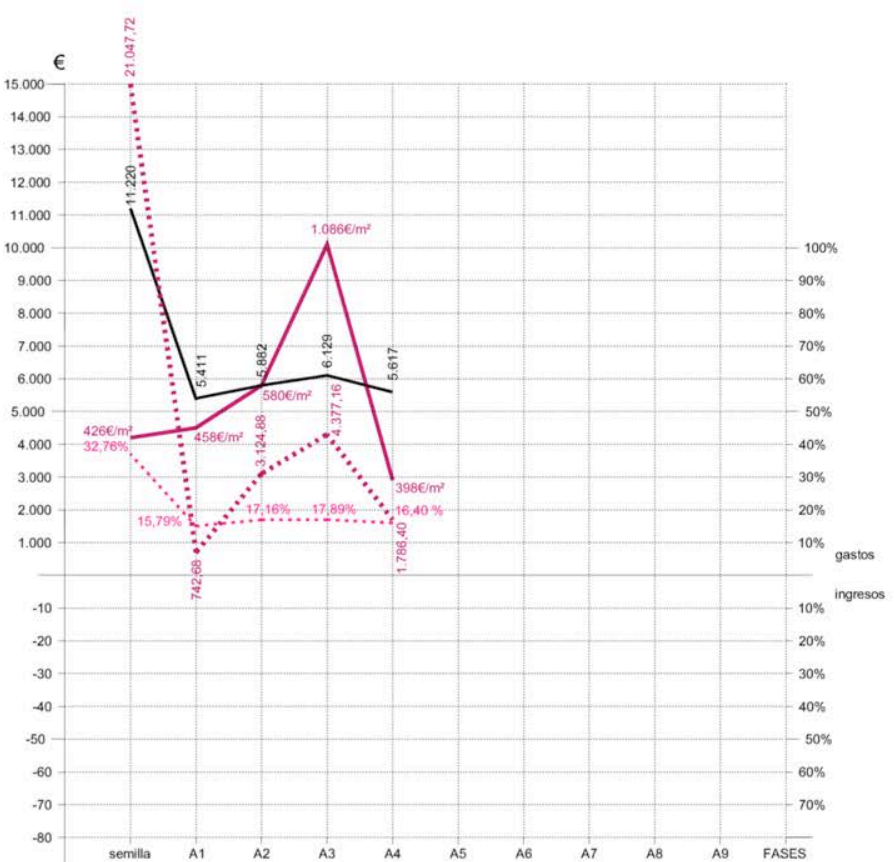

$11.220 €\left(426 € / \mathrm{m}^{2}\right) \quad$ Legalización viv. semilla $5.411 €\left(458 € / \mathrm{m}^{2}\right) \quad$ Legalización ampliación 1 $5.882 €\left(580 € / \mathrm{m}^{2}\right) \quad$ Legalización ampliación 2 $6.129 €\left(1.086 € / \mathrm{m}^{2}\right)$ Legalización ampliación 3 $5.617 €\left(398 € / \mathrm{m}^{2}\right) \quad$ Legalización ampliación 4

\begin{tabular}{|c|c|}
\hline $34.262 €\left(504 € / \mathrm{m}^{2}\right)$ & $\begin{array}{l}\text { Gasto total legalización } \\
\text { progresiva ( } 5 \text { fases) }\end{array}$ \\
\hline $13.314 €\left(195 € / \mathrm{m}^{2}\right)$ & $\begin{array}{r}\text { Gasto total legalización } \\
\text { sin fases }\end{array}$ \\
\hline
\end{tabular}

Patrón de costo total de construcción progresiva

Patrón de costo de legalización progresiva

Patrón de costo de legalización progresiva por metro cuadrado Evolución porcentual del costo de legalización progresiva 


\section{a. Patrón de dinámica familiar.}

El patrón de dinámica familiar que propone el grupo ELEMENTAL en los planos de sus viviendas es un patrón muy simple en ambos casos, especialmente en el caso de la casa ya que únicamente consta de dos fases.

En el caso de la casa se inicia con dos habitantes y en la siguiente fase se duplica el número de personas. Igualmente, en el caso del apartamento se inicia con dos habitantes ( $40 \%$ de ocupación de la vivienda) y no se amplían el número de personas hasta la tercera ampliación que se llega a los tres habitantes. Esto es debido al pequeño tamaño de la vivienda semilla y a la necesidad de individualizar usos antes de poder tener nuevos dormitorios que alberguen a más usuarios. En la última fase del apartamento se obtiene la mayor ocupación de la vivienda que alcanza los cinco habitantes.

\section{b. Patrón de dinámica territorial.}

Debido a que, al igual que en todos los casos estudiados, la propuesta de los arquitectos contempla únicamente a un núcleo familiar en la vivienda, todo el espacio de esta es del tipo familiar.

En el caso de la casa, en la primera fase el $100 \%$ del territorio es privado, debido a que únicamente vive una pareja en la vivienda. Mientras que en la segunda fase el territorio privado se reduce al $32,75 \%$. Esto se debe a que a pesar de ampliar dos nuevas habitaciones, igualmente tendrá que compartirse la habitación que no corresponde a la pareja inicial ya que los habitantes de la vivienda son cuatro.

En el caso del apartamento la situación es similar, en las tres primeras fases el territorio privado es del $100 \%$ puesto únicamente vive una pareja, pero a partir del la cuarta fase la relación territorio privado territorio compartido se altera obteniendo hasta un $62,64 \%$ de territorio compartido en la cuarta fase.

\section{c. Patrón de holgura y hacinamiento.}

Tanto en el caso de la casa para Quinta Monroy como en el caso del apartamento, la holgura y el hacinamiento se ven comprometidos en alguna fase.

En el ejemplo de la casa, encontramos hacinamiento en la primera fase ya que hay dos personas por cuarto. Si bien no alcanzan los límites máximos de hacinamiento vinculados a países en vías de desarrollo (3px/cuarto) está por debajo de los estándares de hacinamiento tolerable en países desarrollados (Ipx/cuarto). Sin embargo, en términos de holgura esta fase se encuentra prácticamente en el límite $\left(15 \mathrm{~m}^{2} / \mathrm{px}\right)$ pero dentro de un margen tolerable ya que cuenta con $16,65 \mathrm{~m}^{2}$ por persona. Es importante señalar como en este caso, en la segunda fase se invierten las cifras. Al añadir dos nuevas habitaciones el hacinamiento disminuye hasta ubicarse en la franja de hacinamiento tolerable con I persona por cuarto, pero sin embargo, al aumentar el número de habitantes de la vivienda y no ser una ampliación muy espaciosa la holgura se reduce a 15,33 $\mathrm{m}^{2}$ por persona acercándose al límite de holgura mínima.

En el caso del apartamento la primera fase inicia igualmente fuera de los términos de confort, con un hacinamiento de 2 personas por cuarto alejado del hacinamiento tolerable (I px/cuarto) pero sin llegar a alcanzar el hacinamiento máximo (3 px/cuarto), y una holgura de $9,75 \mathrm{~m}^{2}$ por persona considerablemente 